\title{
Thrombosis, platelet activation and coagulation in rats. Effects of dietary n-3 fatty acids from fish oil
}

Citation for published version (APA):

Nieuwenhuys, C. M. A. (2001). Thrombosis, platelet activation and coagulation in rats. Effects of dietary $n$ 3 fatty acids from fish oil. [Doctoral Thesis, Maastricht University]. Datawyse. https://doi.org/10.26481/dis.20010914cn

Document status and date:

Published: 01/01/2001

DOI:

$10.26481 /$ dis.20010914cn

Document Version:

Publisher's PDF, also known as Version of record

\section{Please check the document version of this publication:}

- A submitted manuscript is the version of the article upon submission and before peer-review. There can be important differences between the submitted version and the official published version of record. People interested in the research are advised to contact the author for the final version of the publication, or visit the DOI to the publisher's website.

- The final author version and the galley proof are versions of the publication after peer review.

- The final published version features the final layout of the paper including the volume, issue and page numbers.

Link to publication

\footnotetext{
General rights rights.

- You may freely distribute the URL identifying the publication in the public portal. please follow below link for the End User Agreement:

www.umlib.nl/taverne-license

Take down policy

If you believe that this document breaches copyright please contact us at:

repository@maastrichtuniversity.nl

providing details and we will investigate your claim.
}

Copyright and moral rights for the publications made accessible in the public portal are retained by the authors and/or other copyright owners and it is a condition of accessing publications that users recognise and abide by the legal requirements associated with these

- Users may download and print one copy of any publication from the public portal for the purpose of private study or research.

- You may not further distribute the material or use it for any profit-making activity or commercial gain

If the publication is distributed under the terms of Article $25 \mathrm{fa}$ of the Dutch Copyright Act, indicated by the "Taverne" license above, 
Thrombosis, Platelet Activation and Coagulation in

\title{
Rats
}

\author{
Effects of Dietary n-3 Fatty Acids from Fish Oil
}

Cécilia M. A. van den Berg - Nieuwenhuys

Maastricht, 2001 
Van den Berg-Nieuwenhuys, Cécilia M. A.

Thrombosis, coagulation and platelet activation: effects of dietary n-3 fatty acids from fish oil/Cécilia Maria Augusta van den Berg-Nieuwenhuys

Thesis Maastricht University, Maastricht, The Netherlands, 2001. ISBN 90-9014610-5

Coverdesign: Fish, by Carlijn Anna Lotte van den Berg

Production: Datawyse Boekproducties, Maastricht, The Netherlands

C 2001, C.M.A. van den Berg-Nieuwenhuys, Maastricht, The Netherlands 


\title{
Thrombosis, Platelet Activation and Coagulation in Rats
}

\section{Effects of Dietary n-3 Fatty Acids from Fish Oil}

\author{
PROEFSCHRIFT \\ ter verkrijging van de graad van doctor \\ aan de Universiteit Maastricht \\ op gezag van de Rector Magnificus, Prof. Dr. A.C. Nieuwenhuijzen Kruseman, \\ volgens het besluit van het College van Decanen \\ in het openbaar te verdedigen \\ op vrijdag 14 september 2001 om 12.00 uur \\ door
}

Cécilia Maria Augusta van den Berg-Nieuwenhuys

geboren te Amsterdam op 23 april 1965 


\section{Promotor:}

Prof. dr. G. Hornstra

\section{Co-promotor:}

Dr. J.W.M. Heemskerk

Beoordelingscommissie:

Prof. dr. M.P. van Dieijen-Visser (voorzitter)

Dr. K. Hamulyàk

Prof. dr. H.C. Hemker

Dr. M.G.A. Oude Egbrink

Prof. dr. ir. W.H.M. Saris

Studies of this thesis were financially supported by F. Hoffmann-La Roche Ltd, Basel, Switzeriand.

Financial support by the Netherlands Heart Foundation and the Dr. Ir. Van de Laar Stichting for the publication of this thesis is gratefully acknowledged.

Additionally, the author wishes to express her gratitude to Nutricia Nederland B.V. and Novartis Pharma B.V. for their financial support. 
Aan mijn ouders

Voor Jan Willem, Carlijn, Josefien en .... 



\section{Contents}

Chapter 1. Introduction

Chapter 2. Effects of purified eicosapentaenoic and docosahexaenoic acid on arterial thrombosis tendency and platelet function in rats, Biochim Biophys Acta, 1998;1390:313-322.

Chapter 3. Modulation of rat platelet activation by vessel wall-derived prostaglandin and platelet-derived thromboxane: effects of dietary fish oil on thromboxane-prostacyclin balance, Atherosclerosis, 2001;154:355-366.

Chapter 4. Monitoring hypocoagulant conditions in rat plasma: Factors determining the endogenous thrombin potential of tissue factoractivated plasma, Thromb Haemost, 2000;84:1045-1051.

Chapter 5. Hypocoagulant and lipid-lowering effects of dietary $n-3$ polyunsaturated fatty acids with unchanged platelet activation in rats, Atheroscler Thromb Vasc Biol, 1998;18:1480-1489.

Chapter 6. Vitamin K-dependent and -independent hypocoagulant effects of dietary fish oil in rats, submitted.

Chapter 7. The procoagulant effect of thrombin on fibrin(ogen)-bound platelets, Haemostasis, 1998; 28:289-300.

Chapter 8. Initial coagulation-stimulating effect of platelets in flowing rat blood is independent of platelet aggregation.

Chapter 9. Discussion

Summary

Samenvatting

Dankwoord

Curriculum Vitae

Publications 

1

Introduction 


\subsection{Arterial thrombosis}

The circulating blood provides a balanced system of interactions between plasma proteins, blood cells and tissues of the vessel wall. This system keeps the blood flowing under normal conditions. A significant disturbance of this balance, for instance after an injury to the vessel wall, results in formation of a haemostatic plug or a thrombus. Traditionally, thrombus formation is considered to be the result of two processes, i.e. initial assembly of a platelet plug, representing the so-called 'primary haemostasis', and stabilisation of the plug due to coagulation, which part is designated as 'secondary haemostasis'. In a later stage, the more delayed process of fibrinolysis causes the thrombus to be dissolved. While haemostasis represents the physiological response to vessel injury, it has a pathological counterpart in the process of thrombosis, i.e. the occlusion of an intact vessel by an undesired haemostatic plug, which also stops the blood stream. Especially in the case of occlusion of myocardial or brain arteries, this may lead to a life-threatening situation.

Thrombosis is a major cause of death in Western industrialised countries [1]. Arterial thrombus formation leads to or is involved in a variety of cardiovascular diseases, including ischemic heart disease, myocardial infarction, angina pectoris and stroke. In addition, with patients suffering from atherosclerosis, rupture of an atherosclerotic plaque in a diseased vessel often leads to thrombotic vaso-occlusion. Recognised risk factors for arterial thromboses are an increase in certain coagulation factors, the presence of activated blood platelets and impaired fibrinolysis [2-7]. For extensive reviews, see references [8-10]. In addition, plasma levels of triglycerides and of cholesterol in the low-density lipoproteins are important risk factors for atherosclerosis and related cardiovascular diseases [11-13]. In general, factors contributing to abnormal haemostasis and thrombosis are diverse in origin and include platelet factors, coagulation and fibrinolytic components, blood lipids and mediators from the blood vessel wall. Given the complexity of (arterial) thrombosis and the many possible risk factors involved, it will be clear that successful treatment of such disease is a difficult task to achieve. Many drugs are directed towards suppression of only one of the underlying processes or to normalisation of single risk factors. It is thus not a surprise that the efficacy of these interventions is often limited. Already 30 years ago, it was realised that changing to an adequate dietary regime may be a different approach to normalise the pre-thrombotic state. The underlying thought was that a healthy nutritional pattern might lead to optimal levels of many thrombotic factors and circulatory processes. 


\subsection{Polyunsaturated fatty acids in marine oils}

Approximately 30 years ago, it was noted that Greenland Eskimos often showed a tendency of prolonged bleeding, and had a relatively low risk of ischemic heart disease. Initial epidemiological studies suggested the cardio-protective factor to be of dietary origin, i.e. the consumption of large amounts of marine flesh by the Eskimos $[14,15]$. Dietary flesh of marine origin was thus considered as a possible way of 'normalisation' of thrombotic risk factors.

Fatty acids are major components of lipids. Humans are unable to synthesise several of these fatty acids de novo, which are therefore to be acquired by dietary means. These fatty acids are essential for healthy life, as already reported in 1929 $[21,22]$. The essential fatty acids in the diet are comprised of polyunsaturated fatty acids of the $n-6$ class ( $n-6$ PUFAs) and some polyunsaturated fatty acids of the $n-3$ class ( $n-3$ PUFAs). A quantitatively important n-6 PUFA component in the diet is linoleic acid (octadeca-all-cis-9,12-dienoic acid, abbreviated as 18:2 n-6), which can be converted by desaturation and elongation into arachidonic acid (docosa-all-cis-

$\mathrm{n}-6$ fatty acids

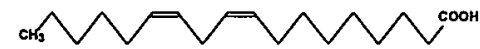

linoleic acid, 18:2 n-6

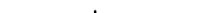

$n-3$ fatty acids

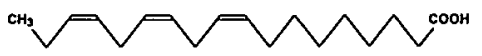

$\alpha$-linolenic acid, $18: 3 \mathrm{n}-3$
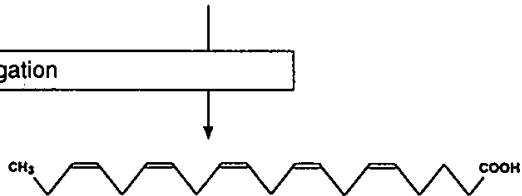

eicosapentaenoic acid, 20:5 n-3

arachidonic acid, 20:4 n-6
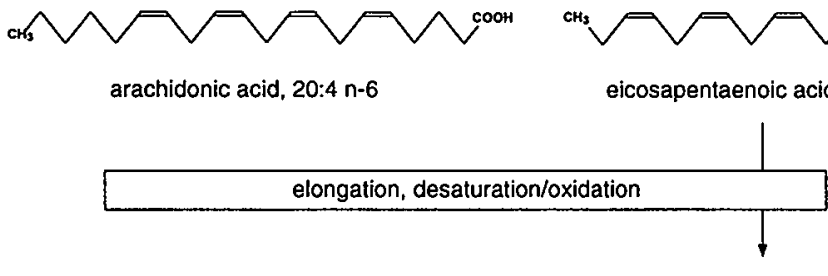
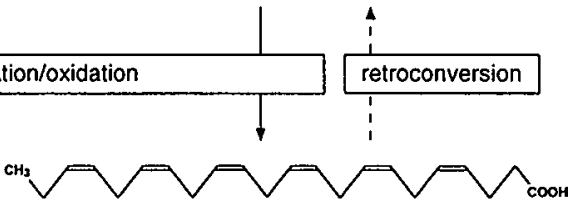

docosahexaenoic acid, $22: 6 n-3$

FIGURE 1.1 Conversion and retroconversion of $n-6$ and $n-3$ polyunsaturated fatty acids (PUFAs). The PUFAs are mainly in the liver converted into longer-chain PUFAs of the same class by elongation and desaturation. In addition, very long chain PUFAs can be degraded into shorter-chain fatty acids of the same class by retroconversion. For designating the individual PUFAs an abbreviation is used, in which the number to the left of the colon indicates the number of total carbon atoms, and the part to the right, the number of double bonds. The indications $n-3$ and $n-6$ refer to the location of the first double bound counted from the methyl end of the carbon chain. 
$5,8,11,14$-tetraenoic acid, also indicated as AA or 20:4 n-6). Thus, AA is characterised as a molecule with 20 carbon atoms and four double bonds. The first double bond is located between the sixth and seventh carbon atom counted from the terminal methyl residue of the acyl chain (FIG. 1.1).

A particular property of oil from fish and sea mammals is that it is rich in $n-3$ PUFAs (also called $\omega 3$ PUFAs). These long-chain fatty acids have their first double bond between the third and fourth carbon atom counted from the terminal methyl residue. The major $n-3$ PUFAs present in fish oils are eicosapentaenoic acid (eicosaall-cis-5,8,11,14,17-pentaenoic acid, abbreviated as EPA or 20:5 n-3) and docosahexaenoic acid (docosa-all-cis-4,7,10,13,16,19-hexaenoic acid, abbreviated as DHA or 22:6 n-3). The first molecule, EPA, thus contains 20 carbon atoms with five methylene-interrupted double bonds, whereas DHA has 22 carbon atoms with six methylene-interrupted double bonds (FIG. 1.1).

Green plants contain a shorter-chain form of n-3 PUFAs, i.e. $\alpha$-linolenic acid (octadeca-all-cis-9,12,15-trienoic acid or 18:3 n-3). This fatty acid can be converted into EPA and DHA through elongation and further desaturation, and oxidation in the case of DHA (FIG. 1.1) $[158,159]$. However, in humans, this conversion appears to occur at a rather low rate [16]. The major source of the incorporated EPA and DHA is thus of dietary origin, mainly marine flesh. As indicated in FIG. 1.1, EPA can be elongated and desaturated to DHA, while DHA can also be degraded to EPA by the process of retro-conversion $[16,17]$.

\subsection{Anti-thrombotic effect of n-3 PUFAs}

Both epidemiological and intervention studies provide evidence that dietary fish or fish oil, containing n-3 PUFAs, lowers the risk of ischemic heart disease [18-20]. In particular, beneficial effects of dietary n-3 PUFAs have been observed with regard to mortality after myocardial infarction [19]. However, not in all studies the cardioprotective effect of fish oil was equally clear [23-25].

Since 1981, many dietary intervention studies, often with healthy volunteers, have been performed to find explanations for this fish oil effect. The results of 37 of such studies, with either fish oil or plain (oily) fish, are given in TABLE 1.1. Where investigated, in most cases fish oil or fish consumption led to an increase in bleeding time, which points to a decreased platelet function. Several but not all reports describe a reduced tendency of (thromboxane-dependent) platelet activation. However, particularly reduced levels of triglycerides are observed. On the other hand, cholesterol in the ('beneficial') high-density lipoproteins may increase in response to high doses of dietary fish oil [26-29]. TABLE 1.1 also indicates that a significant number of studies show a fish oil-induced reduction in the levels of 

humans.

\begin{tabular}{llll}
\hline Dietary effect & Capsules & Capsules & Fish \\
& $(1-6 \mathrm{~g} \mathrm{n}-3$ PUFA/d $)$ & $(>9 \mathrm{~g} \mathrm{n}-3$ PUFA/d) & $(0.3-5 \mathrm{~g} \mathrm{n}-3$ PUFA/d) \\
\hline
\end{tabular}

Fraction of studies with significant effects

\begin{tabular}{|c|c|c|c|}
\hline \multicolumn{4}{|l|}{ Increased: } \\
\hline bleeding time & $3 / 4(9,11,23,32)$ & $3 / 4(17,24,28,32)$ & $2 / 2(12,18)$ \\
\hline \multicolumn{4}{|l|}{ Reduced: } \\
\hline platelet activation & $7 / 9(4,8,9,15,16,23,27,32,33)$ & $2 / 5(2,17,24,28,32)$ & $4 / 5(7,12,18,26,29)$ \\
\hline blood lipids* & $9 / 14(9,15,16,19-23,25,30-33,36)$ & $3 / 4(3,28,32,36)$ & $2 / 2(14,26)$ \\
\hline coagulation $^{5}$ & $5 / 12(5,11,19,20,22,27,31-33,35,36)$ & $2 / 4(6,32,34,36)$ & $1 / 5(1,5,10,18,37)$ \\
\hline \multicolumn{4}{|l|}{ Altered ${ }^{\#:}$} \\
\hline -fibrinolysis & $5 / 11(5,11,20,22,23,25,30-33,36)$ & $3 / 4(6,32,34,36)$ & $3 / 3(5,13,37)$ \\
\hline
\end{tabular}

Review of results from 37 published dietary intervention studies carried out with healthy human volunteers. In these studies, either unpurified fish oil or a n-3 PUFA-enriched supplement was given in the form of capsules at a relatively low dose (1-6 gram n-3 PUFAs per day) or at a high dose ( $>9$ gram n-3 PUFAs per day). Otherwise, n-3 PUFA were consumed in the form of plain fish intake at $>100$ gram fish per day (0.3-5 gram n-3 PUFAs per day). Shown are fractions of studies, in which statistically significant effects of these interventions have been measured. *Essentially triglyceride concentrations, ${ }^{\S}$ mainly fibrinogen and factor VII, "increased or decreased.

Abbreviations for references: 1. Shahar et al, 1993 [30], 2. Li and Steiner, 1990 [31], 3. Svaneborg et al, 1994 [32], 4. Turini et al, 1994 [33], 5. Brown and Roberts, 1991 [34], 6. Møller et al, 1992 [35], 7. Houwelingen van et al, 1988 [36], 8. Skeaff and Holub, 1988 [37], 9. Wojenski et al, 1991 [38], 10. Muller et al, 1989 [39], 11. Nordøy et al, 1994 [40], 12. Thorngren et al, 1984 [41], 13. Emeis et al, 1989 [42], 14. Bang et al, 1971 [43], 15. Prisco et al, 1995 [44], 16. Tremoli et al, 1995 [45], 17. Goodnight et al, 1981 [46], 18. Thorngren and Gustafson, 1981 [47], 19. Østerud et al, 1995 [26], 20. Prisco et al, 1994 [48], 21. Sørensen et al, 1998 [53], 22. Marckmann et al, 1997 [50], 23. Zucker et al, 1988 [51], 24. Scheurlen et al, 1993 [52], 25. Sanders et al, 1997 [27], 26. Hirai et al, 1989 [49], 27. Misso and Thompson, 1995 [54], 28. Simonsen et al, 1988 [28], 29. Mann et al, 1997 [55], 30. Mehta et al, 1988 [56], 31. Oosthuizen et al, 1994 [62], 32. Schmidt et al, 1990 [29], 33. Freese et al, 1997 [58], 34. Hansen et al, 1989 [59], 35. Høstmark et al, 1988 [60], 36. Haglund et al, 1994 [61], 37. Schmidt et al, 1989 [57].

specific coaguiation factors and an altered fibrinolytic activity. Typically, the general outcome of the studies seems hardly to be effected by the dose of consumed $n-3$ PUFA ( $1-6 \mathrm{~g} / \mathrm{d}$ or $>9 \mathrm{~g} / \mathrm{d}$ ) or by the intake form of the $\mathrm{n}-3$ PUFA (capsules of fish oilor fish). Taken together, this short literature review strongly suggests that fish oil has a multi-factorial effect on the haemostatic system, i.e. that it influences a number of 
independent processes and factors which all contribute to thrombosis. Relevant haemostatic processes are described in some detail in the remaining part of this chapter.

\subsection{Platelets}

\section{Platelet activation}

Platelets are small cellular structures in the blood. Under conditions of vessel lesion or vessel wall damage, they aggregate into macroscopic thrombi. Platelets characteristically have a high density of adhesion and signalling receptors on their membrane surface. Platelets can thereby acutely and persistently respond to many changes in their environment. Depending on the receptor type, occupation results in inhibition or stimulation of the platelet activation process. The activation and thrombus formation of platelets is thereby the consequence of many complex intracellular changes. It can be separated in individual responses like shape change (rounding-off), pseudopod formation, secretion of intracellular constituents (among which adenosine diphosphate (ADP)), clustering with other platelets into aggregates, production of PUFA-derived prostanoids, and development of a coagulationpromoting (procoagulant) surface (FIG. 1.2). In all of these responses, an increase in the intracellular free $\mathrm{Ca}^{2+}$ concentration, $\left[\mathrm{Ca}^{2+}\right]$, plays a crucial, stimulating role [6365]. Full description of the signal transduction leading to platelet activation is, due to its high complexity and still incomplete understanding, beyond the scope of this introduction. However, within the context of this thesis, a number of relevant signalling routes are briefly mentioned and are illustrated in FIG. 1.2.

Thrombin, ADP and thromboxane $A_{2}$ stimulate the enzyme phospholipase C- $\beta$ by interacting with $G_{q}$-coupled receptors (the PAR-1, P2Y $Y_{1}$ and $T P \alpha$ receptor, respectively) (FIG. 1.2) [66-68]. Collagen mobilises $\mathrm{Ca}^{2+}$ by signalling through glycoprotein VI, which results in the activation in phospholipase C- $\gamma 2[69,70,157]$. Phospholipase $C$ activation leads to the hydrolysis of phosphatidylinositol 4',5'bisphosphate, yielding both inositol 1',4',5'-trisphosphate (InsP $\left.\mathrm{P}_{3}\right)$ and diacylglycerol. While diacylglycerol is the principal activator of protein kinase $\mathrm{C}$, the formed $\operatorname{InsP}_{3}$ mobilises $\mathrm{Ca}^{2+}$ that is stored in the endoplasmic reticulum to the cytosol.

With all these agonists, the platelet $\mathrm{Ca}^{2+}$ response typically consists of two phases. First, the release of $\mathrm{Ca}^{2+}$ from stores in the endoplasmic reticulum and second the $\mathrm{Ca}^{2+}$ influx from the extracellular medium [63-65,71-73]. When monitored in individual platelets, the various platelet agonists appear to induce a differently shaped $\mathrm{Ca}^{2+}$ response. On the one hand, $A D P$, thromboxane $A_{2}$, or a low dose of thrombin induce oscillating increases in $\left[\mathrm{Ca}^{2+}\right]_{\mathrm{i}}$, which process terminates after 5-10 $\min [72,74]$. Thrombin, at higher doses, causes a continuously high $\mathrm{Ca}^{2+}$ signal, 
which lasts for $15 \mathrm{~min}$ or longer. On the other hand, platelet binding to collagen causes a quite prolonged $\mathrm{Ca}^{2+}$ response, which is essentially non-oscillatory in shape $[75,76]$.

ADP and thrombin activate the $G_{i}$ protein complex through the $P 2 Y_{12}$ receptor and PAR-1 receptor, respectively $[67,160]$. This results in the inhibition of adenylate cyclase and is linked, though in a still poorly understood way, to activation of the fibrinogen receptor, integrin $\alpha_{11 b} \beta_{3}$ (glycoprotein IIb/llla).

Thrombin and collagen also cause the activation of cytosolic phospholipase $A_{2}$ in a way requiring elevated $\left[\mathrm{Ca}^{2+}\right]_{i}$ and protein kinase $C$ mediated protein phosphorylation $[77,78]$. Cytosolic phospholipase $A_{2}$ catalyses the liberation of

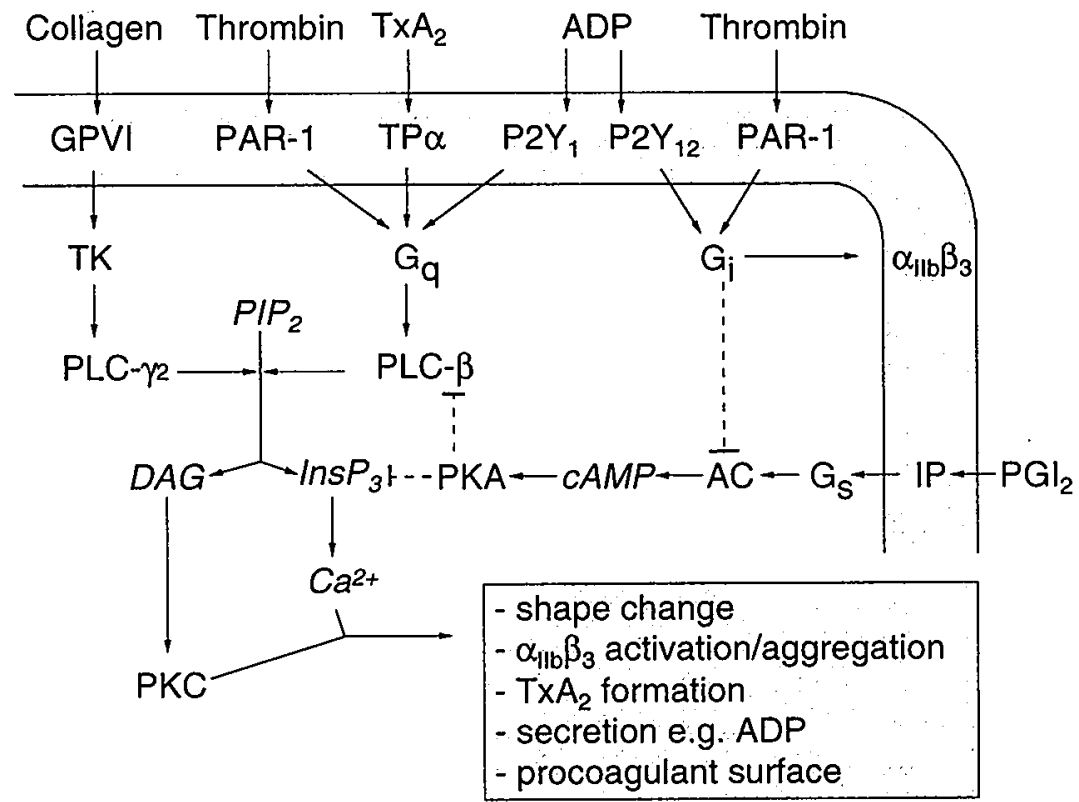

FIGURE 1.2 Schematic presentation of principal signalling routes in platelet activation and the central role of cytosolic $\left[\mathrm{Ca}^{2+}\right]_{\text {i. }}$. For explanations, see text. Solid arrows point to involvement in platelet activation, dashed blocking lines indicate platelet inhibition. Not indicated are signalling routes stimulated by integrin $\alpha_{2} \beta_{1}$ (collagen receptor), PAR-4 (thrombin receptor), P2X, (ADP receptor) and TP $\beta$ (thromboxane receptor- $\beta$ ). Note that prostaglandin $E_{1}$ in a manner resembling that of $P G_{2}$. Abbreviations used: $\alpha_{11 b} \beta_{3}$, fibrinogen receptor; $A C$, adenylate cyclase; ADP, adenosine diphosphate; cAMP, cyclic 3',5'-adenosine monophosphate; DAG, diacylglycerol; GPVI, glycoprotein VI; Gi, guanine binding protein of the inhibitory type; $\mathrm{Gq}$ and $\mathrm{Gs}$, guanine binding proteins of the stimulatory type; Ins $P_{3}$, inositol 1',4',5'-trisphosphate; $I P_{1}$ prostaglandin I-type receptor; $P 2 Y_{1}$ and $P 2 Y_{12}$, purinergic receptors type $2 Y_{1}$ and $2 Y_{12} ; P A R-1$, protease activated receptor type $1 ; P I_{2}$, prostaglandin $I_{2} ; P I P_{2}$, phosphatidylinositol 4',5'-biphosphate; PKA, protein kinase $A$, PKC, protein kinase $C_{i}$ PLC- $\beta$, phospholipase C- $\beta$; PLC- $\gamma 2$, phospholipase C- $\gamma 2$; TK, tyrosine kinase; TP $\alpha$, thromboxane receptor- $\alpha$; TXA $A_{2}$, thromboxane $A_{2}$. 
arachidonic acid (AA) from membrane phospholipids. In activated platelets, $A A$ is converted into prostaglandin $\mathrm{H}_{2}$ by action of the cyclooxygenase synthase and subsequently into thromboxane $A_{2}$ by the action of prostaglandin synthase (FIG. 1.3). These unstable prostanoids are released by platelets and, in turn, potentiate the platelet activation process by interacting with the TP $\alpha$ receptors as described above.

Another $\mathrm{Ca}^{2+}$-dependent process in activated platelets is the so-called procoagulant response. This concerns the surface exposure of the coagulation-

promoting phospholipids, phosphatidylserine and phosphatidylethanolamine, probably by stimulation of a $\mathrm{Ca}^{2+}$-dependent phospholipid scramblase $[79,80]$. This process is strongly dependent on the influx of extracellular $\mathrm{Ca}^{2+}$ and is usually accompanied by the formation of membrane blebs at the platelet surface. It is likely to occur only under potent activating conditions, for instance upon stable platelet adhesion to collagen fibres or platelet interaction with fibrin in the presence of coagulating plasma $[76,81]$.

Platelet aggregation is absolutely dependent on the exposure of high-affinity fibrinogen binding sites of integrin $\alpha_{11 b} \beta_{3}$ at the platelet surface. This integrin is by far the most abundant glycoprotein complex present on platelets $[82,83]$. Various protein kinases, like protein kinase $C$, appear to stimulate the integrin $\alpha_{110} \beta_{3}$ activation $[83,84]$. An increase in $\left[\mathrm{Ca}^{2+}\right]_{i}$ further stimulates this process. Once the fibrinogen binding sites are exposed and the platelets come into contact with each

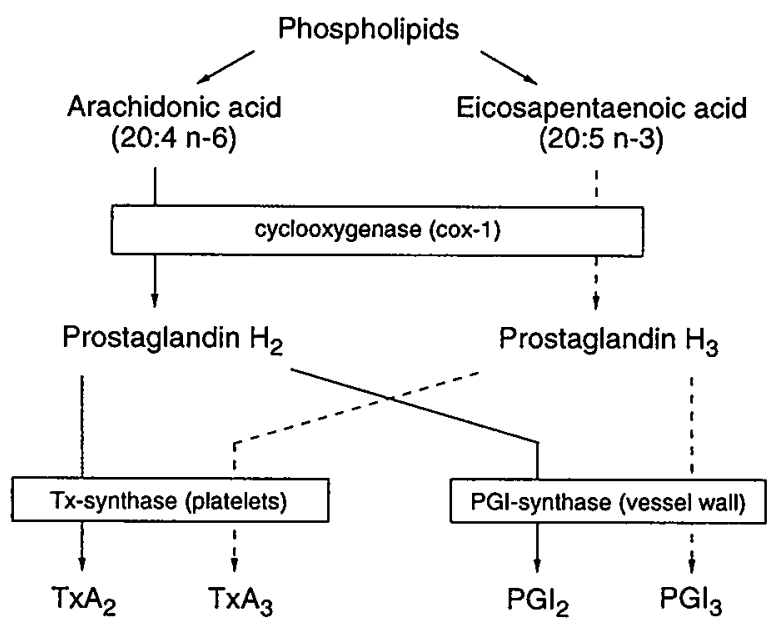

FIGURE 1.3 Scheme of conversion of arachidonic acid into platelet-activating and -inhibiting prostanoids. Solid lines: both in platelets and endothelial cells (vessel wall), free arachidonate is converted into prostaglandin $G_{2}$ and prostaglandin $H_{2}$ by cyclooxygenase (cox-1). The prostaglandin $\mathrm{H}_{2}$, converted by thromboxane (Tx) synthase, serves in platelets as a precursor of thromboxane $A_{2}$ $\left(T \times A_{2}\right.$, platelet-stimulating). In the endothelium prostaglandin $\mathrm{H}_{2}$ acts as a substrate for the plateletinhibiting prostaglandin $\mathrm{I}_{2}\left(\mathrm{PGI}_{2}\right.$ or prostacyclin) that is converted by prostaglandin I (PGI) synthase. Dashed lines: by the same metabolic routes, EPA can be converted into prostanoids of the so-called 3series. Thus, EPA-derived $\mathrm{PGH}_{3}$ is converted into $\mathrm{TXA}_{3}$ in platelets and to $P G I_{3}$ in the vessel wall. 
other by mechanical force, aggregates (thrombi) of platelets and fibrinogen are formed with high efficiency.

Platelets are sensitive to the activation-inhibiting compound prostaglandin $I_{2}$ (prostacyclin). Prostaglandin $I_{2}$ is formed in endothelial cells from $A A$ in an analogous way to platelet thromboxane $A_{2}$ (FIG. 1.3). However, it binds to the IP receptors on the platelet surface, resulting in the activation of the $G_{s}$ protein that then couples to adenylate cyclase [85,86], causing an accumulation of cyclic AMP, which is the unique activator of protein kinase $A$ (FIG. 1.2) $[64,87]$. Protein kinase $A$ inhibits the production of $\operatorname{InsP}_{3}$, decreases $\mathrm{Ca}^{2+}$ mobilisation and establishes the closure of the integrin $\alpha_{110} B_{3}$ receptors $[64,67,71]$.

\section{Dietary n-3 PUFAs and platelet activation}

One of the initial hypotheses to explain the proposed antithrombotic effect of dietary fish was that fish oil may modulate the membrane fatty acid composition and, thereby, the activation tendency of platelets [88]. It has indeed been determined that the consumption of n-3 PUFAs results in a decreased level of $A A$ and increased levels of EPA and DHA in platelet phospholipids $[15,88,89]$. This reduction in platelet AA leads to an almost proportional decrease in thromboxane $A_{2}$ formation after stimulation of the platelets with, for instance, collagen [90,91]. Because (at least in man) the EPA-derived prostanoid thromboxane $A_{3}$ (FIG. 1.3) supports platelet activation in a much less effective manner than thromboxane $A_{2}$, it is assumed that the fish oil-induced reduction in thromboxane $A_{2}$ formation leads to a lower platelet activation tendency [92]. However, in a number of experimental diet studies such an effect on platelet activation was not or hardly observed [93-96].

\subsection{Coagulation}

\section{The coagulation cascade}

Plasma coagulation comprises a complex cascade of enzymatic reactions, which finally results in the formation of a haemostatic fibrin clot. Most coagulation factors are present in plasma as inactive propeptides and need to be cleaved to become proteolytically active. Several pathways lead to fibrin formation $[97,98]$. Presently, the so-called extrinsic coagulation pathway is considered to be the most relevant one in physiology (FIG. 1.4). In this pathway, coagulation is initiated at a damaged site of the vessel wall by presentation of tissue factor, which is normally an encrypted membrane protein. The active tissue factor can be either of vascular origin $[99,100]$, or blood-borne, i.e. derived from leukocytes [101]. Binding of factor VII(a) to the tissue factor leads to activation of factors $\mathrm{IX}$ and $\mathrm{X}$ in a $\mathrm{Ca}^{2+}$-dependent way, with a 
feedback loop towards factor VII activation [98]. In the presence of procoagulant phospholipids and $\mathrm{Ca}^{2+}$, factor IXa associates with its cofactor, factor VIIla. This tenase complex ensures cleavage of factor $X$ into factor $X a$. The produced factor $X a$ has some proteolytic activity towards factor VII and factor V, but is mostly active in the conversion of factor II (prothrombin) to factor lla (thrombin). The so-called prothrombinase complex consists, in addition to factor $\mathrm{Xa}$, of cofactor $\mathrm{Va}, \mathrm{Ca}^{2+}$ and procoagulant phospholipids [102]. Traces of thrombin help to cleave various coagulation factors (e.g. factors $V$ and VIII), which each act as positive feedback loops to enhance the proteolytic cascade. Thus, the formed thrombin ultimately stimulates its own formation. There is a myriad of evidence that activated platelets, exposing phosphatidylserine and phosphatidylethanolamine, form a major source of the procoagulant phospholipids required for adequate tenase and prothrombinase activity $[98,102-104]$. Strictly, the coagulation cascade ends by the thrombin-induced cleavage of fibrinogen and the formation of a fibrin network. However, thrombin clearly plays an additional pivotal role in the haemostatic process, since it also is a potent platelet activator. In plasma, thrombin levels thus need to be strictly controlled. This is achieved by the rapid inactivation of thrombin by its binding to antithrombin and, less abundantly, to $\alpha_{2}$-macroglobulin, $\alpha_{1}$-antitrypsin and platelet

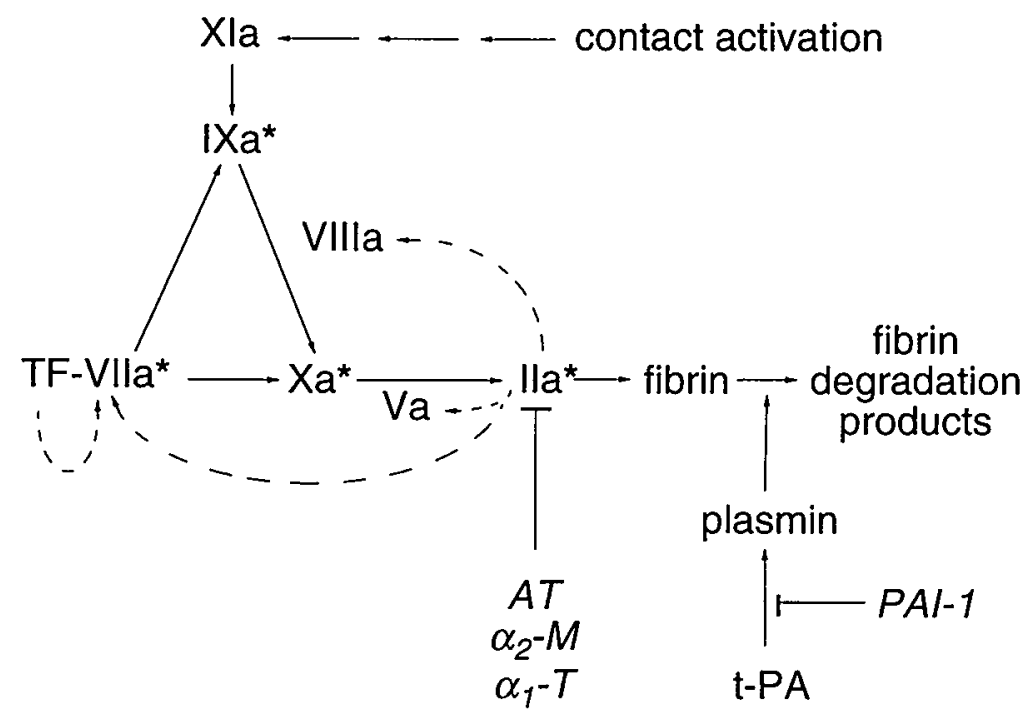

FIGURE 1.4 Simplified pathway of blood coagulation and fibrinolysis. For explanation, see text. Coagulation factors are represented by their roman numbers. Abbreviations: $\alpha_{1}-T, \alpha_{1}$-antitrypsin; $\alpha_{2}-\mathrm{M}$, $\alpha_{2}$-macroglobulin; AT, antithrombin; lla, thrombin; PAI-1, plasminogen activator inhibitor type 1; TF, tissue factor; $t-P A$, tissue type plasminogen activator. Solid arrows point to activation of the coagulation or fibrinolysis cascade, while dashed arrows indicate positive feedback, blocking lines represent inhibition of a reaction or process. Asterisks point to principal ways of stimulation dependent of $\mathrm{Ca}^{2+}$ and platelet-derived negative phospholipids. 
glycoproteins [105]. These thrombin scavengers, therefore, can be considered circulating anticoagulants. Tissue-factor pathway inhibitor and thrombomodulin are other examples of such coagulation-inhibiting factors.

Recently, an elegant method has been developed for the continuous measurement of thrombin activation and inactivation in coagulating plasma, which allows the precise measurement of the coagulation potential of plasma [106]. It was shown that this measurement is more sensitive to detect hypo-coagulant conditions than the traditional measurement of clot formation induced by tissue factor or tissue factor-containing thromboplastin (prothrombin time) [107]. Moreover, the continuous assay, when performed with platelet-containing plasma, directly supports the earlier conclusion that that activated, phosphatidylserine-exposing platelets provide a surface for the tenase and prothrombinase reactions $[79,81,108,109]$.

The coagulation factors II, VII, IX and X all have an amino acid-stretch rich in glutamatic acid residues, which need to be $\gamma$-carboxylated to become coagulationactive. This carboxylation reaction is mainly carried out in the liver as a posttranscriptional event. Vitamin $K$ appears to be a necessary cofactor in the $\gamma$ carboxylation of giutamate residues [110], explaining why these coagulation factors are known as vitamin $\mathrm{K}$-dependent proteins. Anticoagulants such as warfarin inhibit the vitamin $\mathrm{K}$-dependent carboxylation. Especially at a low nutritional vitamin $\mathrm{K}$ intake, the plasma concentrations of the vitamin K-carboxylated coagulation factors appear to be a function of the amount of vitamin $K$ consumed [111,112]. Accordingly, conditions leading to a reduced vitamin $K$ intake or an insufficient vitamin $K$ absorption in the intestine may result in reduced levels of the vitamin $K$-dependent coagulation factors and, thereby, in a diminished coagulation potential.

\section{Dietary n-3 PUFAs and coagulation activation}

Using insensitive coagulation tests such as the prothrombin time, it was initially concluded that $n-3$ PUFA-rich diets were of little effect on the coagulation activity [88]. In later years, several $[30,54,60]$ but not all $[47,113]$ authors have reported on a reduction in fibrinogen levels after intake of dietary fish oil (TABLE 1.1). Although some recent studies failed to detect effects on the coagulation process $[39,47,114]$, a few reports point to a slightly reduced prothrombin time in response to dietary fish oil [54]. Decreased levels of individual coagulation factors, particularly of factors VII and $X$, have also been demonstrated $[30,115-117]$. There is also a report of a lower level of the prothrombin fragment $1+2$ in plasma, suggesting that fish oil may decrease the in vivo formation of thrombin [26]. On the other hand, at least two studies show an increase in fasting level of factor VII in response to fish (oil) diet $[58,90]$. In summary, the literature provides some indications that dietary n-3 PUFAs lower the coagulation profile, but the data are rather inconsistent perhaps because of the difficulty of detecting small hypo-coagulant conditions with classical, global coagulation tests. 


\subsection{Vessel wall and fibrinolysis}

\section{Control of haemostatic activity by the vessel wall}

Blood vessels evidently control haemodynamics. When intact and covered with endothelial cells, the vessel wall will potently suppress the haemostatic process and thus prevent thrombus formation. The endothelium covering the vessel wall plays a key role herein. Recent reviews describe the underlying biochemistry and cell biology in much detail $[118,119]$. In the context of this thesis, only principal regulatory mechanisms are mentioned. The release of nitric oxide and prostaglandin 12, and their subsequent platelet-inhibiting effect accomplish part of the anti-haemostatic effect of endothelial cells [120]. Both compounds have a relatively short half-life time (tens of seconds) in plasma, but they suppress platelet responses to essentially all agonists $[118,121]$. In general, the structurally and functionally intact endothelium can be considered as platelet inhibiting. We realise that the function of the vessel wall extends that of merely being a supply of anti-platelet agents, but again the experimental chapters of this thesis restrict the content of this introduction.

Lesion of a vessel wall or structural damage to the endothelium, e.g. following rupturing of an atherosclerotic plaque, results in a sudden change, where the vessel wall becomes transformed into a haemostatic and thrombogenic surface. Exposure of the sub-endothelial matrix, rich in platelet-adhesive proteins such as collagen and fibronectin, leads to rapid adhesion of circulating platelets. Particularly, under highshear conditions, adhesion also depends on von Willebrand factor, which is deposited in the extracellular matrix by endothelial cells and can also be released by platelets themselves [122]. As indicated above, platelet-collagen contact causes a whole array of activation events in platelets. The extracellular matrix may also contain encrypted tissue factor, which, upon binding to factor VII(a), triggers the coagulation cascade and stimulates thrombin generation $[123,124]$.

Healthy endothelial cells also produce anti-coagulant factors like tissue-factorpathway inhibitor, heparin, antithrombin and thrombomodulin. In addition, they release tissue-type plasminogen activator (t-PA) and plasminogen-activator inhibitor type 1 (PAl-1), both of which are enzymes involved in fibrinolysis (FIG. 1.4). The former, $t-P A$, is responsible for the initial cleavage of plasminogen leading to the formation plasmin, which degrades fibrin clots. In contrast, PAI-1 acts as an antifibrinolytic factor. It serves to rapidly complex with and thus inhibits circulating t-PA, thereby abolishing plasminogen degradation. High fibrinolytic activity, i.e. high clot lysis, is considered to be anti-thrombotic. Accordingly, it is not surprising that low tPA activity and high PAl-1 levels associate positively with an increased risk of ischemic heart disease and myocardial infarction $[117,125]$. 


\section{Dietary n-3 PUFAs and vessel wall function}

Like in other tissues, dietary fish oil and n-3 PUFAs partially replace the AA in the endothelial membrane phospholipids by n-3 PUFAs such as EPA and DHA $[95,126,127]$. The endothelial prostaglandin synthase complex converts AA and EPA into prostaglandin $I_{2}$ and prostaglandin $I_{3}$, respectively (FIG. 1.3). Early data indicate that these prostaglandins are produced at amounts reflecting the AA and EPA content in the membranes, and that they are equally potent in inhibiting platelet activation $[92,128,129]$. Thus, an explanation for the advantageous effect of dietary $n-3$ PUFAs could be that these reduce the platelet-stimulating effect of thromboxane production, while they leave unchanged or even increase the platelet-inhibiting effect of vessel-wall derived prostaglandins. One of the few data supporting this hypothesis is that the urinary concentrations of platelet-derived thromboxane metabolites were low in Eskimos and other subjects consuming fish-oil, while those of endothelialderived prostaglandin metabolites were relatively high $[128,133]$. Accordingly, it has been proposed that fish oil diet may influence the so-called thromboxaneprostaglandin balance of platelet activation in a favourable, i.e. less plateletstimulating, way [130-132].

\section{Dietary $n-3$ PUFAs and fibrinolysis}

Nutritional intake of $n-3$ PUFAs has been associated with increased t-PA activity [117] and with either reduced [56] or increased $[29,35,57,134]$ levels of PAI-1. In one study it is reported that the euglobin clot lysis time, as a parameter representing the total fibrinolytic activity, significantly increases after dietary fish intake [34]. However, other groups were unable to find such an effect of n-3 PUFAs on fibrinolysis has not been detected in other studies $[48,59,135]$. Thus, the effects of dietary $n-3$ PUFA on fibrinolytic parameters are inconclusive.

\subsection{Blood lipids}

\section{Lipid transport in blood}

Lipids are transported in the blood as complexes with amphipathic proteins. Plasma albumin mostly carries free fatty acids. Chylomicrons and various types of lipoprotein particles transport fatty acids, from tissue to tissue, mainly being esterified into triglycerides (sn-1,2,3-triacylglycerols) and phospholipids. Chylomicrons transport the triglycerides (post-prandially) from intestine to liver and peripheral tissue, while the very low-density lipoproteins are responsible for the triglyceride transport from liver to peripheral tissue $[136,137]$. Once the triglycerides are delivered, the very low-density lipoproteins continue their way as remnant low-density lipoproteins, which serve to 
transport cholesterol esters to peripheral cells that are equipped with special receptors for the low-density lipoproteins. In contrast, the high-density lipoproteins transport cholesterol (again in ester form) from the peripheral tissues back to the liver [138]. Evidence is increasing that the triglyceride level is an independent risk factor for cardiovascular disease [13]. Strong risk factors are without doubt an increased level of cholesterol in low-density lipoproteins (or total cholesterol) and a low amount of cholesterol in high-density lipoproteins $[11-13,139,140]$.

\section{Dietary n-3 PUFAs and blood lipids}

Already in 1971, it was clear that Greenland Eskimos had relatively low plasma levels of triglycerides and cholesterol in both very low- and low-density lipoproteins, while the cholesterol in high-density lipoproteins was high in comparison to Danish controls [43]. Later investigations indicated that a reduced triglyceride level, $25-30 \%$, is one of the most consistent effects of dietary n-3 PUFAs [96,141-143]. Total cholesterol is not materially affected by dietary n-3 PUFA, low density lipoprotein cholesterol concentrations tend to rise by $5-10 \%$ and high density lipoprotein cholesterol by $1-3 \%[141,143,144]$.

\subsection{Animal models of arterial thrombosis}

In man, it obviously is difficult to determine the tendency of arterial thrombosis. Accordingly, animal models have been developed to evaluate the possible antithrombotic effects of pharmacological and nutritional interventions. Although rats do naturally not develop thrombosis, this animal species has widely been used to measure arterial thrombus formation, e.g. after artificial damaging of an arterial vessel wall. One of the early methods to determine the thrombosis tendency in rats uses the continuous vessel wall-damaging effect of a plastic loop-shaped canula that is directly inserted into the abdominal aorta. The gradual increase in damage of the vessel wall results in the formation of a thrombus that suddenly becomes vasoocclusive. Various studies have shown that this model is sensitive to anti-platelet drugs and anti-coagulants, and that it responds to the type of dietary fat $[90,145$ 147]. This in vivo model is used in part of the investigations of this thesis.

Although blood lipid metabolism is considerably different between man and rat, both show reduced triglyceride levels after dietary n-3 PUFA $[93,148,149]$. The use of rats to investigate the mechanisms underlying the potential anti-thrombotic effect of dietary n-3 PUFAs is validated by research in various areas. Furthermore, intervention with dietary fish oil appeared to reduce the size of artificially induced infarcts in rats, which effect was accompanied by an increased bleeding time and altered platelet function [150]. Dietary n-3 PUFAs also prolonged the thrombotic occlusion time of cerebral and femoral arteries in rats that were subjected to 
photochemical-induced vessel wall injury $[151,152]$. Finally, many in vitro studies with rats have pointed to effects of dietary n-3 PUFAs on platelet function, coagulation, blood lipids and fibrinolysis [93-95,149,153-156], all of that resemble the effects obtained with humans.

\subsection{Outline of this thesis}

Starting from the premise that fish-oil consumption has a cardiovascular-protective effect, and that this effect is likely to be multi-factorial, this thesis considers the effects of dietary fish oil on a number of haemostatic functions and on the arterial thrombosis tendency. It was aimed to investigate not only individual haemostatic parameters like platelet activation and levels of coagulation factors, but also to monitor in vivo effects and to consider interactions of such parameters. For reasons indicated above, the rat was chosen as animal model to study these effects.

Arterial thrombosis. In CHAPTER 2, a study is described, in which the optimal dose of dietary n-3 PUFAs on arterial thrombosis tendency is determined, using an established in vivo rat model. The effects are also compared of a single dose of EPA, DHA or a mixture of n-3 PUFAs, to determine the anti-thrombotic effects of the individual n-3 PUFAs. Observed effects on the thrombosis tendency are related to effects on platelet function ex vivo.

Platelet activation. CHAPTER 3 describes the results of an investigation on the reducing effects of dietary n-3 PUFAs on the production of both platelet-derived thromboxane and vessel wall-derived prostaglandin $\mathrm{I}_{2}$. Combined effects of these autocoids are considered on the process of platelet activation in a test system, where isolated platelets are incubated with aortic material. In particular, it is investigated is how this dietary intervention influences the thromboxaneprostaglandin balance of platelet activation.

Coagulation. Firstly, it is described how sensitive methods to determine hypocoagulation in human plasma are adapted and validated for use with rat plasma (CHAPTER 4). CHAPTER 5 describes a study on the effects of increasing doses of dietary n-3 PUFAs on the coagulation activity of rat plasma. Platelet function, fibrinolysis parameters and blood lipids are also measured. In addition, the effect of fish-oil diets is compared to the anti-coagulant effect of vitamin $K$ antagonists. CHAPTER 6 then describes the effects of low doses of dietary n-3 PUFAs under conditions of restricted vitamin $\mathrm{K}$ intake. It is questioned whether the proposed hypocoagulant effect of dietary fish oil can completely be ascribed to an altered vitamin $\mathrm{K}$ status.

Interaction of platelet activation and coagulation. in a small study with human plasma, it is investigated by which conditions platelets in contact with fibrin or 
fibrinogen are able to support the coagulation process, i.e. to generate a coagulation-promoting surface (CHAPTER 7). The results obtained are used for experiments, where the interaction of the processes of coagulation and platelet activation to support haemostasis are studied in flowing, whole rat blood, using a combination of microscopic vital imaging techniques (CHAPTER 8).

Discussion. Finally, in CHAPTER 9, the main results of this thesis are discussed, and a model is presented of how dietary n-3 PUFAs may exert their antithrombotic effect by interfering in the interaction of platelet activation and coagulation.

\subsection{References}

1. Murray CJL, Lopez AD. The global burden of disease. In: (Eds). Global Burden of Disease and Injury. Harvard University School of Public Health, Boston, USA, 1996.

2. Trip MD, Cats VM, van Capelle FJL, Vreeken J. Platelet hyperreactivity and prognosis in survivors of myocardial infarction. N Engl J Med. 1990;322:1549-1554.

3. Thaulow E, Erikson J, Sandvik L, Stormorken H, Cohn PF. Blood platelet count and function are related to total and cardiovascular death in apparently healthy men. Circulation. 1991:84:613-617.

4. Meade TW, Ruddock V, Stirling $Y$, Chakrabarti R, Miller GJ. Fibrinolytic activity, clotting factors, and long term incidence of ischaemic heart disease in the Northwick Park Heart Study. Lancet. 1993;342:1076-1079.

5. Heinrich J, Balleisen L, Schulte H, Assmann G, van de Loo J. Fibrinogen and factor VII in the prediction of coronary risk. Results from the PROCAM study in healthy man. Arteriocler Thromb. 1994; 14:54-59.

6. Junker $R$, Heinrich J, Schulte $H$, van de Loo J, Assmann G. Coagulation factor VII and the risk of coronary heart disease in healthy men. Arterioscler Thromb Vasc Biol. 1997;17:1539-1544.

7. Folsom AR, Wu KK, Rosamond WD, Sharett AR, Chambless LE. Prospective study of hemostatic factors and incidence of coronary heart disease. Circulation. 1997;96:1102-1108.

8. Ernst $E_{1}$ Resch KL. Fibrinogen as a cardiovascular risk factor: a meta-analysis and review of the literature. Ann Intern Med. 1993;118:956-963.

9. Calverley DC, Roth GJ. Antiplatelet therapy. aspirin, ticlopidine/clopidogrel, and anti-integrin agents. Hematol Oncol Clin North Am. 1998;12:1231-1249.

10. Bates SM, Weitz Jl. Prevention of activation of blood coagulation during acute coronary ischemic syndromes: beyond aspirin and heparin. Cardiovasc Res. 1999;41:418-432.

11. Gordon T, Kannel WB, Castelli WB, Dawber TR. Lipoproteins, cardiovascular diseases and death: the Framingham study. Arch Intern Med. 1981;141:1128-1131.

12. Tervahauta $M$, Pekkanen $J$, Kivinen $P$, Stengard $J$, Jauhiainen $M$, Ehnholm $C$, Nissinen $A$. Prevalence of coronary heart disease and associated risk factors among elderly Finnish men in the seven countries study. Atherosclerosis. 1993;104:47-59.

13. Austin MA. Plasma triglycerides and coronary heart disease. Arterioscler Thromb. 1991;11:214.

14. Bang HO, Dyerberg J. Plasma lipids and lipoproteins in Greenland west-coast Eskimos. Acta Med Scand. 1972; 192:85-94.

15. Bang HO, Dyerberg J. Lipid metabolism and ischemic heart disease in Greenland Eskimos. In: Draper HH (Eds.) Advances in Nutritional Research. Plenum Press, New York, NY, USA, 1980, p. 1-22.

16. Nettleton JA. $\omega-3$ Fatty acids: comparison of plant and seafood sources in human nutrition. $J$ Am Diet Assoc. 1991;91:331-337. 
17. Schacky von C, Weber PC. Metabolism and effects on platelet function of the purified eicosapentaenoic and docosahexaenoic acid in humans. J Clin Invest. 1985;76:2446-2450.

18. Kromhout $D$, Bosschieter EB, De Lezenne Coulander $C$. The inverse relation between fish consumption and 20-year mortality from coronary heart disease. $N$ Engl $J$ Med. 1985;312:1205-1209.

19. Burr ML, Fehily AM, Gilbert JF, Rogers S, Holliday RM, Sweetman PM, Elwood PC, Deadman NM. Effects of changes in fat, fish, and fibre intakes on death and myocardial reinfarction: diet and reinfarction trail (DART). Lancet. 1989;ii:757-761.

20. Lorgeril de $M$, Renaud S, Mamelle $N$, Salen $P$, Martin J-L, Monjaud I, Guidollet J, Touboul P, Delaye J. Mediterranean $\alpha$-linolenic acid-rich diet in secondary prevention of coronary heart disease. Lancet. 1994;343:1454-1459.

21. Burr GO, Burr MM. A new deficiency disease produced by rigid exclusion of rat from the diet. $J$ Biol Chem. 1929;25:629-638.

22. Burr GO, Burr MM. On the nature and role of fatty acids essential in nutrition. $J$ Biol Chem. 1930;86:587-621.

23. Guallar $\mathrm{E}$, Hennekens $\mathrm{CH}$, Sacks FM, Willett WC, Stampfer MJ. A prospective study of plasma fish oil levels and incidence of myocardial infarction in US male physicians. J Am Coll Cardiol. 1995;25:387-394.

24. Ascherio A, Rimm EB, Stampfer MJ, Giovannucci EL, Willett WC. Dietary intake of marine n-3 fatty acids, fish intake, and the risk of coronary disease among men. $N$ Engl $J$ Med. 1995;332:977-982.

25. Leaf A. Health claims: $\omega-3$ fatty acids and cardiovascular disease. Nutr Rev. 1992;50:150-154.

26. Østerud B, Elvevoll E, Barstad H, Brox J, Halvorsen H, Lia K, Olsen JO, Olsen RL, Sissener C, Rekdal $\varnothing$, Vognild E. Effect of marine oils supplementation on coagulation and cellular activation in whole blood. Lipids. 1995;30:1111-1118.

27. Sanders TA, Oakley FR, Miller GJ, Mitropoulos KA, Crook D, Oliver MF. Influence of $n-6$ versus $n-3$ polyunsaturated fatty acids in diets low in saturated fatty acids on plasma lipoproteins and hemostatic factors. Arterioscler Thromb Vasc Biol. 1997;17:3449-3460.

28. Simonsen T, Nordøy A, Sjunneskog C, Lyngmo V. The effect of cod liver oil in two populations with low and high intake of dietary fish. Acta Med Scand. 1988;223:491-498.

29. Schmidt EB, Varming $K$, Ernst E, Madsen $P$, Dyerberg J. Dose-response studies on the effects of $n-3$ polyunsaturated fatty acids on lipids and haemostasis. Thromb Haemost. 1990;63:1-5.

30. Shahar E, Folsom AR, Wu KK, Dennis BH, Shimakawa T, Conlan MG, Davis CE, Williams OD. Association of fish intake and dietary $n-3$ polyunsaturated fatty acids with a hypocoagulable profile. Arterioscler Thromb. 1993;13:1205-1212.

31. Li X, Steiner M. Fish oil: a potent inhibitor of platelet adhesiveness. Blood. 1990;76:938-945.

32. Svaneborg N, Møller JM, Schmidt EB, Varming K, Lervang HH, Dyerberg J. The acute effects of a single very high dose of $n-3$ fatty acids on plasma lipids and lipoproteins in healthy subjects. Lipids. 1994;29:145-147.

33. Turini ME, Powell WS, Behr SR, Holub BJ. Effects of a fish-oil and vegetable-oil formula on aggregation and ethanolamine-containing lysophospholipid generation in activated human platelets and on leukotriene production in stimulated neutrophils. Am J Clin Nutr. 1994;60:717724.

34. Brown AJ, Roberts DCK. Fish and fish oil intake: effect on haematological variables related to cardiovascular disease. Thromb Res. 1991;64:169-178.

35. Møller JM, Svaneborg N, Lervang H-H, Varming K, Madsen P, Dyerberg J, Schmidt EB. The acute effect of a single very high dose of $n-3$ fatty acids on coagulation and fibrinolysis. Thromb Res. 1992;67:569-577.

36. Houwelingen van AC, Hennissen AAHM, Verbeek-Schippers F, Simonsen T, Kester ADM, Hornstra G. Effect of a moderate fish intake on platelet aggregation in human platelet-rich plasma. Thromb Haemost. 1988;59:507-513.

37. Skeaff CM, Holub BJ. The effect of fish oil consumption on platelet aggregation responses in washed human platelet suspensions. Thromb Res. 1988;51:105-115.

38. Wojenski $\mathrm{CM}$, Silver MJ, Walker J. Eicosapentaenoic acid ethyl ester as an antithrombotic agent: comparison to an extract of fish oil. Biochim Biophys Acta. 1991;1081:33-38. 
39. Muller AD, Houwelingen van AC, van Dam-Mieras MCE, Bas BM, Hornstra G. Effect of a moderate fish intake on haemostatic parameters in healthy males. Thromb Haemost. 1989;61:468-473.

40. Nordøy A, Hatcher L, Goodnight S, Fitzgerald GA, Connor WE. Effects of dietary fat content, saturated fatty acids, and fish oil on eicosanoid production and hemostatic parameters in normal men. J Lab Clin Med. 1994;123:914-920.

41. Thorngren $M$, Shafi $S$, Born GVR. Delay in primary haemostasis produced by a fish diet without change in local thromboxane A2. Br J Haematol. 1984;58:567-578.

42. Emeis JJ, van Houwelingen $A C$, van den Hoogen $\mathrm{CM}$, Hornstra G. A moderate fish intake increases plasminogen activator inhibitor type-1 in human volunteers. Blood. 1989;74:233237.

43. Bang HO, Dyerberg J, Nielsen AB. Plasma lipid and lipoprotein pattern in Greenlandic westcoast Eskimos. Lancet. 1971;i:1143-1145.

44. Prisco D, Filippini M, Paniccia R, Gensini GF, Serneri GGN. Effect of $n-3$ fatty acid ethyl ester supplementation on fatty acid composition of the single platelet phospholipids and on platelet functions. Metabolism. 1995;44:562-569.

45. Tremoli E, Maderna P. Marangoni F, Colli S, Eligini S, Catalano I, Angeli MT, Pazzucconi $F$, Gianfranceschi G, Davi G, Stragliotto $E$, Sirtori $C R$, Galli $C$. Prolonged inhibition of platelet aggregation after $\mathrm{n}-3$ fatty acid ethyl ester ingestion by healthy volunteers. Am J Clin Nutr. 1995;61:607-613.

46. Goodnight SH, Harris W, Connor WE. The effect of dietary $\omega-3$ fatty acid on platelet composition and function in man: a prospective, controlled study. Blood. 1981;58:880-885.

47. Thorngren $M$, Gustafson A. Effects of 11 -week increase in dietary eicosapentaenoic acid on bleeding time, lipids, and platelet aggregation. Lancet. 1981;ii:1190-1193.

48. Prisco D, Paniccia R, Filippini M, Francalanci I, Bandinelli B, Comeglio P, Rostagno C, Abbate $R$, Serneri GGN. No changes in PAI-1 levels after four-month n-3 PUFA ethyl ester supplementation in healthy subjects. Thromb Res. 1994;76:237-244.

49. Hirai A, Terano $T$, Tamura $Y$, Yoshida S. Ejcosapentaenoic acid and adult diseases in Japan: epidemiological and clinical aspects. J Int Med. 1989;225:69-75.

50. Marckmann $P$, Bladbjerg E-M, Jespersen J. Dietary fish oil (4 $\mathrm{g}$ daily) and cardiovascular risk markers in healthy men. Arterioscler Thromb Vasc Biol. 1997;17:3384-3391.

51. Zucker ML, Bilyeu DS, Helmkamp GM, Harris WS, Dujovne CA. Effects of dietary fish oil on platelet function and plasma lipids in hyperlipoproteinemic and normal subjects. Atherosclerosis. 1988;73:13-22.

52. Scheurlen $M$, Kirchner $M$, Clemens MR, Jaschonek $K$. Fish oil preparations rich in docosahexaenoic acid modify platelet responsiveness to prostaglandinendoperoxide/thromboxane $A_{2}$ receptor agonists. Biochem Pharmacol. 1993;46:245-249.

53. Sørensen NS, Marckmann P, Høy CE, van Duyvenvoorde W, Princen HM. Effect of fish-oilenriched margarine on plasma lipids, low-density-lipoprotein particle composition, size, and susceptibility to oxidation. Am J Clin Nutr. 1998;68:235-241.

54. Misso $L$. Fish oil supplementation inhibits platelet aggregation and ATP release induced by platelet-activating factor and other agonists. Platelets. 1995;6:275-282.

55. Mann N, Sinclair A, Pille M, Johnson L, Warrick $G$, Reder E, Lorenz R. The effect of short-term diets rich in fish, red meat, or white meat on thromboxane and prostacyclin synthesis in humans. Lipids. 1997;32:635-644.

56. Mehta J, Lawson D, Saldeen T. Reduction in plasminogen activator inhibitor-1 (PAl-1) with omega-3 polyunsaturated fatty acid (PUFA) intake. Am Heart J. 1988;116:1201-1206.

57. Schmidt EB, Sørensen PJ, Ernst E. Studies on coagulation and fibrinolysis in Greenland Eskimos. Thromb Res. 1989;56:553-558.

58. Freese R, Mutanen M. Small effects of linseed oil or fish oil supplementation on postprandial changes in hemostatic factors. Thromb Res. 1997;85:147-152.

59. Hansen J-B, Olsen JO, Wilsgård L, Østerud B. Effects of dietary supplementation with cod liver oil on monocyte thromboplastin synthesis, coagulation and fibrinolysis. $J$ int Med. 1989;225:133-139.

60. Høstmark AT, Bjerkedal $T$, Kierulf $P$, Flaten $H_{1}$ Ulshagen $K$. Fish oil and plasma fibrinogen. $\mathrm{Br}$ Med J. 1988;297:180-181. 
61. Haglund O, Mehta JL, Saldeen T. Effects of fish oil on some parameters of fibrinolysis and lipoprotein(a) in healthy subjects. Am J Cardiol. 1994;74:189-192.

62. Oosthuizen W, Voster HH, Jerling JC, Barnard HC, Smuts CM, Silvis N, Kruger A, Venter CS. Both fish oil and olive oil lowered plasma fibrinogen in women with high baseline fibrinogen levels. Thromb Haemost. 1994;72:557-562.

63. Heemskerk JWM, Sage SO. Calcium signalling in platelets and other cells. Platelets. 1994:5:295-316.

64. Authi KS. Calcium homeostasis in human platelets. In: von Bruchhausen $F$ and Walter $U$ (Eds.) Handbook of Experimental Pharmacology. Springer, Berlin, 1997, p. 325-370.

65. Heemskerk JWM. Calcium and platelets. In: Pochet R, Donato R, Haiech R, Heizmann C and Gerke V (Eds). The Molecular Basis of Calcium Action in Biology and Medicine. Kluwer Academic Publishers, Dordrecht, the Netherlands, 2000, p. 45-71.

66. Offermanns $\mathrm{S}$, Toombs CF, Hu YH, Simon MI. Defective platelet activation in G $\alpha q$-deficient mice. Nature. 1997;389:183-186.

67. Brass LF, Manning DR, Cichowsky K, Abrams CS. Signaling through $G$ proteins in platelets: to the integrins and beyond. Thromb Haemost. 1997;78:581-589.

68. Coughlin SR. How the protease thrombin talks to cells. Proc Natl Acad Sci USA. 1999;96:11023-11027.

69. Moroi M, Jung SM. Platelet receptors for collagen. Thromb Haemost. 1997;78:439-444.

70. Watson SP. Collagen receptor signaling in platelets and megakaryocytes. Thromb Haemost. 1999;82:365-376.

71. Cavallini L, Coassin M, Borean A, Alexandre A. Prostacyclin and sodium nitroprusside inhibit the activity of the platelet inositol 1,4,5-trisphosphate receptor and promote its phosphorylation. J Biol Chem. 1996;271:5545-5551.

72. Heemskerk JWM, Feijge MAH, Henneman L, Rosing J, Hemker HC. The Ca2t mobilizing potency of $\alpha$-thrombin and thrombin-receptor-activating peptide on human platelets. Concentration and time effects of thrombin induced $\mathrm{Ca}^{2+}$ signaling. Eur $\mathrm{J}$ Biochem. 1997;249:547-555.

73. Sage SO, MacKenzie AB, Jenner S, Mahaut-Smith MP. Purinoceptor-evoked calcium signalling in human platelets. Prostaglandins Leukotrienes Essent Fatty Acids. 1997;57:435438.

74. Heemskerk JWM, Vis $P$, Feijge MAH, Hoyland J, Mason WT, Sage So. Role of phospholipase $\mathrm{C}$ and $\mathrm{Ca}^{2+}$-ATPase in calcium responses of single, fibrinogen-bound platelets. $J$ Biol Chem. 1993:268:356-363.

75. Heemskerk JWM, Vuist WMJ, Feijge MAH, Reutelingsperger CPM, Lindhout T. Collagen but not fibrinogen surfaces induce bleb formation, exposure of phosphatidylserine, and procoagulant activity of adherent platelets: evidence for regulation by protein tyrosine kinase dependent $\mathrm{Ca}^{2}+$ responses. Blood. 1997;90:2615-2625.

76. Heemskerk JWM, Siljander $P$, Vuist WMJ, Breikers $G$, Reutelingsperger CPM, Barnes MJ, Knight CG, Lassila R, Farndale RW. Function of glycoprotein $V \mid$ and integrin $\alpha_{2} \beta_{1}$ in the procoagulant response of single, collagen-adherent platelets. Thromb Haemost. 1999;81:782792.

77. Puri RN. Phospholipase $A_{2}$ : its role in $A D P$ - and thrombin-induced platelet activation mechanisms. Internatl J Biochem Cell Biol. 1998;30:1107-1122.

78. Börsch-Haubold AG, Ghomashchi F, Pasquet S, Goedert M, Cohen P, Gelb MH, Watson SP Phosphorylation of cytosolic phospholipase $A_{2}$ in platelets is mediated by multiple stressactivated protein kinase pathways. Eur J Biochem. 1999;265:195-203.

79. Bevers EM, Comfurius P, Rijn van JLML, Hemker HC, Zwaal RFA. Generation of prothrombinconverting activity and the exposure of phosphatidylserine at the outer surface of platelets. Eur J Biochem. 1982;122:429-436.

80. Zwaal RFA, Schroit AJ. Pathophysiologic implications of membrane phospholipid asymmetry in blood cells. Blood. 1997;89:1121-1132.

81. Reverter JC, Béguin S, Kessels H, Kumar R, Hemker HC, Coller BS. Inhibition of plateletmediated, tissue factor-induced thrombin generation by the mouse/human chimeric $7 \mathrm{E} 3$ antibody. Potential implications for the effect of c7E3 Fab treatment on acute thrombosis and "clinical restenosis". J Clin Invest. 1996;98:863-874. 
82. Kroll $\mathrm{MH}$. Mechanisms of platelet activation. In: Loscalzo J and Schafer Al (Eds). Thrombosis and Hemorrhage. Blackwell Scientific, Boston, USA, 1994, p. 247-277.

83. Shattil SJ, Kashiwagi $H$, Pampori $N$. Integrin signaling: the platelet paradigm. Blood. 1998;91:2645-2657.

84. Hers I, Donath J, van Willigen G, Akkerman JWN. Differential involvement of tyrosine and serine/threonine kinases integrin $\alpha_{\| b} \beta_{3}$ exposure. Arterioscler Thromb Vasc Biol. 1998; 18:404-414.

85. Hourani SM, Cusack NJ. Pharmacological receptors on blood platelets. Pharmacol Rev. 1991;43:243-298.

86. Nakagawa $O$, Tanaka I, Usui $T$, Harada $M$, Sasaki $Y$, Itoh $H$, Yoshimasa $T$, Namba $T$, Narumiya S, Nakao K. Molecular cloning of human prostacyclin receptor CDNA and its gene expression in the cardiovascular system. Circulation. 1994;90:1643-1647.

87. Halbrugge $\mathrm{M}$, Walter $\mathrm{U}$. The regulation of platelet function by protein kinases. In: Huang $\mathrm{C}-\mathrm{K}$ and Sha'afi RI (Eds). Protein Kinases in Blood Cell Function. CRC Press, Boca Raton FL, USA, 1993, p. 246-298.

88. Dyerberg J, Bang HO. Haemostatic function and platelet polyunsaturated fatty acids in Eskimos. Lancet. 1979;ii:433-435.

89. Dyerberg J, Bang HO, Hjørne N. Fatty acid composition of the plasma lipids in Greenland Eskimos. Am J Clin Nutr. 1975;28:958-966.

90. Hornstra G. Dietary Fats, Prostanoids and Arterial Thrombosis. Martinus Nijhoff Publ, The Hague, the Netherlands, 1982.

91. Heemskerk JWM, Hoyland J, Mason WT, Sage SO. Spiking in cytosolic calcium concentration in single fibrinogen-bound fura-2-loaded human platelets. Biochem J. 1992;283:379-383.

92. Needleman P, Raz A, Minkes MS, Ferrendelli JA, Sprecher H. Triene prostaglandins: prostacyclin and thromboxane biosynthesis and unique biological properties. Proc Natl Acad Sci USA. 1979;76:944-948.

93. Herold PM, Kinsella JE. Fish oil consumption and decreased risk of cardiovascular disease: a comparison of findings from animal and human feeding trials. Am J Clin Nutr. 1986;43:566598.

94. Hornstra $G$. The significance of fish and fish-oil enriched food for prevention and therapy of ischaemic cardiovascular disease. In: Vergroesen AJ and Crawford MA (Eds). The Role of Fats in Human Nutrition II. Academic Press, New York, USA, 1989, p. 151-235.

95. Heemskerk JWM, Vossen RCRM, van Dam-Mieras MCE. Polyunsaturated fatty acids and function of platelets and endothelial cells. Curr Opin Lipidol. 1996;7:24-29.

96. Malle E, Kostner GM. Effects of fish oils on lipid variables and platelet function indices. Prostaglandins Leukotrienes Essent Fatty Acids. 1993;49:645-663.

97. Macfarlane RG. An enzyme cascade in the blood clotting mechanism and its function as a biochemical amplifier. Nature. 1964;202:498-500.

98. Mann KG, Krishnaswamy S, Lawson JH. Surface-dependent hemostasis. Semin Hematol. 1992;29:213-226.

99. Nemerson Y. The tissue factor pathway of blood coagulation. Semin Hematol. 1992;29:170176.

100. Nemerson Y, Giesen PL. Some thoughts about localization and expression of tissue factor. Blood Coagul Fibrinolysis. 1998;9 Suppl 1:S45-S47.

101. Giesen PLA, Raugh U, Bohrmann B, Kling D, Roqué M, Fallon JT, Badimon JJ, Himber J, Riederer MA, Nemerson Y. Blood-born tissue factor: Another view of thrombosis. Proc Natl Acad Sci USA. 1999;96:2311-2315.

102. Hemker HC. Thrombin generation, an essential step in haemostasis and thrombosis. In: Bloom AL, Forbes ED, Thomas DP and Tuddenham EGD (Eds.) Haemostasis and Thrombosis. Churchill Livingstone, London, UK, 1994, p. 477-490.

103. Beguin S, Kumar R. Thrombin, fibrin and platelets: a resonance loop in which von Willebrand factor is a necessary link. Thromb Haemost. 1997;78:590-594.

104. Hemker HC, Giesen PLA, Ramjee M, Wagenvoord R, Béguin S. The thrombogram: monitoring thrombin generation in platelet rich plasma. Thromb Haemost. 2000;83:589-591.

105. Béguin $\mathrm{S}$, Lindhout $\mathrm{T}$, Hemker $\mathrm{HC}$. The mode of action of heparin in plasma. Thromb Haemost. 1988;60:457-462. 
106. Hemker HC, Béguin S. Thrombin generation in plasma: its assessment via the endogenous thrombin potential. Thromb Haemost. 1995;74:134-138.

107. Wielders S, Mukherjee M, Michiels J, Rijkers DTS, Cambus JP, Knebel RWC, Kakkar V, Hemker HC, Béguin S. The routine determination of the endogenous thrombin potential, first results in different forms of hyper- and hypocoagulability. Thromb Haemost. 1997;77:629-636.

108. Rosing J, Tans G, Govers-Riemslag JWP, Zwaal RFA, Hemker HC. The role of phospholipids and factor $\mathrm{Va}$ in the prothrombinase complex. J Biol Chem. 1980;255:274-283.

109. Kumar R, Béguin $S$, Hemker HC. The effect of fibrin clots and clot-bound thrombin on the development of platelet procoagulant activity. Thromb Haemost. 1995;74:962-968.

110. Olson RE. Vitamin K. In: Colman RW, Hirsh J, Marder VJ and Salzman EW (Eds.) Hemostasis and Thrombosis. J.B. Lippincott Company, Philadelphia, USA, 1987, p. 846-860.

111. Craciun AM, Groenen-van Dooren MMCL, Thijssen HHW, Vermeer C. Induction of prothrombin synthesis by $\mathrm{K}$-vitamins compared in vitamin $\mathrm{K}$-deficient and in brodifacoumtreated rats. Biochim Biophys Acta. 1988;1380:75-81.

112. Groenen-van Dooren MMCL, Ronden JE, Soute BAM, Vermeer C. Bioavailability of phylloquinone and menaquinones after oral and colorectal administration in vitamin K-deficient rats. Biochem Pharmacol. 1995;50:797-801.

113. Sanders TAB, Vickers $M$, Haines AP. Effect on blood lipids and haemostasis of a supplement of cod-liver oil, rich in eicosapentaenoic and docosahexaenoic acids, in healthy young men. Clin Sci. 1981;61:317-324.

114. Hayashi K, Ohtani H, Kurushima $H$, Nomura SI, Koide $K$, Kunita T, Tanaka K, Yasunobu $Y$, Kambe $M$, Kajiyama $G$. Decreases in plasma lipid content and thrombotic activity by ethyl eicosapentaenoate purified from fish oils. Curr Ther Res. 1995;56:24-31.

115. Lox $\mathrm{CD}$. The effects of dietary marine fish oils (omega-3 fatty acids) on coagulation profiles in men. Gen Pharmac. 1990;21:241-246.

116. Marckmann P, Sandström B, Jespersen J. Low-fat, high fiber diet favorably affects several independent risk markers of ischemic heart disease: observations on blood lipids, coagulation, and fibrinolysis from a trail of middle-aged Danes. Am J Clin Nutr. 1994;59:935-939.

117. Marckmann P. Diet, blood coagulation and fibrinolysis. Dan Med Bull. 1995;42:410-425.

118. Cines DB, Pollak ES, Buck CA, Loscalzo J, Zimmerman GA, McEver RP, Pober JS, Wick TM, Konkle BA, Schwartz BS, Barnathan ES, McCrea KR, Hug BA, Schmidt AM, Stren DM. Endothelial cells in physiology and in the pathophysiology of vascular disorders. Blood. 1998;91:3527-3561.

119. Toborek M, Kaiser S. Endothelial cell functions. Relationship to atherogenesis. Basic Res Cardiol. 1999;94:295-314.

120. Moncada S, Gryglewski RJ, Bunting S, Vane JR. An enzyme isolated from arteries transforms prostaglandin endoperoxides to an unstable substance that inhibits platelet aggregation. Nature. 1976;263:663-665.

121. Siess $W$, Roth $P$, Weber $P C$. Stimulated platelet aggregation, thromboxane $B_{2}$ formation and platelet sensitivity to prostacyclin: a critical evaluation. Thromb Haemost. 1981;45:204-207.

122. Andrews RK, Berndt MC. Adhesion-dependent signalling and the initiation of haemostasis and thrombosis. Histol Histopathol. 1998; 13:837-844.

123. Davie EW. Biochemical and molecular aspects of the coagulation cascade. Thromb Haemost. 1995;74:1-6.

124. Theroux $P$, Fuster $V$. Acute coronary syndromes. Unstable angina and non- $Q$ wave myocardial infarction. Circulation. 1998;97:1195-1206.

125. Jespersen J, Munkvad S, Gram JB. The fibrinolysis and coagulation systems in ischaemic heart disease. Risk markers and their relation to metabolic dysfunction of the arterial intima. Dan Med Bull. 1993;40:495-502.

126. Raederstorff $D$, Moser U. Influence of an increased intake of linoleic acid on the incorporation of dietary n-3 fatty acids in phospholipids and on prostanoid synthesis in rat tissues. Biochim Biophys Acta. 1992;1165:194-200.

127. Vossen RCRM, Feijge MAH, Heemskerk JWM, van Dam-Mieras MCA, Hornstra G, Zwaal RFA. Long-term fatty acid modification of endothelial cells: implication for arachidonic acid distribution in phospholipid classes. J Lipid Res. 1993;34:409-420.

128. Fischer $S$, Weber PC. Prostaglandin $I_{3}$ is formed in vivo in man after dietary eicosapentaenoic acid. Nature. 1984;307:165-168. 
129. Knapp HR, Reilly IAG, Alessandrini P, Fitzgerald GA. In vivo indexes of platelet and vascular function during fish oil administration in patients with atherosclerosis. $N$ Engl $J$ Med. 1986:314:937-942.

130. Dyerberg J, Bang HO, Stoffersen E, Moncada S, Vane JR. Eicosapentaenoic acid and the prevention of thrombosis and atherosclerosis? Lancet. 1978;ii:117-119.

131. Bunting $S$, Moncada $S$, Vane JR. The prostacyclin-thromboxane $A_{2}$ balance: pathophysiological and therapeutic implications. Br Med Bull. 1983;39:271-276.

132. Chin JPF, Dart AM. How do fish oils affect vascular functions? Clin Exp Pharmacol Physiol. 1995:22:71-81.

133. Fischer $\mathrm{S}$, Weber PC, Dyerberg J. The prostacyclin/thromboxane balance is favourably shifted in Greenland Eskimos. Prostaglandins. 1986;32:235-241.

134. Eritsland $J$, Arnesen $H$, Seljeflot 1 , Kierulf $P$. Long-term effects of $n-3$ polyunsaturated fatty acids on haemostatic variables and bleeding episodes in patients with coronary artery disease. Blood Coagul Fibrinolysis. 1995;6:17-22.

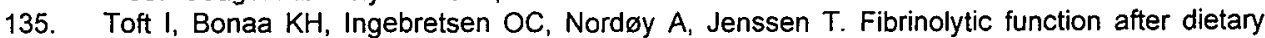
supplementation with omega-3 polyunsaturated fatty acids. Arterioscler Thromb Vasc Biol. 1997;17:814-819.

136. Fielding CJ. Origin and properties of remnant lipoproteins. In: Dietschy JM, Gotto AMj and Ontko JA (Eds). Disturbances in Lipid and Lipoprotein Metabolism. Waverly Press, Baltimore, USA, 1978, p. 83-98.

137. Sherrill BD, Dietschy JM. Characterization of the sinusoidal transport process responsible for uptake of chylomicrons by the liver. J Biol Chem. 1978;253:1859-1867.

138. Zilversmit DB. Lipid transfer proteins. J Lipid Res. 1984;25:1563-1569.

139. Gordon DJ, Probstfelt JL, Garrison RJ, Neaton JD, Castelli WP, Knoke JD, Jacobs jr DR, Bangdiwala S, Tyroler HA. High-density lipoprotein cholesterol and cardiovascular disease. Four prospective American studies. Circulation. 1989;79:8-15.

140. National Cholesterol Education Program. Report of the expert panel on population strategies for blood cholesterol reduction. Circulation. 1991;83:2154-2232.

141. Harris WS. Dietary fish oil and blood lipids. Curr Opin Lipidol. 1996;7:3-7.

142. Sri Kantha S. Dietary effects of fish oils on human health: a review of recent studies. Yale $J$ Biol Medic. 1987;60:37-44.

143. Weber PC, Raederstorff D. Triglyceride-lowering effect of omega-3 LC-polyunsaturated fatty acids-a review. Nutr Metab Cardiovasc Dis. 2000;10:28-37.

144. Harris WS. $n-3$ fatty acids and serum lipoproteins: human studies. Am $J$ Clin Nutr. 1997;65:1645S-1654S

145. Hornstra G, Lussenburg RN. Relationship between the type of dietary fatty acid and arterial thrombosis tendency in rats. Atherosclerosis. 1975;22:499-516.

146. Hornstra $G$. Influence of dietary fish oil on arterial thrombosis and atherosclerosis in animal models and in man. $J$ int Med. 1989;225:53-59.

147. Hornstra $G$, Kester ADM. Effects of the dietary fat type on arterial thrombosis tendency: systematic studies with a rat model. Atherosclerosis. 1997;131:25-33.

148. McIntosh $\mathrm{GH}, \mathrm{McLennan} \mathrm{PL}$, Lawson $\mathrm{CA}$, Bulman $\mathrm{FH}$, Charnock JS. The influence of dietary fats on plasma lipids, blood pressure and coagulation indices in the rat. Atherosclerosis. 1985;55:125-134.

149. Smit MJ, Temmerman AM, Wolters $H$, Kuipers $F$, Beynen AC, Vonk RJ. Dietary fish oilinduced changes in intrahepatic cholesterol transport and bile acid synthesis in rats. $J$ Clin Invest. 1991;88:943-951.

150. Zhu BQ, Sievers RE, Sun YP, Morse FN, Parmley $W W$, Wolfe $C L$. Is the reduction of myocardial infarct size by dietary fish oil the result of altered platelet function? Am Heart $\mathrm{J}$. 1994:127:745-755.

151. Umemura $K$, Toshima $Y$, Asai $F$, Nakashima M. Effect of dietary docosahexaenoic acid supplementation on platelet function: studies in the rat femoral artery thrombosis model. Platelets. 1994;5:214-218.

152. Umemura K, Toshima $Y$, Asia F, Nakashima M. Effect of dietary docosahexaenoic acid in the rat middle cerebral artery thrombosis model. Thromb Res. 1995;78:379-387.

153. Hornstra G. Hemker HC. Clot-promoting effect of platelet-vessel wall interaction: influence of dietary fats and relation to arterial thrombus formation in rats. Haemostasis. 1979;8:211-226. 
154. Heemskerk JWM, Feijge MAH, Kester ADM, Hornstra G. Dietary fat modifies thromboxane $A_{2}-$ induced stimulation of rat platelets. Biochem J. 1991:278:399-404.

155. Chiang M-T, Tsai M-L. Effect of fish oil on plasma lipoproteins, liver glucose-6-phosphate dehydrogenase and glucose-6-phosphatase in rats. Int $J$ Vit Nutr Res. 1995;65:276-282.

156. Frøyland L, Vaagenes H, Asiedu DK, Garras A, Lie O, Berge RK. Chronic administration of eicosapentaenoic acid and docosahexaenoic acid as ethyl esters reduced plasma cholesterol and changed the fatty acid composition in rat blood and organs. Lipids. 1996;31:169-178.

157. Mountford JC, Melford SK, Bunce CM, Gibbens J, Watson SP. Collagen or collagen-related peptide cause $\left[\mathrm{Ca}^{2+}\right]_{i}$ elevation and increased tyrosine phosphorylation in human megakaryocytes. Thromb Haemost. 1999;82:1153-1159.

158. Voss $A$, Reinhart $M$, Sankarappa $S$, Sprecher $H$. The metabolism of $7,10,13,16,19$ docosapentaenoic acid to $4,7,10,13,16,19$-docosahexaenoic acid in rat liver is independent of a 4-desaturase. J Biol Chem. 1991:266:19995-20000.

159. Sprecher H, Luthria DL, Mohammed BS, Baykousheva SP. Reevaluation of the pathways for the biosynthesis of polyunsaturated fatty acids. J Lipid Res. 1995:36:2471-2477.

160. Hollopeter $G$, Jantzen H-M, Vincent $D, L i$ G. England L, Ramzkrishnan V, Yang R-B, Nurden $P$. Nurden $A$, Julius $D$, Conley $P B$. Identification of the platelet ADP receptor targeted by antithrombotic drugs. Nature. 2001;409:202-207. 



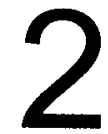

The effects of purified eicosapentaenoic and docosahexaenoic acids on arterial thrombosis tendency and platelet function in rats

Cécile M.A. Nieuwenhuys and Gerard Hornstra

Department of Human Biology, Maastricht University, The Netherlands

Based on: Biochimica et Biophysica Acta 1998; 1390: 313-322. 


\subsection{Abstract}

Dietary eicosapentaenoic acid (EPA) and docosahexaenoic acid (DHA) were compared for their effects on arterial thrombus formation in vivo using a well validated rat model. Platelet aggregation (triggered by collagen or adenosine diphosphate in whole hirudinized blood), thromboxane formation $\left(\mathrm{TxB}_{2}\right)$ and platelet phospholipid fatty acid composition were measured also. Animals fed diets containing hydrogenated coconut oil or sunflower seed oil served as prothrombotic and antithrombotic controls, respectively.

In a first study, rats were fed a mixture of EPA and DHA ethyl esters (FO) in increasing amounts and results indicated that $4 \%$ of n-3 fatty acids had an optimum reducing effect on thrombosis tendency. Dietary administration of FO further resulted in a dose-dependent promotion of disaggregation after collagen-induced aggregation, which significantly correlated with the reduction in platelet $\mathrm{TxB}_{2}$ formation. In a subsequent comparative study, both EPA and DHA ethyl esters affected thrombosis tendency, platelet aggregation and $\mathrm{TxB}_{2}$ formation to a similar extent. In addition, both polyenes increased the apparent thromboxane $A_{2}$-sensitivity of platelets, which appeared negatively related to arterial thrombosis tendency.

We conclude that EPA and DHA have similar reducing effects on arterial thrombogenesis in vivo in rats and have comparable effects on the selected platelet functions in vitro.

\subsection{Introduction}

Coronary heart disease (CHD) is the leading cause of death in Western industrialized countries. Very long-chain, highly unsaturated fatty acids of the n-3 family present in fish oil, e.g. eicosapentaenoic acid (20:5n-3, EPA) and docosahexaenoic acid (22:6n-3, DHA), are thought to be effective in lowering the risk of CHD [1-3]. It is not clear, however, whether or not these two fatty acids are equivalent in affecting the processes involved in atherogenesis and thrombosis. Some results with respect to lipoprotein profile [4,5], vascular smooth muscle cell proliferation [6] and aggregation of platelets in suspension [7,8] have been reported, but studies related to arterial thrombus formation in vivo and platelet aggregation in whole blood have not been published so far.

The present study deals with the comparison of $94 \%$ pure ethyl ester preparations of EPA and DHA for their effects on arterial thrombosis tendency. Since no human arterial thrombosis model is available, this study was performed in rats, 
using an in vivo model for arterial thrombus formation which is sensitive to changes in the type of dietary fat $[9,10]$. Platelet aggregation, thromboxane production, and fatty acid composition were determined as well.

\subsection{Materials and methods}

\section{Materials}

A mixture of EPA and DHA ethyl esters (FO) and the pure EPA and DHA ethyl ester preparations were obtained from F. Hoffmann-La Roche (Basel, Switzerland), sunflower seed oil, TRISUN ${ }^{\oplus}$, beef tallow, hydrogenated coconut oil and olive oil came from Chempri (Raamsdonkveer, The Netherlands), and pelleted stock food was from Hope Farms (Woerden, The Netherlands). The remaining dietary components were supplied by Unilever Research (Vlaardingen, The Netherlands). Narcovet ${ }^{\star}$ was purchased from Apharmo (Arnhem, The Netherlands). Recombinant desulphatohirudin variant 1 ( ${ }^{\mathrm{TM}}$ Revasc) was a gift of Ciba-Geigy (Basel, Switzerland). Collagen type I $\left(\mathrm{Horm}^{\mathrm{TM}}\right.$ ) was obtained from Hormon Chemie (Munich, FRG, Germany), ADP, L- $\alpha$-dinonadecanoyl lecithin (PC, C19:0) and 3,5-di-tert-butyl-4hydroxytoluene were from Sigma (St Louis, MO, USA), isooctane was from Baker Chemicals B.V. (Deventer, The Netherlands) and U46619 was from The Upjohn Company (Kalamazoo, MI, USA). Other chemicals were obtained from Merck (Darmstadt, Germany).

\section{Study design}

Two consecutive studies were performed. First, a dosage study was executed with a mixture of eicosapentaenoic acid (EPA, 20:5n-3) and docosahexaenoic acid (DHA, 22:6n-3) ethyl esters (FO). The effects of increasing amounts of this FO were determined on arterial thrombosis tendency in vivo and platelet function in vitro. From the thrombosis tendency data, the minimum effective dose of FO was selected for a second study, comparing $94 \%$ pure ethyl esters of EPA or DHA for their effects on arterial thrombosis tendency and platelet function. In both the dosage and comparative studies, a prothrombotic and antithrombotic reference diet with wellcharacterized effects on arterial thrombosis tendency were used to check the thrombosis model by comparing the present findings with those of previous studies [10-12]. The Experimental Animal Ethics Committee approved the study.

\section{Animals and diets}

Three-week-old male Wistar rats (Charles River, Sulzfeld, Germany, specific pathogen free) were housed individually in stainless steel cages in a room with controlled lighting ( 12 hours a day) and a constant temperature $\left(23 \pm 0.5^{\circ} \mathrm{C}\right)$ and were 
fed a pelleted stock diet. After two weeks, rats were randomly divided into groups of 24 animals, which received different diets for a total period of 10-11 weeks.

All diets contained $50 \%$ of the digestible energy (en\%) as fat, $23-e n \%$ as casein, and $27-e n \%$ as corn starch (total energy content 19.5 kilo Joule/g). Other dietary components (minerals, vitamins and fiber) were added, as previously described [11]. To prevent lipid peroxidation, the diets were prepared every week and stored at $-20^{\circ} \mathrm{C}$ under nitrogen. The animals received fresh food daily and both water and food were available ad libitum.

In the various experimental diets, the basal fat mixture consisted of beef tallow (34\%), hydrogenated coconut oil (10\%), sunflower seed oil (18\%), TRISUN ${ }^{\otimes}$ (an oleic acid rich sunflower seed oil, $18 \%$ ) and olive oil $(20 \%)$. This resulted in a dietary fatty acid ratio of 2:3:1, for the saturated (SAFA), monounsaturated (MUFA) and polyunsaturated (PUFA) fatty acids, respectively. This fatty acid profile is comparable to the fatty acid composition of the average habitual diet in the Dutch population [13]. All diets contained $2.7 \mathrm{mg}$ cholesterol/MJ.

In the dosage study $2 \%, 4 \%, 8 \%$, and $16 \%$ of the fatty acids $(1,2.5,5$ and 10 en\%, respectively) were replaced by n-3 PUFA from the FO (containing 19.9\% EPA and $36.9 \%$ DHA as ethyl esters; $2 \%$ to $16 \%$ FO groups). A diet without FO served as the control diet (Control).

TABLE 2.1 Relative fatty acid composition of fats extracted from complete diets

(\% of total area under the curve of identified fatty acids)

\begin{tabular}{|c|c|c|c|c|c|c|c|c|c|c|}
\hline \multirow[b]{2}{*}{ Fatty acid } & \multicolumn{2}{|c|}{ Ref. diets } & \multicolumn{5}{|c|}{ Exp. dosage study } & \multicolumn{3}{|c|}{ Exp. comparative study } \\
\hline & $\mathrm{HCO}$ & So & Control & $2 \% F O$ & $4 \% \mathrm{FO}$ & $8 \% \mathrm{FO}$ & $16 \% \mathrm{FO}$ & EPA & DHA & $\mathrm{FO}$ \\
\hline$<14: 0$ & 49.8 & - & 4.8 & 4.7 & 4.6 & 4.3 & 3.9 & 5.7 & 5.7 & 5.7 \\
\hline $16: 0$ & 10.1 & 6.3 & 14.4 & 14.1 & 13.8 & 13.2 & 11.9 & 14.2 & 14.2 & 14.2 \\
\hline $18: 0$ & 11.7 & 5.1 & 10.3 & 10.1 & 9.9 & 9.4 & 8.5 & 9.8 & 9.8 & 9.8 \\
\hline $18: 1 n-9$ & 3.7 & 24.9 & 45.8 & 45.3 & 44.0 & 42.2 & 38.1 & 44.1 & 44.1 & 40.8 \\
\hline $18: 2 n-6$ & 6.5 & 60.9 & 16.1 & 15.9 & 15.5 & 14.9 & 13.6 & 15.2 & 15.1 & 15.2 \\
\hline $20: 5 n-3$ & - & - & - & 0.5 & 1.3 & 2.7 & 5.5 & 3.7 & 0.2 & 1.8 \\
\hline $22: 6 n-3$ & - & - & - & 0.8 & 2.0 & 4.1 & 8.6 & - & 3.7 & 2.6 \\
\hline$n-3 / n-6$ & 0.00 & 0.00 & 0.00 & 0.10 & 0.24 & 0.48 & 1.06 & 0.37 & 0.28 & 0.31 \\
\hline $\mathrm{P} / \mathrm{S}$ & 0.07 & 4.69 & 0.48 & 0.50 & 0.60 & 0.74 & 1.08 & 0.57 & 0.57 & 0.66 \\
\hline
\end{tabular}

Fatty acids which accounted for $\leq 5.0 \%$ in all diets are not shown. -, trace amount $(<0.1 \%)$. Abbreviations: Ref, reference; Exp, experimental diets; HCO, hydrogenated coconut oil; SO, sunflower seed oil; FO, mixture of EPA and DHA ethyl esters; EPA, eicosapentaenoic acid ethyl ester; DHA, docosahexaenoic acid ethyl ester; $n-3 / n-6$, ratio between total of the polyunsaturated fatty acids of the $n-3$ family ( $\left.\sum n-3 F A\right)$ and total of polyunsaturated fatty acids of the $n-6$ family $\left(\sum n-6 F A\right) ; P / S$, ratio between total of polyunsaturated $(\Sigma n-3+\Sigma n-6)$ FA and total of saturated fatty acids. Total unidentified fatty acids varied between 0.2 and $2.7 \%$ of total area under the curve. 
In the comparative study, $4 \%$ of the fatty acids (2 to $3-e n \%)$ were replaced by either eicosapentaenoic ethyl ester (containing 94\% EPA), docosahexaenoic ethyl ester (containing $94 \%$ DHA) or FO.

The dietary fat of the prothrombotic reference diet consisted of $90 \%$ hydrogenated coconut oil and $10 \%$ sunflower seed oil (to prevent essential fatty acid deficiency; $\mathrm{HCO}$ group); for the antithrombotic reference diet sunflower seed oil was used (SO group). The ratio's of SAFA:MUFA:PUFA were 24:1:2 and 1:2:5 for the $\mathrm{HCO}$ and SO diet, respectively.

The fatty acid compositions of the diets, determined by gas chromatography, are given in TABLE 2.1.

\section{Measurement of arterial thrombosis tendency}

After a feeding period of 8 weeks, the arterial thrombosis tendency was measured with the aorta loop technique [9], which has extensively been validated before [11]. Briefly, a loop-shaped polyethylene cannula (the aorta loop) was inserted into the abdominal aorta of fasted rats, anaesthetised with Narcovet ${ }^{\oplus}(6 \mathrm{mg} / \mathrm{m} / \mathrm{kg}$ intraperitoneal). Blood flow through the translucent loop, which protrudes from the body of the animal, was checked visually twice daily. The time between insertion of the loop and its complete thrombotic obstruction, indicated by a change in the colour of the blood from red to dark blue, was defined as the obstruction time (OT).

\section{Blood sampling}

During loop insertion, $1.35 \mathrm{ml}$ blood was collected into a preheated $\left(37^{\circ} \mathrm{C}\right)$ syringe containing $0.15 \mathrm{ml}, 95 \mathrm{mM}$ hirudin (TMRevasc) for the determination of platelet aggregation in whole blood. About 3 weeks after loop obstruction, the animals were anaesthetized with ether and exsanguinated by puncturing their abdominal aorta. Blood was anticoagulated with $20 \%(\mathrm{~V} / \mathrm{v})$ of a mixture of $80 \mathrm{mM}$ trisodium citrate, 52 $\mathrm{mM}$ citric acid and $180 \mathrm{mM}$ glucose or with $9.5 \mathrm{mM}$ (final concentration, f.c.) hirudin ( ${ }^{\mathrm{TM}}$ Revasc), for fatty acid analyses and platelet function measurements, respectively.

\section{Platelet aggregation and disaggregation}

Platelet aggregation was determined with the impedance method in a Chrono-log whole-blood aggregometer (Type 500, Chrono-log Corporation, Havertown, PA, USA) as described before [14]. Under the present experimental conditions, aggregation was followed by disaggregation. Platelets were activated with $2.5 \mu \mathrm{g} / \mathrm{ml}$ (f.c.) collagen (animals 1-12 of each group) or $3 \mu \mathrm{M}$ (f.c.) adenosine diphosphate (ADP, animals 13-24). Using computer-assisted analysis, maximum aggregation (Amax, expressed in ohms, $\Omega$ ) and the aggregation at $15 \mathrm{~min}(A-15, \Omega)$ were determined from the aggregation curves. The maximum degree of disaggregation (DA, \%) was calculated as the difference between A-max and A-15, divided by Amax and multiplied by $100 \%$ ). 
Platelet thromboxane $A_{2}\left(T \times A_{2}\right)$-sensitivity was determined in whole hirudinised blood collected after loop-obstruction and was pretreated with $168 \mu \mathrm{M}$ (f.c.) indomethacin during $2 \mathrm{~min}$, to prevent participation of endogenously formed $\mathrm{TxA}_{2}$. Platelet aggregation in response to the $\mathrm{TXA}_{2}$-mimicking compound $\mathrm{U} 46619$ (250 $\mathrm{nM}$, f.c.) was determined in combination with $1 \mu \mathrm{g} / \mathrm{ml}$ (f.c.) collagen, since rat platelets do not respond to U46619 alone $[15,16]$. The maximum aggregation (Amax-1) was corrected for the aggregation resulting from collagen $(1 \mu \mathrm{g} / \mathrm{ml} \mathrm{f.c.)} \mathrm{only}$

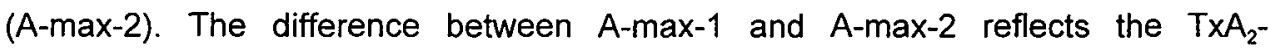
sensitivity for the standard amount of U46619.

\section{Determination of thromboxane $B_{2}$}

Fifteen min after platelet activation, the reaction mixtures centrifuged and stored as described elsewhere $[15,17]$. Concentrations of thromboxane $B_{2}\left(T \times B_{2}\right)$, the stable breakdown product of $\mathrm{TxA}_{2}$, were measured with a competitive enzyme immunoassay purchased from Cayman (Cayman, Ann Arbor, MI, USA). Samples were diluted to fit the optimum detection range, and were analysed in duplicate according to the manufacturer's instructions. $\mathrm{TXB}_{2}$ concentrations were calculated from calibration curves prepared from dilutions of $\mathrm{TxB}_{2}$ standards.

\section{Extraction, isolation and fatty acid analysis of platelet phospholipids}

Blood platelets were isolated and suspended as described before [15] and kept under nitrogen at $-20^{\circ} \mathrm{C}$. Total phospholipid extracts were prepared using a slightly modified [18] method, originally described by Folch and co-workers [19]. Aminopropyl bonded silica columns (Bond Elut column, $500 \mathrm{mg}$, Rochrom Roosendaal, The Netherlands) were used to separate phospholipids ( $P L$ ) from the total lipid extract [20]. PL were saponified and their fatty acids methylated and extracted as described before [21]. Fatty acid methyl esters were separated and quantified using an Autosystem Perkin Elmer gas chromatograph, fitted with a $50 \mathrm{~m}$ CP-SIL 88 polar capillary column with $0.25 \mathrm{~mm}$ internal diameter, film thickness 0.20 $\mu \mathrm{m}$ (Chromopack $\Theta$, Middelburg, The Netherlands) as described earlier [22]. Unidentified peaks were calculated as $\%$ of the total area under the curve and summed.

\section{Statistical analysis}

Logarithmic transformation of obstruction times was performed [10], after which the differences between the groups were tested, either with Student's 2-sample test (the two reference groups, $\mathrm{HCO}$ and SO) or by one-way ANOVA (the experimental groups). Other variables were tested non-parametrically by using the Mann-Whitney $U$ test (the reference groups) or the Kruskal-Wallis test (the experimental groups). $P_{-}$ values $\leq 0.05$ were considered significant. When the Kruskal-Wallis test showed significant differences, the various groups were compared with one another using the 
Mann-Whitney $\mathrm{U}$ test using the Bonferroni correction for multiple group comparisons. $P$-values required for significance were 0.0125 for 4 comparisons (dosage study, comparison with Control group) and 0.017 for 3 comparisons (comparative study, all 3 groups compared with each other). All data are presented as mean \pm sem.

Simple regression analyses was used to determine dose-effect relationships and correlations between various parameters (Pearson). All statistics were performed with Statview 4.1, Abdacus Concepts 1992-94.

\subsection{Results and discussion}

In both the dosage and comparative study, all animals tolerated their diets well, as was concluded from their mean daily food intake and their weight gain. After a feeding period of eight weeks, there were no significant differences in mean body weight between the groups (data not shown).

TABLE 2.2 Fatty acid content of platelet phospholipids after 10-11 weeks of feeding (dosage study) ( $\%$ of identified fatty acids)

\begin{tabular}{|c|c|c|c|c|c|c|c|}
\hline \multirow[b]{2}{*}{ Fatty acid } & \multicolumn{2}{|c|}{ Reference groups (n) } & \multicolumn{5}{|c|}{ Experimental groups ( $n$ ) } \\
\hline & $\mathrm{HCO}(9)$ & SO (11) & Control (11) & $2 \% \mathrm{FO}(12)$ & $4 \% \mathrm{FO}(10)$ & $8 \% \mathrm{FO}(12)$ & $16 \% \mathrm{FO}(12)$ \\
\hline$\sum n-6 F A$ & $38.4 \pm 0.26$ & $37.0 \pm 0.64$ & $32.6 \pm 0.45$ & $30.3 \pm 0.35^{d}$ & $25.1 \pm 0.90^{\circ}$ & $22.1 \pm 0.47^{\circ}$ & $19.8 \pm 0.34^{\circ}$ \\
\hline $20: 4 n-6$ & $24.6 \pm 0.27$ & $18.5 \pm 0.38^{b}$ & $20.9 \pm 0.40$ & $19.3 \pm 0.28^{c}$ & $14.8 \pm 0.60^{\circ}$ & $12.7 \pm 0.24^{\circ}$ & $10.2 \pm 0.23^{\circ}$ \\
\hline $22: 4 n-6$ & $6.6 \pm 0.12$ & $5.8 \pm 0.20^{a}$ & $5.8 \pm 0.27$ & $3.3 \pm 0.13^{\mathrm{e}}$ & $1.9 \pm 0.16^{\circ}$ & $1.0 \pm 0.14^{\mathrm{e}}$ & $0.7 \pm 0.06^{\circ}$ \\
\hline$\Sigma n-3 F A$ & $0.3 \pm 0.07$ & $0.3 \pm 0.16$ & $0.8 \pm 0.11$ & $3.6 \pm 0.21^{\circ}$ & $6.7 \pm 0.49^{\circ}$ & $9.7 \pm 0.29^{\mathrm{a}}$ & $12.5 \pm 0.15^{\circ}$ \\
\hline $20: 5 n-3$ & -1 & - & $0.3 \pm 0.07$ & $1.6 \pm 0.14^{\circ}$ & $3.6 \pm 0.37^{\circ}$ & $5.7 \pm 0.28^{\mathrm{e}}$ & $8.1 \pm 0.28^{\circ}$ \\
\hline $22: 5 n-3$ & $0.1 \pm 0.06$ & $0.1 \pm 0.17$ & $0.2 \pm 0.05$ & $1.2 \pm 0.10^{\circ}$ & $1.9 \pm 0.09^{\circ}$ & $2.4 \pm 0.17^{\mathrm{a}}$ & $2.6 \pm 0.18^{\circ}$ \\
\hline $22: 6 n-3$ & $0.2 \pm 0.03$ & $-\mathrm{b}$ & $0.3 \pm 0.05$ & $0.9 \pm 0.05^{\circ}$ & $1.2 \pm 0.05^{\mathrm{e}}$ & $1.6 \pm 0.09^{\circ}$ & $1.8 \pm 0.18^{\mathrm{e}}$ \\
\hline$n-3 / n-6$ & $0.01 \pm 0.02$ & $20.01 \pm 0.01$ & $0.02 \pm 0.00$ & $0.12 \pm 0.01^{\circ}$ & $0.27 \pm 0.02$ & $0.44 \pm 0.01^{\mathrm{e}}$ & $0.63 \pm 0.02^{\circ}$ \\
\hline
\end{tabular}

The relative (\% of total area under the curve of identified fatty acids) fatty acid composition of platelet phospholipids from diet-modified rats. $n$, number of animals, - , trace amount $(<0.1 \%)$. Abbreviations as in TABLE 2.1. Total unidentified fatty acids varied between $1.7 \%$ and $3.7 \%$ of total area under the curve. Significance of difference between the reference groups: Mann-Whitney U-test a $P \leq 0.01,{ }^{b} P \leq 0.001$. When the Kruskal-Wallis test showed significant differences between the experimental groups $(P \leq 0.05)$, the FO groups were compared with the Control group by using the Mann-Whitney U-test $(P$ doses of level required for significance $\leq 0.0125):{ }^{c} P \leq 0.0125,{ }^{\circ} P \leq 0.0025,{ }^{\circ} P \leq 0.00025$. Data represent mean valuestsem. ' one outlier excluded. 


\section{Dosage study}

Feeding the prothrombotic $(\mathrm{HCO})$ or antithrombotic $(\mathrm{SO})$ reference diets resulted in small but significant differences in the total amounts $(\Sigma)$ of saturated fatty acids ( SSAFA: $54.5 \pm 0.39 \%$ and $53.1 \pm 0.34 \%$ respectively, $P \leq 0.05$ ) and monounsaturated fatty acids ( $\Sigma$ MUFA: $6.4 \pm 0.31 \%$ and $8.1 \pm 0.36 \%$, respectively, $P \leq 0.005$ ) of platelet phospholipids. The content of arachidonic acid was significantly higher in the $\mathrm{HCO}$ group as compared to the SO group (TABLE 2.2). However, the $\Sigma n-6, \Sigma n-3$ fatty acids and their ratio were not significantly different. This is in agreement with previous studies $[11,15,17,23]$.

Feeding increasing amounts of FO resulted in a gradual increase of the n-3 fatty acids, i.e. eicosapentaenoic acid (20:5n-3), docosapentaenoic acid (22:5n-3) and docosahexaenoic acid (22:6n-3) in platelet phospholipids (TABLE 2.2). This occurred mainly at the expense of arachidonic acid (20:4n-6) and adrenic acid $(22: 4 n-6)$. Consequently, the $n-3 / n-6$ ratio increased significantly with increasing dietary FO. There were no significant differences between the groups in the relative amount of $\Sigma$ SAFA (range: from $54.3 \%$ to $55.3 \%$ ) and $\Sigma$ MUFA (range: from $11.9 \%$ to $12.9 \%)$.

The results of arterial thrombosis tendency are listed in TABLE 2.3. The average obstruction time of the SO group was significantly longer than that of the HCO group. This confirmed the well-known antithrombotic effect of dietary SO as compared to HCO $[10,11]$. Previous studies have shown that arterial thrombosis tendency in rats is highly influenced by the ratio between

TABLE 2.3 Arterial thrombosis tendency (obstruction times of aorta loops, OT) in diet-modified rats

\begin{tabular}{|c|c|c|c|c|c|c|c|}
\hline \multicolumn{4}{|c|}{ Dosage study } & \multicolumn{4}{|c|}{ Comparative study } \\
\hline \multicolumn{2}{|c|}{ Type of diet $n$} & \multirow{2}{*}{$\frac{\mathrm{OT}(\log \mathrm{hr})}{2.06 \pm 0.03^{\mathrm{a}}}$} & \multirow{2}{*}{$\frac{\text { OT (hr) }}{115}$} & \multicolumn{2}{|c|}{ Type of diet $n$} & \multirow{2}{*}{$\frac{\text { OT }(\log h r)}{2.08 \pm 0.03^{a}}$} & \multirow{2}{*}{$\frac{\text { OT }(h r)}{119}$} \\
\hline $\mathrm{HCO}$ & 23 & & & $\mathrm{HCO}$ & 23 & & \\
\hline so & 24 & $2.28 \pm 0.03$ & 191 & so & 22 & $2.30 \pm 0.02$ & 200 \\
\hline Control & 23 & $2.12 \pm 0.05^{b}$ & 131 & & & & \\
\hline $2 \% \mathrm{FO}$ & 22 & $2.16 \pm 0.05$ & 144 & EPA & 23 & $2.28 \pm 0.03^{c}$ & 188 \\
\hline $4 \%$ FO & 24 & $2.24 \pm 0.04$ & 175 & DHA & 21 & $2.32 \pm 0.06$ & 208 \\
\hline $8 \% \mathrm{FO}$ & 24 & $2.14 \pm 0.04$ & 138 & FO & 23 & $2.26 \pm 0.04$ & 184 \\
\hline $16 \% \mathrm{FO}$ & 23 & $2.20 \pm 0.04$ & 159 & & & & \\
\hline
\end{tabular}

Abbreviations as in TABLES 2.1 and 2.2. ${ }^{a}$ Significantly different from SO group, $P \leq 0.0001$ (Student ttest). ' No significant differences between the experimental groups of the dosage study and "No significant differences between the experimental groups of the comparative study (ANOVA). Data represent means of log-transformed values of OT \pm sem (log hr) and geometric means (hr). 
saturated fatty acids (P/S ratio) in the diet $[11,16]$ and is most pronounced in the P/S ranges below 0.5 [12]. Since the P/S ratios of the experimental diets used in the present study were between 0.5 and 1.0 (TABLE 2.1), no major differences between the various experimental diets could be expected, unless the fish oil ethyl esters used would have an unusually strong antithrombotic effect. However, this did not appear to be the case, since the OTs were not significantly different between the experimental groups (TABLE 2.3). Only a borderline significance was observed for the mean OT of the $4 \%$ FO group compared to that of the Control group $(P=0.039 ; P$ level required for significance 0.0125 ).

ADP-induced platelet aggregation tended to be lower in the SO compared to the HCO group, $17.7 \pm 0.95 \Omega$ and $19.8 \pm 0.84 \Omega$, respectively, $P=0.079$ ). The disaggregation (DA, \% of A-max) was significantly lower in the so group in comparison with the $\mathrm{HCO}$ group $(56 \pm 4.6 \%$ and $78 \pm 4.4 \%$, respectively, $\mathrm{P}=0.0081$ ). ADP-induced platelet aggregation (range: $15 \pm 1.3 \Omega$ to $20 \pm 1.8 \Omega$ ) and disaggregation (range: $50 \pm 5.8 \%$ to $70 \pm 3.6 \%$ ) were not differently affected by the experimental diets. Similarly, no correlations were found between the dietary FO content and these parameters.

Collagen-induced platelet aggregation and disaggregation seemed higher in the SO group as compared to the $\mathrm{HCO}$ group, but the difference was not significant (FIG. 2.1A and 2.1B). Maximum aggregation was not significantly different between the experimental groups either, but a significant negative correlation was found with
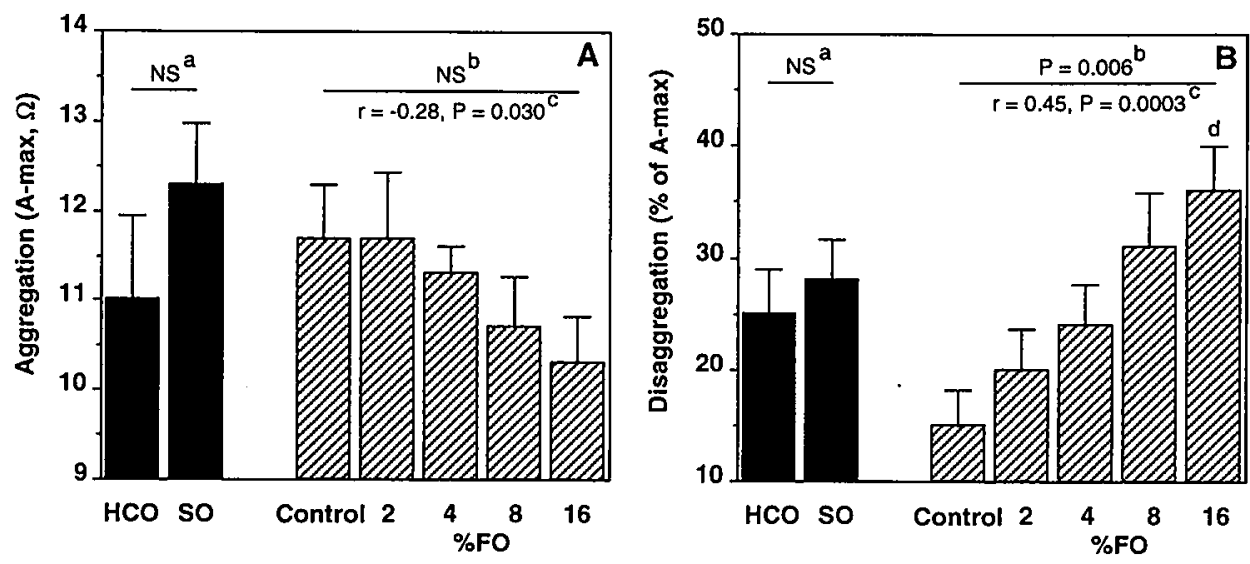

Type of diet

FIGURE 2.1 Collagen-induced platelet activation in whole blood (dosage study). Blood was drawn from diet-modified rats during loop insertion and anticoagulated with $95 \mathrm{mM}$ hirudin. Aggregation $(A)$ and disaggregation (B) of platelets was induced by the addition of $2.5 \mu \mathrm{g} / \mathrm{ml}$ collagen. Abbreviations as in TABLE 2.1. NS, not significant, "Mann-Whitney $U$ test, ${ }^{\circ}$ Kruskal-Wallis test, " Simple regression analysis, ${ }^{\circ}$ Value significantly different from Control group, $P \leq 0.0125$. Data represent mean values \pm sem of 9-12 animals per group. 
the amount of dietary FO ( $n=60, r=-0.28, P=0.030 ; F I G .2 .1 A)$. Platelet disaggregation was significantly influenced by the dietary FO content (FIG. 2.1B). The maximum degree of disaggregation in the $16 \%$ FO group was significantly higher than in the Control group. In addition, regression analysis showed that disaggregation was positively related to the dietary FO dose ( $n=60, r=0.45, P=0.0003$ ).

Although the amount of arachidonic acid in platelet phospholipids was lower in the SO as compared to the $\mathrm{HCO}$ animals (TABLE 2.2), thromboxane $B_{2}\left(T_{x B}\right)$ concentrations tended to be higher ( $F$ IG. 2.2A and 2.2B; $P=0.074$ and $P=0.11$ for ADP- and collagen-induced aggregations, respectively). This has repeatedly been observed before $[11,15]$. FO feeding was associated with marked reductions in $\mathrm{TXB}_{2}$ concentrations for both platelet-activators (FIG. 2.2A and 2.2B). This is in agreement with results obtained by us $[11,15]$ and others (reviewed in [24]) with diets containing fish oil. In addition, $\mathrm{TXB}_{2}$ concentrations were negatively related to the dietary amounts of FO; $n=46, r=-0.52, P=0.0002$; and $n=50, r=-0.60, P<0.0001$ for ADP- and collagen-induced aggregations, respectively. These dietary FO-dependent reductions reached statistical significance from the $4 \%$ FO group on. Correspondingly, the levels of arachidonic acid in the platelet phospholipids were decreased with increasing amounts of dietary FO (TABLE 2.2, $n=57, r=-0.90$, $P<0.0001)$.

Regression analyses revealed that in collagen-activated platelets, $\mathrm{TxB}_{2}$ production correlated inversely with the rate of disaggregation $(n=72, r=-0.35$, $P=0.0033$ ). This suggests that a small production of $\mathrm{TxB}_{2}$ enables a high degree of
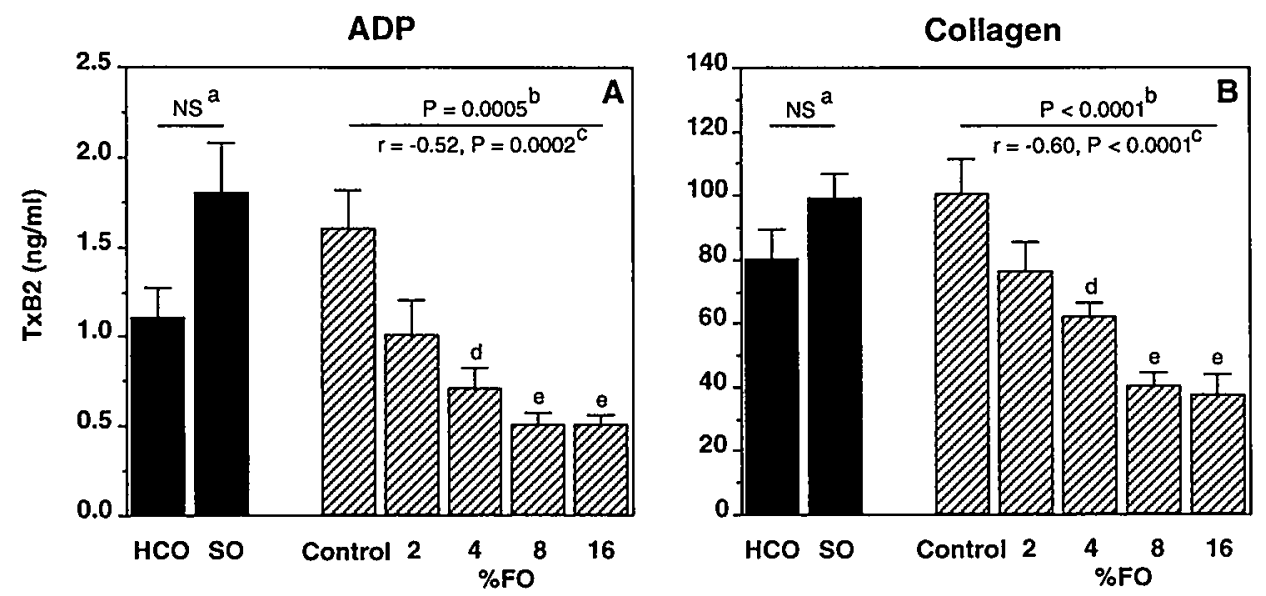

Type of diet

FIGURE 2.2 Thromboxane $B_{2}\left(T \times B_{2}\right)$ produced in whole blood after platelet activation (dosage study). ADP-induced $(A)$ and collagen-induced (B) platelet activation. Abbreviations as in TABLE 2.1. NS, not significant, "Mann-Whitney $U$ test, ${ }^{D}$ Kruskal-Wallis test, ${ }^{\circ}$ Simple regression analysis, Value significantly different from Control group, ${ }^{d} P \leq 0.0125,{ }^{\circ} P \leq 0.0025$. Data represent mean values \pm sem of 8-11 animals per group. 
disaggregation. This suggestion is supported by the relatively high degree of disaggregation in ADP-activated platelets (50-78\%, data not shown in detail), which is associated with the production of small amounts of $\mathrm{TxB}_{2}$ (FIG. 2.2A). Because of these moderate $\mathrm{TxB}_{2}$ amounts, the minor --although significant-- influence of dietary $\mathrm{FO}$ on $\mathrm{TxB}_{2}$ production was not accompanied by changes in disaggregation upon platelet activation with ADP. Consequently, under conditions where dietary FO does not affect disaggregation, it also does not seem to influence aggregation. This observation supports the concept that, in our animal model, dietary FO lowers aggregation in an indirect way: viz. by promoting disaggregation, through reducing $\mathrm{TxA}_{2}$ production.

Thus, increasing amounts of dietary $F O$ resulted in dose-dependent changes in some functional and biochemical parameters related to arterial thrombus formation: i.e. decreased arachidonic acid levels in platelet phospholipids, lower aggregation and $\mathrm{TxB}_{2}$ production by collagen-activated platelets, and increased collagen-induced disaggregation. However, arterial thrombosis tendency in vivo was only marginally affected by the FO containing diets. This indicates that both fatty acids either hardly affect thrombosis tendency or have opposite effects. We, therefore, investigated whether EPA and DHA, when fed separately, affect arterial thrombosis tendency in a different way (comparative study). A diet containing $F O$, served as a 'control'. These three diets contained comparable amount of EPA and/or DHA (TABLE 2.1).

\section{Comparative study}

In the comparative study, the results of the reference groups (TABLES 2.3 and 2.4) are comparable to those described in the dosage study (TABLES 2.2 and 2.3, FIG. 2.1 and 2.2) and thus both studies can be very well compared. In addition, the functional and biochemical differences between the $\mathrm{HCO}$ and $\mathrm{SO}$ reference groups, observed in the present studies, were comparable to the differences observed repeatedly before $[11,15,17,23]$.

Feeding of the three experimental diets caused significant differences in $\Sigma n-6$ and $\Sigma n-3 F A$ in platelet phospholipids (TABLE 2.4). EPA consumption resulted in incorporation of eicosapentaenoic acid (20:5n-3) and docosapentaenoic acid (22:5n$3)$, whereas docosahexaenoic acid (22:6n-3) was only slightly increased as compared to feeding the reference diets. DHA consumption caused the incorporation of docosahexaenoic acid (22:6n-3) and eicosapentaenoic acid (20:5n-3), while dietary $F O$ resulted in relatively high incorporations of all three $n-3$ fatty acids. In addition, irrespective of the type of experimental diet, the amounts of eicosapentaenoic acid were always higher than the docosahexaenoic acid levels. Significant differences between the groups were also observed for arachidonic acid; the levels were highest for the DHA group and lowest for the EPA group. The $\Sigma$ SAFA (range: $51.9 \pm 0.23$ to $52.8 \pm 0.22 \%$ ) and $\Sigma$ MUFA (range: $13.0 \pm 0.28$ to $13.8 \pm 0.30 \%$ ) did 
TABLE 2.4 Fatty acid content of platelet phospholipids after 10-11 weeks of feeding (comparative study) (\% of identified fatty acids)

\begin{tabular}{|c|c|c|c|c|c|}
\hline \multirow[b]{2}{*}{ Fatty acid } & \multicolumn{2}{|c|}{ Reference groups ( $n$ ) } & \multicolumn{3}{|c|}{ Experimental groups $(n)$} \\
\hline & $\mathrm{HCO}(9)$ & SO (11) & EPA (6) & $\mathrm{DHA}(6)$ & $\mathrm{FO}(6)$ \\
\hline$\sum n-6 F A$ & $39.3 \pm 0.54$ & $37.2 \pm 0.29^{\mathrm{a}}$ & $25.7 \pm 0.38^{c, d}$ & $29.4 \pm 0.24$ & $27.2 \pm 0.34$ \\
\hline $20: 4 n-6$ & $25.7 \pm 0.44$ & $19.3 \pm 0.23^{b}$ & $15.7 \pm 0.21^{d}$ & $17.4 \pm 0.28$ & $16.4 \pm 0.40$ \\
\hline $22: 4 n-6$ & $6.2 \pm 0.04$ & $5.3 \pm 0.33$ & $2.1 \pm 0.09$ & $1.7 \pm 0.17$ & $1.6 \pm 0.17$ \\
\hline$\sum n-3 F A$ & $0.6 \pm 0.07$ & $0.3 \pm 0.02$ & $8.1 \pm 0.24^{\mathrm{cod}}$ & $4.5 \pm 0.15^{c}$ & $6.8 \pm 0.21$ \\
\hline $20: 5 n-3$ & $0.1 \pm 0.02$ & $-a^{a}$ & $4.5 \pm 0.17^{c, d}$ & $2.3 \pm 0.14^{c}$ & $3.7 \pm 0.18$ \\
\hline $22: 5 n-3$ & $0.2 \pm 0.04$ & $0.1 \pm 0.04^{\circ}$ & $2.9 \pm 0.13^{\mathrm{c}, d}$ & $0.3 \pm 0.06^{c}$ & $1.9 \pm 0.08$ \\
\hline $22: 6 n-3$ & $0.3 \pm 0.03$ & $0.2 \pm 0.02^{\mathrm{a}}$ & $0.7 \pm 0.06^{\mathrm{c.d}}$ & $1.8 \pm 0.14^{c}$ & $1.2 \pm 0.07$ \\
\hline$n-3 / n-6$ & $0.01 \pm 0.00$ & $0.01 \pm 0.00$ & $0.31 \pm 0.01^{\mathrm{cod}}$ & $0.15 \pm 0.01^{\mathrm{c}}$ & $0.25 \pm 0.01$ \\
\hline
\end{tabular}

The relative ( $\%$ of total area under the curve of identified fatty acids) fatty acid composition of platelet phospholipids from diet-modified rats. - trace amount $(<0.1 \%)$. Total unidentified fatty acids varied between $2.9 \%$ and $4.1 \%$ of total area under the curve. Abbreviations as in TABLES 2.1 and 2.2 . Significance of difference in the reference diets, Mann-Whitney U-test: ${ }^{a} P \leq 0.05,{ }^{b} P \leq 0.01$. When the Kruskal-Wallis test showed significant differences between the experimental diets $(P \leq 0.05)$, the groups were compared with the Mann-Whitney U-test ( $P$-level of significance $\leq 0.017){ }^{c} P \leq 0.017$ different from FO group; ${ }^{\circ} P \leq 0.017$ different from DHA group. 'One outlier excluded. Data represent mean valuestsem.

not differ between the three groups.

There were no differences in the mean OT between the EPA and DHA groups (TABLE 2.3). Moreover, the average OT in these two groups was not significantly different from that in the FO group. A group receiving the Control control diet was not included in this comparative study. However, since the OT of the reference groups are almost identical in both the dosage and comparative study, it seems reasonable to assume that log OT of a Control group would, again, have been about 2.12 . In that case, the OTs of the EPA, DHA and FO groups would have been significantly longer than those of the Control group. In addition, the log OTs of the experimental groups are very similar to that of the antithrombotic SO-reference group. This indicates that EPA, DHA or a mixture of those fatty acids (FO) has comparable reducing effects on arterial thrombosis tendency.

ADP- and collagen-induced platelet aggregation (range: $14 \pm 0.9 \Omega$ to $16 \pm 1.2 \Omega$ and $11.6 \pm 0.7 \Omega$ to $11.8 \pm 1.2 \Omega$, respectively) and disaggregation (range: $61 \pm 7.0 \%$ to $67 \pm 6.7 \%$ and $18 \pm 6.0 \%$ to $27 \pm 5.2 \%$, respectively) were not significantly different between the groups. Similarly, in the samples of these aggregation studies, the levels of $\mathrm{TxB}_{2}$ were equally low (range: $0.8 \pm 0.1 \mathrm{ng} / \mathrm{ml}$ to $1.16 \pm 0.20 \mathrm{ng} / \mathrm{ml}$ and $40.0 \pm 5.1 \mathrm{ng} / \mathrm{ml}$ to $70.5 \pm 11.5 \mathrm{ng} / \mathrm{ml}$ for ADP- and collagen-induced platelet activation, respectively) and not significantly different. The suggestion from the dosage study 
that $T \times B_{2}$ production may influence disaggregation, is supported by results from the comparative study, since $\mathrm{TxB}_{2}$ concentrations in plasma from collagen-activated platelets again correlated with disaggregation values $(n=47, r=-0.34, P=0.020)$.

In both studies, hardly any difference was observed in the maximum aggregation of collagen-activated platelets, although the $\mathrm{TXB}_{2}$ productions were significantly lower in the experimental groups. Since collagen-induced aggregation largely depends on the formation of thromboxane $A_{2}\left(T \times A_{2}\right)$, this suggests that the $\mathrm{TXA}_{2}$-sensitivity of blood platelets increase after $\mathrm{FO}$ feeding. To obtain more information on this issue, platelet $T \times A_{2}$-sensitivity was determined by measuring platelet aggregation in response to the $\mathrm{TXA}_{2}$-mimicking compound U46619. $\mathrm{TXA}_{2}$ sensitivity was significantly higher in the SO group compared to that in the HCO group $(15.1 \pm 0.68$ vs. $10.0 \pm 0.70 \Omega$, respectively, $P<0.0001)$ as has been observed for washed platelets before $[15,25]$. No significant differences were found between the experimental groups (range: $13.3 \pm 0.71$ to $14.9 \pm 0.94 \Omega$ ). In general, the values were comparable to those from the SO group, and this implies an increased $\mathrm{TXA}_{2}$ sensitivity. Further studies are required to compare the relative potencies of dietary $n-6$ and $n-3$ fatty acids to increase the apparent $T \times A_{2}$-sensitivity of blood platelets.

Interestingly, a relatively weak but significant correlation was observed between the obstruction time and platelet $\mathrm{TXA}_{2}$-sensitivity in the same animal, showing that arterial thrombosis tendency in vivo is lower (OT longer), the higher the

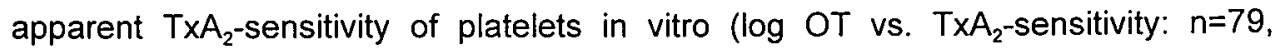
$r=0.30, P=0.0063$ ). The same anomaly has been described before for collageninduced aggregation $[11,17,23]$, that is known to be highly $T X A_{2}$-dependent. Since the OT strongly depends on the dietary $\mathrm{P} / \mathrm{S}$ ratio, this suggests that $\mathrm{TXA}_{2}$-sensitivity and collagen-induced aggregation depend on the P/S ratio of the diet also. The exact mechanism of this is unclear, since the changes in dietary P/S ratio did not result in comparable changes in P/S ratios of platelet phospholipids (TABLES 2.2 and 2.4). Recent work by Heemskerk et al. [16] provided evidence to postulate that subtle changes in cholesterol/phospholipid ratios of platelet plasma membranes result in an altered phospholipase $\mathrm{C}$-mediated transduction of the thromboxane signal. This may explain, at least in part, the dietary fatty acid effects on platelet $\mathrm{TXA}_{2}$-sensitivity and collagen-induced aggregation.

\subsection{Concluding remarks}

This is the first direct comparison between EPA and DHA for their effects on arterial thrombosis tendency and whole blood platelet aggregation in rats. In conclusion, dietary EPA and DHA decreased arterial thrombosis tendency in vivo in a similar way. Their reducing effects on $\mathrm{TxB}_{2}$ production of collagen-activated blood platelets 
was comparable as well, and may have accounted for the observed enhancement of disaggregation. Additionally, the dietary $n-3$ fatty acids in the diet increased the apparent $\mathrm{TXA}_{2}$-sensitivity, which appeared negatively related to arterial thrombosis tendency.

\subsection{Acknowledgements}

We thank Mr. J.S.W. Wierts, Mr. R.F.G. Offermans, Mrs. N.J.J.E. Bitsch and Mrs. A.A.H.M. Hennissen for their technical assistance and animal husbandry. We are grateful to Dr. A. Kester for his advise on statistical evaluations. This project was supported by Hoffmann-La Roche (Basel, Switzerland).

\subsection{References}

1. Herold PM, Kinsella JE. Fish oil comsumption and decreased risk of cardiovascular disease: a comparison of findings from animal and human feeding trials. Am J Clin Nutr. 1986;43:566598.

2. Burr ML, Fehily AM, Gilbert JF, Rogers S, Holliday RM, Sweetman PM, Elwood PC, Deadman NM. Effects of changes in fat, fish, and fibre intakes on death and myocardial reinfarction: diet and reinfarction trail (DART). Lancet. 1989;ii:757-761.

3. Malle $E$, Kostner GM. Effects of fish oils on lipid variables and platelet function indices. Prostaglandins Leukot Essent Fatty Acids. 1993;49:645-663.

4. Kobatake $Y$, Kuroda $K$, Jinnouchi $H$, Nishide $E$, Innami S. Differential effect of dietary eicosapentaenoic and docosahexaenois fatty acid on lowering of triglyceride and cholerterol in the serum of rats on hypercholesterolemic diet. J Nutr Sci Vitaminol. 1984;30:357-372.

5. Frøyland L, Vaagenes H, Asiedu DK, Garras A, Lie O, Berge RK. Chronic administration of eicosapentaenoic acid and docosahexaenoic acid as ethyl esters reduced plasma cholesterol and changed the fatty acid composition in rat blood and organs. Lipids. 1996;31:169-178.

6. Shiina $T$, Terano $T$, Saito J, Tamura $Y$, Yoshida S. Eicosapentaenoic acid and docosahexaenoic acid suppress proliferation of vascular smooth muscle cells. Atherosclerosis. 1993;104:95-103.

7. Andriamampandry MD, Leray $C$, Gutbier $G$, Freund $M$, Cassel $D$, Cazenave JP, Gachet $C$. Diets rich in saturated $\mathrm{n} 9$ and $\mathrm{n} 3$ fatty acids differentially affect the fatty acid composition of phospholipids and function of rat platelets. Platelets. 1996;7:269-276.

8. Ikeda I, Wakamatsu $K$, Inayoshi A, Imaizumi $K$, Sugano $M$, Yazawa $K$. $\alpha$-Linolenic, eicosapentaenoic and docosahexaenoic acids affect lipid metabolism differently in rats. $J$ Nutr. 1994;124:1898-1906.

9. Hornstra G, Vendelmans-Starrenburg A. Induction of experimental arterial occlusive thrombi in rats. Atherosclerosis. 1973;17:369-382.

10. Hornstra G, Lussenburg RN. Relationship between the type of dietary fatty acid and arterial thrombosis tendency in rats. Atherosclerosis. 1975;22:499-516.

11. Hornstra G. Dietary Fats, Prostanoids and Arterial Thrombosis. The Hague: Martinus Nijhoff Publishers; 1982. 
12. Hornstra G, Kester ADM. Effects of the dietary fat type on arterial thrombosis tendency: systematic studies with a rat model. Atherosclerosis. 1997;131:25-33.

13. Sundram $K$, Hornstra $G$, Houwelingen van AC, Kester ADM. Replacement of dietary fat with palm oil: affect on human serum lipids, lipoproteins and apolipoproteins. $B r J$ Nutr. 1992;68:677-692.

14. Houwelingen van AC, Kester ADM, Hornstra G. Effect of moderate fish intake on platelet aggregation and ATP-release in human blood. Nutrition Res. 1989;9:1187-1196.

15. Heemskerk JWM, Feijge MAH, Kalafusz R, Hornstra G. Influence of dietary fatty acids on membrane fluidity and activation of rat platelets. Biochim Biophys Acta. 1989;1004:252-260.

16. Heemskerk JWM, Feijge MAH, Simonis MAG, Hornstra G. Effects of dietary fatty acids on signal transduction and membrane cholesterol content in rat platelets. Biochim Biophys Acta. 1995; 1255:87-97.

17. Rand LM, Hennissen AAHM, Hornstra G. Effects of dietary palm oil on artherial thrombosis, platelet responses and platelet membrane fluidity in rats. Lipids. 1988;23:1019-1023.

18. Hoving EB, Jansen $G$, Volmer $M$, Doormaal van JJ, Muskiet FAJ. Profiling of plasma triglyceride fatty acids as their methylesters by capillairy gas chromatography, preceded by a rapid aminopropyl silica column chromatographic separation of lipid classes. J Chromatogr. 1988;434:395-409.

19. Folch J, Lees $M$, Sloane-Stanley GH. A simple method for the isolation and pusification of total lipids from animal tissues. J Biol Chem. 1957;226:497-509.

20. Kaluzny MA, Duncan LA, Merritt MV, Epps DE. Rapid separation of lipid classes in high yield and purity using bounded phase columns. $J$ Lipid Res. 1985;26:135-140.

21. Morrison WR, Smith LM. Preparation of fatty acid methyl esters and dimethylacetals from lipids with boron fluoride-methanol. J lipid Res. 1964;5:600-608.

22. Engels W, Haaster van CMCJ, Lemmens PJMR, Vusse van der GJ, Hornstra G. Dietary modulation of fatty acid composition of mast cell phospholipids does not affect histamine release induced by compound 48/80. Inflamm Res. 1997;46:185-190.

23. Rand ML, Hennissen AAHM, Hornstra G. Effects of dietary sunflowerseed oil and marine oil on platelet membrane fluidity, arterial thrombosis, and platelet responses in rats. Atherosclerosis. 1986;62:267-276.

24. Hornstra G. The significance of fish and fish-oil enriched food for prevention and therapy of ischaemic cardiovascular disease. In: Vergroesen AJ and Crawford MA (Eds). The Role of Fats in Human Nutrition II. Academic Press Limited, New York, 1989, p. Pages.

25. Heemskerk JWM, Feijge MAH, Kester A, Hornstra G. Dietary fat modifies thromboxane $A_{2}-$ induced stimulation of rat platelets. Biochem J. 1991;278:399-404. 


\section{Modulation of rat platelet activation by vessel wall-derived prostaglandin and platelet-derived thromboxane: effects of dietary fish oil on thromboxane- prostaglandin balance.}

Cécile M. A. Nieuwenhuys, ${ }^{1}$ Marion A. H. Feijge, ${ }^{2}$ René F. G. Offermans, ${ }^{1}$ Arnold D. M. Kester ${ }^{3}$, Gerard Hornstra $^{1}$ and Johan W. M. Heemskerk ${ }^{1,2^{*}}$

Depts. of Human Biology ${ }^{1}$, Biochemistry, ${ }^{2}$ and Medical Information \& Statistics, ${ }^{3}$ University of Maastricht, P.O. Box 616, 6200 MD Maastricht, The Netherlands. 


\subsection{Abstract}

By dietary manipulation of rats with $n-3$ polyunsaturated fatty acids (PUFAs), platelets and endothelium-containing aortic tissue were obtained with decreased levels of arachidonate and increased levels of eicosapentaenoate and docosahexaenoate. These diet-induced changes were accompanied by a reduced formation of thromboxane $A_{2}\left(T_{X A_{2}}\right)$ and prostaglandin $I_{2}\left(\mathrm{PGI}_{2}\right)$ by platelets and aortic tissue, respectively. When platelets were incubated with autologous, aorta-derived $\mathrm{PGI}_{2}$, the dietary modulation of $\mathrm{PGI}_{2}$ generation had a stronger effect on the activation process than the dietary effect on $T_{X A_{2}}$ generation. The platelet-inhibiting effect of $P G I_{2}$ was independent of the type of agonist, and involved both TXA $\mathrm{A}_{2}$-dependent and $\mathrm{TXA}_{2}$ independent activation responses. $\mathrm{PGl}_{2}$ also inhibited the agonist-induced formation of $\mathrm{TXA}_{2}$. In addition, the platelet-inhibitory effect of $\mathrm{PGI}_{2}$ was more prolonged in time than the brief, stimulatory effect of TXA ${ }_{2}$. We conclude that, in the thromboxane-prostaglandin balance of platelet activation, $\mathrm{PGI}_{2}$ plays a more prominent role than $\mathrm{TXA}_{2}$. Furthermore, dietary n-3 PUFAs appear to influence platelet activation more by reducing formation of endothelial $P \mathrm{PI}_{2}$ than by decreasing autocrine-produced $T X A_{2}$. Thus, in rat, the proposed antithrombotic effect of fish oil is unlikely to be caused by an altered thromboxane-prostaglandin balance.

\subsection{Introduction}

In the early seventies, it became clear that Greenland Eskimos, most probably due to the consumption of fish oil with high levels of $n-3$ polyunsaturated fatty acids (PUFAs), have decreased levels of arachidonate in their platelets [1-3]. It was noted that fish oil intake results in a replacement of phospholipid-bound arachidonate by the n-3 fatty acids, eicosapentaenoate and docosahexaenoate. This was considered relevant, because arachidonic acid is the precursor of a whole range of plateletmodulating prostanoids. In activated platelets, arachidonate is converted into $\mathrm{PGH}_{2}$ and $\mathrm{TXA}_{2}$, which stimulate the activation process by binding to the thromboxane receptors. In endothelial cells from the vessel wall, on the other hand, arachidonate is converted into $P G I_{2}$, which inhibits platelet activation following binding to the IP. type of prostaglandin receptors on these cells. An early explanation for the antithrombotic effect of fish oil has been that the eicosapentaenoate-derived $T X A_{3}$, in contrast to arachidonate-derived TXA ${ }_{2}$, has no a more than weakly stimulating effect on platelets, whereas the eicosapentaenoate-derived $\mathrm{PGI}_{3}$ (produced by endothelial cells) is as platelet-inhibiting as is $\mathrm{PGI}_{2}[4,5]$. Thus, fish oil diet may influence the 
thromboxane-prostaglandin balance controlling platelet activation in a favorable, i.e. less platelet-stimulating, way $[6,7]$. From this perspective, the thromboxaneprostaglandin balance is considered to steer the fine-regulation of the activation process, by assuring adequate and poised availability of stimulating (thromboxanes) as well as inhibiting (prostaglandins) prostanoids. Although many studies confirm the beneficial effect of dietary fish oil [8-11], there is still limited evidence that this is based on a changed thromboxane-prostaglandin balance.

The model that platelet-derived thromboxanes and vessel wall-derived prostaglandins control platelet activation in a balanced way assumes, implicitly, that these compounds have opposite, though in strength comparable, effects on the activation process. However, this is most probably not the case. For instance, some physiological platelet agonists (e.g. collagen) rely much stronger on the thromboxane-mediated activation pathway than others (e.g. thrombin) [12], while $\mathrm{PGl}_{2}$ suppresses platelet responses to essentially all agonists [13].

In platelets, the principal effect of receptor occupation by $\mathrm{TXA}_{2}$ is activation of the GTP-binding protein $G_{q}$, which results in a moderate increase in phospholipase $C-\beta$ activity, followed by a $\mathrm{Ca}^{2+}$ signal and protein kinase $\mathrm{C}$ stimulation $[14,15]$. On the other hand, binding of $P G l_{2}$ to its platelet receptor causes activation of $G_{s}$, followed by increased adenylate cyclase activity and stimulation of the CAMPmediated routes of platelet inhibition $[16,17]$, such as a reduced production of $\operatorname{Ins} P_{3}$, a decreased $\mathrm{Ca}^{2+}$ mobilisation, and closure of the integrin $\alpha_{11 b} \beta_{3}$ fibrinogen receptors [15,18-20]. Thus, whereas $\mathrm{PGl}_{2}$ seems to act as a general suppressor of many platelet responses, TXA $A_{2}$ is only one of the many platelet agonists stimulating the phospholipase $C$ pathway.

For the present paper, we investigated how fish-oil feeding influences the balancing effect of thromboxanes and prostaglandins on platelets by a diet study with rats that were fed with various types of $n-3$ PUFAs. The effect of vessel-wall derived prostanoids on the platelet activation process was monitored in mixtures of platelets and supernatants taken from incubated aorta pieces. It appeared that the diet-induced changes in prostaglandin formation had a much larger effect on platelet responsiveness than the changes in thromboxane formation. In addition to this, model studies with rats fed on a standard diet showed that the platelet-inhibiting effect of $\mathrm{PGI}_{2}$ is stronger and more persistent than the weakly stimulating effect of autocrine-produced $T_{X A_{2}}$. 


\subsection{Materials and methods}

\section{Materials}

Fish oil-derived fatty acid ethyl esters, and purified eicosapentaenoate and docosahexaenoate ethyl esters were supplied by Hoffmann-La Roche (Basel, Switzerland). Other dietary components came from sources described elsewhere [21]. $\mathrm{PGl}_{2}$ was bought from Cayman (Ann Harbor, MI). Stocks of $P G l_{2}$ were held in $10 \mathrm{mM} \mathrm{NaOH}$, and diluted immediately before use. $\alpha$-Thrombin from rat plasma was obtained from Sigma (St. Louis, MO), while U46619 came from Biomol (Plymouth Meeting, PA). The origin of other chemicals is as described before [22].

\section{Animals and diets}

Three-week-old, male Wistar rats (Charles River, Sulzfeld, Germany) were housed individually in stainless steel cages and held on a standard, pelleted stock food. After two weeks, the animals were used for a diet study or kept on standard food in case of control experiments. For the diet study, rats were randomly assigned to 5 groups of 13 animals, and then fed with one of five high-fat diets. Diets were equally low in cholesterol $(50 \mu \mathrm{g} / \mathrm{g})$ and arachidonate $(\leq 0.5 \%$ of total fatty acids). The rats from the control group were fed with an oleate-rich diet, composed of saturated fatty acids, monounsaturated fatty acids and n-6 PUFAs in a ratio of 2:3:1 (w/w). This control oil was prepared by mixing equivalent amounts of sunflowerseed oil, beef tallow, hydrogenated coconut oil and olive oil [24]. Other groups of rats received a diet, in which $4 \%(w / w)$ of the control fatty acids (2 to 3-energy\%) were replaced by an $n-3$ PUFA preparation containing either $94 \%$ ethyl eicosapentaenoate (EPA group) or $94 \%$ ethyl docosahexaenoate (DHA group), or by a fish oil preparation with $20 \%$ eicosapentaenoate and $37 \%$ docosahexaenoate (FO group). A fifth group of rats was fed with an n-6 PUFA-rich diet of sunflowerseed oil, containing $61 \%$ linoleate (SO group). All diets had an equal energy content of $19.5 \mathrm{~kJ} / \mathrm{g}$, and contained $50 \%$ of digestible energy as fat, 23-energy $\%$ as casein and 27 -energy $\%$ as corn starch. Minor dietary components (minerals, vitamins, and fiber) were added as before $[22,23]$. To prevent lipid oxidation, the diets were prepared weekly and stored at -20 ${ }^{\circ} \mathrm{C}$ under nitrogen until use. The dietary period was 9-11 weeks, during which water and food were available ad libitum. Mean daily food intake and weight gain were similar for rats of all groups. Control experiments were performed with rats, aged 4-6 months, that were maintained on standard, pelleted stock food. Experimental protocols were approved by the Institutional Animal Care Committee.

\section{Platelet preparation and activation}

The rats were fasted overnight, anaesthetized, and subjected to abdominal aortic puncture. Blood was then collected into citrate-citric acid-glucose and washed platelets were prepared from platelet-rich plasma, as described before [25]. Platelets 
were suspended at a concentration of $1-2 \times 10^{8} / \mathrm{ml}$ in Hepes buffer $\mathrm{pH} 7.4$, consisting of $136 \mathrm{mM} \mathrm{NaCl}, 5.6 \mathrm{mM}$ glucose, $5 \mathrm{mM}$ Hepes, $2.7 \mathrm{mM} \mathrm{KCl}, 2 \mathrm{mM} \mathrm{MgCl}, 0.42 \mathrm{mM}$ $\mathrm{NaH}_{2} \mathrm{PO}_{4}$ and $0.1 \%(\mathrm{w} / \mathrm{v})$ bovine serum albumin. Cells were counted with a Technicon $\mathrm{H}-1$ analyzing system (Bayer, Germany), and used for aggregation and calcium measurements. Aggregation was quantified from the recorded (maximal) changes in light transmission $[21,24]$. To measure changes in cytosolic $\left[\mathrm{Ca}^{2+}\right]_{\mathrm{i}}$, washed platelets $\left(5 \times 10^{8} / \mathrm{ml}\right)$ in Hepes buffer $\mathrm{pH} 7.4$ were loaded with the fluorescent $\mathrm{Ca}^{2+}$ probe, fura-2, in the presence of Pluronic $\mathrm{F}-127,2.5 \%(\mathrm{w} / \mathrm{v})$ bovine serum albumin and apyrase (0.1 unit ADPase/ml), as described before [26] Subsequently, the platelets were washed, and suspended in apyrase-containing Hepes buffer $\mathrm{pH} 7.4\left(1 \times 10^{8} / \mathrm{ml}\right)$. Changes in $\left[\mathrm{Ca}^{2+}\right]_{\mathrm{i}}$ were measured by ratio fluorometry using a SLM/Aminco SPF-500C or DMX-1100 spectrofluorometer, following incubation protocols as described for the aggregation measurements. Calibrations from ratio fluorometric values to $\left[\mathrm{Ca}^{2+}\right]_{i}[26]$ were performed both in the presence and absence of indomethacin. Changes in $\left[\mathrm{Ca}^{2+}\right]_{i}$ were corrected for leakage of Fura- 2 .

Incubates of aortic pieces

From anaesthetised rats, aortas were removed immediately after the collection of blood. Vessels were cleaned from adjacent tissue, opened longitudinally and, during $1 \mathrm{~h}$, kept in ice-cold, freshly made Krebs-Henseleit buffer pH 7.4 (120 mM NaCl, 25.3 $\mathrm{mM} \mathrm{NaHCO}_{3}, 11.2 \mathrm{mM}_{\text {glucose, }} 4.8 \mathrm{mM} \mathrm{KCl}, 1.2 \mathrm{mM} \mathrm{KH}_{2} \mathrm{PO}_{4}, 1.0 \mathrm{mM} \mathrm{CaCl}_{2}$ and 1.0 $\mathrm{mM} \mathrm{MgSO}_{4}$ ) under continuous bubbling with a mixture of $95 \% \mathrm{O}_{2}$ and $5 \% \mathrm{CO}_{2}$ [27]. Where indicated, aspirin $(0.8 \mathrm{mM})$ was present during this period of time. Round pieces of aortic tissue (diameter $3.0 \mathrm{~mm}$ ) were then punched out and immediately incubated at $37^{\circ} \mathrm{C}$ in phosphate-buffered saline $\mathrm{pH} 7.4(137 \mathrm{mM} \mathrm{NaCl}, 6.5 \mathrm{mM}$ $\mathrm{Na}_{2} \mathrm{KPO}_{4}, 2.7 \mathrm{mM} \mathrm{KCl}$ and $1.0 \mathrm{mM} \mathrm{KH}_{2} \mathrm{PO}_{4}$ ), while stirring. For platelet experiments with $\alpha$-thrombin as agonist, one piece of aorta was incubated in $300 \mu$ phosphatebuffered saline; for experiments with collagen, two aortic pieces were incubated in $200 \mu \mathrm{l}$ buffer. After exactly $6 \mathrm{~min}$, a tissue-free sample of $25 \mu \mathrm{l}$ was taken out and added to an aggregometer cuvette containing washed platelets in suspension ( $2 \mathrm{x}$ $10^{8} / 0.5 \mathrm{ml}$ ). Another sample of $100 \mu \mathrm{l}$ was added to a cuvette containing fura-2loaded platelets $\left(2 \times 10^{8} / 2 \mathrm{ml}\right)$, placed in a spectrofluorometer. Simultaneously, a third sample from the incubation fluid was frozen in liquid nitrogen, and stored at -30 ${ }^{\circ} \mathrm{C}$ for later determination of 6-keto $\mathrm{PGF}_{1 \alpha}$.

\section{Incubations of platelets with or without incubates of aortic pieces}

To measure aggregation, $0.5 \mathrm{ml}$ samples $\mathrm{f}$ a platelet suspension $\left(1 \times 10^{8}\right.$ platelets $)$ were transferred to cuvettes $\left(37^{\circ} \mathrm{C}\right)$ that were placed in an automated Chronolog aggregometer (Havertown, PA). After stirring for $1 \mathrm{~min}$ at $900 \mathrm{rpm}, \mathrm{CaCl}_{2}(1 \mathrm{mM}$ ) was added and, at $30 \mathrm{~s}$ thereafter, if applicable, $25 \mu \mathrm{PGI}$ solution ( 0.03 to $30 \mathrm{nM}, \mathrm{f}$.c.) or $25 \mu \mathrm{l}$ incubate of aorta tissue (see below). Exactly $30 \mathrm{~s}$ later, platelet activation was 
started by addition of either collagen or thrombin. Where indicated, the cyclooxygenase inhibitor indomethacin $(55 \mu \mathrm{M})$ was added at $3 \mathrm{~min}$ before the agonist. To measure changes in $\left[\mathrm{Ca}^{2+}\right]_{i}$ in fura-2-loaded platelets, agonists and antagonists were added to cuvettes with platelets $\left(2 \times 10^{8} / 2 \mathrm{ml}\right)$ in concentrations as described for the aggregation assay.

After completion of the activation measurements, $400 \mu \mathrm{l}$ samples were drawn from the incubation mixtures to determine levels of $T X B_{2}$ (reflecting the unstable cyclooxygenase products, $\mathrm{PGH}_{2}$ and $\mathrm{TXA}_{2}$ ). The samples were centrifuged at 18,000 $\mathrm{g}$ for $5 \mathrm{~min}$, and the supernatants were frozen in liquid nitrogen and stored at $-30^{\circ} \mathrm{C}$. In addition, from the aortic incubates, parallel samples were taken to measure the stable $\mathrm{PGI}_{2}$ derivative, 6-keto $\mathrm{PGF}_{1 \alpha}$. Because incubations of the aortas were strictly standardized in amount of tissue $\left(7.1 \mathrm{~mm}^{2}\right.$ in case of platelet activation with thrombin, or $14.2 \mathrm{~mm}^{2}$ for activation with collagen), time ( $360 \mathrm{~s}$ before sampling), and temperature $\left(37{ }^{\circ} \mathrm{C}\right)$, the measured level of 6 -keto $P G F_{1 \alpha}$ can be considered proportional to that of the $\mathrm{PGI}_{2}$ added to platelets (see results).

\section{Lipid analyses}

Total phospholipids were isolated from suspensions of washed platelets and from homogenized aortic pieces by chloroform-methanol extraction and chromatographic separation [28]. Dietary lipids (triglycerides) were isolated from the high-fat diets, using the same procedure. The fatty acid composition of platelet phospholipids and dietary total lipids was determined by gas-liquid chromatography, as described elsewhere [28].

\section{Formation of thromboxanes and prostaglandins}

Levels of $\mathrm{TXB}_{2}$ and 6-keto $\mathrm{PGF}_{1 \alpha}$ were measured with enzyme-linked immunoassay kits from Cayman (Ann Harbor, MI). Cross-reactivity of the latter kit for 6-keto PGF $F_{2 \alpha}$ was $2.1 \%$.

\section{Statistics}

To test the significance of differences between diet groups, a one-way ANOVA was applied using Statview 4.02 (Abdacus Concepts, 1992 to 1993). When the ANOVA test showed statistical significance, a t-test was performed with adjustment of the $\alpha$ level with a factor 0.25 according to the Bonferroni method for multiple comparisons, to determine which of the groups differed from the control group.

The three coefficients for the regression equation $\mathrm{Aggr}=A_{1}+A_{2} \cdot T X A_{2}+$ $A_{3} \cdot P G I_{2}$ were calculated per animal from three sets of aggregation measurements. Coefficients per diet group were compared using a non-parametric Kruskal-Wallis test. In case of significant differences, other diet groups were compared to the control group, as described above. 


\subsection{Results}

Dietary n-3 PUFAs reduce arachidonate levels in platelets and aortic tissue To obtain rats with increased levels of n-3 PUFAs in platelets and endothelium, a long-term intervention study was performed with diets containing various types of $n-3$ PUFAs. As before, we used male Wistar rats that received diets containing high amounts of fat (50 energy\% fat) $[21-24,27]$. In case of the control group, the diet was composed of saturated fatty acids, monounsaturated fatty acids and n- 6 PUFAs in a ratio of 2:3:1 (w/W) (TABLE 3.1). For the other animal groups, $4 \%$ of the fatty acids of the control diet were replaced by either eicosapentaenoate (20:5n-3, EPA group), docosahexaenoate (22:6n-3, DHA group) or a mixture of these n-3 PUFAs (FO group). Animals of a fifth group received high-fat sunflowerseed oil diet containing high levels of $n-6$ PUFAs (SO group). At the end of the dietary period (9-11 weeks), platelet numbers in blood were similar for all groups (about $1.1 \times 10^{\%} / \mathrm{ml}$ ), while the mean platelet volume was slightly decreased from 5.6 to 5.4 in rats fed with $n-3$ PUFA-containing diets.

These dietary interventions led to the expected fatty acid changes in membrane phospholipids from platelets and vessel wall. The platelets from rats fed with SO were somewhat reduced in percentage of arachidonate $(20: 4 n-6)$ in favor of that of linoleate $(18: 2 n-6)$, in comparison to rats from the control group, while the

TABLE 3.1 Global fatty acid composition of high-fat diets.

\begin{tabular}{|c|c|c|c|c|c|}
\hline \multirow[t]{2}{*}{ Fatty acid } & \multicolumn{5}{|c|}{ Type of diet } \\
\hline & \multicolumn{5}{|c|}{ (\% total fatty acids) } \\
\hline $16: 0$ & 14.8 & 6.3 & 14.2 & 14.2 & 14.2 \\
\hline 18:0 & 10.2 & 5.1 & 9.8 & 9.8 & 9.8 \\
\hline$\Sigma$ SAFAs & 35.4 & 12.8 & 34.0 & 33.8 & 33.9 \\
\hline $18: 1 n-9$ & 45.6 & 24.9 & 44.1 & 44.1 & 40.8 \\
\hline$\Sigma$ MUFAs & 47.7 & 25.8 & 46.4 & 46.6 & 43.6 \\
\hline $18: 2 n-6$ & 15.5 & 60.9 & 15.2 & 15.1 & 15.2 \\
\hline$\Sigma n-6$ PUFAs & 15.5 & 60.9 & 15.3 & 15.2 & 17.0 \\
\hline $20: 5 n-3$ & 0 & 0 & 3.7 & 0.2 & 1.8 \\
\hline $22: 6 n-3$ & 0 & 0 & 0 & 3.7 & 2.6 \\
\hline$\Sigma$ n-3 PUFAs & 0.4 & 0.1 & 4.1 & 4.2 & 5.3 \\
\hline
\end{tabular}

Abbreviations of the diets are SO, EPA, DHA and FO, for diets enriched in sunflower-seed oil, eicosapentaenoate, docosahexaenoate and fish oil, respectively. SAFA, MUFA and PUFA indicate saturated, monounsaturated and polyunsaturated fatty acid. Data are percentages of major fatty acids in the diets. Fatty acids are indicated by number of carbon atoms, number of double bounds, and location of the first double bond. 


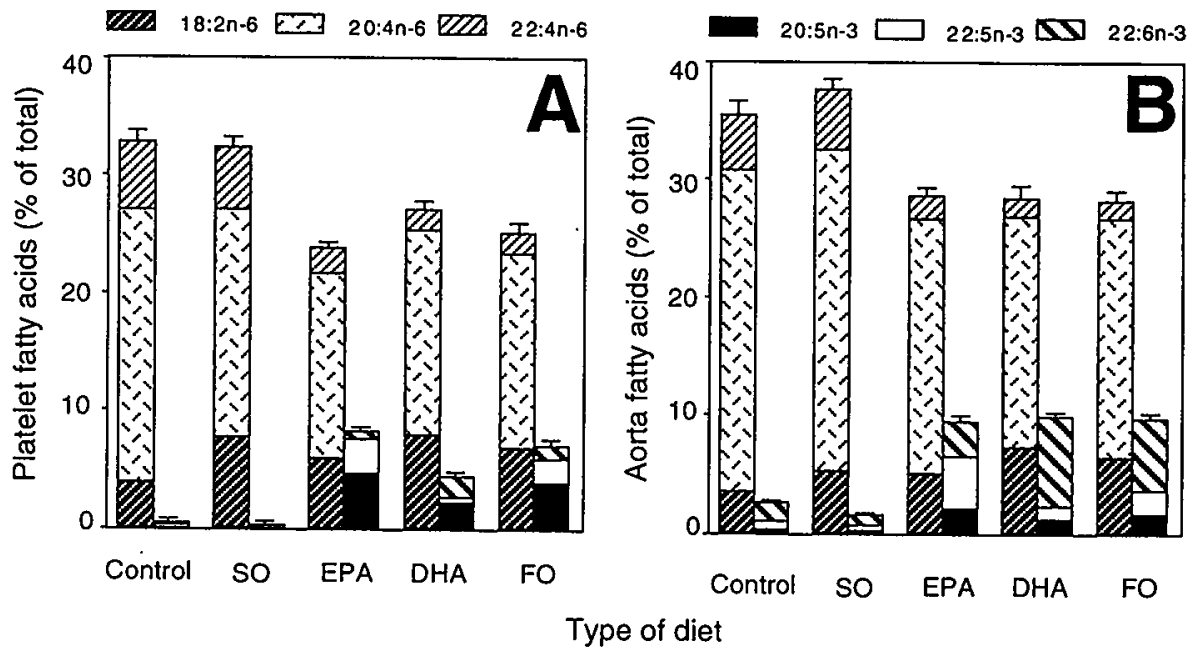

FIGURE 3.1 Global fatty acid composition of phospholipids in platelets and aortas from diet-modified rats. Shown are main $n-6$ and n-3 fatty PUFAs (weight \%) in the total phospholipids isolated from platelets (A) and aortic tissue (B). Abbreviations for diet groups and fatty acids are as in TABLE 3.1. Error bars represent sums of the indicated fatty acids (mean \pm sem, $n=5-6$ ).

proportion of arachidonate in aorta phospholipids was essentially unchanged (FIG. 3.1 ). On the other hand, in the animals fed with EPA, DHA or FO diet, $>25 \%$ of the arachidonate was replaced by eicosapentanoate (20:5n-3), docosapentaenoate $(22: 5 n-3)$ and docosahexaenoate $(22: 6 n-3)$ both in platelets and aortic tissue. Typically, platelets from the latter groups contained relatively high proportions of 20:5n-3 (FIG. 3.1A), whereas aortas were more enriched in 22:6n-3 (FIG. 3.1B). Each of the n-3 PUFA-containing diets reduced the substrate levels of arachidonic acid for eicosanoid production in platelets and vessel wall to a comparable extent.

\section{Antagonistic effects of platelet- and aorta-derived eicosanoids on platelets}

Using platelets and aortic tissue from the various diet groups, we compared the contribution of platelet- and endothelial-derived eicosanoids to the platelet activation process. Aggregation of platelets was thereby measured as a functional parameter, and mobilisation of $\mathrm{Ca}^{2+}$ into the cytosol as a second messenger formed early in the activation pathway [13]. As platelet stimuli, we used submaximal concentrations of thrombin, which acts mainly independently of $\mathrm{TXA}_{2}$ formation, and collagen, which relies more heavily on autocrine production of $\operatorname{TXA}_{2}[12,22]$. Activations were carried out under three different conditions: with platelets in the presence or absence of indomethacin to determine the contribution of $\mathrm{TXA}_{2}$, and with platelets that were treated with cell-free incubates of aortic tissue, containing controlled amounts of vascular eicosanoids [27]. Per set of incubations, the platelets and aortic tissue came 
from the same animal. After completion of the activation, levels of TXB2 were measured, and in samples of the aortic incubates the stable $\mathrm{PGI}_{2}$ derivative, 6-keto $\mathrm{PGF}_{1 \alpha}$ was determined.

Regardless of the type of diet, platelet activation with thrombin caused a more rapid aggregation and a faster increase in cytosolic $\left[\mathrm{Ca}^{2+}\right]_{i}$ than activation with collagen (see FIG. 3.2 for data from control group). As expected, treatment of the platelets with indomethacin, to inhibit thromboxane-mediated events, resulted in a partial block of the aggregation and calcium responses with either agonist (FIG. 3.2). Pre-addition of aortic incubate gave a prolonged suppression of both platelet responses. The degree of suppression increased dose-dependently with the volume
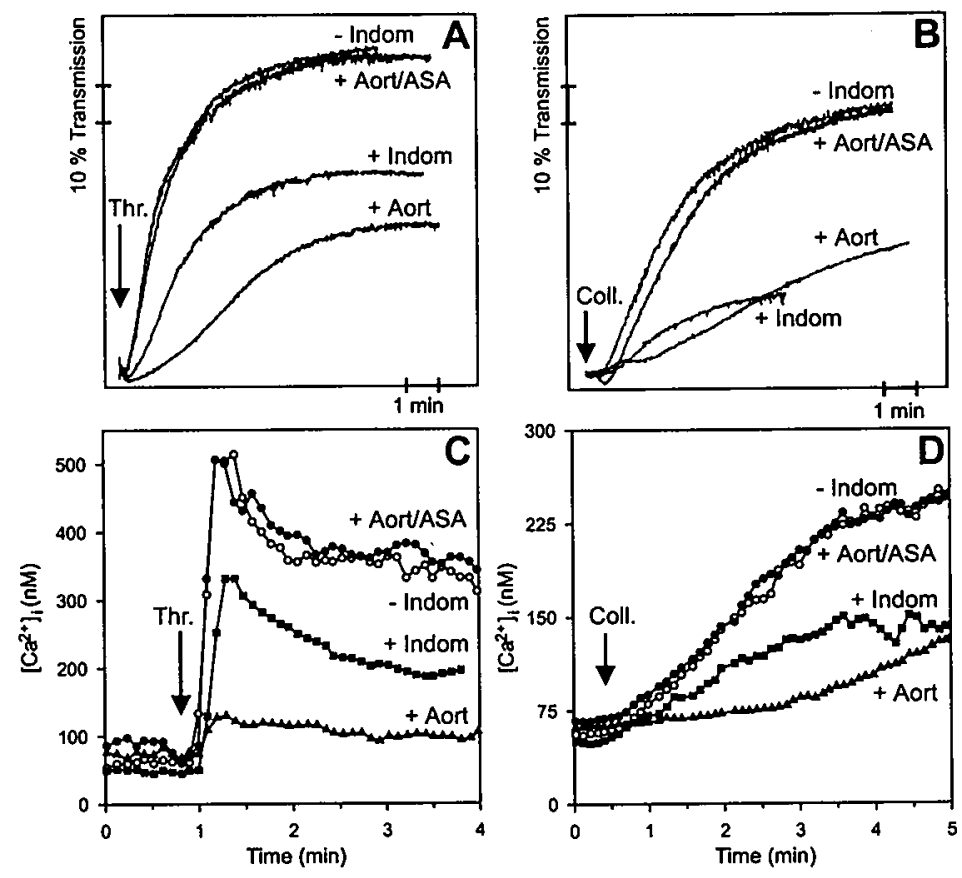

FIGURE 3.2 Suppression of thrombin- and collagen-induced platelet activation by aortic incubates. In aggregometer cuvettes, rat platelets $\left(5 \times 10^{7} / 0.5 \mathrm{ml}\right)$ were stimulated with submaximal concentrations of $2 \mathrm{nM}$ thrombin $(A)$ or $5 \mu \mathrm{g} / \mathrm{ml}$ collagen $(B)$ in the presence of $1 \mathrm{mM} \mathrm{CaCl}_{2}$. Aggregation was followed in the presence (+Indom) or absence (-Indom) of $55 \mu \mathrm{M}$ indomethacin. Aggregation was also recorded with indomethacin-free platelets after $30 \mathrm{~s}$ pre-incubation with $25 \mu \mathrm{l}$ aortic incubate (Aort). Platelets and aorta pieces came from the same animal. Where indicated, aorta pieces were pretreated with aspirin (Aort/ASA). In parallel experiments, Fura-2-loaded platelets $\left(2 \times 10^{8} / 2 \mathrm{ml}\right)$ were activated with $2 \mathrm{nM}$ thrombin (C) or $5 \mu \mathrm{g} / \mathrm{ml}$ collagen (D) in the presence of $1 \mathrm{mM} \mathrm{CaCl}_{2}$, and changes in $\left[\mathrm{Ca}^{2+}\right]_{i}$ were monitored by ratio fluorometry. Again, incubations contained untreated or indomethacin-treated platelets ( \pm Indom), to which $100 \mu$ of either vehicle or aortic incubate (Aort) was added (30 s preincubation). Data are from a representative experiment with platelets from a rat fed with control diet. 

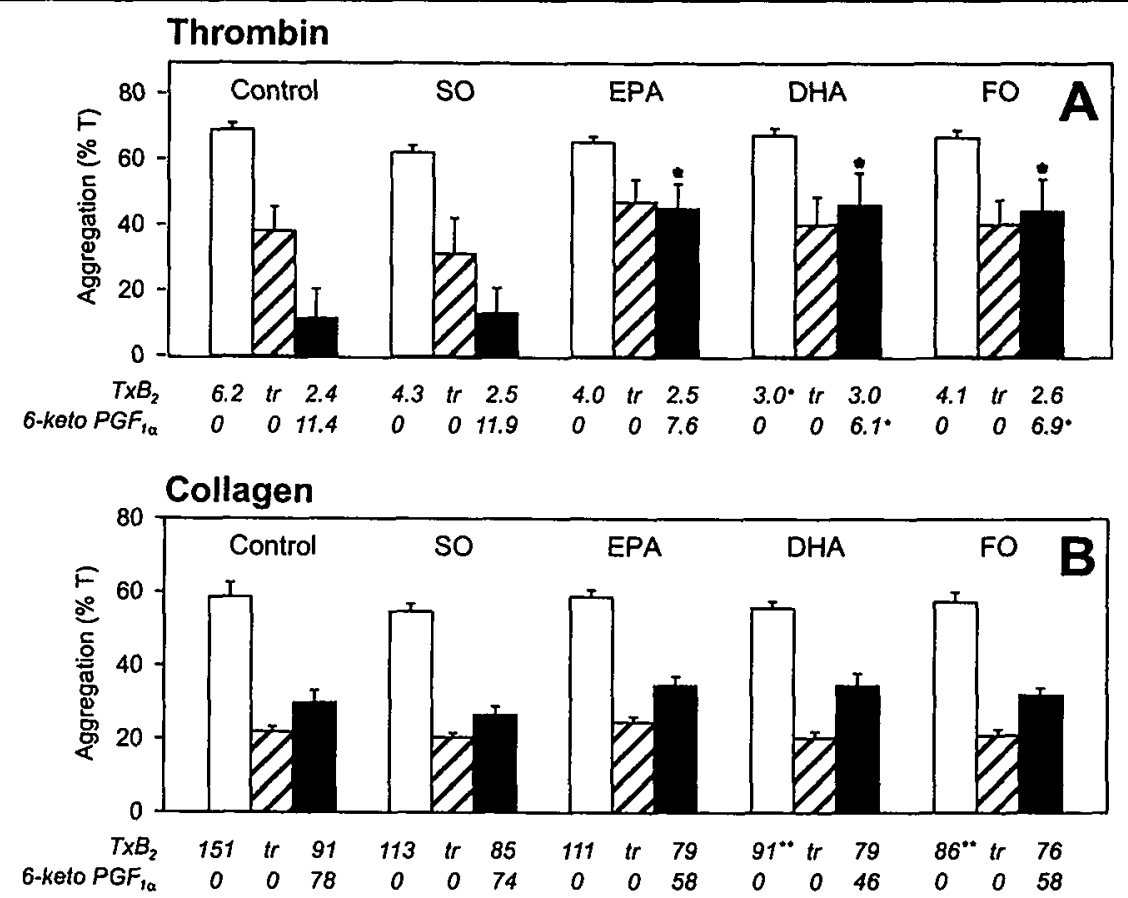

FIGURE 3.3 Diets and modulation of platelet aggregation by platelet- and aorta-derived eicosanoids. Diet-modified platelets were activated with $2 \mathrm{nM}$ thrombin (A) or $5 \mu \mathrm{g} / \mathrm{ml}$ collagen (B), exactly as described for FIG. 3.2. The platelets were either untreated (white bars) or were pretreated with $55 \mu \mathrm{M}$ indomethacin (dashed bars) or aortic incubate (black bars). Platelet aggregation was measured as maximal increases in light transmission after 5 (thrombin) or 10 (collagen) min of activation. Data are mean values \pm sem $(n=9-13)$. Amounts of $T X B_{2}$ were determined in samples taken at times of maximal aggregation $(\mathrm{ng} / \mathrm{ml})$. Concentrations of $P \mathrm{Pl}_{2}$-derived 6-keto $P \mathrm{PF}_{\mathrm{\alpha} \alpha}(\mathrm{ng} / \mathrm{ml})$ were determined in parallel samples taken from aorta incubations. Data given are averaged levels (sem of $10-20 \%, n=9-13$ ). ANOVA of dietary effect in the presence of aortic incubate gives a $P$ value of 0.04 . $P \leq 0.01$ compared to control group ( $t$-test).

of added incubate and with the amount of aorta material per incubation (data not shown). When the aortic pieces were pretreated with aspirin, effects of the incubates on platelet activity were completely abolished. This was true for platelets from the control group (FIG. 3.2), but also for platelets from the other diet groups (data not shown). Thus, the platelet-inhibitory effect of the incubates seems to be predominantly mediated by cyclooxygenase products like $\mathrm{PGl}_{2}$.

Results from the aggregation and calcium measurements per diet group are summarized in FIGS. 3.3 and 3.4, respectively. FIG. 3.3 gives also the levels of TXB and 6-keto $\mathrm{PGF}_{1 \alpha}$ that were measured at the end of the aggregation measurement. Under baseline conditions (no indomethacin or aortic incubate), diet-induced differences in platelet responsiveness towards thrombin or collagen appeared to be absent, regardless of whether aggregation (FIG. 3.3, white bars) or $\mathrm{Ca}^{2+}$ mobilisation 
(FIG. 3.4, white bars) was being measured. Nevertheless, platelet $T X B_{2}$ production was reduced for the rats fed with the n-3 PUFA-containing diets; this reduction was statistically significant for the DHA and FO groups. Similar results of fish oil have been obtained in earlier diet studies with rats $[12,22,23]$. Indomethacin treatment of the platelets reduced the thrombin- and collagen-induced responses to levels that were, again, quite similar for the various diet groups (FIGs. 3.3 and 3.4, dashed bars), indicating that $\mathrm{TXA}_{2}$-independent activation of platelets was also not influenced by the diet type. However, pretreatment with aortic incubates resulted in consistent dietinduced effects. In case of the n-3 PUFA groups (EPA, DHA and FO), the suppressive effect of incubate on platelet reactivity was much smaller than for the control or SO group (FIGS. 3.3 and 3.4, black bars). In line with this diet effect, 6-keto PGF $_{1 \alpha}$ levels were also relatively low in aortic incubates from the n-3 PUFA groups (FIG. 3.3). In all diet groups, the presence of incubate decreased the production of $\mathrm{TXB}_{2}$, which suggests that aorta-derived prostanoids suppress not only platelet reactivity, but also the autocrine production of thromboxane (see below).
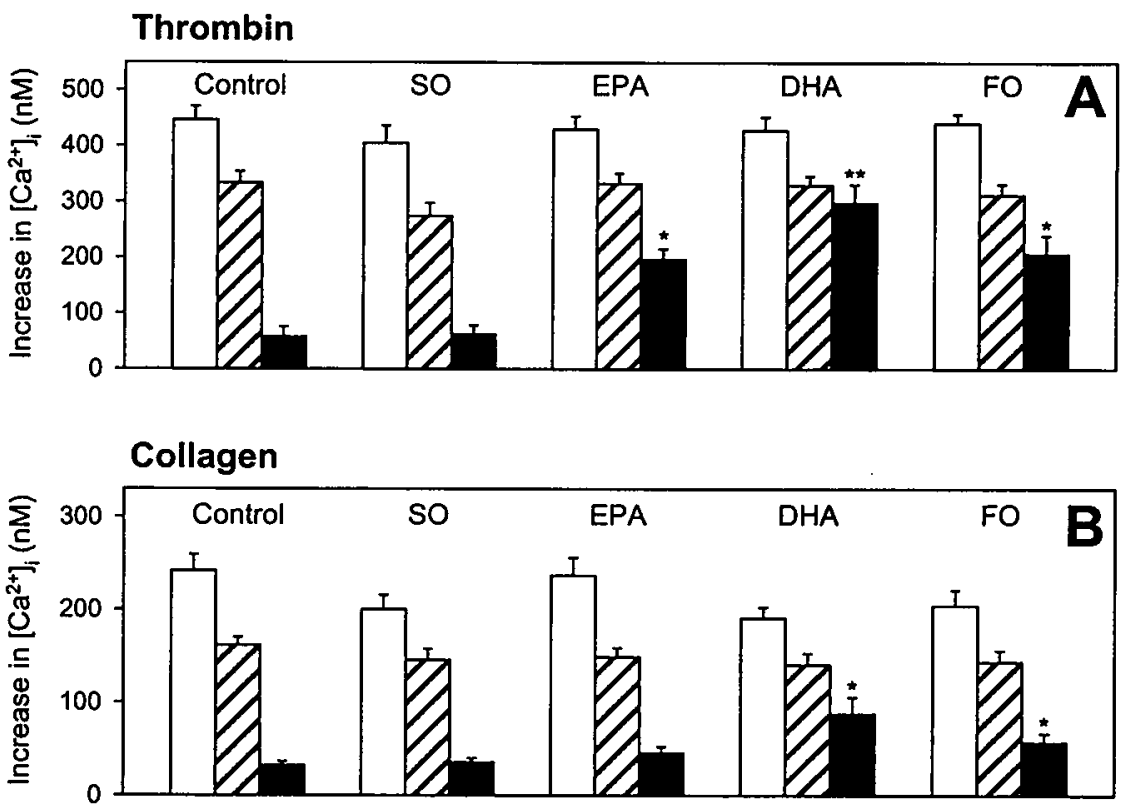

FIGURE 3.4 Dietary effects of platelet- and aorta-derived eicosanoids on platelet calcium responses. Fura-2-loaded platelets were activated with $2 \mathrm{nM}$ thrombin (A) or $5 \mu \mathrm{g} / \mathrm{ml}$ collagen (B), exactly as described for FIG. 3.2. Platelets were activated in the presence of vehicle (white bars), or pretreated with $55 \mu \mathrm{M}$ indomethacin (dashed bars), or $100 \mu \mathrm{l}$ aortic incubate (black bars). Data are maximal increases in cytosolic $\left[\mathrm{Ca}^{2+}\right]_{i}$ (mean \pm sem, $n=9=13$ ). ANOVA of diet-dependent effect on thrombin- and

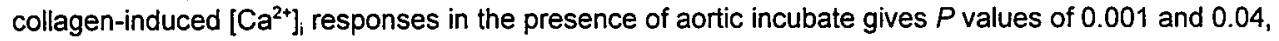
respectively. $P \leq 0.05, " P \leq 0.001$ compared to the control group ( $t$-test). 
Earlier work with human platelets has shown that, at a given dose of agonist, the (calcium, aggregation) responses increase roughly linearly with the amount of produced $\mathrm{TXA}_{2}$ [29]. The data in FIGS. 3.3 and 3.4 can be used to construct equations, describing the modulating effects of $\mathrm{TXA}_{2}$ and $\mathrm{PGI}_{2}$ on platelet responses, if we assume that, for a particular activation condition, a) the levels $\mathrm{TXB}_{2}$ and 6 -keto $P G F_{1 \alpha}$ measured after activation reflect the amounts of $T X A_{2}$ and $P G I_{2}$ present during activation, respectively; b) the effects of $\mathrm{TXA}_{2}$ and $\mathrm{PGI}_{2}$ on platelet activation are linearly related to the levels of these eicosanoids; and c) the observed effects of indomethacin and aortic incubates are solely due to the presence of $T X A_{2}$ and $P G I_{2}$, respectively. For the aggregation measurements with thrombin and collagen, coefficients of the contribution of $\mathrm{TXA}_{2}$ and $\mathrm{PGI}_{2}$ were thus determined per diet group. These coefficients were remarkably similar for the different diet groups, except for relatively high values in the collagen-induced aggregation for the EPA, DHA and FO groups (TABLE 3.2). The increase in coefficients for TXA $A_{2}$ was statistically significant. In earlier diet studies with rats, we have reported that feeding

TABLE 3.2

Modeling the contribution of $\mathrm{TXA}_{2}$ and $\mathrm{PGI}_{2}$ in aggregation of dietmodified platelets.

\begin{tabular}{lccccc}
\hline Coefficient & \multicolumn{6}{l}{ Diet group } & & \\
\cline { 2 - 6 } & Control & SO & EPA & DHA & FO \\
\hline Thrombin & & & & & \\
$A_{1}(\% \mathrm{~T})$ & 42.4 & 35.6 & 47.4 & 44.1 & 48.6 \\
$A_{2}(\% \mathrm{~T} / \mathrm{ng} / \mathrm{ml})$ & 3.6 & 5.0 & 3.5 & 7.1 & 3.7 \\
$A_{3}(\% \mathrm{~T} / \mathrm{ng} / \mathrm{ml})$ & -3.9 & -3.6 & -2.4 & -3.6 & -2.3 \\
Collagen & & & & & \\
$A_{1}(\% \mathrm{~T})$ & 21.5 & 21.5 & 25.5 & 24.9 & 21.4 \\
$A_{2}(\% \mathrm{~T} / \mathrm{ng} / \mathrm{ml})$ & 0.23 & 0.27 & $0.20^{\circ}$ & $0.2 *^{*}$ & $0.40^{*}$ \\
$A_{3}(\% \mathrm{~T} / \mathrm{ng} / \mathrm{ml})$ & -0.21 & -0.21 & -0.21 & -0.26 & -0.35 \\
\hline
\end{tabular}

Diet-modified platelets were activated with thrombin or collagen, and maximal aggregation was measured, as described for FIGS. 3.2 and 3.3. From a set of three aggregation measurements, the equation Aggr $=A_{1}+A_{2} \cdot T X A_{2}+A_{3} \cdot P G I_{2}$ was constructed, in which Aggr represents the aggregation in the presence or absence of $\mathrm{TXA}_{2}$ or $\mathrm{PGI}_{2}$. In the equation, $A_{1}$ represents the aggregation in the absence of the eicosanoids (\% transmission, \%T), $A_{2}$ is a coefficient for the aggregation-stimulating effect of $\mathrm{TXA}_{2}\left(\% \mathrm{~T} / \mathrm{ng} T X A_{2} / \mathrm{ml}\right)$, and $A_{3}$ is a coefficient for the aggregation-reducing effect of $\mathrm{PGI}_{2}$ (\%T/ng PGl $2 / \mathrm{ml}$ ). Let $A g g r_{T X}$ be aggregation measured with platelets alone, producing an amount of $x_{1}$, $\mathrm{TXA}_{2}$ (as estimated from the measured amount of $\left.\mathrm{TXB}_{2}\right)$, then $A_{2}=\left(A g g r_{T X}-A_{1}\right) / x_{1}$. Let $A g g r_{T X P G}$ represent the aggregation of platelets treated with aortic incubate, and $x_{2}$ and $y_{2}$ being the active amounts of $T X A_{2}$ and $P G l_{2}$ under these conditions (as estimated from the measured levels of $T X B_{2}$ and 6-keto $P G F_{1 \alpha 1}$ respectively), then $A_{3}=\left(A g g r_{7 X P G}-A_{1}-A_{2} \cdot x_{2}\right) / y_{2}$. The values of the three coefficients were determined for each diet group by multiple regression analysis, with three aggregation measurements per animal to construct the regression equation. Data given are mean levels $(n=5-8$ for thrombin, $n=8-12$ for collagen). $P \leq 0.012$, and " $P \leq 0.003$ compared to the control group. 
with fish oil increases the $T X A_{2}$-induced signal generation in platelets, probably because of an increased cholesterol content in these platelets $[12,22]$. This dietary effect is likely to be reflected by the present increased TXA $A_{2}$ coefficients which, in turn, suggests that an increased sensitivity towards thromboxane can be achieved not only by feeding with a mixture of n-3 PUFAs (FO diet), but also by feeding rats with purified EPA or DHA.

\section{Effects of $P G I_{2}$ on $T X A_{2}$-dependent and -independent platelet activation}

To directly compare the modulating effects of $T X A_{2}$ and $P G I_{2}$, platelets from rats fed with a standard diet were activated in the presence or absence of indomethacin or controlled amounts of $\mathrm{PGI}_{2}$. As expected, pre-incubation of the platelets with $\mathrm{PGI}_{2}$ caused a dose-dependent inhibition of both the aggregation and calcium responses (FIG. 3.5). Typically, this inhibiting effect of $\mathrm{PGI}_{2}$ was similar for untreated and indomethacin-treated platelets. With thrombin as agonist, the $\mathrm{IC}_{50}$ of $\mathrm{PGI}_{2}$ was 0.5-1 $\mathrm{nM}$ for both the aggregation and calcium responses, over a concentration range of 2$10 \mathrm{nM}$ thrombin. With collagen as agonist, even high doses of $\mathrm{PGl}_{2}$ did not completely suppress platelet reactivity, as has been noted for human platelets [30]. For rat platelets, the $\mathrm{IC}_{50}$ of the $\mathrm{PGI}_{2}$-inhibitable part of the collagen-evoked

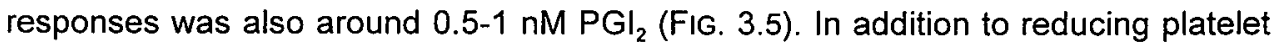
activation, $\mathrm{PGI}_{2}$ also inhibited thrombin- and collagen-evoked production of thromboxane, both at low and high agonist concentrations (TABLE 3.3). Together, these data indicate that $\mathrm{PGl}_{2}$ suppresses both the $\mathrm{TXA}_{2}$-dependent and -independent pathways of platelet activation and, thus, has an inhibitory effect that is much stronger than the stimulatory effect of $T X A_{2}$.

TABLE 3.3 Effect of $\mathrm{PGI}_{2}$ on collagen- and thrombin-induced $\mathrm{TXA}_{2}$ production in platelets.

\begin{tabular}{lcr}
\hline Activation & \multicolumn{2}{c}{$\mathrm{TXB}_{2}(\mathrm{ng} / \mathrm{ml})$} \\
\cline { 2 - 3 } & \multicolumn{1}{c}{$-\mathrm{PGI}_{2}$} & \multicolumn{1}{c}{$+\mathrm{PGI}_{2}$} \\
\hline Thrombin $(2 \mathrm{nM})$ & $4.0 \pm 0.6$ & $<0.5$ \\
Thrombin $(10 \mathrm{nM})$ & $16.6 \pm 2.9$ & $0.9 \pm 0.1$ \\
Collagen $(2.5 \mu \mathrm{g} / \mathrm{ml})$ & $38.8 \pm 6.2$ & $14.6 \pm 4.1$ \\
Collagen $(10 \mu \mathrm{g} / \mathrm{ml})$ & $93.6 \pm 9.4$ & $29.8 \pm 5.4$ \\
\hline
\end{tabular}

Rat platelets were activated with thrombin (2-10 nM) or collagen $(2.5-10 \mu \mathrm{g} / \mathrm{ml})$ as described for FIG. 3.5. The platelets were left untreated or preincubated with $3 \mathrm{nM}$ (thrombin) or $30 \mathrm{nM}$ (collagen) $\mathrm{PGI}_{2}$, as indicated. After completion of the aggregation, levels of $\mathrm{TXB}_{2}$ were determined in supernatants from the incubation mixtures. Data are mean values \pm sem $(n=4-6)$. 

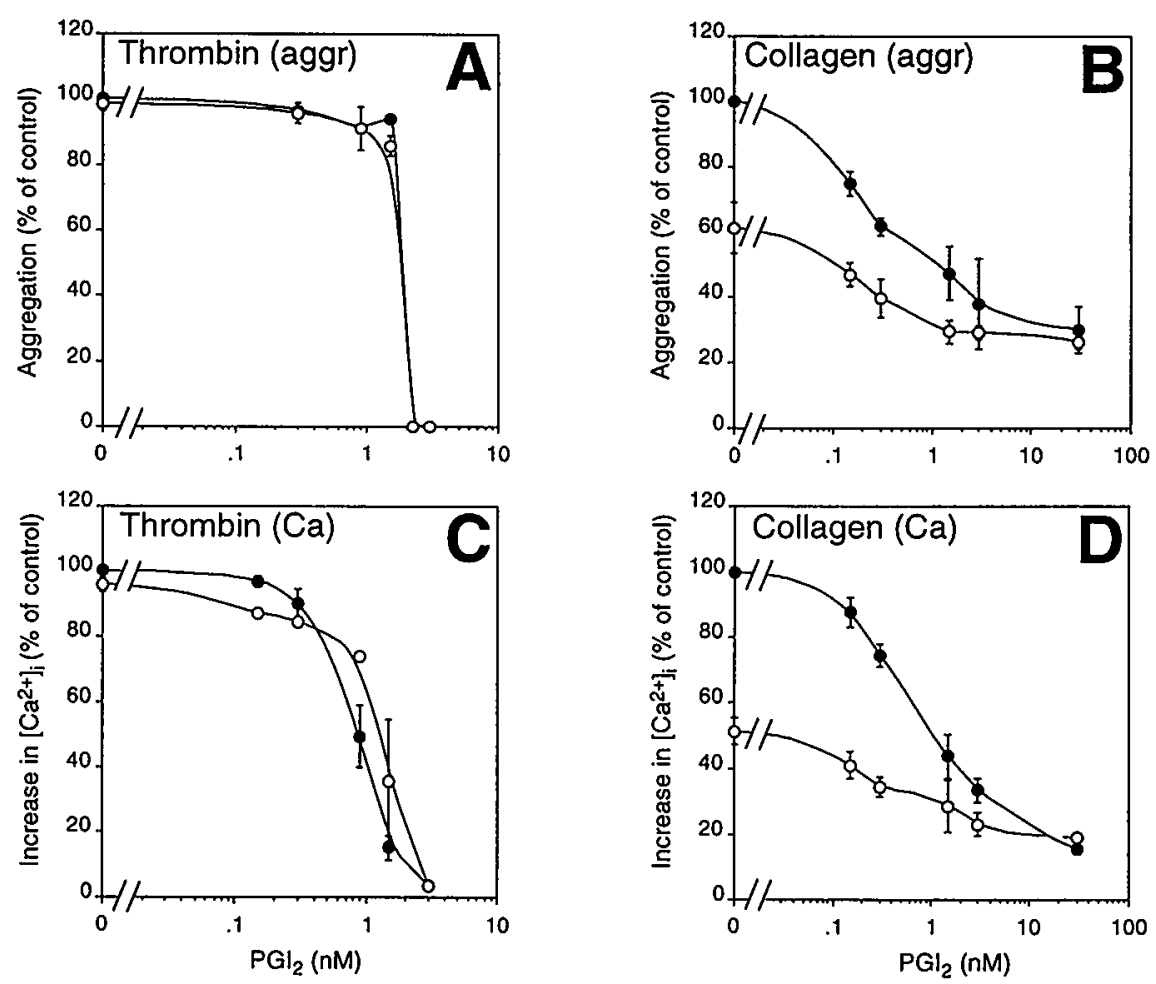

FIGURE 3.5 Dose-dependent effects of $\mathrm{PGI}_{2}$ on platelet aggregation and calcium responses. Fura-2loaded platelets from rats fed standard food were pretreated with indomethacin (open symbols) or were left untreated (closed symbols), and then preincubated with $0.03-30 \mathrm{nM} \mathrm{PGI}_{2}$ for $30 \mathrm{~s}$. The platelets were activated with $10 \mathrm{nM}$ thrombin $(A, C)$ or $10 \mu \mathrm{g} / \mathrm{ml}$ collagen $(B, D)$ in the presence of $1 \mathrm{mM} \mathrm{CaCl}_{2}$. Recorded were maximal platelet aggregation $(A, B)$ and maximal increases in $\left[\mathrm{Ca}^{2+}\right]_{i}(C, D)$. Data are given relative to the control condition without $\left.P G\right|_{2}$, and are expressed as mean values $\pm \operatorname{sem}(n=4-7)$.

In a final set of experiments, again with platelets from rats fed with the standard diet, the influence of $\mathrm{TXA}_{2}$ and $P \mathrm{PGI}_{2}$ on ongoing platelet activity was monitored. Rat platelets were activated with thrombin or collagen and, during the course of the rises in $\left[\mathrm{Ca}^{2+}\right]_{i}$ either $\mathrm{PGl}_{2}$ or indomethacin was added. As indicated in FIG. 3.6, $\mathrm{PGI}_{2}(3 \mathrm{nM})$ caused an immediate, almost complete reversal of the thrombin- and collagen-evoked calcium responses. Indomethacin had a smaller inhibitory effect (FIG. 3.6A), which is consistent with the relatively short and small $\left[\mathrm{Ca}^{2+}\right]_{i}$-increasing effect of the thromboxane receptor agonist U46619 (FIG. 3.6B). Thus, although $\mathrm{PGI}_{2}$ is a short-living molecule, its suppressive effect on platelets appears to be quite prolonged. 


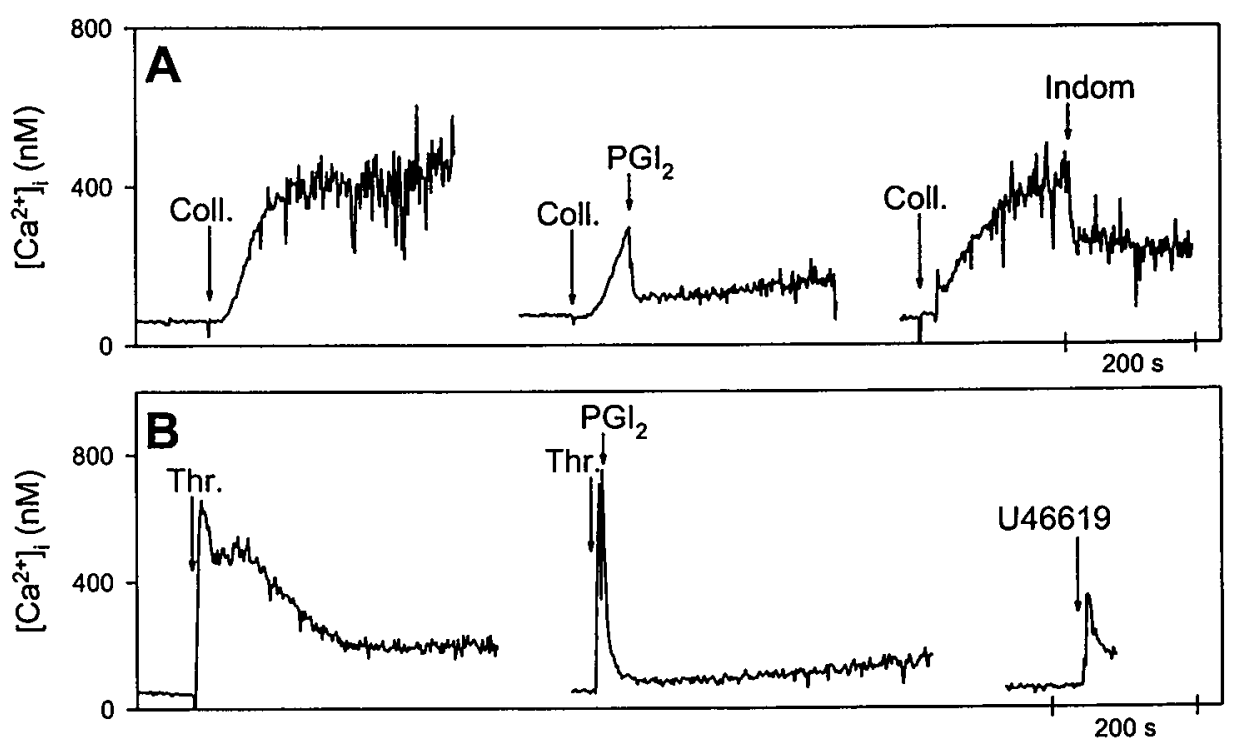

FIGURE 3.6 Time-dependent effects of $\mathrm{TXA}_{2}$ and $\mathrm{PGI}_{2}$ on thrombin- and collagen-induced platelet activation. Fura-2-loaded platelets from rats fed with standard food were stimulated with $10 \mu \mathrm{g} / \mathrm{ml}$ collagen (A) or $10 \mathrm{nM}$ thrombin $(B)$ in the presence of $1 \mathrm{mM} \mathrm{CaCl}{ }_{2} . \mathrm{PGl}_{2}(3 \mathrm{nM})$, indomethacin $(50 \mu \mathrm{M})$, or thromboxane receptor agonist $\mathrm{U} 46619(1 \mu \mathrm{M})$ were given, as indicated. Traces of changes in $\left[\mathrm{Ca}^{2+}\right]_{i}$ are given, representative for three or more experiments.

\subsection{Discussion}

In this chapter, we compared the antagonistic effects of platelet-derived thromboxane and vessel wall-derived prostaglandin on the activation process of rat platelets in two different ways. Firstly, by dietary intervention, platelets and vascular tissue were obtained with an altered production of $\mathrm{TXA}_{2}$ and $\mathrm{PGI}_{2}$ respectively, and used for activation studies. Secondly, in platelets from rats fed a standard diet, the suppressive effect was evaluated of pure $\mathrm{PGI}_{2}$ on the thromboxane-dependent and independent platelet responses.

In the diet study, supplementation to the rats of n-3 PUFAs of variable composition (EPA, DHA and FO diets) but not of n-6 PUFAs (SO diet) lowered the amount of arachidonate in platelet as well as aortic phospholipids and reduced the production of platelet-derived $\mathrm{TXA}_{2}$ and aorta-derived $\mathrm{PGI}_{2}$. There were no typical differences between the EPA, DHA and FO groups, suggesting that dietary eicosapentaenoate and docosahexaenoate have roughly similar effects. This compares well to the results of earlier diet studies from our and other laboratories $[22-24,27,31]$. Thus, as deduced before $[23,33]$, the substrate level of arachidonate 
in the membrane phospholipids is an important factor determining $T X A_{2}$ and $P G I_{2}$ production.

As in earlier work [12,21], platelets from rats fed with n-3 PUFAs appeared not to be changed in activation tendency, despite a significant reduction in $T X A_{2}$ synthesis. For all diet groups, autologous aortic incubate inhibited platelet reactivity, but this inhibition was relatively small for the rats fed with n-3 PUFAs (FIGs. 3.3 and 3.4). The inhibitory effect is most likely to be caused by prostanoids in the incubate $\left(\mathrm{PGI}_{2}\right.$ and if present $\left.\mathrm{PGI}_{3}\right)$, because it was completely abolished after aspirin treatment of the aortas (FIG. 3.2). Thus, contribution of nitric oxide, another potent platelet inhibitor produced by the endothelium [35], seems to be only small under the present conditions. Since the decreased platelet-inhibitory effect of aortic material from the n-3 PUFA groups is accompanied by a decreased (aspirin-suppressed) $\mathrm{PGI}_{2}$ production, it may appear that, a) $\mathrm{PGI}_{2}$ rather than eicosapentaenoate-derived $\mathrm{PGI}_{3}$ is responsible for this dietary effect, and $b$ ) the n-3 PUFA diets modify the activation process stronger by reducing $\mathrm{PGl}_{2}$ formation than by reducing $T X A_{2}$ generation. That the diets mainly acted by altering the production of $P G I_{2}$ and $T X A_{2}$ is confirmed by regression analysis designed to quantify the contribution of $\mathrm{TXA}_{2}$ and $\mathrm{PGI}_{2}$ to the aggregation responses (TABLE 3.2). Although there may be small differences between the individual diets, the only consistent diet-associated effect in the analysis is a relatively high platelet-stimulating effect of $T_{X A_{2}}$ for the DHA, EPA and FO groups (TABLE 3.2). Such an increased sensitivity of $T X A_{2}$ due to dietary fish oil has been measured in earlier work, using the thromboxane analogue U46619 [12]. That the $\mathrm{n}-3$ PUFA-suppressible $\mathrm{PGI}_{2}$ production can account for the overall platelet inhibitory potential of endothelial products has also been noted by others in model experiments with cultured bovine aortic endothelial cells [34].

For platelets from rats fed with standard diet, we found that both the aggregation and calcium responses are particularly sensitive to the $\mathrm{PGl}_{2}$ concentration in the range of 0.1 to $3 \mathrm{nM}$. Prostaglandin $\mathrm{I}_{2}$ strongly inhibited both the thromboxane-dependent and -independent activation pathways in the same concentration range (FIG. 3.5). In addition, it inhibited TXA $A_{2}$ formation evoked by other agonists, putatively because the necessory activation of phospholipase $A_{2}$ is a $\mathrm{Ca}^{2+}$-dependent process [36]. This 'general' platelet-inhibiting effect of $\mathrm{PGl}_{2}$ is most probably mediated by activation of cAMP-dependent protein kinase, followed by phosphorylation of multiple target proteins involved in $\mathrm{Ca}^{2+}$ signal generation and the integrin $\alpha_{\mathrm{Hb}} \mathrm{B}_{3}$ exposure required for platelet aggregation [18-20,37]. This may also explain why $\mathrm{PGI}_{2}$ has a prolonged inhibitory effect on the platelets (FIGS. 3.5 and 3.6), in spite of its short half-life time of about $1 \mathrm{~min}$. Indeed, the cAMP-dependent phosphorylation events have been found to lag much behind occupation of the $\mathrm{PGI}_{2}$ receptors [38]. In contrast, it appears that $\mathrm{TXA}_{2}$ - which is also short-lived - gives only a small activation signal and contributes relatively little to the activation response (see ref. 39). As recently shown by others, the effect of $T X A_{2}$ on platelets may even 
be limited by mobilization of $\mathrm{Ca}^{2+}$ which, then, triggers the secretion of aggregationstimulating substances [40]. Taken together, the present data suggest that the relative weight of $\mathrm{PGI}_{2}$ on the thromboxane-prostaglandin balance of rat platelet activation exceeds that of $T X A_{2}$, and that dietary n-3 PUFAs may reset this balance towards a condition of lower platelet inhibition. Recent work with mutated mice lacking the IP receptors has suggested that the antithrombotic effect of $\mathrm{PGI}_{2}$ is most prominent at sites of vascular damage [41]. Thus, also in rat, the $\mathrm{PGI}_{2}$-reducing effect of fish oil diet may be sensed especially at these sites.

Although human and rat platelets have most of their activation processes in common, care need to be taken to extrapolate the present work with rats to the human situation. A main question in this respect is, to which degree the eicosapentaenoate-derived $\mathrm{PGI}_{3}$ is capable to replace the effects of $\mathrm{PGI}_{2}$. The literature gives only little information on production of $\mathrm{PGI}_{3}$ and subsequent effects on platelets. For instance, in many human studies, $\mathrm{PGI}_{3}$ is measured as a urinary metabolite $[6,7,42]$, which merely points to its presence in the body. Only in a few early papers, effects of $\mathrm{PGI}_{2}$ and $\mathrm{PGI}_{3}$ have directly been compared [5]. On the other hand, the difference between the two species may in fact be small, since there is also uncertainly whether rats fed with fish oil produce $\mathrm{PGI}_{3}$ from eicosapentaenoate $[27,43]$. Thus, with the present hypothesis that vessel wall-derived prostaglandins play a relatively large role in controlling platelet activation in comparison to thromboxanes, it will be important to re-examine the contribution of $\mathrm{PGl}_{3}$ on the thromboxane-prostaglandin balance of platelet activation. It should be noted here that mild aspirin intake is another way to reset this balance by effectively inhibiting cyclo-oxygenase activity of platelets with little effect on this enzyme in the vessel wall $[44,45]$. If applicable to man, the present results imply that maintenance of sufficient $\mathrm{PGl}_{2}$ production is a crucial condition to achieve the antithrombotic effect of aspirin and other thromboxane synthesis inhibitors.

In rat, other effects of dietary fish oil (n-3PUFAs) have been described that are compatible with a decreased risk of thrombosis, e.g. lowering of the levels of blood lipids and of vitamin K-dependent coagulation factors [21]. Thus, at least in rat, fish oil may cause its antithrombotic effect by other means than changing the thromboxane-prostaglandin balance. In the human situation, dietary fish oil is also likely to have a range of various effects on the vascular system. It is thus not unlikely that also in man other, platelet-independent effects play a role in the proposed antithrombotic effect of fish oil. An integrative intervention study to effects of fish oil ( $n-3$ PUFAs) on function of platelets, vessel wall (PG production), blood lipids, and coagulation and fibrinolysis activity, preferably followed by a long-term endpoint measurement, will be needed to clarify this. 


\subsection{Acknowledgements}

We thank A. Hennissen and J. Wierts for analytical assistance and animal husbandry. This study was supported by Hoffmann-La Roche (Basel, Switzerland).

\subsection{References}

1. Dyerberg J, Bang HO, Hjorne N. Fatty acid composition of the plasma lipids in Greenland Eskimos. Am J Clin Nutr. 1975;28:958-966.

2. Dyerberg J, Bang HO. Haemostatic function and platelet polyunsaturated fatty acids in Eskimos. Lancet. 1979;ii:433-435.

3. Bang HO, Dyerberg J. Lipid metabolism and ischemic heart disease in Eskimos. In: Advantages in Nutritional Research, Vol 3 (Draper HH, ed). Plenum Press, New York, 1980. pp. 1-22.

4. Fischer $\mathrm{S}$, Weber $\mathrm{PC}$. Prostaglandin $\mathrm{I}_{3}$ is formed in vivo in man after dietary eicosapentaenoic acid. Nature. 1984;307:165-168.

5. Needleman P, Raz A, Minkes MS, Ferrendelli JA, Sprecher $H$. Triene prostaglandins: prostacyclin and thromboxane biosynthesis and unique biological properties. Proc Natl Acad Sci USA. 1979;76:944-948.

6. Dyerberg J, Bang HO, Stoffersen E, Moncada S, Vane JR. Eicosapentaenoic acid and prevention of thrombosis and atherosclerosis? Lancet. 1978;ii:117-119.

7. Bunting $S$, Moncada $S$, Vane JR. The prostacyclin-thromboxane $A_{2}$ balance: pathophysiological and therapeutic implications. Br Med Bull. 1983;39:271-276.

8. Hornstra G. The significance of fish and fish-oil enriched food for prevention and therapy of ischaemic cardiovascular disease. In: The Role of Fats in Human Nutrition (Vergroesen AJ, Crawford MA, eds). Acad Press, New York, 1989. pp. 151-235.

9. Kromhout D, Bosschieter EB, De Lezenne Coulander C. The inverse relation between fish consumption and 20-year mortality from coronary heart disease. $N$ Engl $J$ Med. 1985;312:1205-1209

10. Ascherio A, Rimm EB, Stamper MJ, Giovannucci EL, Willet WC. Dietary intake of marine n-3 fatty acids, fish intake, and the risk of coronary disease among men. $N$ Engl $J$ Med. 1995;332:977-982.

11. Chin JPF, Dart AM. How do fish oils affect vascular functions? Clin Exp Pharmacol Physiol. 1995;22:71-81.

12. Heemskerk JWM, Feijge MAH, Simonis MAG, Hornstra G. Effects of dietary fatty acids on signal transduction and membrane cholesterol content in rat platelets. Biochim Biophys Acta. 1995;1255:87-97.

13. Siess W. Molecular mechanisms of platelet activation. Physiol Rev. 1989;69:58-178.

14. Offermanns $\mathrm{S}$, Toombs CF, Hu YH, Simon Ml. Defective platelet activation in $\mathrm{G}_{\mathrm{aq}}$-deficient mice. Nature. 1997;389:183-186.

15. Brass LF, Manning DR, Cichowsky K, Abrams CS. Signaling through $G$ proteins in platelets: to the integrins and beyond. Thromb Haemost. 1997;78:581-589.

16. Hourani SM, Cusack NJ. Pharmacological receptors on blood platelets. Pharmacol Rev. 1991;43:243-298.

17. Nakagawa $O$, Tanaka I, Usui $T$, Harada $M$, Sasaki $Y$, Itoh $H$, Yoshimasa $T$, Namba $T$, Narumiya S, Nakao K. Molecular cloning of human prostacyclin receptor cDNA and its gene expression in the cardiovascular system. Circulation. 1994;90:1643-1647.

18. Watson SP, McConnell RT, Lapetina EG. The rapid formation of inositol phosphates in human platelets by thrombin is inhibited by prostacyclin. J Biol Chem 1984;259:13199-13203.

19. Cavallini $L$, Coassin $M$, Borean A, Alexandre A. Prostacyclin and sodium nitroprusside inhibit the activity of the platelet inositol 1,4,5-trisphosphate receptor and promote its phosphorylation. J Biol Chem. 1996;271:5545-5551. 
20. Authi KS. Calcium homeostasis in human platelets. In: Handbook of Experimental Pharmacology, Vol 126, Platelets and Their Factors (von Bruchhausen F, Walter $U$, eds) Springer, Berlin, 1997. pp. 325-370.

21. Nieuwenhuys CMA, Béguin S, Offermans RFG, Emeis JJ, Hornstra G, Heemskerk JWM. Hypocoagulant and lipid-lowering effects of dietary $n-3$ polyunsaturated fatty acids with unchanged platelet activation in rats. Arterioscler Thromb Vasc Biol. 1998;18:1480-1489.

22. Heemskerk JWM, Feijge $M A H_{1}$ Kester $A$, Hornstra $G$. Dietary fat modifies thromboxane $A_{2}-$ induced stimulation of rat platelets. Biochem J. 1991;278:399-404.

23. Hornstra G. Dietary Fats, Prostanoids and Arterial Thrombosis. Nijhoff Publ, The Hague, the Netherlands, 1982.

24. Nieuwenhuys CMA, Hornstra G. The effects of purified eicosapentaenoic and docosahexaenoic acids on arterial thrombosis tendency and platelet function in rats. Biochim Biophys Acta. 1997:1390:313-322.

25. Heemskerk JWM, Feijge MAH, Sage SO, Walter $U$. Indirect regulation of $\mathrm{Ca}^{2+}$ entry by cAMPdependent and CGMP-dependent protein kinases and phospholipase $C$ in rat platelets. Eur $J$ Biochem. 1994;223:543-551.

26. Heemskerk JWM, Feijge MAH, Rietman E, Hornstra G. Rat platelets are deficient in internal $\mathrm{Ca}^{2+}$ release and require influx of extracellular $\mathrm{Ca}^{2+}$ for activation. FEBS Lett. 1991;284: 223226.

27. Hornstra G, Christ-Hazelhof E, Haddeman E, ten Hoor F, Hughteren DH. Fish oil feeding lowers thromboxane and prostacyclin production by rat platelets and aorta and does not result in the formation of $\mathrm{PGI}_{3}$. Prostaglandins. 1981;21:727-737.

28. Engels $W$, van Haaster CMCJ, Lemmens PJMR, van der Vusse GJ, Hornstra G. Dietary modulation of fatty acid composition of mast cell phospholipids does not affect histamine release induced by compound 48/80. Inflamm Res. 1997;46:185-190.

29. Feijge MAH, Lacabaratz-Porret $\mathrm{C}$, van Pampus ECM, Hamulyàk $\mathrm{K}$, Lévy-Toledano $\mathrm{S}$, Enouf $\mathrm{J}$, Heemskerk JWM. Contribution of thromboxane and endomembrane $\mathrm{Ca}^{2+}$-ATPases to variability in $\mathrm{Ca}^{2+}$ signalling of platelets from healthy volunteers. Platelets. 1998;9:179-183.

30. Smith JB, Dangelmaier C, Selak MA, Ashby B, Daniel J. Cyclic AMP does not inhibit collageninduced platelet signal transduction. Biochem J. 1992;283:889-892.

31. Raederstorff $D$, Moser $U$. Influence of an increase intake of linoleic acid on the incorporation of dietary (n-3) fatty acids in phospholipids and on prostanoid synthesis in rat tissues. Biochim Biophys Acta. 1992;1165:194-200.

32. Heemskerk JWM, Vossen RCRM, van Dam-Mieras MCE. Polyunsaturated fatty acids and function of platelets and endothelial cells. Curr Opin Lipidol. 1996;7:24-29.

33. Sanigorski AJ, Odea K, Sinclair AJ. n-3 Fatty acids reduce in vitro thromboxane production while having little effect on in vitro prostacyclin production in the rat. Prostagland Leukotr Essential Fatty Acids. 1994;50:223-228.

34. Bénistant C, Achard F, Marcelon G, Lagarde M. Platelet inhibitory functions of aortic endothelial cells. Effects of eicosapentaenoic and docosahexaenoic acids. Atherosclerosis. 1993;104:27-35.

35. Cines DB, Pollak ES, Buck CA, Loscalzo J, Zimmerman GA, McEver RP, Pober JS, Wick TM, Konkle BA, Schwartz BS, Barnathan ES, McCrae KR, Hug BA, Schmidt AM, Stern DM. Endothelial cells in physiology and in the pathophysiology of vascular disorders. Blood. 1998; $91: 3527-3561$.

36. Billah MM, Lapetina EG, Cuatrecasas $P$. Phospholipase $A_{2}$ and phospholipase $C$ activities of platelets. Differential substrate specificity $\mathrm{Ca}^{2+}$ requirement, $\mathrm{pH}$ dependence, and cellular localization. J Biol Chem. 1980;255;10227-10231.

37. Shattil SJ, Kashiwagi $H$, Pampori N. Integrin signaling: the platelet paradigm. Blood. 1998;91:2645-2657.

38. Halbrügge M, Walter U (1993) In: Protein Kinases in Blood Cell Function (Huang CK, Sha'afi RI, eds) CRC Press, Boca Raton, FL. pp. 245-298.

39. Heemskerk JWM, Feijge MAH, Henneman L, Rosing J, Hemker HC. The $\mathrm{Ca}^{2+}$-mobilizing potency of $\alpha$-thrombin and thrombin-receptor-activating peptide on human platelets. Concentration and time effects of thrombin-induced $\mathrm{Ca}^{2+}$ signaling. Eur J Biochem. 1997;249:547555. 
40. Paul BZS, Jin J, Kunapuli SP. Molecular mechanism of thromboxane A2-induced platelet aggregation. Essential role for $P 2 T_{A C}$ and $\alpha_{2 A}$ receptors. J Biol Chem. 1999;274:29108-29114,

41. Murata T, Ushikubi F, Matsuoka T, Hirata M., Yamasaki A, Sugimoto Y, Ichikawa A, Aze Y, Tanaka $T$, Yoshida N, Ueno A, Oh-ishi S, Narumita S. Altered pain perception and inflammatory response in mice lacking prostacyclin receptor. Nature. 1997;388:678-682.

42. Kinsella JE, Lokesh B, Stone RA. Dietary n-3 polyunsaturated fatty acids and amelioration of cardiovascular disease: possible mechanisms. Am J Clin Nutr. 1990;52:1-28.

43. Knapp HR, Salem N. Formation of $\mathrm{PGI}_{3}$ in the rat during dietary fish oil supplementation. Prostaglandins. 1989;38:509-521.

44. Masotti G, Galanti G, Poggesi L, Abbate R, Neri-Serneri GG. Differential inhibition of prostacyclin production and platelet aggregation by aspirin. Lancet. 1979;ii:1213-1217.

45. Antiplatelet Trialists' Collaboration. Collaborative overview of randomised trials of antiplatelet therapy; prevention of death, myocardial infarction, and stroke by prolonged antiplatelet therapy in various categories of patients. Br Med J. 1994;308:81-106. 


\section{4}

\section{Monitoring hypocoagulant conditions in rat plasma: factors determining the endogenous thrombin potential of tissue factor-activated plasma}

Cécile M. A. Nieuwenhuys ${ }^{1}$, Marion A.H. Feijge ${ }^{2}$, Suzette Béguin ${ }^{2}$ and Johan W. M. Heemskerk ${ }^{1,2}$

From the Departments of Human Biology and Biochemistry ${ }^{2}$, University of Maastricht, The Netherlands.

Based on: Thrombosis and Haemostasis, 2000;84:1045-4051 


\subsection{Abstract}

In human plasma, automated continuous monitoring of the formation and inactivation of thrombin during the coagulation process provides an adequate way to detect hypo- and hypercoagulant conditions. Here, we describe an analogous procedure to determine the endogenous thrombin potential (ETP), i.e. the free thrombin concentration-time integral, of coagulating rat plasma. When activated with tissue factor, the ETP of plasma from Wistar rats was comparable to the ETP of human plasma, in spite of a relatively short half-life time of free thrombin in rat plasma. The ETP was highly sensitive to heparin as well as to administration of vitamin $\mathrm{K}$ antagonist or feeding of the animals with a vitamin K-deficient diet. In plasma that was activated under sub-optimal conditions (reduced levels of tissue factor or vitamin Kdependent coagulation factors), the ETP increased with the rate of thrombin formation in the first minutes of the coagulation process. Since both parameters are dependent of the prothrombin concentration, it appears that this level plays an important role in determining both the initial and total activity of the coagulation system. Thus, automated measurement of free thrombin during the coagulation process of rat plasma allows a detailed analysis of hypocoagulability in this animal model.

\subsection{Introduction}

The proteolytic enzyme thrombin is a pivotal player in haemostasis. When present in plasma, it causes the formation of fibrin clots and acts as a potent stimulating agent for platelets and cells in the vessel wall. Thrombin is formed in plasma via a network of reactions involving multiple coagulation factors that interact which each other in a complex manner [1]. It accumulates upon start of the coagulation process, stimulates its own formation and, once formed, it binds to various factors including fibrin and becomes rapidly inactivated by complex formation with antithrombin with a rate proportional to its concentration [2]. Earlier work with human plasma has indicated that continuous registration of the formation and inactivation of thrombin is a prerequisite for appropriate assessment of plasma coagulability [3-5]. Such a procedure allows determination of the free thrombin concentration-time integral which, by definition, is the endogenous thrombin potential (ETP) of the coagulating plasma. The ETP can thus be considered a parameter for the cumulative effect of thrombin during the coagulation process as a whole [2]. For the human system, the ETP is found to be sensitive for conditions influencing prothrombin activation as well as thrombin inactivation, thereby making it a good reporter of plasma hypo- as well as 
hypercoagulability [2,4-6]. For instance, the ETP is diminished with low concentrations of heparin or other anticoagulants, and increased in coagulating plasma from patients with antithrombin deficiency, coronary artery disease or deep venous thrombosis. Recently, the original laborious procedure of ETP measurement, requiring repeated manual sampling, has been supplemented with a fully automated procedure. Herein, a low-affinity chromogenic thrombin substrate, such as Msc-ValArg-pNA (MVA-pNA) or SQ68, is directly added to the coagulating plasma, and the thrombin activity in the mixture is followed by automated sampling and analysis of the colour development [6]. Because the thrombin substrate per se interferes with the coagulation process, it was initially necessary to compare the automated procedure with the original manual sampling method.

In recent years, the rat has gained new interest as an animal model for arterial and venous thrombosis $[7-10]$. Current methods to monitor the coagulation profile of rat plasma, however, are either insensitive or rely on the use of human plasma. Clotting times such as the prothrombin time (PT) or the activated partial thromboplastin time (APTT) measure only the initial formation of thrombin required for fibrin formation. However, when the plasma clots most of the prothrombin is still to be converted [2], and, thus, the PT and APTT do not reflect the activity of the coagulation process as a whole. Coagulation factors in rat plasma are usually measured in a non-autologous way, i.e. by dilution in factor-deficient plasma from human origin [11], meaning that the activities of specific rat factors are assessed against the 'background' of the human coagulation system.

We therefore considered it of relevance to develop a procedure to measure the total activity of the rat coagulation system by using only or mainly autologous, ratderived factors. Recently, we have applied the manual method of ETP measurement to detect in rat plasma the subtle hypocoagulant effects of dietary fish oil [12]. Here, we report in more detail on the kinetics of thrombin formation and inactivation of the rat coagulation system. Furthermore, we describe a fully automated procedure to measure the ETP in rat plasma, which allows identification of the factors determining the plasma coagulability of this animal model.

\subsection{Materials and methods}

\section{Materials}

Pelleted stock diet and vitamin K-deficient food were obtained from Hope Farms (Woerden, the Netherlands). Dioleoyl phosphatidylcholine, dioleoyl phosphatidylserine, kaolin, rat thrombin and warfarin were purchased from Sigma (St. Louis, MO, USA). Human prothrombin and $\alpha$-thrombin were obtained as described elsewhere [12a]. Recombinant human tissue factor and actin FS were 
from Dade (Miami, FL, USA), and H-Gly-Pro-Arg-Pro-OH (GPRP, Pefablock) from Pentapharm (Basel, Switzerland). Reptilase and agihal came from Boehringer (Mannheim, Germany). The low-affinity chromogenic thrombin substrate Msc-ValArg-pNA (MVA-pNA) was prepared by Dr. D. Rijkers, as described before [13]. The high-affinity thrombin substrate H-D-Phe-Pip-Arg-pNA (S2238) was obtained from Chromogenix (Mölndal, Sweden). Thromborel $S$ and human factor-deficient plasmas were obtained from Behring (Marburg, Germany), and coagulation factor diluent from Instrumentation Laboratory (Milano, Italy). Ancrod, unfractionated heparin (4th International heparin standard, $0.05 \mathrm{U} / \mathrm{ml}$ ), and low molecular weight heparin (1st International heparin standard, $0.05 \mathrm{U} / \mathrm{ml}$ ) were bought from the National Institute for Biological Standards and Control (London, UK). Rat thromboplastin was prepared from rat brains by acetone extraction, following conventional procedures [14], and stored at $-70^{\circ} \mathrm{C}$. Thrombotest reagent was from Nycomed (Oslo, Norway). Protac came from Kordia (Leiden, the Netherlands).

\section{Animals and diets}

Male Wistar rats (250-300 g, Charles River, Sulzfeld, Germany) were housed at 23 ${ }^{\circ} \mathrm{C}$ and fed with pelleted stock diet [12]. Where indicated, male Wistar rats (150 g) were fed for 3 days with a vitamin K-deficient diet or with a control, vitamin K-rich diet [15]. Where indicated, other rats were injected intraperitoneally with $3 \mathrm{mg} / \mathrm{kg}$ warfarin $[16,17]$, and blood was then collected at variable times ( 4 to $27 \mathrm{~h}$ ) after injection. Rats were fasted overnight before bleeding, to prevent interference of the spectroscopic measurements by plasma turbidity. The animal studies were approved by the institutional Animal Care Committee.

\section{Blood sampling}

Rats were anaesthetized with Nembutal before collection of blood by abdominal aortic puncture. After bleeding, the animals were killed by heart puncture. Rat blood was collected into $0.1 \mathrm{vol}$ of $130 \mathrm{mM}$ trisodium citrate, and immediately centrifuged at $1200 \mathrm{~g}$ for $15 \mathrm{~min}\left(22^{\circ} \mathrm{C}\right)$. The collected plasma fraction was centrifuged at $18,000 \mathrm{~g}$ for $5 \mathrm{~min}\left(22^{\circ} \mathrm{C}\right)$, after which platelet-free plasma was frozen at $-70^{\circ} \mathrm{C}$, and stored at this temperature until use.

\section{Standard coagulation times and coagulation factors}

Global coagulation times were measured in rat plasma samples that were diluted 5-

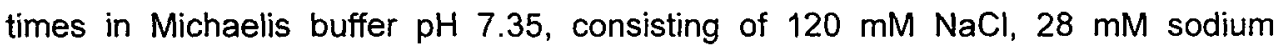
barbiturate and $25 \mathrm{mM}$ sodium acetate [14]. For measuring the PT, to $50 \mu \mathrm{l}$ samples of prediluted plasma, $100 \mu$ was added of a preheated mixture of rat thromboplastin (diluted $1: 40$ in Michaelis buffer) and $\mathrm{CaCl}_{2}(10 \mathrm{mM}$, f.c.). To measure the APTT, 53 $\mu \mathrm{l}$ of prediluted samples were mixed with $53 \mu \mathrm{l}$ actin FS (ten-times diluted in Michaelis buffer). After $3 \mathrm{~min}$ of incubation at $37^{\circ} \mathrm{C}, 53 \mu \mathrm{l} \mathrm{CaCl}(20 \mathrm{mM})$ was added 
to start the coagulation. Coagulation times were measured with an $\mathrm{ACL}$, using calibration curves of diluted, pooled rat plasma.

Coagulation factors $\mathrm{II}, \mathrm{V}$ and $\mathrm{VII-X}$ were measured in rat plasma samples diluted 25- to 400-times with factor diluent using human, factor-deficient plasma [12]. Antithrombin levels were measured with the Coamatic antithrombin test kit from Chromogenix.

\section{Half-life time of thrombin}

To measure the half-life time of thrombin in rat plasma, a thrombin preparation was made by coagulating the euglobulin fraction of (rat or human) pooled plasma, following earlier described procedures for the human system [18]. Briefly, an euglobulin precipitate was dissolved into $1 \mathrm{vol}$ of $0.13 \mathrm{M}$ trisodium citrate, and diluted $4: 5(\mathrm{v} / \mathrm{v})$ with buffer I, containing $100 \mathrm{mM} \mathrm{NaCl}, 50 \mathrm{mM}$ Tris- $\mathrm{HCl}$ and $0.05 \%(\mathrm{w} / \mathrm{v})$ bovine serum albumin $(\mathrm{pH} 7.35)$. Thrombin generation in the euglobulin fraction was triggered at $37{ }^{\circ} \mathrm{C}$ by adding $1 \mu \mathrm{M}$ phospholipids (a sonicated dispersion of phosphatidylcholine : phosphatidylserine, $80: 20, \mathrm{~mol} / \mathrm{mol}), 16.7 \mathrm{mM} \mathrm{CaCl}_{2}$ and recombinant human tissue factor for $5 \mathrm{~min}$.

To measure the half-life time of thrombin, $20 \mu$ l of the thrombin-containing euglobulin mixture was mixed with $80 \mu \mathrm{l}$ of pre-warmed, citrated rat plasma. Alternatively, $20 \mu \mathrm{l}$ of a solution of commercial rat thrombin was added to the rat plasma. As quickly as possible, $10 \mu \mathrm{l}$ aliquots were sampled into buffer II, composed of $100 \mathrm{mM} \mathrm{NaCl}, 50 \mathrm{mM}$ Tris-HCl, $20 \mathrm{mM}$ EDTA, $0.2 \mathrm{mM} \mathrm{S2238}$ and $0.05 \%$ bovine serum albumin ( $\mathrm{pH} 7.90)$. Thrombin concentrations in these samples were measured by following (linear) increases in optical density (OD) at $405 \mathrm{~nm}$ [18]. Note that for the concentration determination of rat thrombin, it is assumed that rat and human $\alpha$ thrombin cleave $\mathrm{S} 2238$ at the same rate (see also below).

\section{Manual measurement of the ETP}

Formation and degradation of thrombin was measured in samples that were manually taken from coagulating rat plasma, following procedures as described for the human plasma system [5]. Briefly, citrated platelet-free plasma was diluted $4: 5$ $(\mathrm{v} / \mathrm{V})$ with buffer I. After adding $1 \mu \mathrm{M}$ sonicated phospholipid vesicles (phosphatidylcholine : phosphatidylserine, $80: 20, \mathrm{~mol} / \mathrm{mol}$ ), the mixture was incubated at $37^{\circ} \mathrm{C}$, and coagulation was started by addition of $16.7 \mathrm{mM} \mathrm{CaCl}_{2}$ (f.c.) and a specific trigger. For the extrinsic system, this trigger was rat thromboplastin or recombinant human tissue factor, diluted as to give a clotting time of $25 \mathrm{~s}$. For the intrinsic system, the mixture was incubated with $25 \mu \mathrm{g} / \mathrm{ml}$ kaolin during $5 \mathrm{~min}$ before addition of $\mathrm{CaCl}_{2}$ plus phospholipids. At fixed time intervals after start, $10 \mu \mathrm{l}$ aliquots were sampled into cuvettes containing $490 \mu$ of preheated $\left(37^{\circ} \mathrm{C}\right)$ buffer II. In each cuvet, colour development was stopped after $2 \mathrm{~min}$ by adding $300 \mu \mathrm{l}$ of $1 \mathrm{M}$ citric acid. Precise sampling and stopping times were recorded by a personal computer 
connected to pushbutton-equipped pipettes. The OD value of each cuvette was read in time at $405 \mathrm{~nm}$, and the chromogenic activity was calculated and automatically converted to the thrombin concentration of the coagulation mixture by reference to a calibration curve for human $\alpha$-thrombin (see below). Fibrin clots were manually removed from the coagulation mixture, immediately after their formation. By comparing the chromogenic activity of mixtures of purified rat and human thrombin, it appeared that the thrombin from either species converts $\mathrm{S} 2238$ at a similar rate.

Thrombin concentration-time plots were corrected for the accumulation of thrombin bound to protease inhibitors, which hydrolyses S2238 but is inactive in coagulation. This was done with a numerical fitting procedure, as described before $[3,18]$. Early reports indicate that $\alpha_{1}$-macroglobulin is a main component of these inhibitors in rat plasma [19]. By definition, the ETP of plasma is the area under the reconstructed time-curve of thrombin formation and degradation (expressed as $\mathrm{nM}$ thrombin-min). For routine measurements, ETP values of plasma samples were corrected for slight day-to-day variation by comparison with pooled rat plasma.

To measure the ETP of coagulating human plasma, citrated pooled plasma was activated with human recombinant tissue factor, phospholipids and $\mathrm{CaCl}_{2}$, as described [4]. The fibrin clot was removed immediately after its appearance.

\section{Automated measurement of the ETP}

Formation and inactivation of thrombin in coagulating rat plasma were also followed in an automated way, by recording cleavage of the low-affinity chromogenic thrombin substrate, MVA-pNA, which was directly added to plasma. Purified rat thrombin cleaved MVA-pNA with a rate comparable to that of human $\alpha$-thrombin.

In comparison to the procedure used for human plasma [6], various changes were made. The inability to defibrinate the plasma from Wistar rats greatly hindered measurement of colour increases due to substrate cleavage, because insoluble fibrin polymers interfered with the measurement outcome. Fibrin formation was therefore prevented by the addition of $7.5 \mathrm{mM}$ GPRP (f.c.) to citrated samples of rat plasma. The samples $(40 \mu \mathrm{l})$ were diluted with $1 \mathrm{vol}(40 \mu \mathrm{l})$ of buffer $\mathrm{I}$, after which a $20 \mu \mathrm{l}$ mixture was added of recombinant human tissue factor $(0.24 \mathrm{nM})$ and phospholipids (phosphatidylcholine : phosphatidylserine, $80: 20, \mathrm{~mol} / \mathrm{mol}, 6.7 \mu \mathrm{M}$ ). Coagulation was triggered by adding a $20 \mu \mathrm{l}$ mixture of MVA-pNA $(3 \mathrm{mM})$ and $\mathrm{CaCl}_{2}(100 \mathrm{mM})$. Where indicated, $20 \mu \mathrm{l}$ rat thromboplastin (diluted 1:50 in buffer I) was used, instead of recombinant human tissue factor. Activations were routinely carried out in a Cobas Fara laboratory automaton, where the $O D$ at $405 \mathrm{~nm}$ was automatically measured every $30 \mathrm{~s}$ during a period of 15-30 min.

To correct the measured OD values for contribution of $\alpha$-macroglobulin-bound thrombin (which is coagulation-inactive), the chromogenic activity of the thrombin- $\alpha$ macroglobulin complex was determined by an automated fitting procedure [6]. Briefly, let the total colour signal $(P)$ be the sum of the signals produced by free 
thrombin $(A)$ and by the $\alpha$-macroglobulin complex $(B)$, then $P(t)=A(t)+B(t)$. With the velocity of formation of the $\alpha$-macroglobulin complex being first order with respect to the free thrombin concentration, and with the sampling times being short compared to the rate of $O D$ change, the signal at sample number $n$ is described by the equation, $P_{n}=A_{n}+k\left(A_{0}+A_{1}+. .+A_{n}\right)$, or otherwise, $A_{n}=(1-k) A_{n-1}+\left(P_{n}-P_{n-1}\right)$. Because $A_{0}$ and $P_{0}$ are zero, $A_{n}$ can be calculated from the measured $O D$ values provided that $k$ is known. The correction constant, $k$, is dependent on the functional concentration of $\alpha$-macroglobulin, on kinetic parameters of the $\alpha$-macroglobulin-thrombin complex and on the sampling interval. By numerical fitting, $k$ was varied, until it rendered a steady-state level of $A$ at the end of the coagulation reaction. This level is the required $O D$ end level, caused by the chromogenic effect of free thrombin. The $O D$ level is expressed as micromolar of MVA-pNA substrate cleaved, using the molar extinction coefficient of p-nitroanilide at $405 \mathrm{~nm}$ of $9.93 \times 10^{3} \mathrm{~cm}^{-1} \mathrm{~mol}^{-1}$. Total substrate cleavage by free thrombin (in $\mu M$ p-nitroanilide) represents the ETP. Because the MVA-pNA substrate slows down the thrombin decay by competing with antithrombin, the ETP values thus obtained depend on the particular experimental conditions, e.g. plasma dilution, substrate type and concentration.

\section{Statistics}

The relative method error of ETP measurements was determined as the method error $\left(s_{M}\right)$ divided by the mean, with $s_{M}=\sqrt{ }\left(d^{2} / 2 n\right)$ ( $d=$ difference between $n$ duplicate test samples).

\subsection{Results}

Thrombin formation and decay in coagulating rat plasma

Kinetics of thrombin formation and inactivation were followed in coagulating rat and human plasma by determining the thrombin concentration in samples that were manually taken from the plasmas at regular intervals. This procedure allows comparison of the coagulation process under autologous conditions. Citrated human plasma was thus triggered with recombinant human tissue factor, and citrated rat plasma was activated with thromboplastin isolated from rat brain. Phospholipids and $\mathrm{CaCl}_{2}$ were added in concentrations required for optimal support of the coagulation. Plasma from Wistar rats could not be defibrinated by using fibrinogen polymerisation agents like ancrod, reptilase or agihal (data not shown). ${ }^{\prime}$ For this reason, the coagulation was activated without previous defibrination, and the fibrin clots were manually removed immediately after their formation. When the human plasma was

\footnotetext{
'Plasma from WKY rats gave incomplete fibrin formation when pre-incubated with $0.5 \mathrm{U} / \mathrm{ml}$ ancrod, and plasma from Lewis rats could also not be defibrinated with ancrod.
} 

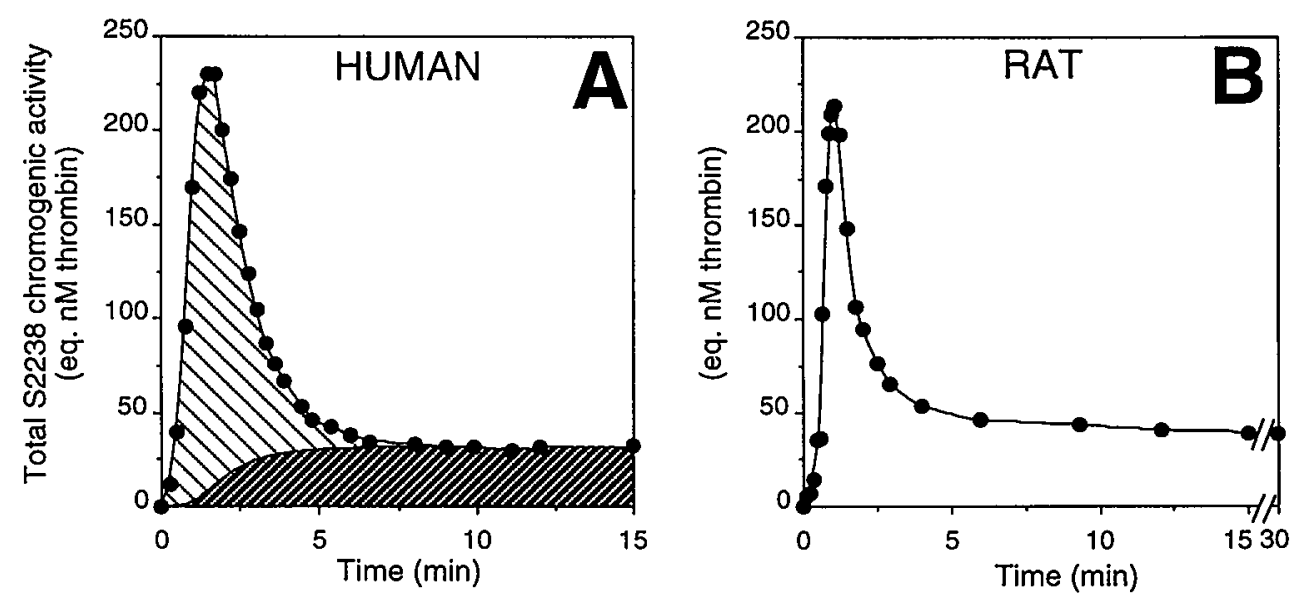

FIGURE 4.1 Kinetics of thrombin formation and decay in coagulating human and rat plasma. (A) Citrated human plasma was triggered with recombinant human tissue factor $(30 \mathrm{pM})$, phospholipids and $\mathrm{CaCl}_{2}$. (B) Citrated rat plasma was activated by autologous (rat) thromboplastin (final dilution $1: 300$ ), phospholipids and $\mathrm{CaCl}_{2}$. Levels of chromogenically active thrombin were measured in samples manually taken from the coagulation mixture, using the chromogenic substrate $\$ 2238$ (dots). Thrombin concentration is determined from the known chromogenic activity of human $\alpha$-thrombin towards S2238. Black area indicates chromogenic activity due to accumulation of $\alpha$-macroglobulin-bound thrombin. Lightly hatched area represents activity of free, coagulation-active thrombin. Curves shown are exemplary for 16 or more independent experiments.

activated with $\mathrm{CaCl}_{2}$ and $40 \mathrm{pM}$ human recombinant tissue factor, which is sufficient to ensure maximal prothrombin conversion [6], thrombin was rapidly formed with a maximal rate of $27.3 \pm 5.4 \mathrm{nM} / \mathrm{min}$ (mean \pm sem, $\mathrm{n}=4$ ), and a maximal concentration reached after $1.5 \mathrm{~min}$ (FIG. 4.1A). At later times, thrombin declined to reach a steadystate end level. Activation of rat plasma with autologous thromboplastin, at a maximally effective dose, resulted in rates of formation and inactivation of thrombin that were both faster than in the human system (FIG. 4.1B). At start, the maximal rate of thrombin formation attributed to $75.7 \pm 10.3 \mathrm{nM}$ thrombin/min (mean \pm sem, $n=4$ ), while the maximal thrombin concentration was reached within $1 \mathrm{~min}$ of stimulation.

\section{Half-life time of thrombin in rat plasma}

The course of the thrombin generation curve in rat plasma suggests not only that thrombin is rapidly formed, but also that the enzymatic capacity of thrombin in this plasma is relatively limited. This was verified by measuring the decay rate of thrombin in minimally diluted rat plasma. Thrombin, freshly prepared from a coagulated euglobulin plasma fraction, was added to citrated (non-defibrinated) rat plasma, after which the rate of its inactivation was determined (FIG. 4.2). Although these experiments were somewhat variable in outcome due to formation of fibrin, a large number of determinations gave an averaged half-life time of $9.9 \pm 0.4 \mathrm{~s}$ 


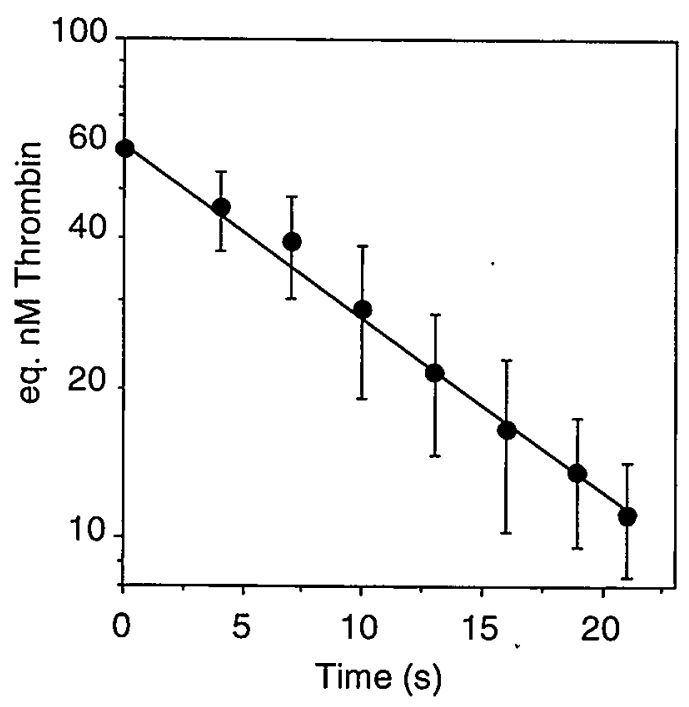

Figure 4.2 Rate of antithrombin-dependent inactivation of thrombin in rat plasma. Thrombin of the coagulated euglobulin plasma fraction was added to citrated plasma, as indicated in Materials and Methods.

Disappearance of chromogenic activity was determined in samples taken from the incubation mixture at various time intervals. Data are mean values $\pm S D(n=12)$.

(mean $\pm S D, n=12$ ). A similar inactivation rate was measured when a purified preparation of rat thrombin was added to the rat plasma (data not shown). This halflife time is significantly shorter than that of (human or rat) thrombin in human plasma, which was assessed at $17 \mathrm{~s}$ for human thrombin added to plasma of similar dilution [4]. In rat plasma, the level of antithrombin was determined as $120 \pm 3 \%$ (mean \pm sem, $n=3$ ) of the human plasma level. Since antithrombin is a major thrombin inactivator, it is not unlikely that this high level contributes to the relatively short thrombin life time in rat plasma. Levels of factors II (prothrombin), V, VII, VIII, IX and X were also relatively high in plasma from Wistar rats, i.e. $185,890,310,250,95$ and $70 \%$ of the levels found in human plasma, respectively (as determined using human factordeficient plasmas). This may explain the relatively fast thrombin formation in coagulating rat plasma (FIG. 4.1B).

\section{Determination of the ETP in rat plasma}

Earlier work with human plasma has shown that the experimental curve of thrombin generation and inactivation needs correction for the chromogenic activity of coagulation-inactive, $\alpha$-macroglobulin-bound thrombin (see FIG. 4.1A), by using a mathematical fitting procedure $[2,18]$. The similarity in shape of the human and rat thrombin generation curves (FIG. 4.1), together with the relatively short half-life time of thrombin in rat plasma indicate that, also in the rat system, both antithrombin and $\alpha$-macroglobulin inactivate the thrombin formed. Application of the correction procedure to the curve of thromboplastin-activated rat plasma gave a time-plot of changes in free thrombin concentration (FIG. 4.3A). Plotting these data as the time integral of the free thrombin concentration gave a curve representing the accumulation of proteolytic capacity of free thrombin (FIG. 4.3B). With rat throm- 

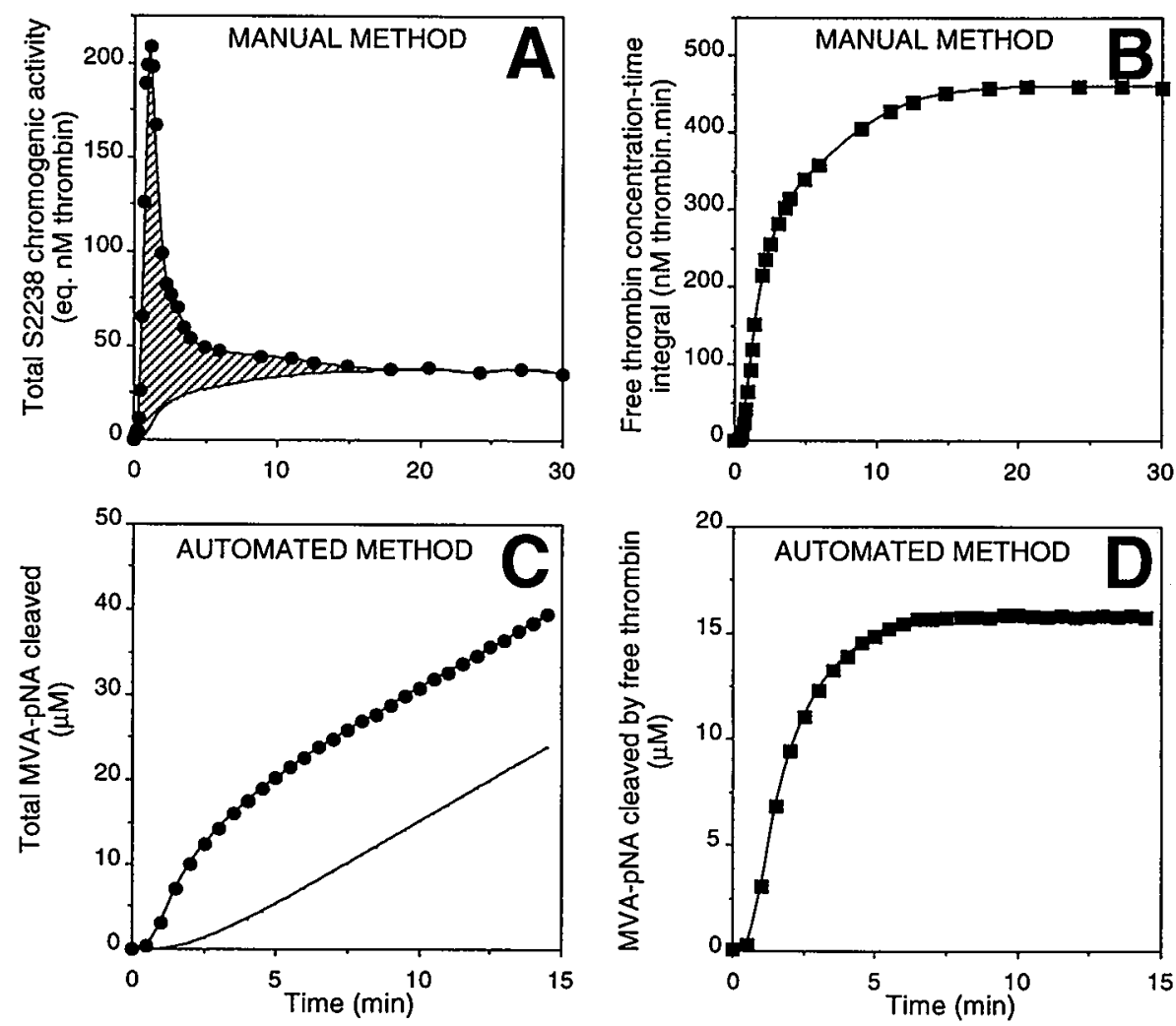

FIGURE 4.3 Manual and automated measurements of ETP in rat plasma. ( $A, B)$ Manual, subsampling measurement of ETP in plasma, triggered with rat thromboplastin (final dilution $1: 300$ ), phospholipids and $\mathrm{CaCl}_{2}$. (A) $\mathrm{S} 2238$ chromogenic activity was measured (dots) in samples taken from the coagulation mixture at regular intervals. Hatched area represents the contribution of free, coagulationactive thrombin. Solid line represents chromogenic activity of $\alpha$-macroglobulin-bound thrombin. (B) Plot of time-integral of free thrombin concentration (i.e. hatched area from panel A) versus time. End level of $450 \mathrm{nM}$ thrombin min, reached after $15 \mathrm{~min}$, represents ETP under this condition. (C, D) Automated measurement of ETP in GPRP-treated plasma, triggered with rat thromboplastin, phospholipids and $\mathrm{CaCl}_{2}$ in the presence of chromogenic MVA-pNA. (C) Plot of measured chromogenic activity in the plasma (dots). Solid line represents chromogenic activity of $\alpha$-macroglobulin-bound thrombin, as obtained by numerical fitting. (D) Plot of chromogenic activity of free, coagulation-active thrombin. The end level of $16.0 \mu \mathrm{M} p$-nitroanilide cleaved is proportional to the ETP as $\mathrm{nM}$ thrombin-min. Note different labeling of the $y$-axes in panels A-D.

boplastin as trigger a maximal integral level was reached after 15-20 min which, by definition, is the ETP. This level attributed to $434 \pm 21 \mathrm{nM}$ thrombin.min (mean \pm sem, $n=8$ ). When triggering with recombinant human tissue factor $(40 \mathrm{pM})$, a similar ETP was obtained of $465 \pm 14 \mathrm{nM} \cdot \min$ (mean \pm sem, $n=9$ ). These values are comparable to the normal ETP range of human plasma of $400-480 \mathrm{nM} \cdot \min [5,6]$. 
$\mathrm{nM} \cdot \min (\mathrm{n}=4)$. In the latter case, thrombin appeared after a lag time of several min (data not shown), as for the human intrinsic system [4].

To measure the ETP with chromogenic substrates in an automated way, turbidity due to fibrin clot formation needed to be prevented. This was done by preincubating the rat plasma with the fibrin polymerisation inhibitor, GPRP [20]. When tested in the human coagulation system, such incubation was of no more than little effect on the thrombin generation [13]. Addition of $7.5 \mathrm{mM}$ GPRP to undiluted rat plasma was sufficient to fully inhibit clot formation during the time of the coagulation assay. Thrombin formation was followed by monitoring the cleavage of chromogenic peptide-derivative, MVA-pNA (0.5 mM), which was directly added to the plasma. This compound has a low-affinity for thrombin, thus minimising its interference with the activity of the coagulation system. The $K_{m}$ for human thrombin has been determined at $0.88 \mathrm{mM}$, while its $K_{m}$ for human factor $\mathrm{Xa}$ is $9.55 \mathrm{mM}$ [6]. Using purified preparations of rat and human thrombin, we checked that MVA-pNA was cleaved at similar rates by either enzyme.

When MVA-pNA-containing rat plasma was activated with rat thromboplastin, phospholipids and $\mathrm{CaCl}_{2}$ (final plasma content $33 \%$ ), this resulted in a gradual increase in absorbance due to $p$-nitroanilide accumulation, reaching a maximal rate after about $90 \mathrm{~s}$ (FIG. 4.3C). After computer-assisted correction for the contribution of $\alpha$-macroglobulin-bound thrombin, a time plot was constructed of the colour development due to free thrombin (FIG, 4.3D). The stable end level, being expressed as micromolar $p$-nitroanilide cleaved by free thrombin, is a measure of the ETP (see Materials and Methods). Control experiments showed that the thrombin half-life time was increased to $18 \mathrm{~s}$ at this plasma dilution. Using the manual sampling method, it was further checked that the presence of GPRP decreased the ETP of tissue factoractivated rat plasma with only $10 \%$.

When the automated measurement was carried out with pooled rat plasma and either rat thromboplastin or recombinant human tissue factor (40 pM), similar tracings were obtained, although the end level was slightly higher when using recombinant tissue factor (FIG. 4.4A). In six experiments with recombinant tissue factor, this end level was determined at $20.6 \pm 0.5 \mu \mathrm{M}$ substrate converted (mean \pm sem). The relative method error of the automated measurement, using thromboplastin or recombinant tissue factor, was $5.20 \%$ ( $n=23$ parallel samples). It should be noted that this ETP measure is dependent on experimental factors like the plasma dilution and the substrate concentration.

\section{Sensitivity of the ETP for hypocoagulant conditions}

To establish the sensitivity of the automated assay for antithrombin action, the rat plasma was pretreated with unfractionated or low-molecular weight heparin. Either heparin type caused a dose-dependent inhibition of the thrombin potential (data not shown). At a dose of $0.05 \mathrm{U} / \mathrm{ml}$, unfractionated heparin inhibited the ETP by about 

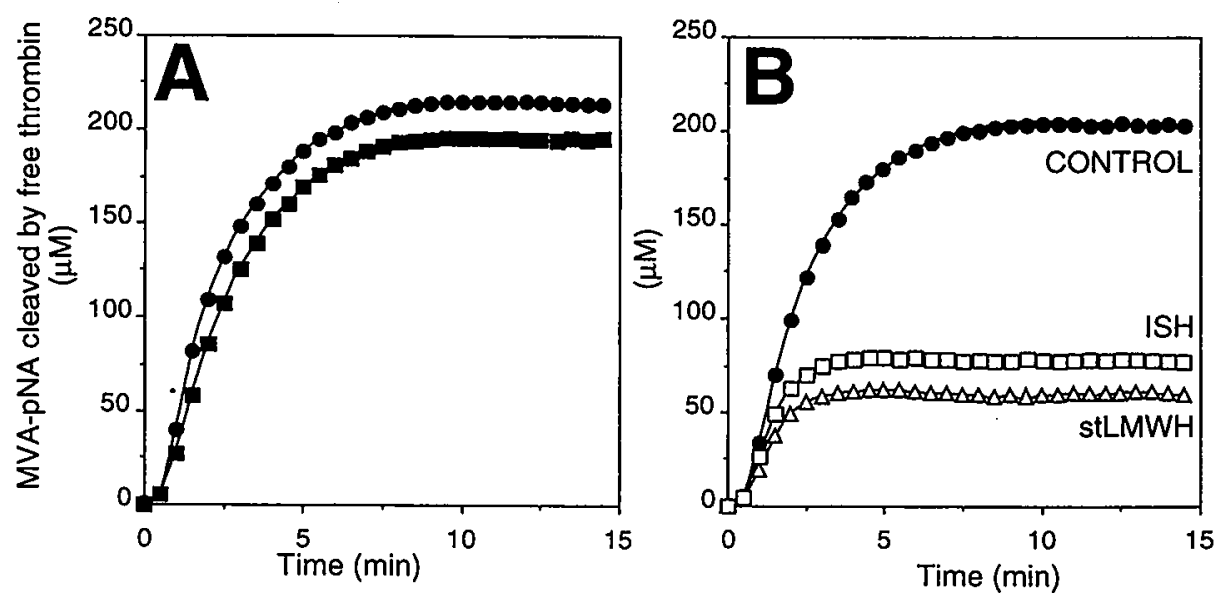

FIGURE 4.4 Effect of tissue factor source and heparins on automated ETP measurement. (A) Rat plasma containing MVA-pNA was activated with rat thromboplastin (squares, final dilution $1: 300$ ) or recombinant human tissue factor (dots, $40 \mathrm{pM}$ ) in the presence of phospholipids and $\mathrm{CaCl}_{2}$. (B) MVApNA-containing plasma was triggered by recombinant human tissue factor $(40 \mathrm{pM})$, phospholipids and $\mathrm{CaCl}_{2}$ in the absence (dots) or presence of $0.05 \mathrm{U} / \mathrm{ml} 4$ th International standard heparin (open squares, ISH) or $0.05 \mathrm{U} / \mathrm{ml}$ 1st International standard low molecular-weight heparin (open triangles, stLMWH). Plots represent chromogenic activity of free, coagulation-active thrombin, after correction for the activity of $\alpha$-macroglobulin-bound thrombin (see FIG. 4.3). Traces are representative for at least three independent experiments.

$60 \%$, whereas low-molecular weight heparin inhibited by $70 \%$ (FIG. 4.4B). Both heparin forms prolonged the prothrombin time of rat plasma from $26.2 \mathrm{~s}$ to only 29.0 s.

Vitamin $\mathrm{K}$ antagonists such as warfarin are well-known reducers of the coagulation activity in rats $[16,17,21]$. When tested with the automated method, it appeared that rat treatment with a single dose of warfarin $(3 \mathrm{mg} / \mathrm{kg}$, i.p.) resulted in a considerable reduction in rate of substrate cleavage and in final ETP value after $4 \mathrm{~h}$ of warfarin injection (FIG. 4.5A). At later times after warfarin injection, further decreases in rate of substrate cleavage and in ETP value were observed, which effects were accompanied by an equal decrease in plasma prothrombin level (FIG. 4.5B). In comparison, the level of factor $\mathrm{VII}$, which is a vitamin $\mathrm{K}$-dependent coagulation factor with a shorter half-life time in rat plasma, i.e. $2.6 \mathrm{~h}$ versus $9.0 \mathrm{~h}$ for prothrombin [22], declined even faster (FIG. 4.5B).

To evaluate the sensitivity of the automated method in monitoring the vitamin $\mathrm{K}$ state, plasma from control rats was mixed in various proportions with plasma from rats that were treated with warfarin for $27 \mathrm{~h}$. The ETP value appeared to decrease linearly with the fraction of warfarin plasma and, thus, with the levels of vitamin Kdependent coagulation factors. As apparent from FIG. $4.5 \mathrm{C}$, the presence of $5 \%$ warfarin plasma could already be detected. 

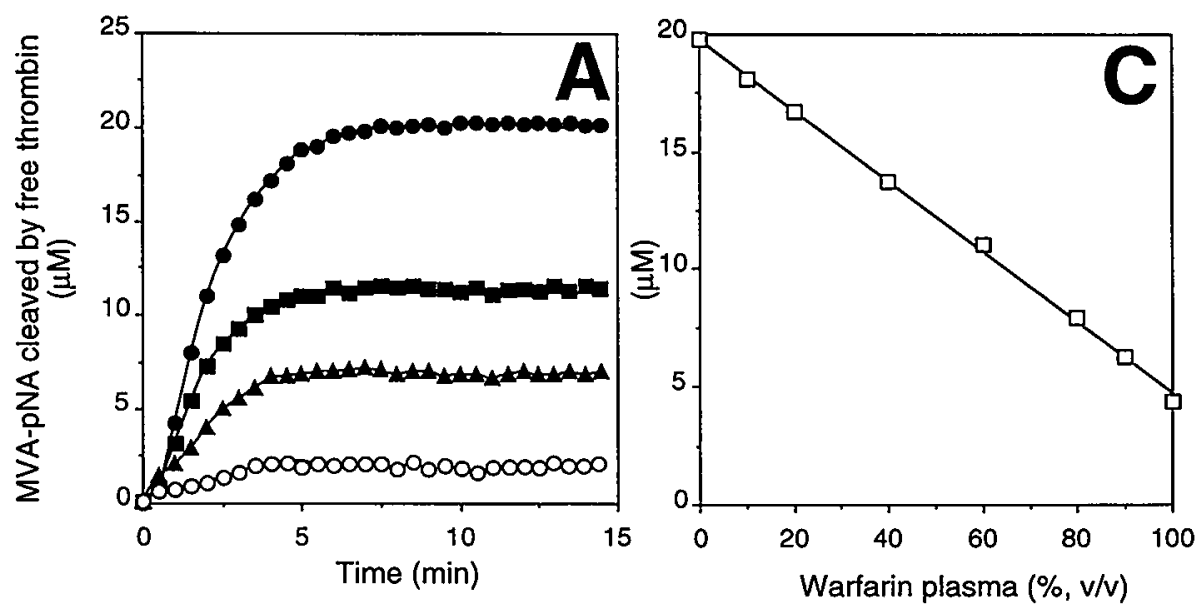

\begin{tabular}{|c|c|c|c|c|c|}
\hline$B$ & $\begin{array}{l}\text { Warfarin } \\
\text { treatment (h) }\end{array}$ & Rate & $\begin{array}{l}\text { ETP } \\
\text { (\% of }\end{array}$ & $\begin{array}{l}\text { Fil } \\
\text { ontrol) }\end{array}$ & FVII \\
\hline & $\begin{array}{ll}0 & (\bullet) \\
4 & (\mathbf{E}) \\
11 & (\Delta) \\
27 & (0)\end{array}$ & $\begin{array}{c}100 \\
60 \\
30 \\
8\end{array}$ & $\begin{array}{l}100 \\
53 \\
31 \\
11\end{array}$ & $\begin{array}{l}100 \\
55 \\
35 \\
15\end{array}$ & $\begin{array}{c}100 \\
25 \\
5 \\
2\end{array}$ \\
\hline
\end{tabular}

FIGURE 4.5 Sensitivity of plasma ETP to warfarin treatment. Rats were injected with a single dose of warfarin ( $3 \mathrm{mg} / \mathrm{kg}$, i.p.) at 4-27 h before bleeding, or were not injected (controls). (A) Plasma, obtained after 0 (dots), 4 (squares), 11 (triangles) or 27 (open circles) hours of warfarin injection, was triggered with recombinant human tissue factor $(40 \mathrm{pM})$, phospholipids and $\mathrm{CaCl}_{2}$. FIGURES represent accumulation of MVA-pNA chromogenic activity due to free thrombin. (B) Values of maximal rate of thrombin formation and of ETP in comparison to plasma prothrombin (FII) and factor VII (FVII) for the various warfarin-treated rats. (C) Plasma from control rats was mixed in various proportions with plasma from rats treated with warfarin for $11 \mathrm{~h}$. Mixtures were activated, and ETP values were measured, as described above. The ETP level is linearly related to the percentage of warfarin plasma $(y=198-1.50 x$, $\mathrm{R}=0.99$ ), and essentially proportional to the prothrombin concentration. Data shown are representative for 2 or 3 independent measurements.

Another way to achieve hypocoagulant conditions is by feeding the animals with a vitamin $\mathrm{K}$-deficient diet. After with such a diet for 3 consecutive days, the ETP was be reduced to $57 \%$ of the original value (FIG. 4.6), which effect was accompanied by a similar reduction in prothrombin level ( $50 \%$ of control).

It was attempted to find out whether the assays may also detect hypercoagulant activity of rat plasma, as established for the human system $[6,23]$. In man, an important cause of plasma hypercoagulability is defective action of the protein $\mathrm{C}$ pathway. Protein $\mathrm{C}$ activation thus has a potent reducing effect on thrombin generation in human plasma $[24,25]$. Unfortunately, the commonly used activator of protein $C$, the snake venom protease protac, was completely inactive when incubated with rat plasma (data not shown). 


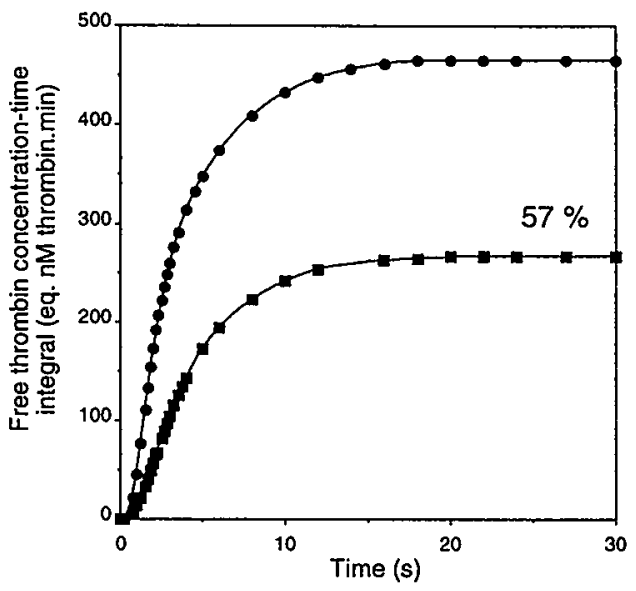

FIGURE 4.6 Effect of vitamin K'deficient diet on plasma ETP. Rats were fed for 3 days with a standard (dots) or a vitamin K-deficient (squares) diet. Plasma was activated with recombinant human tissue factor (40 pM), phospholipids and $\mathrm{CaCl}_{2}$, and accumulation of free thrombin was monitored in time. Plots are given of thrombin concentration-time integrals (see FIG. 4.3), and are representative for 3 measurements.

\section{Factors determining the ETP of tissue factor-activated rat plasma}

The results described above suggest that the rate, and thus the amount, of thrombin formed in the early phase of coagulation is can determine the ETP of the whole coagulation process, and that the plasma prothrombin controls its own cleavage rate already at the start of coagulation. This was verified in a number of experiments, where the rat plasma was activated with sub-optimal levels of recombinant tissue factor. In control plasma the initial, maximal rate of MVA-pNA substrate cleavage increased with the tissue factor concentration over a range of $0.5-40 \mathrm{pM}$ (FIG. 4.7A). This was accompanied by a gradual increase in ETP level, although the latter parameter levelled off at around $10 \mathrm{pM}$ tissue factor (FIG. 4.7B). Above this tissue factor concentration, essentially all prothrombin in the plasma appeared to be converted into thrombin (data not shown). The same experiment was performed with plasma from rats that were treated with warfarin from $6 \mathrm{~h}$. This treatment reduced the prothrombin and factor VII levels to $65 \%$ and $30 \%$ of the control levels, respectively. The warfarin treatment appeared to reduce both the maximal rate of substrate cleavage and the ETP by $30-35 \%$, independently of the tissue factor concentration used (FIG. 4.7A-B). Essentially the same results were obtained when a low dose of $0.02 \mathrm{U} / \mathrm{ml}$ unfractionated heparin was added to the control plasma, to facilitate thrombin inactivation (FIG. 4.7A-B). When for the various activation conditions, the ETP was plotted as a function of the cleavage rate, a curve was obtained, which reached a plateau value that was about $30 \%$ lower for the warfarin plasma than for the control plasma (FIG. 4.7C). Together, these results suggest that the maximal thrombin concentration, reached early in the coagulation process, and, thus, the rate of thrombin formation, limits the proteolytic activity of thrombin during the coagulation process as a whole.

To investigate whether indeed the prothrombin concentration acts as a limiting factor, purified human prothrombin (2-5 $\mu \mathrm{M})$ was added to the plasma before 

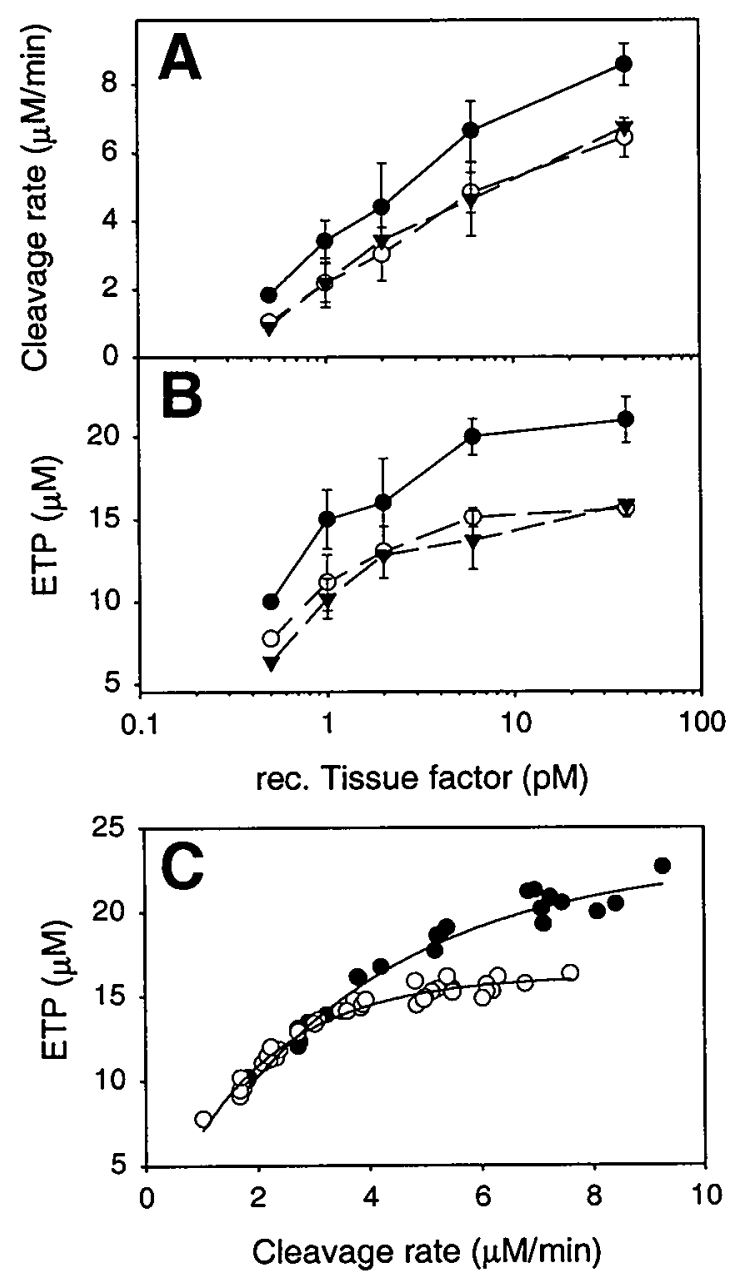

FIGURE 4.7 Relation of thrombin formation rate and ETP. Plateletfree plasma was taken from control rats or from rats that were bled after $6 \mathrm{~h}$ of injection with warfarin. Where indicated, 0.02 $\mathrm{U} / \mathrm{ml}$ 4th International standard heparin (ISH) was added to the control plasma. Plasma was activated with $0.5-40 \quad \mathrm{pM}$ recombinant tissue factor (TF), phospholipids and $\mathrm{CaCl}_{2}$ in the presence of chromogenic MVApNA. After correction for colour development due to $\alpha$-macroglobulin-bound thrombin, $(A)$ the maximal rate of substrate cleavage $(\mu \mathrm{M} \quad p$-nitroanilide cleaved/min) determined after about $1 \mathrm{~min}$ of activation and, (B) the total amount of cleaved substrate (i.e., ETP in $\mu \mathrm{M} p$ nitroanilide) were determined. Dots, plasma from control rats; open circles, plasma from warfarin-treated rats; triangles, plasma from control rats containing $0.02 \mathrm{U} / \mathrm{ml} \mathrm{ISH}$. Data are mean values $\pm S D(n=3-6)$. (C) Plot of ETP as a function of the maximal substrate cleavage rate from the measurements shown in panels $\mathrm{A}$ and $\mathrm{B}$.

the coagulation was started. This resulted in a dose-dependent increase in both the rate of substrate accumulation and the final ETP level. With control plasma and $2 \mu \mathrm{M}$ prothrombin added, the rate increased from $5.6 \pm 0.4 \mu \mathrm{M} / \mathrm{min}$ to $8.4 \pm 1.0 \mu \mathrm{M} / \mathrm{min}$, and the ETP from $17.8 \pm 2.8 \mu \mathrm{M}$ to $36.1 \pm 3.8 \mu \mathrm{M}$ substrate converted (means \pm sem, $\mathrm{n}=4$ ). With warfarin plasma and $2 \mu \mathrm{M}$ prothrombin, the rate increased from $3.6 \pm 0.2 \mu \mathrm{M} / \mathrm{min}$ to $6.5 \pm 0.4 \mu \mathrm{M} / \mathrm{min}$, and the ETP from $12.7 \pm 0.1$ to $31.8 \pm 1.2 \mu \mathrm{M}$ substrate converted (means \pm sem, $n=6$ ). 


\subsection{Discussion}

Determination of the coagulation potential of rat plasma, as performed with the automated assay described here, appears to be a sensitive way of detecting hypocoagulability. Similarly as the manual sampling method to measure the ETP, which has already been described in an earlier paper [12], the present assay is designed as to rely on autologous (animal species-specific) factors, i.e. brain-derived thromboplastin and blood plasma. The rat coagulation system can thus be studied under fully autologous conditions using only rat-derived factors and proteins. However, during the course of this study it appeared that preparations of human recombinant tissue factor were of similar, or even somewhat higher, activity in stimulating the coagulation process than thromboplastin isolated from rat brain. This result stimulated us to routinely use the well-defined human factor preparation in subsequent experiments. It is noted that the automated procedure of ETP measurement differs in two important ways from the original, manual method described for the human system: the presence of GPRP to inhibit fibrin polymerisation instead of using defibrinated plasma, and the addition of chromogenic substrate directly to the coagulating plasma. Clearly, both GPRP and the chromogenic substrate will influence the course of the coagulation process.

To validate the automated method, in which chromogenic thrombin substrate is present in the coagulating plasma, it needs to be compared to the manual, subsampling measurement of the ETP, where the measurement of thrombin formation can not interfere with the coagulation process. We indeed found that either method responded well to the presence of vitamin $K$ antagonists or thrombin inactivators (see also Ref. 12). The subsampling method was used to directly compare the coagulation systems of rat and man. In thromboplastin/ $\mathrm{CaCl}_{2}$-activated rat plasma the rate of thrombin formation was relatively fast, when compared to that of tissue factor-activated human plasma (FIG. 4.1). Further, under conditions of minimal plasma dilution, the thrombin in rat plasma had a much shorter decay time than thrombin in human plasma (see FIG. 4.2). This suggests that, in rat plasma, thrombin scavengers such as antithrombin more rapidly inactivate the thrombin formed. This idea is supported by the high antithrombin concentration in rat plasma (though this was measured in a non-autologous way), and by the high sensitivity of the rat ETP assay to added heparin. The rapid thrombin formation in rat plasma may be explained by the observation that the levels of a number of coagulation factors in rat plasma are fairly high, particularly prothrombin and factors V, VII and VIII (albeit again measured with human reagents).

Like the more laborious sampling procedure, the automated ETP method is sensitive enough to detect low concentrations of heparin in rat plasma (FIG. 4.4). It also allows detection of small changes in vitamin K-dependent coagulation factors either caused by intervention with vitamin K-antagonists (FIG. 4.5) or by feeding with 
Like the more laborious sampling procedure, the automated ETP method is sensitive enough to detect low concentrations of heparin in rat plasma (FIG. 4.4). It also allows detection of small changes in vitamin K-dependent coagulation factors either caused by intervention with vitamin K-antagonists (FIG. 4.5) or by feeding with a vitamin K-deficient diet (FIG. 4.6). Accordingly, this method can find a useful application in monitoring the vitamin $\mathrm{K}$ state of rats.

For the outcome of the ETP assay, particularly the initial rate of thrombin formation, which determines the maximal amount of thrombin formed (i.e. the maximal rate of MVA-pNA substrate cleavage), appears to be an important determinant. Not only in control plasma, but also in plasma from warfarin-treated rats or heparin-containing plasma, the ETP increased with the amount of thrombin formed in the first minutes of the coagulation process (FIG. 4.7). Moreover, addition of extra (human) prothrombin to these plasmas resulted in a considerable increase in thrombin formation rate that was accompanied by a similar increase in final ETP level. Accordingly, these results suggest that the prothrombin level plays an important role in determining both the initial and total activity of the coagulation system. In other words, in the coagulating rat plasma, the thrombin formation rate and the amount of thrombin formed seems to be restricted by the level of the prothrombin substrate of the prothrombinase complex. This holds for activation conditions where the coagulation reaches completion (i.e. all prothrombin cleaved) with high tissue factor concentrations, but also for sub-optimal conditions with lower tissue factor concentrations (see FIG. 4.7).

The method introduced in this paper can easily be applied to determine the coagulation potential of plasma from other mammalian laboratory animals, provided that two conditions are met. An obvious species of interest is mice, where the action mechanism of the haemostatic system still needs to be resolved [26]. Firstly, it needs an adequate source of tissue factor, e.g. autologous brain-derived thromboplastin. Secondly, chromogenic peptides are required that function as low-affinity substrates for the animal thrombin forms. Pilot experiments have shown that the substrates used in the present study can also be used for coagulation measurements of mouse and guinea pig plasma.

\subsection{Acknowledgements}

We thank R.F.G. Offermans and R. van Oerle for analytical assistance. We thank Drs. H. C. Hemker, G. Hornstra and G. Tans for valuable comments and discussions. We acknowledge Dr. D. Rijkers for preparation of MVA-pNA. This study was supported by Hoffmann-La Roche (Basel, Switzerland). 


\subsection{References}

1. Mann KG. Biochemistry and physiology of blood coagulation. Thromb Haemost. 1999;82: 165174.

2. Hemker HC, Béguin S. Thrombin generation in plasma: its assessment via the endogenous thrombin potential. Thromb Haemost. 1995;74:134-138.

3. Hemker HC, Willems GM, Béguin S. A computer assisted method to obtain the prothrombin activation velocity in whole plasma independent of thrombin decay processes. Thromb Haemost. 1986;56:9-17.

4. Béguin S, Wielders S, Lormeau JC, HC Hemker. The mode of action of CY216 and CY222 in plasma. Thromb Haemost. 1992;67:33-41.

5. Hemker HC, Wielders $\mathrm{S}$, Kessels $\mathrm{H}$, Béguin $\mathrm{S}$. Continuous registration of thrombin generation in plasma: its use for the determination of the thrombin potential. Thromb Haemost. 1993;70 33-41.

6. Wielders S, Mukherjee M, Michiels J, Rijkers DTS, Cambus JP, Knebel RWC, Kakkar V, Hemker HC, Béguin $S$. The routine determination of the endogenous thrombin potential, first results in different forms of hyper- and hypocoagulability. Thromb Haemost 1997;77:629-636.

7. Bernat A, Mares AM, Defreyn JP, Herbert JM. Effect of various antiplatelet agents on acute arterial thrombosis in the rat. Thromb Haemost. 1993;70:812-816.

8. Eriksson BI, Carlsson S, Halvarsson M, Risberg B, Mattsson C. Antithrombotic effect of two low molecular weight thrombin inhibitors and a low-molecular weight heparin in a caval vein thrombosis model in the rat. Thromb Haemost. 1997;78:1404-1407.

9. Andriamampandry MD, Leray $C$, Freund M, Cazenave JP, Gachet $C$. Antithrombotic effects of $(\mathrm{n}-3)$ polyunsaturated fatty acids in rat models of arterial and venous thrombosis. Thromb Res. 1999;93:9-16.

10. Nieuwenhuys CMA, Hornstra G. The effects of purified eicosapentaenoic and docosahexaenoic acids on arterial thrombosis tendency and platelet function in rats. Biochim Biophys Acta. 1998;1390:313-322.

11. Karges HE, Funk KA, Ronneberger $H$. Activity of coagulation and fibrinolysis parameters in animals. Arzneim-Forsch/Drug Res. 1994;6:793-797.

12. Nieuwenhuys CMA, Béguin S, Offermans RFG, Emeis JJ, Hornstra G, Heemskerk JWM. Hypocoagulant and lipid-lowering effects of dietary n-3 polyunsaturated fatty acids with unchanged platelet activation in rats. Arterioscler Thromb Vasc Biol. 1998;18:1480-1489.

12a. Tans G, Janssen-Claessen T, Hemker HC, Zwaal RFA, Rosing J. Meizothrombin formation during factor Xa-catalyzed prothrombin activation. Formation in a purified system and plasma. $J$ Biol Chem. 1991;266:21864-21873.

13. Rijkers DTS, Wielders SJH, Béguin S, Hemker HC. Prevention of the influence of fibrin and $\alpha_{2}-$ macroglobulin in continuous measurement of the thrombin potential: implications for an endpoint determination of the optical density. Thromb Res. 1998;89:161-169.

14. Van Dam-Mieras MCE, Muller AD, Hemker HC. Proenzymes, enzymes, inhibitors, cofactors. In: Bergmeyer HU, Bergmeyer J, Grassl M (eds), Methods of Enzymatic Analysis, 1988, Vol V. Weinheim, Germany: VCH Publishers, pp. 352-365.

15. Groenen-van Dooren MMCL, Ronden JE, Soute BAM, Vermeer C. Bioavailability of phylloquinone and menaquinones after oral and colorectal administration in vitamin K-deficient rats. Biochem Pharmacol. 1995;50:797-801.

16. Tollersrau OK, Kvalvaag AH, Helgeland L. Biosynthesis and clearance of prothrombin in warfarin-treated rats. Biochim Biophys Acta. 1989;1010:35-40.

17. Pratt SK, Win MJ, Park BK. The disposition of enantiomers of warfarin following chronic administration to rats: relationship to anticoagulant response. I Pharm Pharmacol. 1989;41:743-746.

18. Béguin $S$, Kessels $H$, Dol F, Hemker HC. The consumption of antithrombin III during coagulation, its consequences for the calculation of prothrombinase activity and the standardisation of heparin activity. Thromb Haemost. 1992;68:136-142.

19. Gauthier F, Genell S, Mouray H, Ohlsson K. Interactions in vitro and in vivo between rat serum protease inhibitors and anodal and cathodal rat trypsin and chymotrypsin. Biochim Biophys Acta. 1979;566:200-210. 
18. Béguin $S$, Kessels $H$, Dol $F$, Hemker HC. The consumption of antithrombin III during coagulation, its consequences for the calculation of prothrombinase activity and the standardisation of heparin activity. Thromb Haemost. 1992;68:136-142.

19. Gauthier F, Genell S, Mouray H, Ohlsson K. Interactions in vitro and in vivo between rat serum protease inhibitors and anodal and cathodal rat trypsin and chymotrypsin. Biochim Biophys Acta. 1979;566:200-210.

20. Laudano AP, Doolittle RF. Synthetic peptide derivatives that bind fibrinogen and prevent polymerization of fibrin monomers. Proc Natl Acad Sci USA. 1978;75:3085-3089.

21. Craciun AM, Groenen-van Dooren MMCL, Thijssen HHW, Vermeer C. Induction of prothrombin synthesis by K-vitamins compared in vitamin K-deficient and in brodifacoumtreated rats. Biochim Biophys Acta. 1998;1380:75-81.

22. Vainieri $H$, Wingard LJ. Effect of warfarin on the kinetics of the vitamin K-dependent coagulation factors in rats. J Pharmacol Exp Ther. 1977;201:507-517.

23. Faber K. Thrombotic tendency in young stroke patients. 1998, Ph.D. Thesis, Maastricht University, the Netherlands.

24. Esmon CT. The roles of protein $\mathrm{C}$ and thrombomodulin in the regulation of blood coagulation. $J$ Biol Chem. 1989;264:4743-4746.

25. Nicolaes GAF, Thomassen MCLGD, van Oerle R, Hamulyàk K, Hemker HC, Tans G, Rosing J. A prothrombinase-based assay for detection of resistance to activated protein $\mathrm{C}$. Thromb Haemost. 1996;76:404-410.

26. Tsakiris DA, Scudder L, Hodivala-Dilke K, Hynes RO, Coller BS. Hemostasis in the mouse (Mus musculus): a review. Thromb Haemost. 1999;81:177-188. 


\section{Hypocoagulant and lipid-lowering effects of dietary $n-3$ polyunsaturated fatty acids with unchanged platelet activation in rat}

Cécile M.A. Nieuwenhuys ${ }^{1}$, Suzette Béguin ${ }^{2}$, René F.G. Offermans ${ }^{1}$, Jef J. Emeis ${ }^{3}$, Gerard Hornstra ${ }^{1}$ and Johan W.M. Heemskerk ${ }^{1.2}$

From the Departments of Human Biology ${ }^{1}$ and Biochemistry ${ }^{2}$, University of Maastricht, and the Gaubius Laboratory ${ }^{3}$, TNO-PG, Leiden, The Netherlands. 


\subsection{Abstract}

Effects were investigated of dietary polyunsaturated fatty acids (PUFA) on blood lipids and processes determining the haemostatic potential: platelet activation, coagulation and fibrinolysis. Wistar rats were fed during 8-10 weeks with a high-fat diet containing various amounts (2-16\%) of n-3 PUFA derived from fish oil (FO), or with a diet enriched in n-6 PUFA from sunflower seed oil (SO). Only the FO diets caused a reduction in mean platelet volume, platelet arachidonate level and in formation of thromboxane $B_{2}$ by activated platelets, but none of the diets had a measurable effect on platelet activation. The FO-rich diets decreased the plasma concentration of triglycerides and cholesterol, while the SO diet reduced only the triglycerides. Parameters of fibrinolysis and standard coagulation times, i.e. the activated partial thromboplastin time and prothrombin time, were only marginally influenced by these diets. In contrast, dietary FO, but not SO, led to decreased levels of the vitamin $\mathrm{K}$-dependent coagulation factors, prothrombin and factor VII, while the level of antithrombin III was unchanged. The endogenous thrombin potential (ETP) was measured, as an assay developed to detect the hypo-coagulable state of plasma. After activation with tissue factor and phospholipids, the ETP was reduced by $23 \%$ or more in plasma from animals fed with $>4 \%$ FO. No significant effect of SO diet on the ETP was observed. Control experiments with plasma from warfarintreated rats indicated that the ETP was more sensitive to changes in prothrombin concentration than in factor VII concentration. Taken together, these results indicate that, in rats, prolonged administration of $n-3$ but not $n-6$ PUFA can lead to a hypocoagulable state of plasma through a reduced capacity of vitamin K-dependent thrombin generation with unchanged thrombin inactivation by antithrombin III.

\subsection{Introduction}

In the early seventies, it was already noted that Greenland Eskimos often show a tendency of prolonged bleeding, and suffer relatively little from ischemic heart disease. Initial epidemiological studies suggested that the putative cardio-protective factor was of dietary origin and, in particular, resulted from the consumption of large amounts of marine oils by these Eskimos [1,2]. Although nowadays the relationship between fish consumption and cardiovascular health is well-documented, the mechanism responsible for the protective effect is still debated $[3,4]$.

An initial hypothesis was that dietary marine oils prolong bleeding as a consequence of fatty acid-modulating effects on platelets. Consumption of fish oil 
(FO), rich in $n-3$ polyunsaturated fatty acids (PUFA), causes replacement of $n-6$ PUFA by $n-3$ PUFA in the platelet phospholipids, i.e. arachidonic acid is mainly replaced by eicosapentaenoic and docosahexaenoic acid. During platelet activation, arachidonate is released from the phospholipids and then converted into prostaglandin $\mathrm{H}_{2}$ and thromboxane $A_{2}$, which strongly potentiate the activation process. Once released, eicosapentaenoate is however converted into the metabolites, prostaglandin $H_{3}$ and thromboxane $A_{3}$, which both support platelet activation in a much less effective manner [5]. On the other hand, both the arachidonate- and eicosapentaenoate-derived vessel-wall products, prostaglandin $\mathrm{I}_{2}$ and $l_{3}$, are considered to be equally potent in inhibiting platelet activation. Accordingly, the original explanation for the advantageous effect of dietary n-3 PUFA was that it suppresses the platelet-stimulating effect of thromboxane production, while leaving unchanged the platelet-inhibiting effect of vessel-wall derived prostacyclins $[5,6]$. Dietary intervention studies have indeed demonstrated that $n-3$ PUFA (i.e. FO) effectively decrease the release of thromboxane $A_{2}$ by platelets. However, in only part of such studies, the reduced thromboxane formation was accompanied by a decreased activation tendency of the platelets, while in other reports platelet activation was unchanged or even increased [7-9].

More recently, other mechanisms have been put forward to explain the healthprotecting effect of FO-rich diets. Various authors have shown that FO reduces the plasma concentrations of cholesterol and triglycerides [2,10-12]. Others have stated that dietary FO may decrease the levels of specific clotting factors in plasma [13-15], although global coagulation measurements usually failed to detect diet-induced effects on the coagulation process $[16,17]$.

Supplementation of FO diets rich in n-3 PUFA to laboratory rats results in effects that, to a certain degree, resemble those of human nutritional studies. Lipidlowering effects of FO-rich diets have often been documented in rats $[18,19]$. In earlier work from our laboratories, it has been shown that FO-fed rats have an increased bleeding time and contain platelets with consistently reduced levels of arachidonic acid [20]. However, we $[21,22]$ and others $[23,24]$ have also found that the reduced production of thromboxane by these platelets was not accompanied by a decreased platelet activation tendency or by a diminished transduction of activating signals. This suggests that the bleeding effect may be due to factors other than reduced platelet activation. In the present paper, we report of a study with rats, in which we investigated the effects of various doses of FO-derived n-3 PUFA on a variety of factors involved in normal and abnormal haemostasis: blood lipids, platelet activation, coagulation and fibrinolysis. As a comparison, we used a diet derived from sunflower seed oil (SO) that was highly enriched in n-6 PUFA. While both types of diets appeared to act lipid-lowering and did no more than marginally influence platelet activation, the FO-containing diets were unique in decreasing the coagulant state of the plasma, as detected by a sensitive assay measuring the endogenous 
thrombin potential (ETP). This hypocoagulant effect was most likely due to a FOinduced lowering of the levels of vitamin K-dependent coagulation factors.

\subsection{Materials and methods}

\section{Materials}

Beef tallow, hydrogenated coconut oil and olive oil came from Chempri (Raamsdonkveer, The Netherlands), pelleted stock diet was from Hope Farms (Woerden, The Netherlands), and FO fatty acid ethyl esters were obtained from Hoffmann-La Roche (Basel, Switzerland). TrisunTM, sunflower seed oil (SO) and the remaining dietary components were supplied from Unilever (Vlaardingen, The Netherlands). Recombinant disulfatohirudin (variant 1 Revasc ${ }^{T M}$ ) was a gift from Ciba-Geigy (Basel, Switzerland). Warfarin and kaolin were bought from Sigma (St. Louis, MO), prothrombin- and factor VII-deficient plasma and thromborel $S$ came from Behring (Marburg, Germany), and recombinant tissue factor was from Dade (Miami, FL). Human factor VII was purchased from Kordia (Leiden, The Netheriands). Human prothrombin was a kind gift of Dr. J. Rosing (Maastricht, The Netherlands). Chromogenic substrate for thrombin, S2238, and test kits for antithrombin III were obtained from Chromogenix (Mölndal, Sweden). Kits for determination of thromboxane $\mathrm{B}_{2}$ came from Cayman (Ann Harbor, MI). The origin of other chemicals was as described before [22].

\section{Animals and diets}

Three-week-old, male Wistar rats (Charles River, Sulzfeld, Germany) were individually housed in stainless steel cages at $23^{\circ} \mathrm{C}$ and fed with pelleted stock diet. After two weeks, the rats were randomly divided into six groups of 24 animals, and fed with one out of six high-fat diets for a period of 8-10 weeks. All diets had equal energy contents of $19.5 \mathrm{~kJ} / \mathrm{g}$, and contained $50 \%$ of digestible energy as fat, 23energy $\%$ (en\%) as casein and $27-e n \%$ as cornstarch. Other dietary components (minerals, vitamins, and fiber) were added as before [20]. Cholesterol was equally low in all diets, i.e. $50 \mu \mathrm{g} / \mathrm{g}$. To prevent lipid peroxidation, the diets were prepared weekly and stored at $-20^{\circ} \mathrm{C}$ under nitrogen until use. Water and food were available to the animals ad libitum. The Institutional Animal Care Committee approved the studies.

Rats from the control group were fed with a control diet composed of saturated fatty acids, monounsaturated fatty acids and n-6 polyunsaturated fatty acids (PUFA) in a ratio of 2:3:1 (w/w). This diet was prepared by the mixing of equivalent amounts of $\mathrm{SO}$, beef tallow, hydrogenated coconut oil and olive oil. Other rats received a diet in which $2 \%, 4 \%, 8 \%$ or $16 \%(w / w)(1,2.5,5$ and $10-e n \%$, 
respectively) of the fatty acids were replaced by n-3 PUFA from a FO preparation containing $19.9 \%$ ethyl eicosapentaenoate and $36.9 \%$ ethyl docosahexaenoate (2$16 \%$ FO groups). Rats from the sixth group were fed with a SO-rich diet composed of saturated fatty acids : monounsaturated fatty acids : $n-6$ PUFA in a ratio of 1:2:5 (w/w) (SO group). Mean daily food intake and weight gains were similar for animals of each diet group.

Control experiments were performed using rats fed with pelleted stock food. Where indicated, the animals were injected intraperitoneally with $1 \mathrm{mg}$ of dissolved warfarin, and blood was collected at 4,11 or 27 hours after injection.

\section{Blood sampling and blood cell characteristics}

The rats were fasted overnight, anaesthetised with diethyl ether, and subjected to abdominal aortic puncture. From 12 animals per diet group, $1 \mathrm{ml}$ of blood was collected into dry EDTA $(5 \mu \mathrm{mol})$, and $10.8 \mathrm{ml}$ of blood collected into $1.2 \mathrm{ml}$ of $80 \mathrm{mM}$ trisodium citrate. From the other rats, $2 \mathrm{ml}$ of blood was collected into trisodium citrate solution $(80 \mathrm{mM})$, and the remaining other $10 \mathrm{ml}$ into $2 \mathrm{ml}$ of citrate-citric acidglucose ( $80 \mathrm{mM}$ trisodium citrate, $52 \mathrm{mM}$ citric acid and $180 \mathrm{mM}$ glucose). EDTAanticoagulated blood was used to count blood cells and to determine mean cell volumes using a Technicon $\mathrm{H}-1$ analysing system (Bayer, Mijdrecht, The Netherlands).

To prepare standard plasma, blood from 10 rats, fed on pelleted stock diet, was collected into $80 \mathrm{mM}$ trisodium citrate, and then centrifuged firstly at $1200 \times \mathrm{g}$ for 15 minutes and subsequently at $18,000 \times \mathrm{g}$ for 5 minutes, after which the plateletfree plasma fractions were pooled.

\section{Preparation of platelet-rich plasma and washed platelets}

Blood collected on citrate was used to prepare platelet-rich plasma by centrifugation at $2800 \times \mathrm{g}$ for 10 seconds [25]. Platelet-free plasma was prepared by centrifugation of part of the platelet-rich plasma at $18,000 \times \mathrm{g}$ for 5 minutes. After dilution with platelet-free plasma to $210^{8}$ platelets $/ \mathrm{ml}$, the resulting platelet suspension was used for aggregation studies. Blood collected on citrate-citric acid-glucose was used to prepare washed platelets [25]. In this case, the platelets were finally suspended in Hepes buffer $\mathrm{pH} 7.4$, consisting of $136 \mathrm{mM} \mathrm{NaCl}, 5.6 \mathrm{mM}$ glucose, $5 \mathrm{mM}$ Hepes, 2.7 $\mathrm{mM} \mathrm{KCl}, 2 \mathrm{mM} \mathrm{MgCl}, 0.42 \mathrm{mM} \mathrm{NaH}_{2} \mathrm{PO}_{4}$ and $0.1 \%(\mathrm{w} / \mathrm{v})$ bovine serum albumin.

\section{Platelet activation and aggregation}

Platelet shape change and aggregation were measured with platelet-rich plasma $\left(2 \cdot 10^{8}\right.$ platelets $\left./ \mathrm{ml}\right)$ in an automated aggregometer under stirring at $37^{\circ} \mathrm{C}$ [21]. Coagulation was blocked by adding $1 \mu \mathrm{M}$ recombinant hirudin, after which $5 \mathrm{mM}$ $\mathrm{CaCl}_{2}$ was added to measure platelet activation under $\mathrm{Ca}^{2+}$-rich conditions. Aggregation of washed platelets was determined in a similar way, except that hirudin 
was absent and $\mathrm{CaCl}_{2}$ was added to a concentration of $1 \mathrm{mM}$. After 10 minutes of activation, samples were taken form the platelet suspensions and centrifuged at $18,000 \times \mathrm{g}$ for 5 minutes. The supernatants were collected for later determination of thromboxane $\mathrm{B}_{2}$. Aggregation rate (\%T/min), time of onset of aggregation (s), shape change $(\% \mathrm{~T})$ and maximal aggregation (\%T) were determined from the optical transmission curves using computer-assisted analyses.

For measurements of cytosolic $\left[\mathrm{Ca}^{2+}\right]_{\text {i, }}$ washed platelets suspended in Hepes buffer $\mathrm{pH} 7.4\left(5 \cdot 10^{8} / \mathrm{ml}\right)$ were incubated with fluorescent fura-2 acetoxy-methyl ester in the presence of pluronic F-127, as described [25]. After loading, the cells were resuspended at $1 \cdot 10^{8}$ platelets $/ \mathrm{ml}$ in the same buffer.

\section{Lipid analyses}

Total phospholipids were isolated from suspensions of washed platelets by chloroform-methanol extraction, as described elsewhere [26]. Concentrations of total cholesterol, of cholesterol in high-density lipoproteins and triglycerides were determined in diluted plasma samples with an automated Cobas-Bio analyser (Roche, Nutley, NJ).

\section{Fibrinolysis}

Blood collected on citrate was immediately centrifuged at $1200 \times \mathrm{g}$ for 15 minutes and, subsequently, at $18,000 \times \mathrm{g}$ for 5 minutes to obtain platelet-free plasma. This was frozen in liquid nitrogen and stored at $-80^{\circ} \mathrm{C}$. Plasminogen activator inhibitor and tissue type plasminogen activator were quantified, as described before for the rat fibrinolytic system [27].

\section{Coagulation parameters}

Activated partial thromboplastin time (APTT) and prothrombin time (PT) were determined in platelet-free plasma activated with kaolin/phospholipids and rat-brain thromboplastin, respectively, as described elsewhere [28]. Fibrinogen in plasma was determined according to Clauss [29]. Prothrombin was measured in plasma samples diluted 1:50-80 (v/v) with a buffer composed of $28.5 \mathrm{mM} \mathrm{Na-barbital} \mathrm{and} 126 \mathrm{mM}$ $\mathrm{NaCl}(\mathrm{pH} 7.35)$, using a coagulation assay with prothrombin-deficient plasma and thromborel S [30]. Factor VII was measured under similar conditions, however with factor VII-deficient plasma. Antithrombin III levels were determined on a Boehringer (Mannheim, Germany) coagulation apparatus with a test kit from Chromogenix (Mölndal, Sweden) following the manufacturer's instructions.

\section{Endogenous thrombin potential}

Formation and degradation of thrombin was measured in rat plasma, basically as described for the human plasma system [31,32], although several adjustments needed to be made. Briefly, citrated platelet-free plasma was diluted $4: 5(\mathrm{v} / \mathrm{v})$ with a 
buffer $\mathrm{pH} 7.35$, consisting of $50 \mathrm{mM}$ Tris- $-\mathrm{HCl}, 100 \mathrm{mM} \mathrm{NaCl}$ and $0.05 \%(w / v)$ bovine serum albumin. After adding $1 \mu \mathrm{M}$ of sonicated phospholipid vesicles (phosphatidyl choline : phosphatidyl serine, $80: 20, \mathrm{~mol} / \mathrm{mol}$ ), the mixture was equilibrated at $37^{\circ} \mathrm{C}$ and coagulation was started by adding $16.7 \mathrm{mM} \mathrm{CaCl}_{2}$ and recombinant human tissue factor diluted as to give a clotting time of 25 seconds. At fixed time intervals after start, $10 \mu \mathrm{l}$ aliquots were sampled into cuvettes containing $490 \mu \mathrm{l}$ of a preheated $\left(37^{\circ} \mathrm{C}\right)$ mixture of $100 \mathrm{mM} \mathrm{NaCl}, 50 \mathrm{mM}$ Tris- $\mathrm{HCl}(\mathrm{pH} 7.9), 20 \mathrm{mM}$ EDTA,

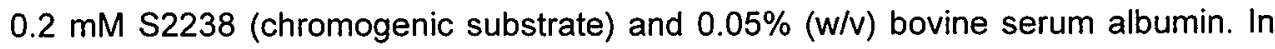
each cuvette, colour development was stopped after 2 minutes by adding $300 \mu \mathrm{l}$ of 1 $M$ citric acid. Precise sampling and stopping times was recorded by a personal computer connected to pushbutton-equipped pipettes. The absorption value of each cuvette was read at $405 \mathrm{~nm}$, the amidolytic activity was calculated and converted to the thrombin concentration of the coagulation mixture by reference to a calibration curve for human $\alpha$-thrombin. Fibrin clots were manually removed from the coagulation mixture immediately after their formation (about 45 seconds).

Plotting of the amidolytic activity of the samples as a function of time resulted in curves of thrombin formation and degradation. However, for the conversion of amidolytic activity to concentration of active thrombin (i.e. the thrombin not bound to protease inhibitors) a correction was made for the accumulation of thrombin that was capable to hydrolyse $\mathbf{S} 2238$ but inactive in coagulation, by using a numerical fitting procedure [33]. In rat plasma, unlike human plasma, this concerns mainly thrombin that is bound to $\alpha_{1}$-macroglobulin [34]. By definition, the endogenous thrombin potential (ETP) of coagulating plasma is the area under the reconstructed and corrected time-curve of thrombin formation and degradation [31]. The ETP determined in this way appeared to be valuable for detection of the hypocoagulable state of rat plasma (CHAPTER 4). Measured ETP values of plasma samples from dietmodified animals were corrected for a slight day-to-day variation by daily comparison with the ETP value of pooled plasma from rats on commercial stock food.

\section{Statistical analyses}

To evaluate the significance of differences between the various diet groups, a test of one-way analysis of variances (ANOVA) was applied using Statview 4.1 (Abdacus Concepts 1992-1994). When the ANOVA test showed statistical significance, a t-test was performed with adjustment of the $\alpha$-level with a factor of 0.2 according to the Bonferroni method for multiple comparisons, to determine which of the groups differed from the control group. Dose-dependency of the effects of increasing amounts of FO in the diet was disclosed by linear regression analysis according to Pearson [35]. 


\subsection{Results}

\section{Effects of fish oil and sunflower seed oil diets on blood cells}

To evaluate the long-term effects of dietary n-3 and n-6 PUFA on crucial haemostatic functions, Wistar rats were fed during 8-10 weeks with one out of six high-fat diets (TABLE 5.1): a control diet enriched in monounsaturated fatty acids (mainly oleate); a diet in which $2,4,8$ or $16 \%$ (w/w) of the fatty acids were replaced by n-3 PUFA (mainly eicosapentenoate and docosahexaenoate) originating from $\mathrm{FO}(2,4,8$ and $16 \%$ FO groups, respectively); and a diet containing $60 \%$ n-6 PUFA, mainly linoleate, derived from sunflower oil (SO group). All diets were low in arachidonate content $( \pm 0.5 \%)$. At the end of the feeding period, numbers of leukocytes, erythrocytes and platelets in blood were counted to evaluate possible dietary effects on blood cell formation or turnover. However, no diet-dependent effects were observed, except that mean platelet volume was decreased significantly and dose-dependently $(R=-$ $0.49, P=0.0008$ ) in rats from the FO groups. For the control group, this parameter amounted to $7.1 \pm 0.1 \mathrm{fl}$, while for $16 \%$ FO group it was $6.6 \pm 0.1 \mathrm{fl}$ (mean \pm sem, $n=8-9$, $P=0.01$ ).

Effects of diets on membrane composition and activation of platelets

Platelets from the diet-modified rats were analysed for their membrane fatty acid

TABLE 5.1 Global fatty acid composition of high-fat diets

(\% of total area under the curve of identified fatty acids)

\begin{tabular}{|c|c|c|c|c|c|c|}
\hline \multirow[b]{2}{*}{ Fatty acid } & \multicolumn{6}{|c|}{ Type of diet } \\
\hline & Control & $2 \% \mathrm{FO}$ & $4 \% \mathrm{FO}$ & $8 \% \mathrm{FO}$ & $16 \% \mathrm{FO}$ & so \\
\hline $16: 0 \quad 14.4$ & 14.1 & 13.8 & 13.2 & 11.9 & 6.3 & \\
\hline $18: 0 \quad 10.3$ & 10.1 & 9.9 & 9.4 & 8.5 & 5.1 & \\
\hline$\Sigma$ SAFA 33.9 & 33.3 & 32.4 & 31.0 & 28.0 & 13.0 & \\
\hline $18: 1 n-9$ & 45.8 & 45.3 & 44.0 & 42.2 & 38.1 & 24.9 \\
\hline$\Sigma M U F A$ & 49.7 & 49.0 & 47.9 & 46.0 & 41.8 & 25.9 \\
\hline $18: 2$ n-6 & 16.1 & 15.9 & 15.5 & 14.9 & 13.6 & 60.9 \\
\hline $20: 4 n-6$ & 0 & 0.1 & 0.1 & 0.2 & 0.5 & 0 \\
\hline$\Sigma n-6$ PUFA & 16.2 & 16.1 & 15.8 & 15.4 & 14.6 & 60.9 \\
\hline $20: 5 n-3$ & 0 & 0.5 & 1.3 & 2.7 & 5.5 & 0 \\
\hline $22: 6 n-3$ & 0 & 0.8 & 2.0 & 4.1 & 8.6 & 0 \\
\hline$\Sigma n-3$ PUFA & 0.1 & 1.5 & 3.7 & 7.5 & 15.5 & 0.1 \\
\hline
\end{tabular}

Weight percentages are given of major fatty acids in the diets. Abbreviations for diet groups: FO, fish oil; SO, sunflowers seed oil; SAFA, MUFA, PUFA stand for saturated, monounsaturated and polyunsaturated fatty acids, respectively. Individual fatty acids are indicated by number of carbon atoms, number of double bonds and site of the first double bond. 


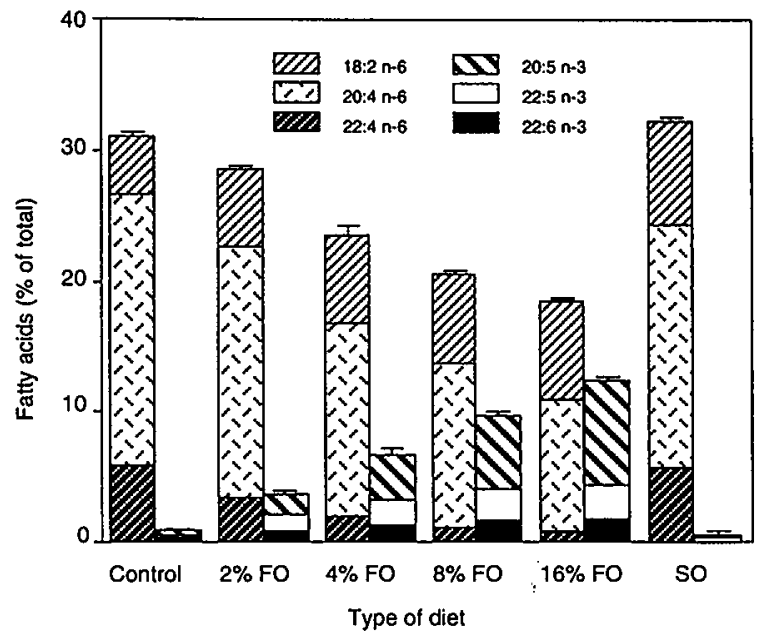

FIGURE 5.1 Global fatty acid composition of platelet phospholipids from the diet-modified rats. Given are the main forms of $n-6$ and $n-3$ PUFA recovered from extracted platelet phospholipids.

Abbreviations for diet groups and fatty acids are as in TABLE 5.1. Values are weight percentages of fatty acids (mean \pm sem, $n=9$ 12). Error bars are for the sum of the indicated fatty acids.

composition. As expected, increasing amounts of FO caused a gradual replacement of $20: 4 n-6$ by $n-3$ PUFA in the platelet phospholipids (FIG. 5.1). Notably, the levels of eicosapentaenoate $(20: 5 \quad n-3)$, docosapentaenoate $(22: 5 \quad n-3)$ and docosahexaenoate (22:6 n-3) were increased at the expense of arachidonate (20:4 $n-6)$ and adrenate $(22: 4 n-6)$. Platelets from the SO group differed from the control group only in slightly increased levels of linoleate $(18: 2 n-6)$ at the expense of arachidonate.

Platelet function was studied by measuring shape change and aggregation tendency in the presence of recalcified plasma with hirudin as anticoagulant, following stimulation with sub-maximal doses of ADP or collagen. Aggregation studies were also carried out with washed platelets (in the absence of plasma) upon stimulation with sub-maximal concentrations of thrombin or collagen. These agonists were chosen because, in suspensions of rat platelets, collagen acts predominantly through the generation of thromboxane $A_{2}$, while ADP and thrombin activate largely in a thromboxane-independent way [22]. No significant diet-induced effects on platelet aggregation were observed, irrespective of the activation conditions used, and regardless of whether the maximal aggregation (TABLE 5.2) or the onset or the rate of aggregation (data not shown) were compared. Similarly, no diet-induced influence on platelet shape change could be detected (TABLE 5.2). Experiments carried out with fura-2-loaded platelets resulted in the same thrombin- and collagenevoked increases in cytosolic [ $\mathrm{Ca}^{2 *}{ }_{i}$ for all diet groups, suggesting that the regulation of this important second messenger was not modified by the FO or SO diets (TABLE 5.2). 


\begin{tabular}{|c|c|c|c|c|c|c|c|}
\hline \multirow[b]{2}{*}{ Activation condition } & \multicolumn{6}{|l|}{ Type of diet } & \multirow{2}{*}{$\frac{\text { Statistics }}{P^{\star}}$} \\
\hline & Control & $2 \% \mathrm{FO}$ & $4 \% \mathrm{FO}$ & $8 \% \mathrm{FO}$ & $16 \% \mathrm{FO}$ & so & \\
\hline \multicolumn{8}{|c|}{ Recalcified platelet-rich plasma } \\
\hline \multicolumn{8}{|c|}{ ADP } \\
\hline shape change & $13.9 \pm 1.6$ & $13.3 \pm 2.6$ & $13.1 \pm 2.0$ & $12.2 \pm 1.0$ & $11.3 \pm 1.5$ & $10.8 \pm 1.6$ & $\mathrm{NS}^{\dagger}$ \\
\hline aggregation & $47.7 \pm 6.3$ & $51.8 \pm 10.4$ & $50.4 \pm 7.4$ & $45.9 \pm 4.6$ & $42.8 \pm 5.6$ & $43.5 \pm 7.1$ & NS \\
\hline \multicolumn{8}{|l|}{ Collagen } \\
\hline shape change & $16.3 \pm 2.8$ & $18.7 \pm 1.7$ & $17.8 \pm 1.6$ & $15.9 \pm 1.4$ & $13.6 \pm 6.1$ & $10.8 \pm 1.8$ & NS \\
\hline aggregation & $76.6 \pm 10.0$ & $088.8 \pm 4.8$ & $91.2 \pm 4.2$ & $80.4 \pm 4.3$ & $73.1 \pm 9.6$ & $75.2 \pm 10.5$ & NS \\
\hline \multicolumn{8}{|l|}{ Washed platelets } \\
\hline \multicolumn{8}{|l|}{ Thrombin } \\
\hline shape change & $8.7 \pm 1.2$ & $6.8 \pm 0.8$ & $9.8 \pm 1.3$ & $8.6 \pm 0.9$ & $11.0 \pm 0.7$ & $7.5 \pm 1.1$ & 0.07 \\
\hline aggregation & $48.5 \pm 5.7$ & $55.2 \pm 3.4$ & $59.6 \pm 7.2$ & $54.8 \pm 4.5$ & $64.4 \pm 4.2$ & $57.1 \pm 4.3$ & NS \\
\hline$\Delta\left[\mathrm{Ca}^{2+}\right]_{\mathrm{i}}$ & $830 \pm 122$ & $2 \quad$ ND & $850 \pm 129$ & $804 \pm 102$ & $2909 \pm 112$ & $852 \pm 66$ & NS \\
\hline \multicolumn{8}{|l|}{ Collagen } \\
\hline shape change & $7.5 \pm 1.2$ & ND & $6.8 \pm 1.3$ & $5.3 \pm 0.8$ & $9.0 \pm 1.0$ & $6.3 \pm 1.0$ & NS \\
\hline aggregation & $23.3 \pm 2.5$ & ND & $18.3 \pm 2.3$ & $20.8 \pm 4.1$ & $22.3 \pm 3.6$ & $26.1 \pm 3.1$ & NS \\
\hline$\Delta\left[\mathrm{Ca}^{2+}\right]_{\mathrm{i}}$ & $197 \pm 56$ & ND & $133 \pm 25$ & $172 \pm 38$ & $202 \pm 37$ & $148 \pm 24$ & NS \\
\hline
\end{tabular}

Platelet-rich plasma $\left(2 \cdot 10^{8}\right.$ platelets $\left./ \mathrm{ml}\right)$ was supplemented with $1 \mu \mathrm{M}$ hirudin and recalcified with $5 \mathrm{mM}$ $\mathrm{CaCl}_{2}$. Platelet activation was started by addition of $0.5 \mu \mathrm{M}$ ADP or $5 \mu \mathrm{g} / \mathrm{ml}$ collagen $(n=6-10)$. Washed platelets $\left(2 \cdot 10^{8} / \mathrm{ml}\right)$ were activated with $2 \mathrm{nM}$ thrombin $(n=11-14)$ or $5 \mu \mathrm{g} / \mathrm{ml}$ collagen $(n=6-8)$ in the presence of $1 \mathrm{mM} \mathrm{CaCl}_{2}$. Shape change and maximal aggregation of platelets were determined from changes in light transmission (\%T). Rises in $\left[\mathrm{Ca}^{2+}\right]_{i}(\mathrm{nM})$ were measured in fura-2-loaded platelets by ratio fluorometry. Values are means \pm sem. NS, not significant; ND, not determined. ANOVA.

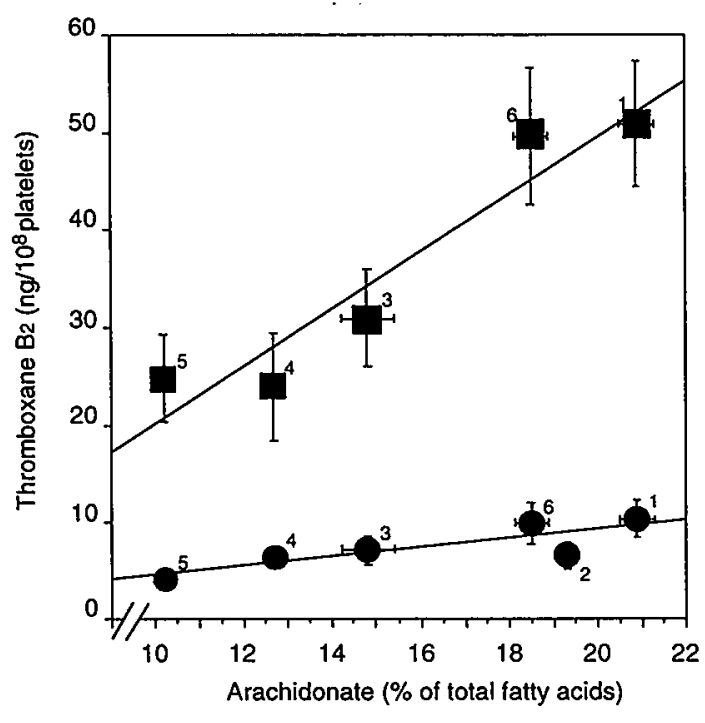

FIGURE 5.2 Effects of diets on platelet arachidonate content and thromboxane formation in activated platelets. Arachidonic acid was measured in total platelet phospholipids. Thromboxane $B_{2}$ was determined after activation of washed platelets with collagen (squares) or thrombin (dots) under the conditions indicated in TABLE 5.2. Numbers refer to the various diet groups: 1 , control group; $2-5,2 \%$, $4 \%, 8 \%$ and $16 \%$ FO groups, respectively; 6 , SO group. Data are mean values \pm sem $\quad(n=7-13)$. Calculated Pearson correlation coefficient $(R)$ and degree of significance $(P)$ are for collagenactivated platelets, $R=0.95$ and $P=0.043$, and for thrombin-activated platelets, $R=0.83$ and $P=0.013$. 
At the end of the aggregation measurements with washed platelets, samples were taken for determination of platelet-derived thromboxane $B_{2}$ (a stable breakdown product of thromboxane $A_{2}$ ). When comparing the diet groups, a good correlation was obtained between arachidonate level in the platelet phospholipids and thromboxane formation after activation with either thrombin or collagen (FIG. 5.2). Thus, as reported before [22], dietary effects on platelet arachidonate concentration were reflected by altered eicosanoid production without, however, leading to a measurably changed activation tendency of the cells.

\section{Effects of diets on blood lipids, fibrinolysis and global coagulation}

In plasma from rats fed with control diet, the triglyceride level was relatively high, $0.42 \mathrm{mM}$. This level gradually decreased with the dose of dietary FO to 0.12 $\mathrm{mM}$ for the $16 \%$ FO group (TABLE 5.3). Rats from the SO group had a similar, reduced level of plasma triglycerides. In contrast to the SO diet, the FO diets also caused a considerable reduction in plasma cholesterol concentration. Since most of the rat cholesterol was collected as high-density lipoproteins, this type of cholesterol was also decreased in the FO groups (TABLE 5.3).

Important positive and negative regulators of the fibrinolytic activity, both in rat and in man, are tissue-type plasminogen activator and plasminogen activator inhibitor-1, respectively [27]. These fibrinolytic parameters were altered by neither the SO nor the FO diets, when compared to the control diet (TABLE 5.4). In contrast, the plasma level of fibrinogen, i.e. the immediate precursor of fibrin, was slightly increased in the $4 \%$ and $8 \% \mathrm{FO}$ groups.

As a first estimate of the activities of the intrinsic and extrinsic coagulation pathways, plasma samples were used to measure global clotting times, i.e. the activated partial thromboplastin time (APTT) and the prothrombin time (PT). Both clotting times were similar for rats from the control and FO groups (TABLE 5.4). In contrast to what was previously found [20], the PT was somewhat prolonged in the

TABLE 5.3 Effects of diets on triglycerides and cholesterol levels in rat plasma

\begin{tabular}{|c|c|c|c|c|c|c|c|c|}
\hline \multirow{2}{*}{$\begin{array}{l}\text { Plasma } \\
\text { levels } \\
(\mathrm{mM})\end{array}$} & \multicolumn{6}{|c|}{ Type of diet } & \multicolumn{2}{|c|}{ Statistics } \\
\hline & Control & $2 \% \mathrm{FO}$ & $4 \% \mathrm{FO}$ & $8 \% \mathrm{FO}$ & $16 \% \mathrm{FO}$ & so & $P^{*}$ & $R^{\dagger}$ \\
\hline Triglycerides & $0.42 \pm 0.07$ & $0.44 \pm 0.10$ & $0.34 \pm 0.04$ & $0.16 \pm 0.03^{\ddagger}$ & $0.12 \pm 0.03^{\S}$ & $0.18 \pm 0.05^{ \pm}$ & 0.0004 & $4-0.54$ \\
\hline Total-C & $2.12 \pm 0.09$ & $1.78 \pm 0.10$ & $1.71 \pm 0.13^{\ddagger}$ & $1.18 \pm 0.06^{\pi}$ & $1.18 \pm 0.08^{\pi}$ & $2.05 \pm 0.08$ & $<0.0001$ & $1-0.70$ \\
\hline HDL-C & $1.75 \pm 0.08$ & $1.58 \pm 0.11$ & $1.46 \pm 0.13$ & $0.89 \pm 0.06^{\mathbb{R}}$ & $0.89 \pm 0.06^{\pi}$ & $1.83 \pm 0.07$ & $<0.0001$ & $1-0.70$ \\
\hline
\end{tabular}

Plasma levels were determined of triglycerides, total cholesterol (Total-C) and cholesterol in highdensity lipoproteins (HDL-C). Values are means \pm sem $(n=10)$. ANOVA; 'Pearson correlation coefficient; $P$-values of post-hoc t-test analyses compared to control group: ${ }^{\ddagger} P \leq 0.01,{ }^{5} P \leq 0.002$ and "P $\leq 0.0002$. 
TABLE 5.4 Effect of diets on fibrinolysis, fibrinogen and global coagulation

\begin{tabular}{|c|c|c|c|c|c|c|c|c|}
\hline \multirow[t]{2}{*}{ Variable } & \multicolumn{6}{|c|}{ Type of diet } & \multicolumn{2}{|c|}{ Statistics } \\
\hline & Control & $2 \% \mathrm{FO}$ & $4 \% \mathrm{FO}$ & $8 \% \mathrm{FO}$ & $16 \% \mathrm{FO}$ & so & $P^{*}$ & $R^{t}$ \\
\hline $\mathrm{t}-\mathrm{PA}(\mathrm{ng} / \mathrm{mL})$ & $2.29 \pm 0.10$ & $2.11 \pm 0.18$ & $2.31 \pm 0.20$ & $2.30 \pm 0.28$ & $2.72 \pm 0.23$ & $2.36 \pm 0.12$ & NS & ND \\
\hline PAl-1 (ng/mL) & $3.9 \pm 0.2$ & $4.0 \pm 0.3$ & $3.4 \pm 0.2$ & $3.4 \pm 0.3$ & $3.6 \pm 0.2$ & $3.8 \pm 0.3$ & NS & ND \\
\hline Fibr. (mg/mL) & $2.00 \pm 0.05$ & $2.12 \pm 0.02$ & $2.18 \pm 0.04^{\ddagger}$ & $2.31 \pm 0.05^{\S}$ & $1.89 \pm 0.05$ & $2.13 \pm 0.05$ & 0.0001 & -0.18 \\
\hline $\operatorname{APTT}(s)$ & $30.7 \pm 0.4$ & $29.4 \pm 0.3$ & $30.1 \pm 0.4$ & $30.4 \pm 0.4$ & $30.5 \pm 0.6$ & $30.7 \pm 0.3$ & NS & 0.08 \\
\hline PT (s) & $21.2 \pm 0.3$ & $21.3 \pm 0.2$ & $21.5 \pm 0.3$ & $21.2 \pm 0.2$ & $21.8 \pm 0.2$ & $23.4 \pm 0.4^{\S}$ & 0.0001 & 0.13 \\
\hline Prothr. (\%) & $94.3 \pm 8.7$ & $81.2 \pm 6.6$ & $77.4 \pm 8.8$ & $69.9 \pm 6.1$ & $63.1 \pm 5.2^{* \star}$ & $85.8 \pm 11.2$ & 0.063 & -0.41 \\
\hline
\end{tabular}

Levels of tissue-type plasminogen activator antigen (t-PA, $n=9-10)$, plasminogen activator inhibitor-1 (PAl-1, $n=9-10)$, fibrinogen (Fibr.) $(n=22-24)$ and prothrombin (Prothr.) (\% of standard rat plasma, $n=7-$ 12) were measured in plasma samples, as described in Materials and Methods. Standard coagulation times, activated partial thromboplastin time (APTT) and prothrombin time (PT), were measured in 20times diluted samples $(n=22-24)$. Values are means \pm sem. NS, not significant; ND, not determined. ANOVA; $P$-values of post-hoc t-test analyses compared to control group with ${ }^{\ddagger} P \leq 0.002,{ }^{5} P \leq 0.0002$, and ${ }^{* *} P=0.0079$, "Pearson correlation coefficient with ${ }^{*} P=0.006$ (comparing FO groups).

SO group. As a crucial component of both the intrinsic and extrinsic coagulation systems, prothrombin concentrations were measured. In spite of the similar values of APTT and PT, prothrombin appeared to decrease with the amount of n-3 PUFA in the FO diets in a dose-dependent way (Pearson correlation with $R=-0.41$ and $P=0.006$, TABLE 5.4). When comparing the various FO groups, the difference in prothrombin concentration between the control and the $16 \%$ FO group was of borderline significance (ANOVA with $P=0.063$ ). Prothrombin in the plasma from rats fed with SO was unchanged, when compared to the control plasma (TABLE 5.4).

Global clotting measurements such as the APTT and PT are by their way of operation rather insensitive in detecting hypocoagulable conditions and may, thus, be unable to detect small reductions in coagulation factors. We therefore searched for a more sensitive coagulation assay not suffering from this limitation. This was found in a test, which has recently been developed for the human coagulation system, determining the endogenous thrombin potential (ETP).

\section{Effects of diets on the ETP and vitamin K-dependent coagulation factors}

In human clotting plasma, the ETP determines the total enzymatic capacity of thrombin during the coagulation process as a whole, taking into account both the rise and subsequent fall of thrombin concentration. The result of the ETP assay is therefore sensitive for conditions influencing either prothrombin activation or thrombin inactivation $[31,36]$. Using rats that were fed on a commercial stock diet, initial experiments showed that the ETP is reduced in the presence of low doses of 


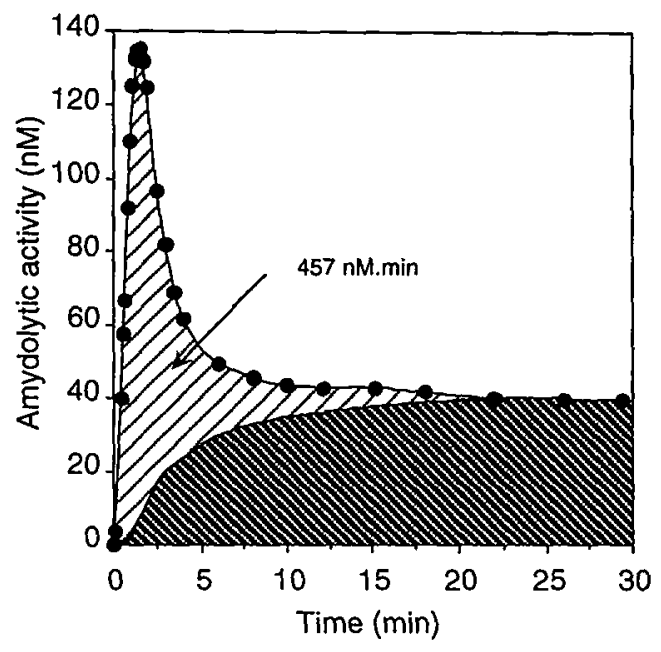

FIGURE 5.3 Kinetics of thrombin formation and inactivation in coagulating rat plasma. Changes in amidolytically active thrombin were determined in platelet-free plasma from rats kept on stock food. The plasma was activated with $\mathrm{Ca}^{2+}$. phospholipids and tissue factor (see Materials and Methods). Samples from the coagulation mixture were taken to measure amidolytic activity (dots). Dark hatched area indicates amidolysis due to the accumulation of $\alpha_{1}$-macroglobulin-bound thrombin. Light hatched area indicates activity of coagulation-promoting thrombin (ETP), amounting to $457 \mathrm{nM} \cdot \mathrm{min}$.

heparin and of decreased levels of vitamin K-dependent coagulation factors, indicating that this assay can detect a hypocoagulable state of rat plasma (CHAPTER 4). Triggering of the rat extrinsic coagulation system with phospholipids, $\mathrm{Ca}^{2+}$ and recombinant tissue factor resulted in a high amidolytic activity, reaching a maximum after about 2 minutes and then decreasing rapidly (FIG. 5.3). Conversion of amidolytic activity to concentration of free thrombin was carried out by correcting for the thrombin that is inactivated by binding to $\alpha_{1}$-macroglobulin, but still contributes to the chromogenic assay. Similarly as described for the human system [31], the stable end level of the amidolytic activity was used to determine the accumulation of such inactivated thrombin. After this correction, the area under the thrombin concentration-time curve reached a value of $445 \pm 38 \mathrm{nM}$ min (mean \pm sem, $n=4$ ) which, by definition, is the ETP of the activated plasma (FIG. 5.3). Plasma activation with thromboplastin prepared from rat brain resulted in a similar ETP value of $434 \pm 21$ $n M \min (n=5)$. Since these preparations of thromboplastin appeared to be rather unstable, however, these were not used for further experiments.

Application of this assay to plasma from rats fed with n-3 or n-6 PUFA gave consistent, diet-induced effects. For rats fed with at least $4 \%$ FO (2.5-en\%), the ETP of tissue-factor activated plasma was about $22 \%$ lower than for rats from the control group (FIG. 5.4). In contrast, feeding the rats with SO did not significantly influence the ETP. Using a limited number of remaining plasma samples, we investigated whether the relatively low ETP in the FO groups was a consequence of either decreased thrombin formation or increased thrombin inactivation. In plasma of rats from the control group and the $8 \%$ and $16 \%$ FO groups, we thus measured the levels of antithrombin III (a major thrombin inactivator) and factor VII (rate limiting in extrinsic coagulation). When compared to the control group, the antithrombin III concentration remained $99 \pm 3.0 \%$ and $100 \pm 4.6 \%$ (mean \pm sem, $n=7-11$ ) in the $8 \%$ and 

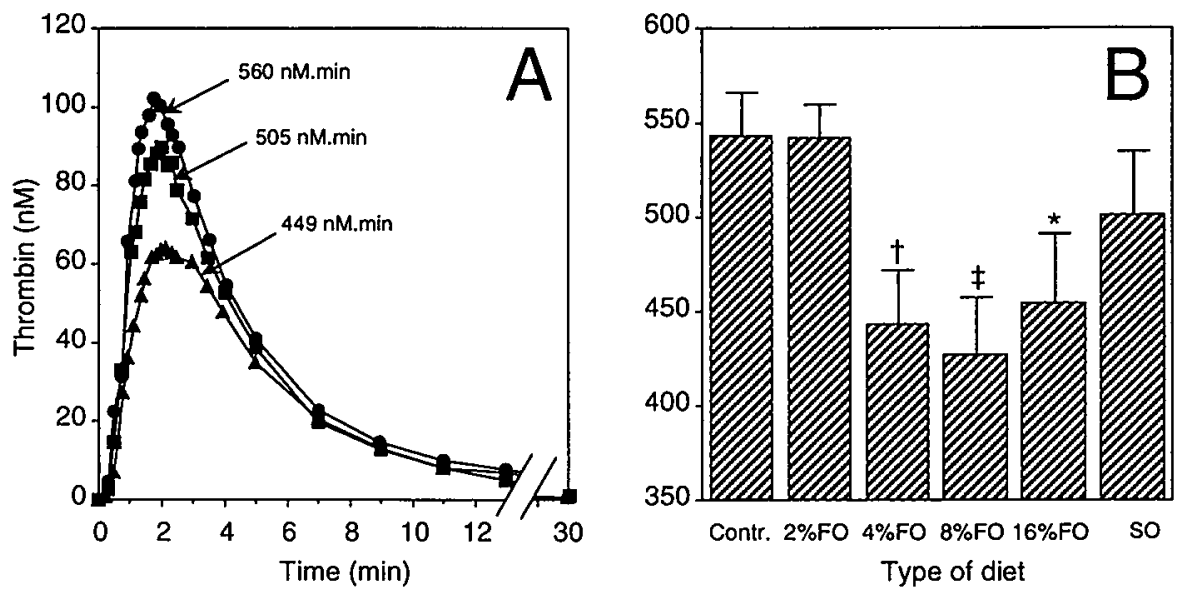

FIGURE 5.4 Effects of FO and SO diets on endogenous thrombin potential (ETP). Plasma from dietmodified rats was activated with $\mathrm{Ca}^{2+}$, phospholipids and tissue factor. (A) Curves of thrombin formation and inactivation were determined and corrected for $\alpha_{1}$-macroglobulin-bound thrombin (see FIG. 5.3). Shown are representative curves obtained with plasma from rats fed with control diet ( $)$, $8 \%$ FO diet (A) or SO diet (D). (B) Bars represent ETP values calculated from these curves per diet group (mean \pm sem, $n=7-9$ ). Statistics: ANOVA with $P=0.016$; $t$-test analysis with $P=0.029,{ }^{t} P=0.013$ and $\ddagger P=0.005$ compared to the control group.

$16 \%$ FO groups, respectively. On the other hand, factor VII was significantly reduced in the FO groups to $74 \pm 9.0 \%$ and $74 \pm 8.7 \%$, respectively (mean \pm sem, $n=8-10$, $P<0.05)$.

Since the vitamin K-dependent coagulation factors, prothrombin and VII, were both decreased in the FO-fed animals, it was of interest to know which of these changes can explain the lowering effect of FO diet on the coagulation potency (ETP). To investigate this, rats maintained on commercial stock food were treated with the vitamin $\mathrm{K}$ antagonist, warfarin, during a variable time period of 4-27 hours. Because the half-life time of factor VII in rat is much shorter than that of prothrombin, i.e. 2.6 versus 9.0 hours [37], this resulted in plasmas with reduced prothrombin and even more severely decreased factor VII concentrations. Adequate combinations of these plasma preparations resulted in mixtures that were variable in factor VII or prothrombin level, while the other factor was kept constant. Plasma mixtures in which the prothrombin concentration was reduced to about $55 \%$ gave a proportional decrease in tissue-factor induced ETP, independently of whether factor VII was decreased to $25 \%$ or $51 \%$ of its original concentration (FIG. 5.5A). Similarly, in plasma mixtures where the prothrombin level was reduced to about $35 \%$, the EPT was reduced correspondingly, irrespective of a decrease in factor VII concentration to $43 \%$ or $8 \%$ of its original value (FIG. $5.5 \mathrm{~B}$ ). The main effect of a low factor VII level here was an increased delay in the thrombin formation. 


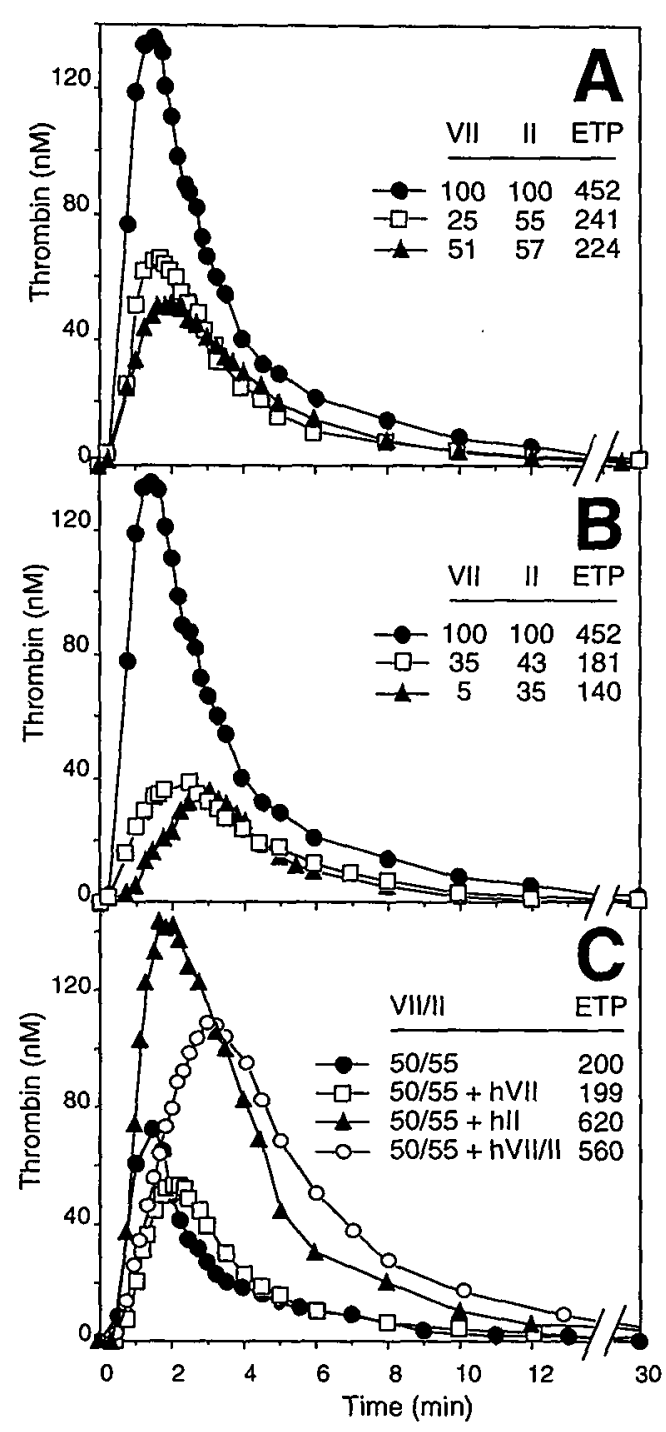

FIGURE 5.5 Effects of prothrombin and factor VII on thrombin formation and decay in rat plasma. Rats on stock food were treated with warfarin during 4. 11 or 27 hours or remained untreated. The warfarin treatment reduced the plasma levels of prothrombin and factor VII to 55 and $25 \%$ (4 hours), 35 and $5 \%$ ( 11 hours) or 15 and $2 \%$ ( 27 hours) of the levels in untreated rats, respectively. Plasma samples from these rats were mixed in various ways, and then activated with $\mathrm{Ca}^{2+}$, phospholipids and tissue factor to determine the ETP. For each curve, final levels of factor VII and prothrombin (factor II) are indicated (plasma from untreated rats taken as $100 \%$ ), as well as the measured ETP values (in nM.min). (A) Thrombin generation curves of: plasma from untreated rats (๑), plasma from 4 hour-treated rats $(\square)$, plasma mixture $(1: 1, v / v)$ of untreated and 27 hourtreated rats (A). (B) Thrombin generation curves of: plasma from untreated rats (0), plasma mixture (1:2) of untreated and 27 hour-treated rats (Ф), plasma from 11 hour-treated rats (A). (C) Purified human prothrombin $(1.25 \mu \mathrm{M})$ and/or human factor VII $(0.05 \mu \mathrm{M})$ was added to a plasma mixture (1:1) of untreated and 27 hour-treated rats, after which thrombin generation was essayed. Variables are no addition (๑), addition of factor VII (O), prothrombin (A), or prothrombin + factor VII (O). Data are representatives of $2-4$ independent experiments.

To confirm that the ETP is more determined by the prothrombin than the factor VII level, we measured the effects of addition of purified prothrombin and factor VII on the coagulation potential of a plasma mixture with $50 \%$-reduced concentrations of these factors. Since pure rat coagulation factors could not be obtained in sufficiently high amounts, these experiments were performed with human factors. Prothrombin and factor VII were added in concentrations as to give normal clotting times (using the concerning factor-deficient plasma). As shown in F/G. $5.5 \mathrm{C}$, supplementation of purified factor VII had no effect on the tissue-factor induced ETP. 
while addition of prothrombin, either alone or in combination with factor VII, had a strongly increasing effect on the ETP. Similar results were obtained with plasma preparations that contained normal levels of these factors or were more severely depleted in prothrombin/factor VII concentrations (data not shown).

\subsection{Discussion}

Dietary FO and SO reduce plasma lipids but have no more than marginal effects on platelet activation or fibrinolysis

In the present study with Wistar rats, we determined the effects on haemostatic functions of high-fat diets containing various amounts of n-3 PUFA (derived from FO) or $n-6$ PUFA (originating from SO) in comparison to a control diet containing $50 \%$ monounsaturated fatty acids. After a dietary period of 8-10 weeks, the FO-derived fatty acids had been accumulated well in the platelet phospholipids at the expense of mainly arachidonic acid. This replacement was already detectable at the lowest dose of $2 \% \mathrm{FO}$ and increased with the FO content in the diet (FIG. 5.1). The production of thromboxane by activated platelets decreased proportionally with the reduction in platelet arachidonate level (FIG. 5.2), which confirms our earlier conclusion that the substrate level of arachidonate esterified in the phospholipids is a major determinant of the rate of eicosanoid production $[9,21]$. However, in spite of the greatly reduced capacity of thromboxane production by platelets from the higher FO groups, no dietary effects could be measured on platelet activation with either washed platelets or platelets in autologous plasma, using a variety of agonists (TABLE 5.2). The SO diet was of minor influence on platelet fatty acid composition, thromboxane production and activation tendency, when compared to the control group. Taken together, these no more than marginal effects of dietary n-3 and n-6 PUFA on platelet activation tendency confirm the findings of earlier feeding studies with rats [21-24]. It should be noted here that the haemostatic role of the arachidonic acid pathway in rat is less well defined and may be less important than in man. For instance, whereas in rat thrombosis models aspirin appears to have little effect on arterial thrombosis, inhibitors of thromboxane $A_{2}$ synthase $[38,39]$ and thromboxane receptor antagonists [40] both reduce the formation of occlusive thrombi.

Both the FO and SO diets led to reduced plasma lipid levels, albeit in different ways. Triglycerides as well as cholesterol tended to decrease with increasing amounts of dietary FO, while only the triglyceride component was lowered in the SO group (TABLE 5.3). Similar results have been obtained by other investigators $[18,19]$, which indicated to us that the administered diets caused the expected effects in the animals. Not much is known of FO-induced effects on fibrinolysis in rats. In the present study, we measured two rate-determining parameters of fibrin degradation, 
i.e. the levels of plasminogen activator inhibitor-1 and tissue-type plasminogen activator. Both remained unchanged after the FO or SO diets, which suggests that fibrinolysis is not a major target of this type of dietary intervention. On the other hand, plasma fibrinogen was increased in the $4 \%$ and $8 \%$ FO groups. Although such an n-3 PUFA-induced increase has also been found by others $[6,13]$, it should be noted that this is not a consistent finding $[8,12]$.

Dietary FO but not SO evokes a hypocoagulable state in rat plasma

Published investigations on dietary fat-induced effects on coagulation factors or coagulation potency in rat are scarce, making it difficult to compare our data with the literature. We found a consistent, dose-dependent reduction in prothrombin level of animals fed with FO-containing diets (TABLE 5.4). In addition, we detected a reduced level of factor VII in the plasma from rats fed with $8 \%$ or $16 \%$ FO. This apparently is of significance, since both clotting factors are of crucial importance in haemostasis: factor VII and its activated form as coagulation initiators, and prothrombin as the immediate precursor of thrombin, which amplifies the coagulation cascade and causes the formation of fibrin clots. Intriguingly, this reduction in coagulation factors was not reflected by an increase in (standard) coagulation times, i.e. in neither the PT nor the APTT were changed, although the APTT is moderately sensitive for hypocoagulable states such as in haemophilia or heparin treatment. The reduction in prothrombin level stimulated us to make use of an assay with much higher sensitivity for hypocoagulable conditions, i.e. the endogenous thrombin potential (ETP), determining the thrombin concentration-time integral of coagulating plasma. The result of this assay is an estimation of the total enzymatic capacity of thrombin during the time period of the clotting process and, as such, a linear parameter of the coagulation potential of plasma [36]. Application of this assay to plasma from Wistar rats on stock food showed a high sensitivity to conditions interfering with either thrombin formation (reduction of vitamin K-dependent coagulation factors) or thrombin inactivation (heparin) (CHAPTER 4).

The tissue-factor induced ETP of plasma from the rats receiving $>2 \%$ FO was decreased in comparison to the control group (FIG. 5.4). Since the level of antithrombin III (an important vitamin K-independent anticoagulant) remained unchanged, we can conclude that dietary FO leads to a hypocoagulable state of rat plasma, by influencing the (vitamin K-dependent) thrombin formation rather than thrombin inactivation. To demonstrate which of the changes in clotting factors were responsible for the hypocoagulant effect, control studies were performed with plasma from rats that were treated with warfarin during various times. Due to the quite different half-life times of the various vitamin $\mathrm{K}$-dependent coagulation factors, i.e. prothrombin $>$ factors $I X$ and $X>$ factor VII, these resulted in plasma preparations that were most depleted in factor VII and much less depleted in prothrombin. By combining these plasmas, mixtures could be prepared containing variable amounts 
of either factor VII or prothrombin (and intermediate amounts of factors $I X$ and $X$ ). Determination of the ETP in these plasmas strongly suggested that the prothrombin level is the major determinant of the coagulation efficacy (FIG. 5.5). Whereas the factor VII level may well influence the initial rate of thrombin formation (FIG. 5.5B), it apparently is of less importance for the coagulation potency. Essentially the same conclusion has been drawn in earlier studies with human plasma, i.e. that primarily the variation in prothrombin level determines the thrombin generation and, hence, the antithrombotic effect of anticoagulant therapy [41].

It is tempting to speculate on the mechanism whereby vitamin K-dependent coagulation factors are reduced after FO diet. Vitamin $K$ is a highly lipophilic molecule, which needs to be transported through the blood in a lipid-bound way. It is possible that the strong reduction in lipoprotein-bound cholesterol and triglycerides, also observed after feeding FO (TABLE 5.3), limits the transport of vitamin $K$ and thereby the synthesis of vitamin K-dependent clotting factors in the liver. Recent studies have indeed pointed to a positive correlation between levels of blood lipids and factor VII $[15,42-44]$. Typically, in our study with rats, the SO diet was essentially without hypocoagulant effect while causing a reduction in only triglycerides and not in cholesterol, which would imply that cholesterol plays a more important role in vitamin $\mathrm{K}$ delivery than triglycerides.

There is little literature concerning effects of n-3 PUFA-supplemented diets on coagulation in man, putatively because many investigators have used global assays (APTT or PT) that are rather insensitive in detecting hypocoagulable conditions. Of the individual coagulation factors, mainly factor VII has been studied, since it is considered a possible risk factor of cardiovascular disease. In a limited number of human nutrition studies, small decreasing effects FO on factor VII activity have indeed been reported $[13,15,17]$. However, none of these studies included sensitive coagulation measurements, e.g. as determination of the coagulation potential. It will therefore be important to see whether dietary FO (n-3 PUFA) causes similar hypocoagulant effects in man as reported here in rats.

Summarising, we present evidence that n-3 PUFA, when administered to rats as FO mixtures, cause decreased levels of plasma lipids and have no major effects on platelet activation or fibrinolysis. On the other hand, they appear to lead to a hypocoagulable state, because of a reducing effect on the levels of vitamin Kdependent coagulation factors. Such an hypocoagulant effect is not seen with dietary n-6 PUFA. 


\subsection{Acknowledgements}

We thank N. Bitsch, A. Muller, R. van Oerle and J. Wierts for analytical assistance and animal husbandry, and $A$. Kester for statistical evaluations. Hoffmann-La Roche (Basel, Switzerland) supported this study.

\subsection{References}

1. Bang HO, Dyerberg J. Plasma lipids and lipoproteins in Greenland west coast Eskimos. Acta Med Scand. 1972;192:85-94.

2. Bang HO, Dyerberg J. Lipid metabolism and ischemic heart disease in Greenland Eskimos. In; Draper HH (Ed.) Advantages in Nutritional Research. Plenum Press, New York, NY, 1980, p. 1-22.

3. Goto $\mathrm{Y}$, Tamachi H, Moriguchi EM. Eicosapentaenoic acid and atherosclerosis. Prostaglandins Leucot Essent Fatty Acids. 1993;48:337-342.

4. Chin JPF. Marine oils and cardiovascular reactivity. Prostaglandins Leucot Essent Fatty Acids. 1994;50:211-222.

5. Needleman P, Raz A, Minkes MS, Ferrendelli JA, Sprecher H. Triene prostaglandins: prostacyclin and thromboxane biogenesis and unique biological properties. Proc Natl Acad Sci USA. 1979;76:944948.

6. Dyerberg J, Bang HO. Haemostatic function and platelet polyunsaturated fatty acids in Eskimos. Lancet. 1979;ii:433-435.

7. Herold PM, Kinsella JE. Fish oil consumption and decreased risk of cardiovascular disease: a comparison of findings from animal and human feeding trials. Am J Clin Nutr. 1986;43:566598.

8. Hornstra G. The significance of fish and fish-oil enriched food for prevention and therapy of ischaemic cardiovascular disease. In: Vergroesen AJ, Crawford MA (Eds). The Role of Fats in Human Nutrition. New York: Academic Press, 1989, p. 151-235.

9. Heemskerk JWM, Vossen RCRM, van Dam-Mieras MCE. Polyunsaturated fatty acids and function of platelets and endothelial cells. Curr Opin Lipidol. 1996;7:24-29.

10. Sri Kantha S. Dietary effects of fish oils on human health: a review of recent studies. Yale $J$ Biol Medic. 1987;60:37-44.

11. Leaf A, Weber PC. Cardiovascular effects of n-3 fatty acids. N Engl J Med. 1988;318:549-557.

12. Malle $E$, Kostner $G M$. Effects of fish oils on lipid variables and platelet function indices. Prostaglandins Leukot Essent Fatty Acids. 1993;49:645-663.

13. Lox CD. The effects of dietary marine fish oils (omega-3 fatty acids) on coagulation profiles in men. Gen Pharmac. 1990;21:241-246.

14. Shahar E, Folsom AR, Wu KK, Dennis BH, Shimakawa T, Conlan MG, Davis CE, Williams OD. Association of fish intake and dietary $n-3$ polyunsaturated fatty acids with a hypocoagulable profile. Arterioscler Thromb. 1993;13:1205-1212.

15. Mennen LI, Schouten EG, Grobbee DE, Kluft C. Coagulation factor VII, dietary fat and blood lipids: a review. Thromb Haemost. 1996;76:492-499.

16. Muller AD, van Houwelingen AC, van Dam-Mieras MCE, Bas BM, Hornstra G. Effect of a moderate fish intake on haemostatic parameters in healthy males. Thromb Haemost. 1989;61:468-473.

17. Hayashi $K$, Ohtani $H$, Kurushima $H$, Nomura SI, Koide $K$, Kunita $T$, Tanaka $K$, Yasunobu $Y$, Kambe $M$, Kajiyama $G$. Decreases in plasma lipid content and thrombotic activity by ethyl eicosapentate purified from fish oils. Curr Ther Res. 1995;56:24-31. 
18. McIntosh GH, McLennan PL, Lawson CA, Bulman FH, Charnock JS. The influence of dietary fats on plasma lipids, blood pressure and coagulation indices in the rat. Atherosclerosis. 1985;55:125-134.

19. Smit MJ, Temmerman AM, Wolters $H$, Kuipers $F$, Beynen AC, Vonk RJ. Dietary fish oilinduced changes in intrahepatic cholesterol transport and bile acid synthesis in rats. $J$ Clin Invest. 1991;88:943-951.

20. Hornstra G. Dietary Fats, Prostanoids and Arterial Thrombosis. The Hague, The Netherlands: Nijhoff Publ., 1982.

21. Heemskerk JWM, Feijge MAH, Kester A, Hornstra G. Dietary fat modifies thromboxane $A_{2}-$ induced stimulation of rat platelets. Biochem J. 1991;278: 399-404.

22. Heemskerk JWM, Feijge MAH, Simonis MAG, Hornstra G. Effects of dietary fatty acids on signal transduction and membrane cholesterol content in rat platelets. Biochim Biophys Acta. 1995;1255:87-97.

23. Winocour PD, Kinlough-Rathbone RL, Morazain R, Mustard JF. The effect of dietary saturated fat and cholesterol on platelet function, platelet survival and response to continuous aortic injury in rats. Atherosclerosis. 1987;65:37-50.

24. Andriamampandry MD, Leray C, Gutbier G, Freund M, Cassel D, Cazenave JP, Gachet C. Diets rich in saturated $n-9$ and $n-3$ fatty acids differentially affect the fatty acid composition of phospholipids and function of rat platelets. Platelets. 1996;7:269-276.

25. Heemskerk JWM, Feijge MAH, Sage SO, Walter $U$. Indirect regulation of $\mathrm{Ca}^{2+}$ entry by cAMP. dependent and CGMP-dependent protein kinases and phospholipase $\mathrm{C}$ in rat platelets. Eur $\mathrm{J}$ Biochem. 1994;223:543-551.

26. Engels W, van Haaster CMCJ, Lemmens PJMR, van der Vusse GJ, Hornstra G. Dietary modulation of fatty acid composition of mast cell phospholipids does not affect histamine release induced by compound 48/80. Inflamm Res. 1997;46:185-190.

27. Emeis JJ, Hoekzema R, Vos de AF. Inhibiting interleukin-1 and tumor necrosis factor- $\alpha$ does not reduce induction of plasminogen activator inhibitor type-1 by endotoxin in rats in vivo. Blood. 1995;85:115-20.

28. Van Dam-Mieras MCE, Muller AD, Hemker HC. Proenzymes, enzymes, inhibitors, cofactors. In: Bergmeyer HU, Bergmeyer J, Grass' M (Eds.) Methods of Enzymatic Analysis, Vol V. Weinheim, Germany: VCH Publ., 1988:352-365.

29. Clauss A. Gerinnungsphysiologische Schnellmethode zur Bestimmung des Fibrinogens. Acta Haemat. 1957:17:237-246.

30. Tervahauta $M$, Pekkanen J, Kivinen $P$, Stengard J, Jauhiainen M, Ehnholm $C$, Nissinen A. Prevalence of coronary heart disease and associated risk factors among elderly Finnish men in the seven countries study. Atherosclerosis. 1993;104:47-59.

31. Béguin S, Wielders S, Lormeau JC, Hemker HC. The mode of action of CY216 and CY222 in plasma. Thromb Haemost. 1992;67:33-41.

32. Hemker $\mathrm{HC}$, Wielders $\mathrm{S}, \mathrm{Kessels} \mathrm{H}$, Béguin $\mathrm{S}$. Continuous registration of thrombin generation in plasma: its use for the determination of the thrombin potential. Thromb Haemost. 1993;70:33-41.

33. Hemker HC, Willems GM, Béguin S. A computer assisted method to obtain the prothrombin activation velocity in whole plasma independent of thrombin decay processes. Thromb Haemost. 1986;56:9-17.

34. Gauthier $F$, Genell $S$, Mouray $H_{1}$ Ohlsson K. Interactions in vitro and in vivo between rat serum protease inhibitors and anodal and cathodal rat trypsin and chemotrypsin. Biochim Biophys Acta. 1979;566:200-210.

35. Glantz SA. Primer of statistics. New York: McGraw-Hill Book Company; 1987.

36. Hemker $\mathrm{HC}$, Béguin $\mathrm{S}$. Thrombin generation in plasma: its assessment via the endogenous thrombin potential. Thromb Haemost. 1995;74:134-138.

37. Vainieri $\mathrm{H}$, Wingard LJ. Effect of warfarin on the kinetics of the vitamin K-dependent clotting factors in rats. J Pharmacol Exp Ther. 1977;201:507-517.

38. Imura $Y$, Kiyota $Y$, Nagai $Y$, Nishikawa $K$, Terashita Z. Beneficial effects of CV-4151 (isbogrel), a thromboxane $A_{2}$ synthase inhibitor, in a rat middle cerebral artery thrombosis model. Thromb Res. 1995;79:95-107.

39. Bernat A, Mares AM, Defreyn G, Maffrand JP, Herbert JM. Effect of various antiplatelet agents on acute arterial thrombosis in the rat. Thromb Haemost. 1993;70:812-816. 
40. Schumacher WA, Steinbacher TE, Heran CL, Megill JR, Durham SK. Effects of antithrombotic drugs in a rat model of aspirin-insensitive arterial thrombosis. Thromb Haemost. 1993;69:509514.

41. Xi M, Béguin S, Hemker HC. The relative importance of the factors II, VII, IX and X for the prothrombinase activity in plasma of orally anticoagulted platelets. Thromb Haemost. 1989;62:788-791.

42. Miller GJ, Martin JC, Mitropoulos KA, Reeves BEA, Thompson RL, Meade TW, Cooper JA, Cruickshank JK. Plasma factor VII is activated by postprandial triglyceridaemia, irrespective of dietary fat composition. Atherosclerosis. 1991;86:163-171.

43. Connelly JB, Roderick PJ, Cooper JA, Meade TW, Miller GJ. Positive association between self-reported fatty food consumption and factor VII coagulant activity, a risk factor for coronary heart disease, in 4246 middle-aged men. Thromb Haemost. 1993;70:250-252.

44. Hoffman CJ, Lawson WE, Miller RH, Hultin MB. Correlation of vitamin Kdependent clotting factors with cholesterol and triglycerides in healthy young adults. Arterioscler Thromb. 1994;14:1737-1740. 


\section{Vitamin K-dependent and vitamin K- independent hypocoagulant effects of dietary fish oil in rats}

Cécile M. A. Nieuwenhuys ${ }^{1}$, Marion A. H. Feijge ${ }^{2}$, Cees Vermeer ${ }^{2}$, Adje H. H. M. Hennissen ${ }^{1}$, Suzette Béguin ${ }^{2}$ and Johan W. M. Heemskerk ${ }^{1,2}$

Departments of Human Biology ${ }^{1}$ and Biochemistry ${ }^{2}$, Maastricht University, P. O. Box 616, 6200 MD Maastricht, The Netherlands. 


\subsection{Abstract}

In rats, dietary fish oil causes a plasma triglyceride-lowering as well as hypocoagulant effect. The latter is apparent from reduced levels of vitamin Kdependent coagulation factors and a decreased thrombin-forming potential of the coagulating plasma. Here we describe that intervention with low levels of $n-3$ polyunsaturated fatty acids (about 2.5-energy\%, either from purified eicosapentaenoate or docosahexaenoate or from a fish oil preparation) resulted in no more than a small reduction in coagulation factors, when supplied as part of a highfat diet relatively rich in vitamin $\mathrm{K}$. Plasma triglycerides also remained unchanged. On the other hand, when feeding rats with low-fat or high-fat diets restricted in vitamin, intervention with 3-energy $\%$ of $n-3$ polyunsaturated fatty acids (fish oil) caused only a lowering in triglycerides in combination with high-fat. Fish oil however caused reduction in coagulation potential and levels in vitamin $\mathrm{K}$-dependent coagulation factors (prothrombin and factor VII) that were most prominent with the low-fat diet. This difference was reflected in the vitamin $K$ levels in the liver of the animals. In addition, regardless of the fat content the vitamin $\mathrm{K}$-independent coagulation factor $\mathrm{V}$ was decreased in the fish-oil groups. Taken together, these results indicate that, in the rat, the hypocoagulant effect of a low dose of n-3 polyunsaturated fatty acids is most apparent at low intakes of both vitamin $\mathrm{K}$ and fat, is not linked to the triglyceride plasma level, but involves modulation of both vitamin $\mathrm{K}$ - dependent and -independent coagulation factors.

\subsection{Introduction}

Both epidemiological and intervention studies indicate that a moderate intake of fish or fish oil decreases the risk of cardiovascular disease [1-3]. Fish oil consumption is thus considered to be an environmental factor that may contribute to the prevention of arterial thrombosis. This supposed antithrombotic effect of fish oil is generally ascribed to its high content of $n-3$ polyunsaturated fatty acids (PUFAs), i.e. mainly eicosapentaenoic and docosahexaenoic acid. That dietary n-3 PUFAs have a healthpromoting effect also appears from the observation that they cause a moderately prolongation in bleeding time [4]. Investigations as to explain these fish-oil effects have concentrated on monitoring the influence of $n-3$ PUFAs on plasma lipids $[4,5]$, platelet function $[1,4,6]$ and activity of the fibrinolytic system $[1,7]$. Whereas there is little uncertainty on the lipid-lowering effects of this diet type, the influence of platelet and fibrinolysis activity, if observed at all, is usually small. 
Cross-sectional studies indicate that, en gros, the levels of circulating triglycerides positively associate with the fasting and the postprandial coagulant activity of factor VII (which is an established risk factor for thrombosis) [8]. Furthermore, in patients with hyperlipidemia, positive relations are observed between plasma lipids (particularly triglycerides) and the vitamin K-dependent procoagulants (factors II, VII, IX and X) [9-12]. This leads to the idea that the levels of coagulation factors are somehow linked to the plasma lipid state, which is consistent with the reported binding of vitamin K-dependent factors to triglyceride-rich lipoproteins both under in vitro and in vivo conditions $[13,14]$. These factor concentrations ultimately depend on the vitamin $\mathrm{K}$ (mainly vitamin $\mathrm{K}_{1}$ and $\mathrm{K}_{2}$ ) intake and its content in the diet. Since triglyceride-rich lipoproteins are the main carriers of $K$ vitamins in plasma $[15,16]$, it is likely that factors that influence the metabolism of triglyceride-rich lipoproteins also affect the transport and tissue activity of vitamin $K$. Together, this raises the possibility that the lipid-lowering effect of fish oil affects the delivery of vitamin $\mathrm{K}$ to the liver and, thereby, reduces the synthesis of active vitamin $\mathrm{K}$ dependent coagulation proteins [17].

The literature provides limited studies to combined effects of fish oil on plasma triglycerides and on coagulation profile [8]. A few human studies report on a reduction in coagulation factors, particularly factor VII, as a result of the daily intake of fish oil [18-20]. However, functional consequences on the coagulation activity were not detected, probably because the overall coagulation assays used are rather insensitive for hypo-coagulant conditions.

In vivo models with rats have shown that the intake of dietary fish oil or purified eicosapentaenoate or docosahexaenoate reduce the tendency of arterial thrombosis in these animals [21-23]. Using sensitive coagulation assays, we have recently been able to demonstrate that the feeding with n-3 PUFAs (dose-dependently) results in a reduced coagulation activity, due to a decreased rate of thrombin formation accompanied by a lowering in levels of the vitamin K-dependent coagulation factors II (prothrombin) and VII [17]. This hypo-coagulant effect was accompanied by lower plasma lipid levels, whereas fibrinolysis and platelet activation remained unchanged. Similar indications for lower coagulation and lipid profiles in rats fed with high doses of $n-3$ PUFAs have been reported by others $[24,25]$. In rats the intake of vitamin $K$ and thus the coagulation process can easily be changed by dietary means $[26,27]$, the rat seems to provide a useful animal model to study the influence of fish oil on vitamin $\mathrm{K}$-dependent coagulation.

Knowing that in humans the intake of n-3 PUFAs is usually rather low, we investigated, in rat, the effects of reduced amounts of these fatty acids on the coagulation system and the lipid profile. Because of the possibly involvement of vitamin $\mathrm{K}$ in the hypo-coagulant effect, we performed diet studies at both high and relatively low amounts of vitamin $\mathrm{K}$. First, rats were fed with diets rich in vitamin $\mathrm{K}$ and containing different forms of $n-3$ PUFAs. The lipid profile of the plasma was 
determined and the coagulation potential was measured using an assay highly sensitive for changes in both thrombin formation and thrombin inactivation $[28,29]$, which was specially automated for the purpose of this work. In a second study, rats were fed with n-3 PUFAs that were given as parts of a (low- or high-fat) diets containing a limited amount of vitamin $\mathrm{K}$, to determine the importance of (lipid-driven) distribution of vitamin $\mathrm{K}$ on the coagulant activity.

\subsection{Materials and methods}

\section{Materials}

Fish oil triglycerides (Ropufa, two batches), and purified preparations of eicosapentaenoate and docosahexaenoate ethyl esters were supplied by HoffmannLa Roche (Basel, Switzerland). Standard fat mixture was prepared by Unilever Research (Vlaardingen, The Netherlands). Specific vitamin K-deficient diets were obtained from Hope Farms (Woerden, The Netherlands). Other dietary components came from sources described elsewhere [7,22]. Vitamin $K_{1}$, warfarin, bovine thrombin, dioleoyl phosphatidylcholine and dioleoyl phosphatidylserine came obtained from Sigma (St. Louis, MO, USA). Ecarin from Echis carinatus venom and H-Gly-Pro-Arg-Pro-OH (GPRP) were obtained from Pentapharm (Basel, Switzerland). Low-affinity thrombin substrate Msc-Val-Arg-pNA was prepared and used, as described before [30]. Chromogenix (Mölndal, Sweden) supplied the substrate H-D-Phe-Pip-Arg-pNA (S2238) as well as a kit to measure plasma antithrombin. Thromborel $S$, and human plasmas deficient in factor II, V, VII or X were from Behring (Marburg, Germany). Coagulation factor diluent came from Instrumentation Laboratory (Milano, Italy), and thrombotest reagent was from Nycomed (Oslo, Norway). Recombinant human tissue factor and actin-activated cephaloplastin reagent were purchased from Dade (Miami, FL, USA). Thromboplastin was isolated from rat brain, as described before [31].

\section{Animals and diets study A.}

Three-week-old, male Wistar rats (Charles River, Sulzfeld, Germany) were held on a standard, pelleted stock food. After two weeks, the animals were randomly assigned to four groups of 12 animals, and then fed with one of four high-fat diets. The standard fat mixture, used for the four diets, was composed of saturated fatty acids, monounsaturated fatty acids and n-6 PUFAs in a ratio of 2:3:1 (w/w). It was prepared by mixing equivalent amounts of sunflowerseed oil, beef tallow, hydrogenated coconut oil and olive oil [22]. Other dietary components (casein, cornstarch, minerals, fiber and vitamins) were added as usual $[17,22]$. The diets had an equal energy content of $19.5 \mathrm{~kJ} / \mathrm{g}$, and contained $50 \%$ of digestible energy (en\%) as fat, $23-\mathrm{en} \%$ 
as casein and $27-e n \%$ as cornstarch. The determined amounts of vitamin $K_{1}$ and $K_{3}$ were 0.13 and $2.21 \mu \mathrm{g} / \mathrm{g}$, respectively. To prevent lipid oxidation, diets were prepared weekly and stored at $-20^{\circ} \mathrm{C}$ under nitrogen.

Rats from the high-fat control group received a diet containing $50-e n \%$ of the standard fat mixture (TABLE 6.1). In the diet of other groups, $4 \%(w / w)$ of the control fat was replaced by an n-3 PUFA concentrate of either $94 \%$ ethyl eicosapentaenoate (EPA group) or $94 \%$ ethyl docosahexaenoate (DHA group). In the diet of the fourth group, $5 \%(\mathrm{w} / \mathrm{w})$ of the fatty acids were replaced by a fish oil preparation with $20 \%$ eicosapentaenoate and $37 \%$ docosahexaenoate as triglycerides (FO group). The contents of cholesterol $(50 \mathrm{\mu g} / \mathrm{g})$ and arachidonate $(<0.5 \%$ of total fatty acids) were low in all diets. During the dietary period of 10 weeks, water and food were available ad libitum. Weekly intake of diets and body weight increase were similar for the animals from all diet groups.

TABLE 6.1 Global fatty acid composition and content of diets.

\begin{tabular}{|c|c|c|c|c|c|c|c|c|}
\hline \multirow[b]{2}{*}{ Diet type } & \multicolumn{4}{|l|}{ Study A } & \multicolumn{4}{|l|}{ Study B } \\
\hline & Control & EPA & DHA & $\mathrm{FO}$ & LF-Contr & $\mathrm{F}-\mathrm{FO}$ & HF-Control & HF-FO \\
\hline \multicolumn{9}{|c|}{ Fatty acid composition ( $\%$ of total fatty acids) } \\
\hline$<16: 0$ & 9.4 & 8.9 & 8.9 & 8.9 & 8.0 & 4.9 & 8.5 & 8.1 \\
\hline $16: 0$ & 14.8 & 14.2 & 14.2 & 14.2 & 15.6 & 9.6 & 14.9 & 14.0 \\
\hline $18: 0$ & 10.2 & 9.8 & 9.8 & 9.8 & 10.4 & 6.2 & 10.2 & 9.6 \\
\hline$\Sigma$ SAFA & 35.5 & 34.0 & 33.8 & 33.9 & 35.1 & 21.9 & 34.9 & 32.9 \\
\hline $18: 1 n-9$ & 45.6 & 44.1 & 44.1 & 40.8 & 44.6 & 25.3 & 45.6 & 42.4 \\
\hline$\Sigma$ MUFAs & 48.3 & 46.4 & 46.6 & 43.6 & 48.8 & 29.3 & 48.9 & 45.8 \\
\hline $18: 2 n-6$ & 15.5 & 15.2 & 15.1 & 15.2 & 15.5 & 9.0 & 15.6 & 14.6 \\
\hline$\Sigma$ n-6 PUFA & 15.8 & 15.3 & 15.2 & 17.0 & 15.7 & 11.1 & 15.8 & 15.0 \\
\hline $20: 5 n-3$ & 0 & 3.7 & 0.2 & 1.8 & 0 & 21.6 & 0 & 3.3 \\
\hline $22: 6 n-3$ & 0 & 0 & 3.7 & 2.6 & 0 & 13.2 & 0 & 2.1 \\
\hline$\Sigma n-3$ PUFA & 0.4 & 4.1 & 4.2 & 5.3 & 0.4 & 37.7 & 0.4 & 6.2 \\
\hline \multicolumn{9}{|c|}{ Fatty acid content ( $\%$ of energy) } \\
\hline$\Sigma$ SAFA & 17.8 & 17.0 & 16.9 & 17.0 & 3.4 & 2.1 & 17.5 & 16.5 \\
\hline$\Sigma$ MUFA & 24.2 & 23.3 & 23.3 & 21.8 & 4.6 & 2.8 & 24.5 & 22.9 \\
\hline$\Sigma n-6$ PUFA & 7.9 & 7.7 & 7.6 & 8.4 & 1.6 & 1.1 & 7.9 & 7.5 \\
\hline$\Sigma n-3$ PUFA & 0.2 & 2.1 & 2.1 & 2.7 & 0 & 3.6 & 0.2 & 3.1 \\
\hline
\end{tabular}

Study A: Control, EPA, DHA and FO indicate high-fat control, and eicosapentaenoate-, docosahexaenoate- and fish oil-containing diets, respectively. Study B: LF, low-fat; HF, high-fat diets; Control and FO indicate control and fish oil-containing diets, respectively. SAFA, saturated fatty acids, MUFA, mono-unsaturated fatty acids, PUFA, polyunsaturated fatty acids. Individual fatty acids are indicated by number of $\mathrm{C}$ atoms, number of double bonds, and site of the first double bond. 


\section{Animals and diets study $B$.}

Male Lewis rats, bred in the institute and aged 3 weeks, were kept on standard pelleted stock food during 1 week. The animals were then fed with a fatty acid-poor, vitamin $\mathrm{K}$-deficient diet during another 2 weeks, to reach severe vitamin $\mathrm{K}$ deficiency. This diet was composed of the usual mixture of casein, cornstarch, minerals, fiber and vitamins (but no vitamin $K$ ), to which was added an equal amount ( $w / w)$ of cooked rye flocks.

Subsequently, the vitamin K-deficient rats were randomly divided over 4 groups of 12 animals, and then fed during 10 weeks with a low-fat or high-fat diet containing $1.1 \mu \mathrm{g}$ vitamin $\mathrm{K}_{1} / \mathrm{g}$ food (no vitamin $\mathrm{K}_{3}$ ). The low-fat diets had an energy content of $13.7 \mathrm{~kJ} / \mathrm{g}$ with $10-\mathrm{en} \%$ as fat, while $23-\mathrm{en} \%$ and $67-\mathrm{en} \%$ were supplied as proteins and carbohydrates, respectively (food in intake per animal about $19 \mathrm{~g} / \mathrm{day}$ ). High-fat diets had an energy content of $19.5 \mathrm{~kJ} / \mathrm{g}$, containing $50-\mathrm{en} \%$ as fat, and 23 and $27-\mathrm{en} \%$ as proteins and carbohydrates (intake per animal about $13 \mathrm{~g} / \mathrm{day}$ ). Because rats consume fixed amounts of energy per day, the daily consumption of proteins was thus similar for all diet groups. Fibers, vitamins and minerals were also added in amounts that the expected intake was similar for the high-fat and low-fat groups. Half of the rats on low-fat diet, received $50 \%(\mathrm{w} / \mathrm{w})$ of the fatty acids as a fish oil-triglyceride preparation with $36 \%$ eicosapentaenoate and $23 \%$ docosahexaenoate (low-fat FO group) (TABLE 6.1). In the high-fat diet of the fourth group, $10 \%(\mathrm{w} / \mathrm{w})$ of the fatty acids were replaced by the fish oil mixture (high-fat FO group). Mean daily food intake and weight gain were similar for rats of all groups.

Before starting study $B$, an experiment was undertaken to determine the minimal dose of vitamin $K$ intake required for maximal vitamin $K$-dependent coagulant activity. Twelve male Lewis rats were fed with the fatty acid-poor, vitamin K-deficient diet during 2 weeks, after which the animals (in groups of 2) were held for another 2 weeks on the above-described low-fat or high-fat diets, however containing different amounts of vitamin $\mathrm{K}_{1}$. The institutional Animal Care Committee approved the experimental protocols.

\section{Plasma and liver collection}

Rats were fasted overnight, and anaesthetized with ketamine before drawing blood $(0.5 \mathrm{ml})$ by tail puncture where indicated. At the end of the dietary periods, the rats (faster overnight) were anaesthetized with Nembutal, blood (10-13 $\mathrm{ml}$ ) was taken by aortic puncture, and the animals were killed. The blood was collected into 0.1 vol of $130 \mathrm{mM}$ trisodium citrate, after which the mixture was immediately centrifuged at $1200 \mathrm{~g}$ for $15 \mathrm{~min}\left(22^{\circ} \mathrm{C}\right)$. The plasma fraction was then centrifuged at $18,000 \mathrm{~g}$ for 5 $\mathrm{min}$ to prepare platelet-free plasma. Plasmas were frozen at $-70^{\circ} \mathrm{C}$, and stored at this temperature until use. Livers were removed from the killed animals, and also frozen and stored at $-70^{\circ} \mathrm{C}$. 


\section{Coagulation measurements}

Prothrombin time and activated partial thromboplastin time were determined using an ACL 300 (Instrumentation Laboratory) in plasma samples 5-times diluted in Michaelis buffer $\mathrm{pH} 7.35$ (120 mM NaCl, $28 \mathrm{mM}$ sodium barbiturate and $25 \mathrm{mM}$ sodium acetate). For measuring the prothrombin time, to $50 \mu \mathrm{l}$ of diluted plasma, $100 \mu \mathrm{l}$ of a pre-warmed mixture of rat thromboplastin (diluted 1:40 in Michaelis buffer) and $\mathrm{CaCl}_{2}$ (10 $\mathrm{mM}$ ) was added. To measure the activated partial thromboplastin time, a $53 \mu l$ sample of diluted plasma was mixed with $53 \mu \mathrm{l}$ of actin-activated cephaloplastin reagent (5-times diluted in Michaelis buffer). After 3 min of incubation $\left(37^{\circ} \mathrm{C}\right), 53 \mu \mathrm{l}$ $\mathrm{CaCl}_{2}(20 \mathrm{mM})$ was added to start the coagulation.

Fibrinogen was measured on an $\mathrm{ACL} 300$, after activation of diluted plasma (40-times in Michaelis buffer) with $350 \mathrm{nM}$ bovine thrombin. To measure rat active coagulation factors, plasma samples were diluted in factor diluent as follows: 1:50-80 $(\mathrm{v} / \mathrm{v})$ for prothrombin, 1:100-400 for factor $\mathrm{V}, 1: 200-400$ for factor $\mathrm{VII}$, and 1:10-25 for factor $X$. For each assay, $40 \mu \mathrm{l}$ of the prediluted sample was added to $40 \mu \mathrm{l}$ of corresponding human factor-deficient plasma. After $1 \mathrm{~min}$ of incubation in an $\mathrm{ACL}$, coagulation was started by addition of $80 \mu$ thromborel $S$ (dissolved according to the manufacturer's instructions).

Prothrombin was also measured in an autologous way by incubating $60 \mu \mathrm{l}$ of 5-times diluted plasma (in $29 \mathrm{mM}$ sodium barbital and $126 \mathrm{mM} \mathrm{NaCl}, \mathrm{pH}$ 7.35) with $60 \mu \mathrm{l}$ thrombotest reagent (containing chromogenic thrombin substrate) and $60 \mu \mathrm{l}$ ecarin $(33 \mathrm{U} / \mathrm{ml})$. Formation of thrombin was then measured automatically with an ACL. Antithrombin was determined in freshly diluted plasma samples (1:40 in 137 $\mathrm{mM} \mathrm{NaCl}$ ), using a chromogenous kit for human antithrombin using instructions provided by the supplier. For all assays, calibration curves were generated using pooled plasma from Wistar rats.

\section{Automated measurement of endogenous thrombin potential}

The formation and inactivation of thrombin in coagulating rat plasma were followed in an automated way, by following the cleavage of the low-affinity chromogenic substrate, Msc-Val-Arg-pNA, which was directly added to plasma. The used method followed that earlier described for the human coagulation system [30]. Briefly, to citrated plasma samples, $3.6 \mathrm{mg} / \mathrm{ml}$ GPRP (f.c.) was added to prevent fibrin clot formation. The samples $(40 \mu \mathrm{l})$ were then diluted with 1 vol $(40 \mu l)$ buffer $\mathrm{l}(100 \mathrm{mM}$ $\mathrm{NaCl}, 50 \mathrm{mM}$ Tris- $\mathrm{HCl}$ and $0.05 \%$ (w/v) bovine serum albumin, $\mathrm{pH} 7.35$ ). The $80 \mu \mathrm{l}$ samples were pre-incubated with a $20 \mu$ mixture of recombinant human tissue factor $(0.24 \mathrm{nM})$ and phospholipids (dioleoyl phosphatidylcholine : dioleoyl phosphatidylserine, $80: 20, \mathrm{~mol} / \mathrm{mol}, 6.7 \mu \mathrm{M})$. Coagulation was triggered by addition of a $20 \mu \mathrm{l}$ mixture of $\mathrm{CaCl}_{2}(100 \mathrm{mM})$ to which Msc-Val-Arg-pNA (3 mM) was added. Where indicated, $20 \mu \mathrm{l}$ rat thromboplastin (diluted 1:50 in buffer l) was used instead of tissue factor. Activations were carried out in a Cobas Fara laboratory automaton, 
in which colour development at $405 \mathrm{~nm}$, i.e. $p$-nitroanilide production, was measured every $30 \mathrm{~s}$ during a period of at least $15 \mathrm{~min}$. Corrections were made for substrate cleavage by $\alpha$-macroglobulin-bound thrombin by using an automated fitting procedure [28].

\section{Other methods}

Gas-chromatographic analysis of the fatty acid composition of diets was performed according to established procedure [22]. Levels of vitamin $K_{1}$ and $K_{3}$ in food and liver were determined in lipid extracts by high-performance liquid chromatography, using the method of electrochemical reduction and fluorometric detection [32,33]. Plasma levels of triglycerides, total cholesterol and cholesterol in high-density lipoproteins were measured, as described before [17].

\section{Statistics}

To evaluate the significance of differences between diet groups, the non-parametric Kruskal-Wallis test was applied. If this test showed statistical significance, a MannWhitney test was used with adjustment of the $\alpha$-level according to the Bonferroni method for multiple comparisons, when applicable, in order to determine which of the diet groups differed from the control group (Statview 4.5, Abacus Concepts, 1995). Spearman correlation analysis was used, where applicable.

\subsection{Results}

Effects of various n-3 PUFAs on blood lipids and coagulation parameters

Earlier results have indicated that prolonged feeding of Wistar rats with a high-fat diet, in which $4 \%$ or more (i.e. $\geq 2-e n \%$ ) of the fatty acids was replaced by n-3 PUFAS from fish oil, resulted in a decrease in prothrombin and factor VII levels [17]. This fish oil effect was accompanied by a significant reduction in the coagulation potential of the plasma [17], as measured with a sensitive, integrative assay, where thrombin formation and inactivation were followed in samples taken from the coagulating plasma [29]. In this work, we firstly concentrated on the effects of low levels of $n-3$ PUFAs on lipid levels and coagulation activity using this sensitive test system. In study $A$, the animals were fed for 10 weeks with a high-fat control diet, or a high-fat diet containing $4-5 \%$ of the fatty acids as ethyl eicosapentaenoate or ethyl docosahexaenoate (EPA and DHA groups, respectively) or a mixture of fish oilderived triglycerides (FO group). The rats of the EPA, DHA and FO groups thus received about 2.5-en\% as $n-3$ PUFAs (TABLE 6.1). Vitamin $K$ was given at a level of $2.3 \mu \mathrm{g} / \mathrm{g}$ food.

As a result of this intervention, the plasma levels of total cholesterol and 
Effects of dietary n-3 PUFAs on blood lipids and coagulation parameters at high vitamin $K$ intake

\begin{tabular}{|c|c|c|c|c|}
\hline \multirow[b]{2}{*}{ Parameter } & \multicolumn{4}{|l|}{ Diet type } \\
\hline & Control & EPA & DHA & FO \\
\hline Total cholesterol (mM) & $2.33 \pm 0.05$ & $1.94 \pm 0.06^{\star \star}$ & $1.79 \pm 0.07^{\text {** }}$ & $1.78 \pm 0.07^{\star \star}$ \\
\hline HDL cholesterol (mM) & $1.93 \pm 0.13$ & $1.71 \pm 0.03$ & $1.07 \pm 0.19^{\star \star}$ & $1.42 \pm 0.09^{*}$ \\
\hline Triglycerides (mM) & $0.56 \pm 0.09$ & $0.54 \pm 0.04$ & $0.61 \pm 0.04$ & $0.57 \pm 0.05$ \\
\hline $\operatorname{PT}(s)$ & $24.5 \pm 1.2$ & $24.5 \pm 1.0$ & $23.9 \pm 0.9$ & $24.1 \pm 1.0$ \\
\hline $\operatorname{APTT}(s)$ & $19.3 \pm 0.4$ & $20.1 \pm 0.4$ & $20.1 \pm 0.3$ & $20.6 \pm 0.3$ \\
\hline Factor II (\%) & $102.1 \pm 1.1$ & $102.5 \pm 1.9$ & $98.1 \pm 1.5$ & $97.3 \pm 1.5^{*}$ \\
\hline Thrombin potential (\%) & $97.4 \pm 3.1$ & $98.5 \pm 2.1$ & $97.3 \pm 2.9$ & $92.3 \pm 2.4$ \\
\hline
\end{tabular}

Rats were fed with a high-fat control diet (Control), or with high-fat diets containing 2-en\% to 3 -en\% eicosapentaenoate (EPA), docosahexaenoate (DHA) or a mixture of fish-oil-derived $n-3$ PUFAs (FO) for 10 weeks (Study A). The rats were fasted overnight, and plasmas were prepared to measure total cholesterol, cholesterol in high-density lipoproteins (HDL), triglycerides and prothrombin (factor II). Prothrombin time (PT), activated partial thromboplastin time (APTT), and the endogenous thrombin potential of plasma were measured, as described in Materials and Methods. Levels are expressed as percentages of the levels in pooled rat plasma. Data are mean values \pm sem $(n=7-11)$. Significance of difference compared to the control group with $P<0.05$ (Kruskal-Wallis test) is indicated by: ${ }^{*} P<0.02$ and ${ }^{\star \star} P<0.002$ (Mann-Whitney test).

cholesterol in high-density lipoproteins (which forms most of the cholesterol in rat plasma) were decreased with about $25 \%$ in the DHA and FO groups and to a lower degree in the EPA group (TABLE 6.2). Levels of triglycerides were similar for all diet groups. The overall coagulation times (prothrombin time and activated partial thromboplastin time) were not influenced by the diet type but, as before [29], the prothrombin concentration was significantly decreased in the FO group.

In plasma from these rats, the thrombin-forming potential was measured in an automated way, following a procedure that was developed for the human system [30]. Rat plasma was thus incubated with a low-affinity thrombin substrate, Msc-ValArg-pNA, and then activated with optimal amounts of recombinant tissue factor, phospholipids and $\mathrm{CaCl}_{2}$. The substrate cleavage was continuously followed in time by measuring colour development, while clot formation was prevented by addition of the fibrin polymerization inhibitor, GPRP. Control experiments showed that the thrombin potential of plasma, as measured in this way, was sensitive to treatment of the rats with heparin or vitamin $K$ antagonists (CHAPTER 4). When this automated method was used to determine the thrombin potential of the plasmas, no effect was observed of the type of feeding (TABLE 6.2).

Together, this indicates that this low intake of n-3 PUFAs, regardless of their source, is insufficient to reach a hypocoagulant effect. Hypothesizing that the vitamin $\mathrm{K}$ transport to the liver can be influenced by the content and type of the dietary fat, 
TABLE 6.3 Effects of n-3 PUFAs on blood lipids and coagulation parameters under conditions of restricted vitamin $\mathrm{K}$ intake

\begin{tabular}{lcccc}
\hline \multicolumn{5}{c}{ Diet type } \\
\cline { 2 - 5 } Parameter & Low-fat Control & Low-fat FO & High-fat Control & High-fat FO \\
\hline Total cholesterol (mM) & $1.58 \pm 0.07$ & $1.57 \pm 0.08$ & $1.66 \pm 0.05$ & $1.49 \pm 0.04^{\star \star}$ \\
Triglycerides (mM) & $0.54 \pm 0.04$ & $0.54 \pm 0.06$ & $0.67 \pm 0.07$ & $0.44 \pm 0.06^{\star \star}$ \\
PT(s) & $22.6 \pm 0.7$ & $22.1 \pm 0.5$ & $21.8 \pm 0.6$ & $22.6 \pm 0.3$ \\
APTT (s) & $31.3 \pm 1.0$ & $31.2 \pm 0.6$ & $30.2 \pm 0.5$ & $31.7 \pm 0.7^{\star}$ \\
Factor II (\%) & $104.4 \pm 7.7$ & $90.5 \pm 7.7^{\star \star}$ & $112.7 \pm 9.1$ & $100.5 \pm 6.4$ \\
Factor V (\%) & $104.3 \pm 5.5$ & $85.3 \pm 2.5^{\star \star}$ & $118.3 \pm 7.4$ & $100.0 \pm 5.6^{\star}$ \\
Factor VII (\%) & $76.3 \pm 6.1$ & $66.5 \pm 4.6$ & $72.7 \pm 5.1$ & $65.7 \pm 4.7$ \\
Factor X (\%) & $95.7 \pm 4.6$ & $88.4 \pm 6.1$ & $105.3 \pm 5.4$ & $96.0 \pm 4.9$ \\
Antithrombin (\%) & $118.3 \pm 7.5$ & $127.2 \pm 8.7$ & $133.3 \pm 3.8$ & $121.1 \pm 7.8$ \\
Fibrinogen (g/l) & $2.5 \pm 0.2$ & $2.6 \pm 0.2$ & $2.5 \pm 0.2$ & $2.5 \pm 0.2$ \\
Vitamin K (ng/g liver) & $45.1 \pm 4.2$ & $23.7 \pm 2.5^{\star \star}$ & $27.4 \pm 1.8$ & $25.4 \pm 6.2$ \\
\hline
\end{tabular}

Rats were fed with low-fat or high-fat control (Control) diets containing limited amounts of vitamin $\mathrm{K}_{1}$ $($ Study $B$ ). In the diet of animals of the FO group, 3-en\% of the fatty acids were replaced by $n-3$ PUFAs. In plasma from fasted animals, lipids and coagulation factors were measured, as described for TABLE 6.2. Factor concentrations are expressed as percentages of the levels in pooled rat plasma. Abbreviations are as in TABLE 6.2. Vitamin $\mathrm{K}$ was quantified in liver tissue taken from the rats. Data are mean values \pm sem $(n=10-12)$. Significance of difference compared to the corresponding control group: ${ }^{\star} P<0.10,{ }^{\star \star} P<0.05$ (Mann-Whitney test).

we questioned whether fish oil effects on the coagulation system may be more pronounced under conditions of a lower intake of vitamin $\mathrm{K}$ and total fat.

Hypocoagulant effect of dietary fish oil under restricted intake of vitamin $K$ and fat The usual protocol to determine vitamin K-antagonistic activity of food components is, first, to induce vitamin $\mathrm{K}$ deficiency by feeding the animals with an essentially vitamin K-free diet, and then to switch to the diet of choice containing a limited amount of vitamin $\mathrm{K}$. When male Wistar rats were subjected to this protocol, even prolonged feeding ( 5 weeks) with vitamin K-deficient diet resulted in only partial reduction in vitamin $\mathrm{K}$-dependent coagulation factors (data not shown). The difficulty to achieve total vitamin $\mathrm{K}$ deficiency was probably due to the tendency of coprophagy of these rats. We therefore switched to Lewis rats, seemed to respond better to dietary vitamin $\mathrm{K}$ depletion [34].

Feeding of the Lewis rats with vitamin K-deficient diet for 7 days resulted in a reduction of the level of coagulation-active prothrombin to $10-15 \%$ of the control value ( $n=12$, see also below). The deficient rats were then fed with a low- or a highfat diet with 10 or 50 -en\% as fat, respectively, to which variable amounts of vitamin $K_{1}$ were added (0.2-1.2 $\mu \mathrm{g} / \mathrm{gram}$ food). The fatty acid composition of either type of 


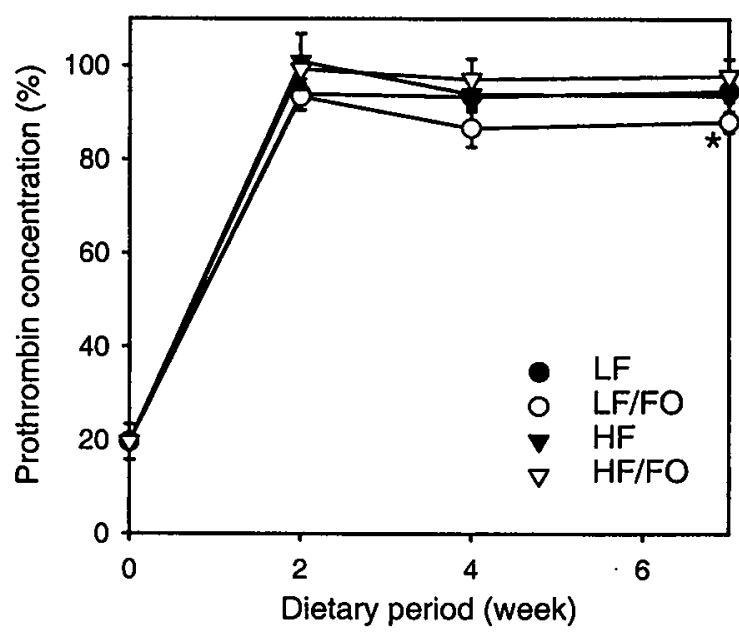

Figure 6.1 Effect of dietary fish oil under conditions of restricted vitamin $\mathrm{K}$ intake on plasma prothrombin concentration. Vitamin K-deficient rats were fed with low-fat (LF) or high-fat (HF) diet containing a limited amount of vitamin $K_{1}$ (study $B$ ). In the diet of animals of the FO group, 3-en\% of the fatty acids were replaced by $n-3$ PUFAs. During the dietary intervention, prothrombin was determined in blood samples drawn by tail puncture. Data are expressed as percentages of the prothrombin level in pooled rat plasma, and represent mean values \pm sem $(n=5$ 9). Significance of difference compared to the corresponding (LF or HF) control group: ${ }^{*}=0.067$ (Mann-Whitney test).

diets was similar to that of study A (TABLE 6.1). After two weeks of feeding, prothrombin levels were measured in plasma samples. For both the low- and high-fat diet, the minimal requirement for optimal prothrombin synthesis was found to be 0.55 $\mu \mathrm{g}$ vitamin $K_{1} / \mathrm{g}$ food, which value is close to that determined in earlier studies with Lewis rats [34]. Thus, the dietary fat content is of little influence on the accumulation of vitamin $\mathrm{K}$-dependent coagulation factors.

In the next diet study (study B), Lewis rats were made vitamin K-deficient, and then fed with the same low- and high-fat diets containing 2-times the minimal dose of vitamin $K_{1}$ required for optimal coagulation, i.e. $1.1 \mu \mathrm{g} / \mathrm{g}$ food. This dose was chosen as to prevent hypo-coagulant activity due to day-to-day variation in food intake [34]. For both the low- and high-fat diets of half of the rats, 3-en\% of the fatty acids were replaced by $n-3$ PUFAs derived from fish oil (FO groups) (TABLE 6.1). After 2 weeks of feeding, the prothrombin level was reversed to $90-100 \%$ of the control value in all dietary groups (FIG. 6.1). After 4-7 weeks of feeding, only the low-fat fish oil group showed a small decrease in prothrombin concentration.

At the end of the dietary period of 10 weeks, plasma cholesterol and triglycerides were somewhat reduced in the high-fat FO group, but not so in the lowfat FO group, when compared to the corresponding control groups (TABLE 6.3). The prothrombin concentration was significantly reduced in the low-fat FO group, but insignificantly in the high-fat FO group. Levels of other vitamin K-dependent coagulation factors, i.e. factors $\mathrm{VII}$ and $\mathrm{X}$, tended to be reduced after fish-oil feeding in combination with the low-fat. Furthermore, the plasma activity of factor $V$, which is a vitamin $\mathrm{K}$-independent coagulation factor, was decreased in both the low-fat and the high-fat FO groups. The fish-oil diets did neither influence the plasma antithrombin and fibrinogen levels, nor the overall coagulation times (TABLE 6.3). 


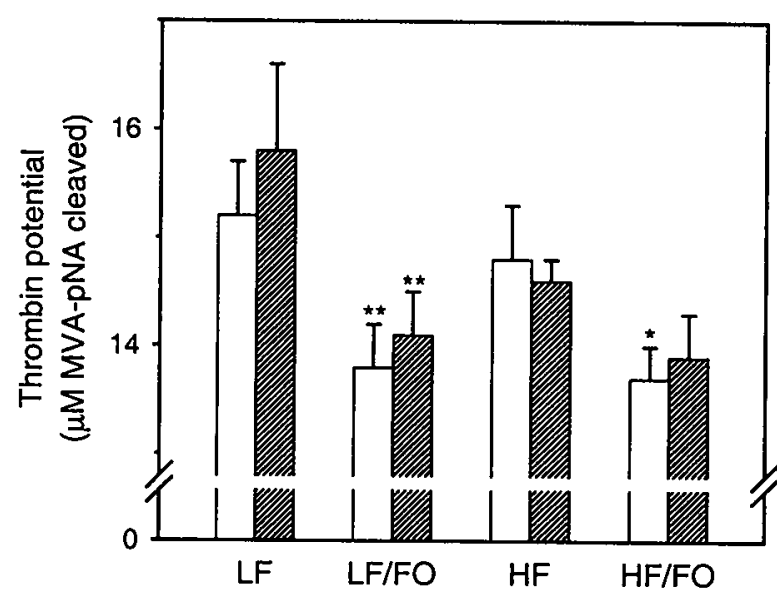

FIGURE 6.2 Effect of dietary fish oil under conditions of restricted vitamin $\mathrm{K}$ intake on the thrombin potential of plasma. Rats were fed with low-fat (LF) or high-fat (HF) in the presence or absence of fish-oil n-3 PUFAs (FO), as described for FIG. 6.1 (study B). Plasma, collected at the end of the dietary period, was activated with $\mathrm{CaCl}_{2}$ and phospholipids in the presence of either recombinant human tissue factor (white bars) or thromboplastin from rat brain (hatched bars). Data are represented as $\mu \mathrm{M}$ of Msc-Val-Arg-pNA cleaved during the coagulation process, and are corrected for the substrate cleavage by $\alpha$-macroglobulin-bound thrombin (mean values \pm sem, $n=6-12$ ). Significance of difference compared to the corresponding control group: ${ }^{*} P<0.10,{ }^{* *} P<0.05$ (Mann-Whitney).

Measurement of the thrombin-forming potential of the plasmas using the automated, thrombin generation method, resulted in a $10 \%$ reduction for the low-fat FO group when compared to the control, regardless of the stimulation of the plasma with recombinant human tissue factor or rat brain-derived thromboplastin (FIG. 6.2). Fish oil in combination with high-fat caused a smaller, non-significant decrease in thrombin generation.

Livers from the diet-modified animals were analyzed for vitamin $K$ content. The highest level of vitamin $K_{1}$ was detected in the rats fed with control, low-fat (TABLE 6.3). Feeding with of fish-oil (in combination with low-fat) or with high-fat (regardless of the presence of fish-oil) substantially reduced the vitamin $K_{1}$ content in the liver.

The various endpoint data from individual animals $(n=39-44)$ of all four diets groups were compared by correlation analysis. Positive correlations were obtained between plasma levels of prothrombin and factor $V$, prothrombin and factor VII, and prothrombin and factor $X(P<0.05)$. A weaker correlation was present between the level of prothrombin and the thrombin potential $(P<0.10)$.

\subsection{Discussion}

Here, we describe that prolonged feeding of rats with a low dose of fish oil can result in diminished coagulation activity. As in earlier studies [17], hypo-coagulancy was 
most clearly detectable with an assay measuring the total accumulation of thrombin during the whole coagulation process, which was fully automated to the purpose of this study (FIG. 6.2). The present data shed more light on the mechanism of dietinduced hypo-coagulant condition. Firstly, the vitamin $\mathrm{K}$ and fat contents of the food are likely to be important factors in this effect of n-3 PUFAs. Under conditions of limited vitamin $K_{1}$ intake (study $B$ ), the fish oil given as part of a low-fat diet gave the most consistent, hypo-coagulant effect in terms of both a reduced thrombin potential and reduced levels of coagulation factors (FIG. 6.1 and 6.2, TABLE 6.3). This effect was accompanied by a reduced vitamin $K_{1}$ content of the liver, which suggests that fish oil, when supplied as part of a low-fat diet, lowers the vitamin $\mathrm{K}$ absorption in the liver. Surprisingly, a similar reduction in hepatic vitamin $K_{1}$ content was observed in rats fed with high-fat diets, regardless of the presence or absence of fish-oil.

The diets of the rats contained about 3-en\% n-3 PUFAs, which is significantly lower than the levels of 5-10-en\% n-3 PUFAs used by other investigators $[24,25]$. Earlier, we have described that fish-oil feeding of rats does not lead to a decreased activation tendency of platelets, as would be predicted from the reduced accumulation of arachidonate in these cells. Instead, platelets may even show increased activation in response to dietary n-3 PUFAs [36,37]. Accordingly, the coagulation-lowering effect described in the present paper is likely to play an important role in the proposed antithrombotic effect of fish oil (see introduction). A reduced vitamin $K$ content in the liver after intake of $n-3$ PUFAs has also been detected by others, who have fed rats with higher levels of n-3 PUFAs (ethyl esters) than in the present study [25]. Thus, depending on the nutritional conditions, reduced vitamin $\mathrm{K}$ accumulation may contribute to the hypocoagulant effect of fish oil. It may be noted that the diet content used of $1.1 \mu \mathrm{g}$ vitamin $\mathrm{K} / \mathrm{g}$ food corresponds to the averaged dietary vitamin $\mathrm{K}$ intake in a healthy human population.

In spite of this dietary effect, the hepatic levels of vitamin $K_{1}$ in the fish-oil fed rats (study $B$ ) are likely to be sufficiently high for complete or nearly complete vitamin $\mathrm{K}$-dependent carboxylation of the vitamin-dependent coagulation factors [34]. This appears also from the observed fast accumulation of (vitamin K-dependent) prothrombin, after the vitamin K-deficient rats were set on a (low- or high-fat) diet with or without fish oil (FIG. 6.1). Thus, the reduced accumulation of vitamin $K$ in the liver is probably not the only explanation for the lowering effect of $n-3$ PUFAs on the coagulation potential. In study $B$ we found that a low dose of fish oil reduced the prothrombin concentration and the coagulation potential without any effect on the (fasting) triglyceride level. This suggests that the coagulation-lowering effect of dietary n-3 PUFAs is not directly linked to their effect on (fasting) triglycerides. The same applies to the (fasting) plasma cholesterol levels. For instance, in study A, all sources of $n-3$ PUFAs tested (eicosapentaenoate, docosahexaenoate and the fish-oil concentrate) influenced the coagulation no more than slightly, but caused a major reduction in plasma cholesterol. Others have indicated that fish oil influences the 
coagulation system by postprandial effects on the plasma lipids $[38,39]$. However, such an effect seems to be different from the present effects, because we analyzed blood samples only from overnight-fasted animals.

A surprising observation in study $B$ is that fish oil not only influenced the vitamin $\mathrm{K}$-dependent coagulation, but also lowered the vitamin $\mathrm{K}$-independent factor $V$ (TABLE 6.3). This diet was however without influence on the antithrombin and fibrinogen levels, suggesting that it does not impair the secretion of these proteins by the liver. We note that also a human study reports on a decrease in plasma factor $V$ after the dietary intake of $3 \mathrm{~g}$ of fish-oil daily [18]. Accordingly, it is possible that dietary n-3 PUFAs act by reducing the plasma production or the half-life time of the coagulation factors, in part in a way involving vitamin $K$, but also partially independent of this vitamin.

An attractive, albeit yet speculative, explanation for the (vitamin $K$ independent) hypo-coagulant effect may come from recent literature of specific effects of n-3 PUFAs on transcriptional activity $[40,41]$. For instance, in the hepatic system, dietary PUFAs influence gene expression by an altered generation of prostanoids or by changing the transcription effect of peroxisome proliferatoractivated receptor $\alpha$. (PPAR $\alpha)$ [42]. In mice, feeding of n-3 PUFAs appears to downregulate the hepatic mRNA level of sterol regulatory element-binding protein-1 (SREBP-1) [43], suggesting a coordinated effect on lipogenic gene transcription [44]. With respect to the coagulation system, both eicosapentaenoic and docosahexaenoic acid can prevent the activation of monocytic tissue factor perhaps via downregulation of the endotoxin receptor [45]. It is thus worth considering that n-3 PUFAs may, directly or indirectly, alter the hepatic expression and secretion of (vitamin Kdependent and -independent) coagulation factors, although clearly more research is needed to establish this hypothesis.

\subsection{Acknowledgements.}

We thank N. Bitsch, R. F. G. Offermans and J. Wierts ( $\dagger$ ) for animal husbandry and analytical assistance. We also acknowledge $\mathrm{L}$. J. Schurgers for performing vitamin $\mathrm{K}$ measurements. This study was supported by Hoffmann-La Roche (Basel, Switzerland). 


\subsection{References}

1. Hornstra G. The significance of fish and fish-oil enriched food for prevention and therapy of ischaemic cardiovascular disease. In: Vergroesen A, editor. The role of Fats in Human Nutrition. New York: Academic Press; 1989. p. 151-235.

2. GISSI Preventione Investigators. Dietary supplementation with n-3 polyunsaturated fatty acids and vitamin $E$ after myocardial infarction. Lancet. 1991;354:447-455.

3. Gillum RF, Mussolini ME, Madans JH. The relationship between fish oil consumption and stroke incidence: the NHANES I epidemiologic follow-up study. Arch Int Medic. 1996;156:537542.

4. Malle E, Kostner GM. Effects of fish oil on lipids and platelet function. Prostagl Leukotr Essential Fatty Acids. 1993;49:645-663.

5. Bonaa $\mathrm{KH}$, Bjerve $\mathrm{KS}$, Nordoy A. Habitual fish consumption, plasma phospholipid fatty acids, and serum lipids: the Tromso study. Am J Clin Nutr. 1992;55:1126-1134.

6. Mori TA, Beilin LJ, Burke V. Ritchie J. Interactions between dietary fat, fish, and fish oil and their effects on platelet function in men at risk of cardiovascular disease. Arterioscler Thromb Vasc Biol .1997;17:279-286.

7. Braden GA, Knapp HR, Fitzgerald DJ, Fitzgerald GA. Dietary fish oil accelerates the response to coronary thrombolysis with tPA. Evidence for a modest platelet inhibitory effect in vivo. Circulation. 1990;82:178-187.

8. Mennen LI, Schouten EG, Grobbee DE, Kluft C. Coagulation factor VII, dietary fat and blood lipids: a review. Thromb Haemost. 1996;76:492-499.

9. Burns $P$, Hoffman CJ, Katz JP, Miller RH, Lawson WE, Hultin MB. Vitamin K-dependent clotting factors are elevated in young adults who have close relatives with ischemic heart disease. J Lab Clin Med. 1993;122:720-727.

10. Constantino M, Merskey C, Kudzma DJ, Zucker MB. Increased activity of vitamin Kdependent clotting factors in human hyperlipoproteinaemia: association with cholesterol and triglyceride levels. Thromb Haemost. 1977;38:465-474.

11. Fuller JH, Keen $H$, Jarrett RJ, Omer T, Meade TW, Chakrabarti R, North WR, Stirling $Y$. Haemostatic variables associated with diabetes and its complications. Br Med J. 1979;2:964966.

12. Bruckert E, Cavalho de Sousa J, Giral P, Soria C, Chapman MJ, Caen J, de Gennes JL. Interrelationship of plasma triglyceride and coagulant factor VII levels in normotriglyceridemic hypercholesterolemia. Atherosclerosis. 1989;75:129-135.

13. Cavalho de Sousa J, Soria JC, Ayrault-Jarrier M, Pastier D, Bruckert E, Admiral J, Bereziat G, Caen JP. Association between coagulation factors VII and $X$ with triglyceride-rich lipoproteins. $J$ Clin Pathol. 1988;41:940-944.

14. $X u N$, Dahlbäck B, Ohlin AK, Nilsson A. Association of vitamin K-dependent coagulation proteins and $\mathrm{C} 4 \mathrm{~b}$ binding protein with triglyceride-rich lipoproteins of human plasma. Atheroscler Thromb Vasc Biol. 1998;18:33-39.

15. Shearer MJ. Vitamin K. Lancet. 1995;345:229-34.

16. Lamon-Fava S, Sadowski JA, Davidson KW, O'Brien ME, McNamara JR, Schaefer EJ. Am J Clin Nutr. 1998;67:1226-1231.

17. Nieuwenhuys CMA, Béguin S, Offermans RFG, Emeis JJ, Hornstra G, Heemskerk JWM. Hypocoagulant and lipid-lowering effects of dietary $n-3$ polyunsaturated fatty acids with unchanged platelet activation in rats. Arterioscler Thromb Vasc Biol. 1998;18:1480-1489.

18. Lox CD. The effects of dietary marine fish oils ( $\omega-3$ fatty acids) on coagulation profiles in men. Gen Pharmacol. 1990;21:241-246.

19. Dhahar E, Folsom AR, Wu KK, Dennis BH, Shimakawa T, Conlan MG, Davis CE, Williams OD. Associations of fish intake and dietary $n-3$ polyunsaturated fatty acids with a hypocoagulable profile. The atherosclerotic risk in communities (ARIC) study. Arterioscler Thromb. 1993;13:1205-1212.

20. Marckmann P, Bladbjerg EM, Jespersen J. Dietary fish oil (4 g daily) and cardiovascular risk markers in healthy men. Arterioscler Thromb Vasc Biol. 1997;17:3384-3391. 
21. Andriamampandry MD, Leray $C$, Freund $M$, Cazenave JP, Gachet $C$. Antithrombotic effects of n-3 polyunsaturated fatty acids in rat models of arterial and venous thrombosis. Thromb Res. 1999:93:9-16.

22. Nieuwenhuys CMA, Hornstra G. The effects of purified eicosapentaenoic and docosahexaenoic acids on arterial thrombosis tendency and platelet function in rats. Biochim Biophys Acta. 1998:1390: 313-322.

23. Hornstra G. Dietary Fats, Prostanoids and Arterial Thrombosis. The Hague (the Netherlands): Nijhoff Publ; 1981.

24. Mclntosh GH, McLennan PL, Lawson CA, Bulman FH, Charnock JS. The influence of dietary fats on plasma lipids, blood pressure and coagulation indices in the rat. Atherosclerosis. 1985; $55: 125-134$.

25. Andriamampandry MD, M. Freund, M. L. Wiesel, S. Rhinn, C. Ravanat, J. P. Cazenave, C. Leray, and $C$. Gachet. Diets enriched in $n-3$ fatty acids affect rat coagulation factors dependent on vitamin K. C R Acad Sci Paris. 1998;321:413-421.

26. Craciun AM, Groenen van Dooren MMCL, Thijssen HHW, Vermeer $C$. Induction of prothrombin synthesis by $\mathrm{K}$-vitamins compared in vitamin K-deficient and in brodifacoumtreated rats. Biochim Biophys Acta. 1998;1380:75-81.

27. Groenen-van Dooren MMCL, Ronden JE, Soute BAM, Vermeer C. Bioavailability of phylloquinone and menaquinones after oral and colorectal administration in vitamin $\mathrm{K}$ deficient rats. Biochem Pharmacol. 1995;50:797-801.

28. Wielders $S$, Mukherjee M, Michiels J, Rijkers DTS, Cambus JP, Knebel RWC, Kakkar V, Hemker HC, Béguin $S$. The routine determination of the endogenous thrombin potential: first results in different forms of hyper- and hypocoagulability. Thromb Haemost. 1997;77:629-635.

29. Hemker HC, Wielders S, Kessels H, Béguin S. 1993. Continuous registration of thrombin generation in plasma: its use for the determination of the thrombin potential. Thromb Haemost. 1993;70:617-624.

30. Rijkers DTS, Wielders SJH, Béguin S, Hemker HC. Prevention of the influence of fibrin and $\alpha_{2}$-macroglobulin in continuous measurement of the thrombin potential: implications for an endpoint determination of the optical density. Thromb Res. 1998;89:161-169.

31. Van Dam-Mieras MCE, Muller AD, Hemker HC. Proenzymes, enzymes, inhibitors, cofactors. In: Bergmeyer HU, Bergmeyer J, Grassi M, editors. Methods of Enzymatic Analysis, Vol. V. Weinheim (Germany): VHC Publ; 1988. p. 352-365.

32. Schurgers LJ, Geleijnse JM, Grobbee DE, Pols HAP, Hofman A, Witteman JCM, Vermeer C. Nutritional intake of vitamins $K_{1}$ (phylloquinone) and $K_{2}$ (menaquinone) in The Netherlands. $J$ Nutr Environm Med. 1999;9:115-122.

33. Gijsbers BLMG, Jie KSG, Vermeer C. Effect of food composition on vitamin $\mathrm{K}$ absorption in human volunteers. Br J Nutr. 1996;76:223-229.

34. Ronden JE, Thijssen HHW, Vermeer $\mathrm{C}$. Tissue distribution of K-vitamers under different nutritional regimens in the rat. Biochim Biophys Acta. 1998;1379:16-22.

35. Uematsu $T$, Nagashima $S$, Niwa $M$, Kohno KI, Sassa $T$, Ishii $M$, Tomono $Y$, Yamato $C$, Kanamaru $M$. Effect of dietary fat content on oral bioavailability of menatetrenone in humans. J Pharmacol Sci. 1996;85:1012-1016.

36. Nieuwenhuys CMA, Feijge MAH, Offermans RFG, Kester ADM, Hornstra G, Heemskerk JWM. Modulation of rat platelet activation by vessel wall-derived prostaglandin and plateletderived thromboxane: effects of dietary fish oil on thromboxane-prostaglandin balance. Atherosclerosis. 2001;154:355-366.

37. Heemskerk JWM, Feijge MAH, Kester A, Hornstra G. Dietary fat modifies thromboxane $A_{2}$ induced stimulation of rat platelets. Biochem J. 1991;278:399-404.

38. Larsen LF, Bladbjerg EM, Jespersen J, Marckmann P. Effects of dietary fat quality and quantity on postprandial activation of blood coagulation factor VII. Arterioscler Thromb Vasc Biol. 1997;17:2904-2909.

39. Silveira A, Karpe $F$, Johnsson $H$, Bauer $K$, Hamsten $A$. In vivo demonstration in humans that large postprandial triglyceride-rich lipoproteins activate coagulation factor VII through the intrinsic coagulation pathway. Arterioscler Thromb Vasc Biol. 1996;16:1333-1339.

40. Fernandes G. Troyes DA, Jolly JA. The effects of dietary lipids on gene expression and apoptosis. Proc Nutr Soc. 1998;57:543-550. 
41. Sessler AM, Ntambi JM. Polyunsaturated fatty acid regulation of gene expression. $J$ Nutr. 1999;128:923-926.

42. Jump $D B$, Thelen $A$, Mater $M$. Dietary polyunsaturated fatty acids and hepatic gene expression. Lipids. 1999;34:S209-S212.

43. Kim HJ, Takahashi M, Ezaki O. Fish oil feeding decreases mature sterol regulatory elementbinding protein 1 (SREBP-1) by downregulation of SCEBP-1c MRNA in mouse liver. A possible mechanism for downregulation of lipogenic enzyme mRNAs. J Biol Chem. 1999;274:25892-25898.

44. Xu J, Nakamura MT, Cho HP, Clarke SD. Sterol regulatory element binding protein-1 is suppressed by dietary polyunsaturated fatty acids. A mechanism for the coordinate suppression of lipogenic genes by polyunsaturated fats. J Biol Chem. 1999;274:23577-23583.

45. Chu AJ, Walton MA, Prasad JK, Seto A. Blockade by polyunsaturated $n-3$ fatty acids of endotoxin-induced monocytic tissue factor activation is mediated by the depressed receptor expression in THP-1 cells. J Surg Res. 1999;87:217-224. 


\section{The procoagulant effect of thrombin on fibrin(ogen)-bound platelets}

Marijke W. Sanders, ${ }^{1}$ Cécile M. A. Nieuwenhuys, ${ }^{1}$ Marion A. H. Feijge, ${ }^{1,2}$ Martin Rook, ${ }^{3}$ Suzette Béguin, ${ }^{2}$ Johan W. M. Heemskerk ${ }^{1,2}$

1.2Departments of Human Biology and Biochemistry, University of Maastricht, P.O. Box 616, 6200 MD Maastricht, and ${ }^{3}$ Department of Medical Physiology and Sports Medicine, University of Utrecht, The Netherlands.

Based on: Haemostasis 1998;28:289-300 (Karger, Basel) 


\subsection{Abstract}

In a final stage of activation, platelets become procoagulant because of the appearance of phosphatidylserine (PS) at the membrane outer surface. This PS exposure requires a rise in cytosolic $\left[\mathrm{Ca}^{2}\right]_{\mathrm{l}}$ is accompanied by formation of membrane blebs, and stimulates the formation of thrombin from its precursor prothrombin. Here, we investigated whether thrombin, as a potent platelet agonist, can induce this procoagulant response in plasma-free platelets interacting with fibrin or fibrinogen through their integrin $\alpha_{110} B_{3}$ receptors. First, in platelets that were stimulated to spread over fibrin or fibrinogen surfaces with adrenaline, addition of thrombin and $\mathrm{CaCl}_{2}$ caused a potent $\mathrm{Ca}^{2+}$ signal that in about $30 \%$ of the cells was accompanied by exposure of PS. At low doses, integrin $\alpha_{11 b} B_{3}$ receptor antagonist (RGD peptide) inhibited platelet spreading as well as thrombin-evoked PS exposure. Second, in platelet-fibrinogen microaggregates that were preformed in the presence of adrenaline, thrombin/ $\mathrm{CaCl}_{2}$ induced PS exposure and bleb formation of about $35 \%$ of the cells. Third, a potent, thrombin-dependent stimulation of prothrombinase activity was measured in platelet suspensions that were incubated with a fibrin clot. These results indicate that, in the absence of coagulating plasma, thrombin is a moderate inducer of the procoagulant response of platelets, once integrin $\alpha_{116} B_{3}$ mediated interactions are stimulated (by adrenaline) and $\mathrm{CaCl}_{2}$ is present.

\subsection{Introduction}

In recent years, it has become clear that primary haemostasis through platelet activation and secondary haemostasis through coagulation are mutually dependent processes, which strongly amplify each other [1-3]. When platelets are activated at a site of vessel wall injury, this transforms their outer membrane surface from coagulation-inactive to highly coagulation-supporting, largely because negatively charged phosphatidylserine (PS) becomes exposed to the blood plasma [1,4-8]. The exposure of PS stimulates the activation of coagulation factors, which finally results in the generation of thrombin from its precursor prothrombin [9-11]. The externalisation of PS is a consequence of loss of the transbilayer phospholipid asymmetry in the platelet plasma membrane, most likely due to the $\mathrm{Ca}^{2+}$-dependent activation of a phospholipid scramblase located in this membrane $[12,13]$. Once produced, thrombin acts as one of the most potent physiological platelet activators, stimulating at least two different plasma membrane receptors [14-16]. The platelet surface thus appears to be a site of both thrombin formation and thrombin reactivity, which raises the intriguing possibility that thrombin supports its own formation by 
inducing PS exposure on the platelet surface.

Initial studies with suspensions of platelets have indicated that thrombin and also a thrombin receptor (PAR-1) -activating oligopeptide are only very weak activators of PS exposure and, thus, of the platelet procoagulant response $[9,17,18]$, in spite of the fact that they potently induce other platelet responses such as an increase in cytosolic $\left[\mathrm{Ca}^{2}\right]_{i}$, secretion and platelet aggregate formation. It appeared that co-stimulation of the platelets with thrombin, ADP and collagen was needed to obtain a significant, albeit still low, degree of PS exposure $[8,9,19]$. This clearly contrasted to the situation, where platelets were stimulated with other potent $\mathrm{Ca}^{2+}$ elevating agents, such as $\mathrm{Ca}^{2+}$-ionophores or complement factors, which markedly induced PS exposure. This has led to the conclusion that these agents evoke additional or more potent signalling steps than can be achieved by thrombin alone [20-22].

Recently, we have described that thrombin is nevertheless capable to elicit PS exposure in a low, but significant number of platelets in contact with immobilised fibrinogen. The activation processes of these platelets resemble those of platelets bound to collagen fibers, the latter of which display a potent and prolonged increase in $\left[\mathrm{Ca}^{2+}\right]$, followed by formation of plasma membrane blebs and PS exposure [23]. Since platelet-fibrinogen adhesive interactions are mediated by integrin $\alpha_{111} \beta_{3}$ receptors [24-26], and since the ligand occupation of these integrins results in additional (outside-in) signalling steps [27], it is tentative to assume that such signal transduction is involved in the thrombin-evoked platelet procoagulant response. A similar conclusion has been drawn from experiments using platelet-rich plasma, where it was found that integrin $\alpha_{110} \beta_{3}$-mediated binding to fibrin clots significantly contributes to the coagulation-promoting activity of the platelets $[28,29]$. However, in this case the presence of plasma made it difficult to separate effects of platelet stimulation from those of coagulation stimulation.

In the present study, we address the question whether, in the absence of plasma, the thrombin-evoked procoagulant response indeed relies on integrin $\alpha_{11 b} \beta_{3}$ mediated interactions of the platelets with fibrinogen or fibrin. To investigate this, washed platelets were brought into contact with these adhesive substrates in various ways, after which the effect of thrombin was determined on surface exposure of PS or consequent prothrombinase-stimulating activity. This was firstly studied in platelets that were spread on immobilised fibrin or fibrinogen surfaces; next, in platelets that were clustered in fibrinogen aggregates; and finally, in suspensions of platelets that were incubated with a preformed fibrin clot. Platelet activation as such was monitored from the changes in $\left[\mathrm{Ca}^{2+}\right]$, after loading the cells with fluorescent $\mathrm{Ca}^{2+}$ probes, while the procoagulant response was visualised from the cell morphology (bleb formation) and the capability of the platelet surface to bind the PS-specific probe, FITC-labelled annexin $\vee[23,30]$. 


\subsection{Materials and methods}

\section{Materials}

Apyrase, bovine fibrinogen (type IV), bovine serum albumin and human $\alpha$-thrombin were bought from Sigma (St. Louis, MO, U.S.A.). Ancrod was obtained from Knoll (Ludwigshafen, Germany), and agihal, a purified fraction from the venom of Agkistrodon halys halys, was a kind gift from Dr. L. Yukelson (Tashkent, Uzbekistan). Annexin V labelled with fluorescein isothiocyanate (FITC-annexin V, Apoptest) came from Nexins Research (Hoeven, the Netherlands) and dRGDW was from RhônePoulenc (Paris, France). Purified (anti)coagulation factors and other fluorescent compounds were obtained from sources, described before [14].

\section{Preparation of Fibrin Monomers and Fibrin Clots}

To prepare fibrin monomers, bovine fibrinogen was dissolved in $0.9 \%(\mathrm{w} / \mathrm{v}) \mathrm{NaCl}$ at a concentration of $15 \mathrm{mg} / \mathrm{ml}$. A fibrin clot was prepared by adding $2.5 \mathrm{mM}$ EDTA followed by $10 \mathrm{nM}$ thrombin. After $2 \mathrm{~h}$ of incubation at $37^{\circ} \mathrm{C}$, the resulting clot was removed and dispersed to fibrin monomers by sonication in a small volume of $17 \mathrm{mM}$ acetic acid [31]. The monomeric material was precipitated by addition of an equal volume of $2.5 \mathrm{mM}$ EDTA in $300 \mathrm{mM}$ sodium borate buffer $\mathrm{pH} 7.4$, followed by centrifugation at $2200 \mathrm{rpm}$ for $10 \mathrm{~min}$. This dispersion/precipitation procedure was repeated three times, after which a transparent suspension of monomeric fibrin in 17 $\mathrm{mM}$ acetic acid was obtained. This was stored at $4^{\circ} \mathrm{C}$ until use.

Macroscopic fibrin clots were prepared by incubation of $250 \mu \mathrm{l}$ fibrinogen solution $\left(10 \mathrm{mg} / \mathrm{ml} 0.9 \% \mathrm{NaCl}\right.$ ) with $5 \mu \mathrm{l}$ ancrod $(30 \mathrm{U} / \mathrm{ml})$ at $37^{\circ} \mathrm{C}$ for $30 \mathrm{~min}$. Fibrin formation occurred at a plastic spatula that was placed into the mixture. The formed clots were isolated and washed, and were devoid of thrombin or other coagulation factors, as described before [28].

\section{Isolation of Platelets and Loading with Fluorescent Probes}

Platelet-rich plasma was isolated from fresh blood obtained from healthy donors. Where indicated, the plasma was used to prepare Fura-2-loaded platelets, following routine procedures [14]. For confocal laser scanning experiments, platelets in plasma were not Fura-2-loaded but incubated with $5 \mu \mathrm{M}$ Fluo-3 acetoxymethyl ester, because the latter $\mathrm{Ca}^{2+}$ probe absorbs at the $488 \mathrm{~nm}$ line of an argon laser. After two wash steps, fluorescent-labelled platelets were suspended in Hepes buffer $\mathrm{pH} 7.45$, composed of $136 \mathrm{mM} \mathrm{NaCl}, 10 \mathrm{mM}$ Hepes, $5 \mathrm{mM}$ glucose, $2.7 \mathrm{mM} \mathrm{KCl}, 2 \mathrm{mM} \mathrm{MgCl}$, $0.2 \%(\mathrm{w} / \mathrm{v})$ bovine serum albumin and apyrase (0.1 U ADPase/ml). Suspensions were adjusted to $1-2 \times 10^{8}$ platelets $/ \mathrm{ml}$. 


\section{Preparation of Coverslips}

Round glass coverslips (diameter $22 \mathrm{~mm}$ ) were degreased with ethanol:2 $\mathrm{M} \mathrm{HCl}$ $(1: 1, v / v)$, rinsed with water and then with $0.9 \%(w / v) ~ N a C l$. Some of the coverslips were coated with $100 \mu$ f fibrinogen solution $(10 \mathrm{mg} / \mathrm{ml} 0.9 \% \mathrm{NaCl}$ ) for $15 \mathrm{~min}$. Where indicated, the fibrinogen-cleaving agent agihal $(3 \mathrm{U} / \mathrm{ml})$ was added to prepare fibrincoated coverslips. After $15 \mathrm{~min}$ of incubation, non-adherent material was manually removed, leaving a thin layer of polymeric fibrin on the coverslip surface. Other coverslips were sprayed with fibrin monomers $(250 \mu \mathrm{g} /$ coverslip), and allowed to stand for $1 \mathrm{~h}$. After the various coating procedures, the coverslips were rinsed twice with $0.9 \% \mathrm{NaCl}$, and post-incubated with Hepes buffer $\mathrm{pH} 7.45$ containing $2 \%(\mathrm{w} / \mathrm{v})$ bovine serum albumin to shield any uncoated glass.

\section{Fluorescence and Phase-Contrast Video Imaging of Single Platelets}

Fura-2-loaded platelets in Hepes buffer $\mathrm{pH} 7.45$ were incubated on coated coverslips

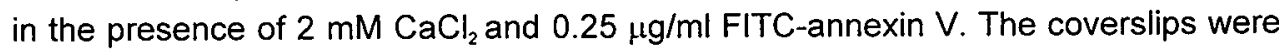
mounted in a $1 \mathrm{ml}$ temperature-controlled incubation chamber that was placed on the stage of an inverted microscope. Changes in Fura-2 fluorescence were detected in individual cells, using a Quanticell 700 fluorometric video imaging system equipped with both excitation and emission filter wheels (Applied Imaging, Newcastle, U.K.) [23]. Excitation light was passed alternately through filters of 340 and $380 \mathrm{~nm}$ wavelengths, and $505 \mathrm{~nm}$ fluorescence was observed with an intensified chargecoupled device camera (Photonic Sciences, Robertsbridge, U.K.), working at standard video rate and connected to the inverted microscope. Four-times averaged, background-subtracted fluorescence ratio images were thus obtained every 1-2 s. The images were stored to a $128 \mathrm{MByte}$ real-time image processor. Calibration of $340 / 380 \mathrm{~nm}$ fluorescence ratio to $\left[\mathrm{Ca}^{2+}\right]_{\text {i }}$ was according to standard procedures [32], using fixed calibration values [14]. Accumulation of FITC-annexin $V$ at the platelet surface was determined from local increases in fluorescence at excitation and emission wavelenghts of 485 and $535 \mathrm{~nm}$, respectively [23]. At regular times, fluorescence recordings were alternated with phase-contrast recordings by transillumination with white light and using a Vista VPM 6132 high-resolution, chargecoupled device camera (Norbain, U.K.), also connected to the microscope.

High-resolution, confocal fluorescence images from aggregates of Fluo-3loaded or FITC-annexin V-labelled platelets were recorded with a Nikon RCM 8000 confocal system (Tokyo, Japan), operating at video rate and connected to an inverted microscope. An argon laser was used as light source. Eight images were real-time averaged, which resulted in frames collected at a rate of $3.8 \mathrm{~Hz}$. Detection of Fluo-3 and fluorescein fluorescence was at $488 \mathrm{~nm}$ excitation and $500-550 \mathrm{~nm}$ emission. 


\section{Measurement of Prothrombinase Activity of Clot-Bound Platelets}

Thrombin-free fibrin clots were incubated at $37^{\circ} \mathrm{C}$ with washed platelets $\left(1 \times 10^{8} / 0.5\right.$ $\mathrm{ml})$ in nominally $\mathrm{Ca}^{2+}$-free Hepes buffer $\mathrm{pH} 7.45$. Adrenaline $(10 \mu \mathrm{M})$ and/or thrombin (4 nM) were added, as desired. After $45 \mathrm{~min}$ of incubation, clots with adhering platelets were transferred to polystyrene tubes containing $50 \mu \mathrm{l}$ Hepes buffer $\mathrm{pH}$ 7.35, composed of $150 \mathrm{mM} \mathrm{NaCl}, 20 \mathrm{mM}$ Hepes and $0.05 \%(\mathrm{w} / \mathrm{v})$ bovine serum albumin. Prothrombinase activity was assayed in half of these tubes, while the other tubes served to determine the platelet number. Prothrombin-converting activity was measured during $15 \mathrm{~min}$ in the presence of $2 \mathrm{mM} \mathrm{CaCl}_{2}, 7 \mathrm{nM}$ factor $\mathrm{Va}, 0.3 \mathrm{nM}$ factor $\mathrm{Xa}$ and $2 \mu \mathrm{M}$ prothrombin, i.e. under conditions where the coagulation factors were non-limiting. Reactions were stopped by taking samples and adding these to an ice cold buffer ( $\mathrm{pH} 7.9)$, containing $150 \mathrm{mM} \mathrm{NaCl}, 20 \mathrm{mM}$ Hepes, $20 \mathrm{mM}$ EDTA and $0.05 \%$ bovine serum albumin. Thrombin formation was linear with platelet membrane surface and approximately linear in time from 5-15 min. Thrombin was measured in the samples using the chromogenic substrate S-2238. Platelet number was determined by lysis of the cells with $1 \%(\mathrm{w} / \mathrm{v})$ Triton-X-100, and determination of lactate dehydrogenase activity in the lysates. Measurements were performed at least in triplicate.

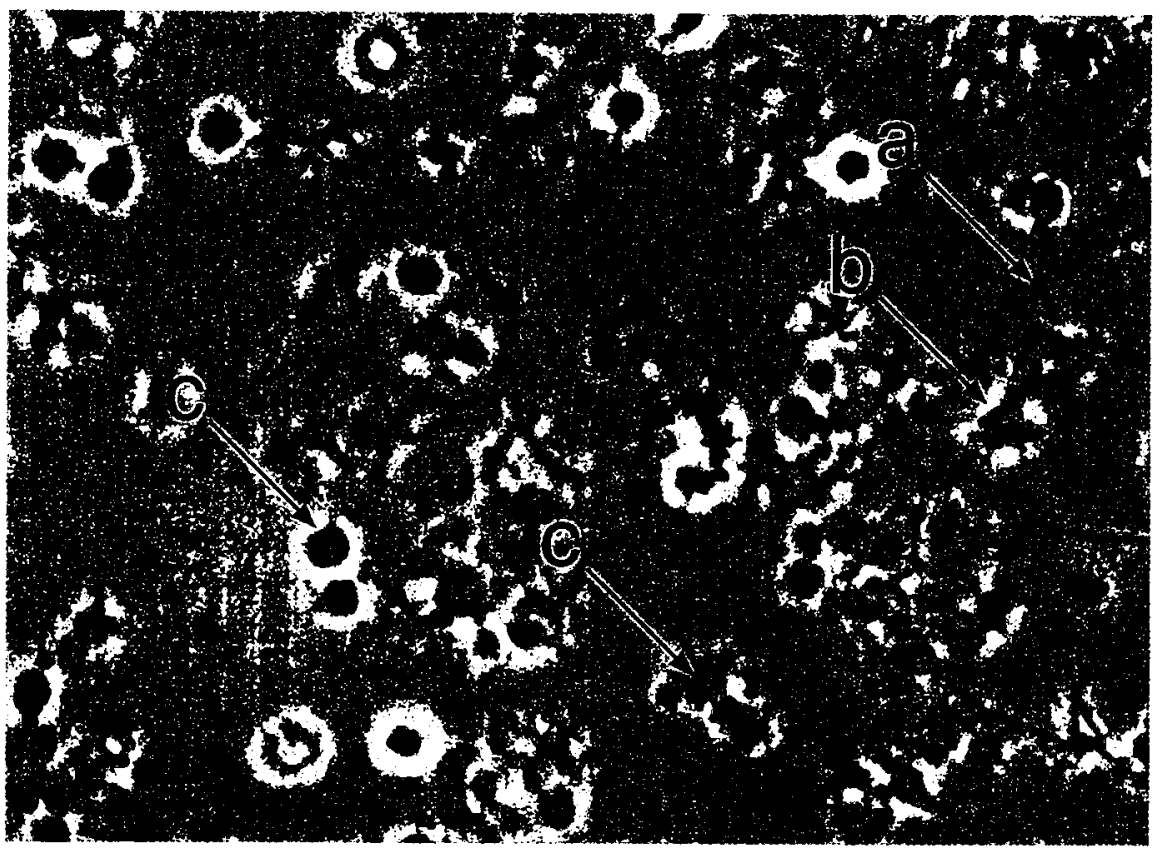

FIGURE 7.1 Morphology of thrombin-activated platelet on immobilised fibrin. Platelets spread on a fibrin surface in the presence of adrenaline $(10 \mu \mathrm{M})$. Subsequently, $\mathrm{CaCl}_{2}(2 \mathrm{mM})$ and thrombin $(4 \mathrm{nM})$ were added, and phase-contrast images were recorded $15 \mathrm{~min}$ later. Arrows indicate fibrin fiber $(a)$ and spread $(b)$ and bleb-forming $(c)$ platelets. 


\subsection{Results}

\section{Platelets Adhering to Immobilised Fibrin or Fibrinogen}

A microscopic camera-based system equipped for quasi-simultaneous detection of phase-contrast and fluorescent images was used to monitor morphology, changes in $\left[\mathrm{Ca}^{2+}\right]$ and accumulation of FITC-annexin V binding sites (i.e. PS exposure) of single, Fura-2-loaded platelets. In a first set of experiments, platelets were added to coverslips that were precoated with polymeric fibrin or fibrinogen. The fibrin matrices were formed in the absence of thrombin by incubating fibrinogen on coverslips with the snake-venom protease agihal. This resulted in a thin layer of fibrin fibers alternated with amorphous structures (FIG. 7.1, arrow a). To stimulate integrin $\alpha_{11} B_{3}$ mediated adhesion $[33,34]$ to these surfaces, platelets on coverslips were stimulated with adrenaline $(10 \mu \mathrm{M})$. This resulted in rapid spreading of the cells both with the fibrin (FIG. 7.1, arrow $b$ ) and fibrinogen [23] coatings. Subsequent application of thrombin $(4 \mathrm{nM})$ in combination with $\mathrm{CaCl}_{2}(2 \mathrm{mM})$ caused a gradual change in morphology of various platelets spread on fibrin (FIG. 7.1, arrows $c$ ) or fibrinogen (not shown): they changed into balloon-like structures decorated with small membrane blebs at the surface.
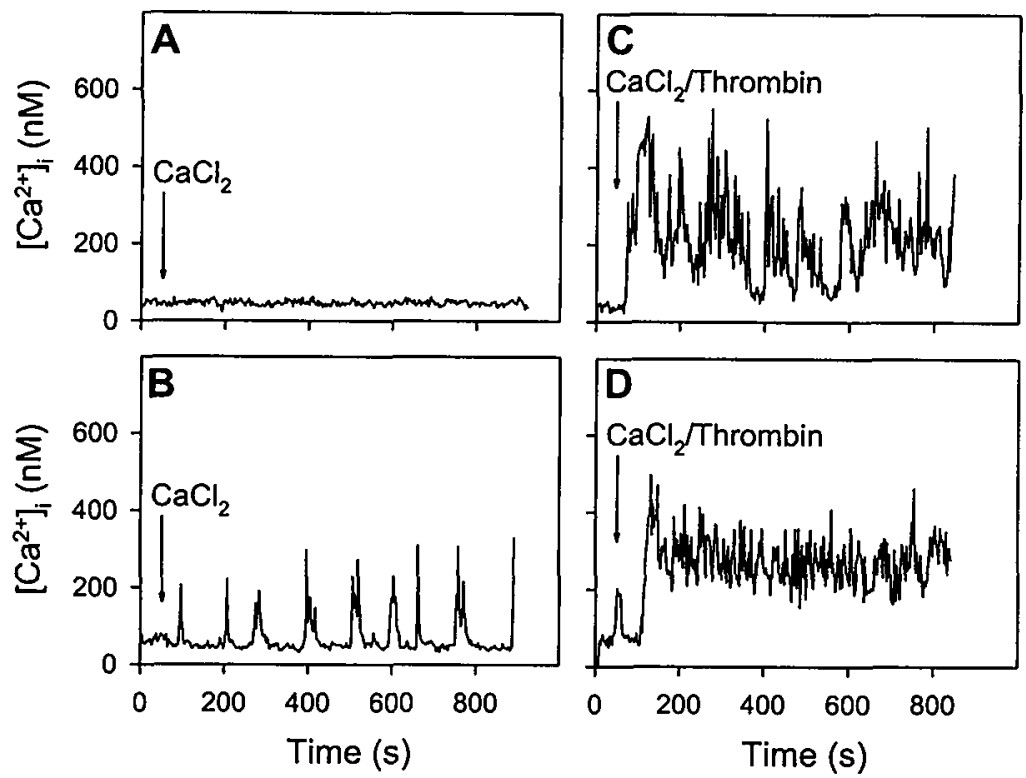

FIGURE 7.2 Calcium responses of single, fibrin-bound platelets. Fura-2-loaded platelets spread on immobilised fibrin in the presence of adrenaline $(10 \mu \mathrm{M})$ for $30 \mathrm{~min}$. Changes in $\left[\mathrm{Ca}^{2+}\right]_{i}$ were then recorded by fluorescence video imaging upon addition of $2 \mathrm{mM} \mathrm{CaCl}_{2}(A, B)$ or $2 \mathrm{mM} \mathrm{CaCl}$ plus $4 \mathrm{nM}$ thrombin $(C, D)$. Traces are responses of individual platelets, representative for $>30$ cells $(n=3$ experiments). 
A similar change in morphology was earlier observed in platelets adhering to collagen fibers. In that case, the blebbing response was accompanied by a prolonged $\mathrm{Ca}^{2+}$ signal and subsequent PS exposure [23]. This prompted us to monitor $\left[\mathrm{Ca}^{2+}\right]_{i}$ in the adrenaline-treated platelets spread on fibrin or fibrinogen. In the absence of $\mathrm{CaCl}_{2}$ and thrombin, $\left[\mathrm{Ca}^{2+}\right]$ remained continuously low in about $90 \%$ of the platelets on fibrin of fibrinogen, while the other $10 \%$ of the cells showed incidental spiking in $\left[\mathrm{Ca}^{2 *}\right]_{\text {. }}$ In case of fibrin, addition of $2 \mathrm{mM} \mathrm{CaCl}_{2}$ caused in $68 \%(21 / 31)$ of the platelets $\left[\mathrm{Ca}^{2+}\right]_{i}$ spikes (FIG. $7.2 \mathrm{~B}$ ), which had a low frequency of $0.8 \pm 0.1 \mathrm{~min}^{-1}$ (mean \pm sem, $n=18$ ), whereas $\left[\mathrm{Ca}^{2+}\right]$, remained low in other cells (FiG. 7.2A). Only incidentally, a platelet responded by a more continuous elevation in $\left[\mathrm{Ca}^{2+}\right]_{i}$. With fibrinogen as a surface, platelets responded similarly to $\mathrm{CaCl}_{2}$, but now an averaged spiking frequency was measured of $1.7 \pm 0.3 \mathrm{~min}^{-1}$ ( $n=17$ cells). As described earlier [30], this type of low-frequency spiking is probably a response of the spreading platelets to endogenously secreted ADP. When $4 \mathrm{nM}$ thrombin was added together with $\mathrm{CaCl}_{2}$, this resulted in potent $\mathrm{Ca}^{2+}$ signals with either adhesive surface. In case

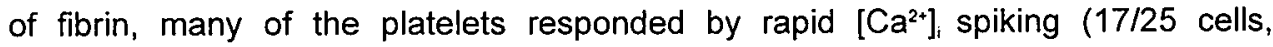
frequency $\left.>4 \mathrm{~min}^{-1}\right)$ (FIG. 7.2C), whereas other platelets (8/25) showed a continuous $\left[\mathrm{Ca}^{2+}\right]$, rise without return to the baseline level (FIG. 7.2D). With fibrinogen surface, thrombin/ $/ \mathrm{CaCl}_{2}$ addition evoked similar effects (data not shown, but see Ref. 14). Since some of the platelets responded to thrombin by a continuous increase in

TABLE 7.1 Effect of thrombin and $\mathrm{CaCl}_{2}$ on responses of platelets bound to fibrin or fibrinogen.

\begin{tabular}{|c|c|c|c|c|c|}
\hline \multirow[t]{3}{*}{ Coverslip-coating } & \multirow[t]{3}{*}{ Thrombin } & \multicolumn{4}{|c|}{ Addition of $\mathrm{CaCl}_{2}$} \\
\hline & & \multicolumn{2}{|c|}{ during spreading } & \multicolumn{2}{|c|}{ after spreading } \\
\hline & & high $\left[\mathrm{Ca}^{2+}\right]_{\mathrm{i}}$ & PS exposure & high $\left[\mathrm{Ca}^{2+}\right]_{i}$ & PS exposure \\
\hline & $(\mathrm{nM})$ & \multicolumn{4}{|c|}{ (\% of adherent platelets) } \\
\hline Control" & 0 & $5 \pm 2$ & $1 \pm 1$ & $2 \pm 1$ & $1 \pm 0.5$ \\
\hline Fibrin & 0 & $5 \pm 1$ & $2 \pm 1$ & $8 \pm 2$ & $4 \pm 2$ \\
\hline Fibrin & 4 & $44 \pm 5$ & $12 \pm 6$ & $50 \pm 6$ & $29 \pm 7$ \\
\hline Fibrin monomers & 4 & $47 \pm 9$ & $10 \pm 2$ & nd“ & nd \\
\hline Fibrinogen & 4 & $66 \pm 8$ & $6 \pm 2$ & $71 \pm 8$ & $28 \pm 4$ \\
\hline
\end{tabular}

Fura-2-loaded platelets were allowed to spread on coverslips coated with polymeric fibrin, fibrin monomers or fibrinogen in the presence of $10 \mu \mathrm{M}$ adrenaline. Non-adherent platelets were removed after the first $15 \mathrm{~min}$ of incubation. After another $30 \mathrm{~min}$, either vehicle or thrombin ( $4 \mathrm{nM}$ ) was added. As indicated, $\mathrm{CaCl}_{2}(2 \mathrm{mM})$ was present from the start of the incubation (during platelet spreading) was given together with thrombin (after the completion of spreading). After $15 \mathrm{~min}$ of vehicle or thrombin addition, the platelets were counted that were elevated in $\left[\mathrm{Ca}^{2+}\right]_{i}$ and stained with FITC-labelled annexin $V$ (PS exposing), using fluorescence video imaging techniques. Data are mean numbers \pm sem $(n=4-6$ experiments, $>150$ platelets per experiment). "Pretreated with $2 \%$ bovine serum albumin; "nd, not determined. 
$\left[\mathrm{Ca}^{2+}\right]_{i}$, it was of interest to measure exposed PS of these cells.

Accordingly, $\left[\mathrm{Ca}^{2+}\right]_{i}$ levels and FITC-annexin V-binding capacity were directly compared for a larger number of platelets spread on polymeric or monomeric fibrin or on fibrinogen (TABLE 7.1). As expected, in the absence of thrombin, only a small fraction of the platelets bound annexin $V$. However, this fraction considerably increased after addition of thrombin and $\mathrm{CaCl}_{2}$, regardless of whether the cells had spread on fibrin, fibrin monomers of fibrinogen (TABLE 7.1). As observed before [23], essentially all annexin $\mathrm{V}$-positive platelets were increased in $\left[\mathrm{Ca}^{2+}\right]_{i}$, but not all $\left[\mathrm{Ca}^{2+}\right]_{i}$ elevated cells bound annexin $\mathrm{V}$. Typically, when $\mathrm{CaCl}_{2}$ was added simultaneously with thrombin, the number of annexin V-binding platelets was much higher $(28-29 \%)$ than upon earlier $\mathrm{CaCl}_{2}$ application during the spreading phase $(6-12 \%)$, while the platelet fraction with increased $\left[\mathrm{Ca}^{2+}\right]$, was hardly affected by the time of addition (TABLE 7.1). Nevertheless, the number of PS-exposing platelets never reached a level higher than $30 \%$, even not after prolonged incubation times.

Evidence that integrin $\alpha_{110} \beta_{3}$-mediated events were involved in the thrombin/CalC $\mathrm{C}_{2}$-evoked induction of PS exposure was obtained by using the integrin receptor antagonist, dRGDW. In the presence of high dRGDW concentrations $>0.2$ $\mathrm{mM}$ ), platelet binding to both fibrin and fibrinogen surfaces was completely abolished (data not shown). However, at a low concentration of $10 \mu \mathrm{M}$ dRGDW, the adrenaline-stimulated platelets still bound to the surfaces, but they did not spread. Addition of thrombin ( $4 \mathrm{nM}$ ) resulted in spiking $\mathrm{Ca}^{2+}$ signals in most of the bound cells. With this dRGDW concentration, the fraction of annexin V-positive cells on fibrin decreased considerably with $89 \pm 6 \%$ (mean \pm sem, $n=4$ experiments).
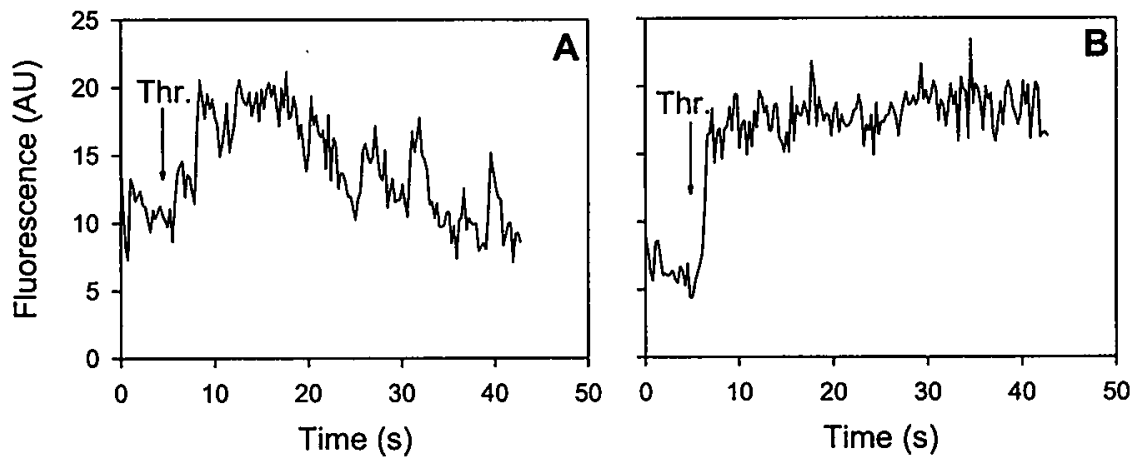

FIGURE 7.3 Confocal recording of thrombin-evoked calcium responses of platelets in a fibrinogen aggregate. Suspensions of fluo-3-loaded platelets containing fibrinogen $(1 \mathrm{mg} / \mathrm{ml})$ were stimulated with adrenaline $(10 \mu \mathrm{M})$ under gentle stirring. The resulting small platelet thrombi were immobilised on a fibrinogen-coated coverslip and monitored on changes in fluo-3 fluorescence by confocal laser scanning microscopy. $\mathrm{CaCl}_{2}(2 \mathrm{mM})$ was added immediately before start of the recording, and thrombin $(4 \mathrm{nM})$ was given as indicated. Increases in fluorescence indicate increases in $\left[\mathrm{Ca}^{2+}\right]_{i}$. Signals of two platelets are shown within a single aggregate. Data are typical for 3 experiments. 


\section{Platelets in Fibrinogen Aggregates}

To determine whether fibrin(ogen)-bound, integrin $\alpha_{1 \mid} B_{3}$-activated platelets were more reactive towards thrombin in terms of the procoagulant response under different, physiological conditions, we considered the effects of thrombin on platelets in microaggregates. Small aggregates consisting of 10-50 platelets were prepared by slowly stirring a platelet suspension with fibrinogen $(1 \mathrm{mg} / \mathrm{ml})$ and adrenaline $(10 \mu \mathrm{M})$. After immobilising on a fibrinogen-coated coverslip, the aggregates were observed on the level of single cells by using high-frequency confocal laser scanning microscopy. For part of the experiments, the platelets were prelabeled with the $\mathrm{Ca}^{2+}$ probe Fluo-3 (excitable by the $488 \mathrm{~nm}$ line of the argon laser), whereas for other measurements FITC-labelled annexin $V$ was used as a probe. Addition of thrombin $/ \mathrm{CaCl}_{2}$ to the Fluo-3-labelled platelets caused potent $\mathrm{Ca}^{2+}$ signals, which in $20 \%$ of the analysed cells (4/20 platelets, 4 aggregates) were spiking in shape (FIG. 7.3A) and in the remaining $80 \%$ were continuously high (FIG. 7.3B), thus indicating that thrombin physically reached most or all aggregated platelets. Images of Fluo-3 fluorescence taken after $10 \mathrm{~min}$ of thrombin activation showed that $84 \pm 7 \%$ of the platelets (meantsem, 8 aggregates) was elevated in $\left[\mathrm{Ca}^{2+}\right]_{i}$ (FIG. 7.4A). However, at this time point, only $36 \pm 10 \%(n=7)$ of the aggregated cells appeared to stain with FITCannexin V. As shown in FIG. 7.4B, most of the annexin V-binding platelets had a balloon-shaped appearance. In the control condition without thrombin, $<0.5 \%$ of the aggregated platelets were annexin $V$ positive. Thus, again, thrombin stimulated PS exposure in part of the platelets.
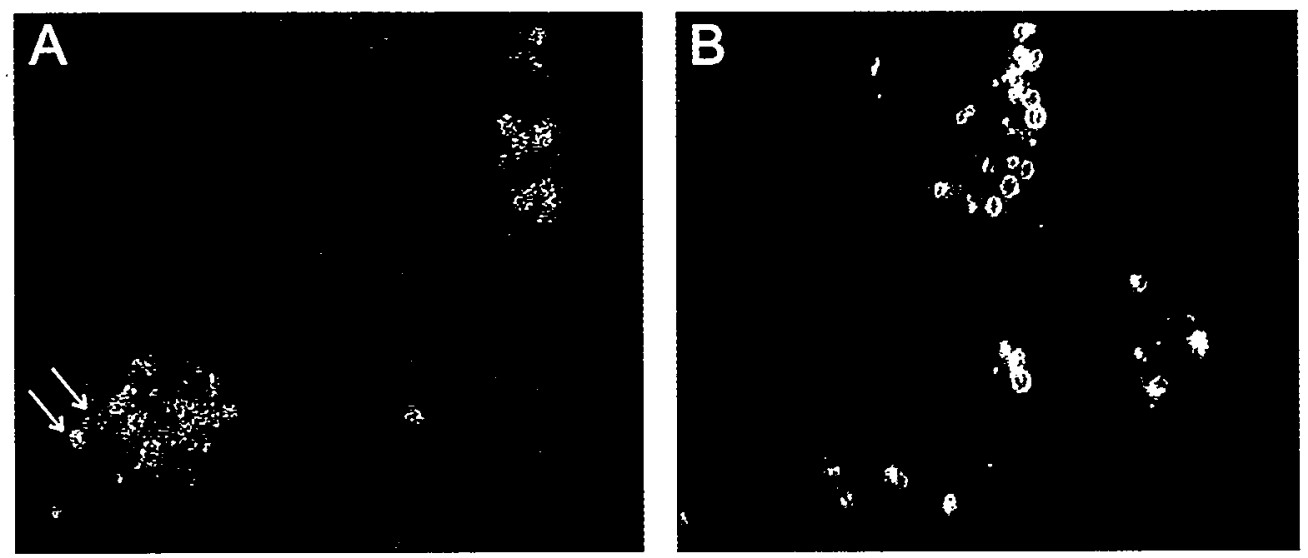

FiguRE 7.4 Confocal fluorescent images of activated platelets in a fibrinogen aggregate. Platelet aggregates were immobilised and stimulated with thrombin, as described for F1G. 7.3. Experiments were carried out with either fluo-3-loaded platelets $(A)$ or unloaded platelets in the presence of 0.25 $\mu \mathrm{g} / \mathrm{ml} \mathrm{FITC}$-labelled annexin $V(B)$. In panel $A$, elevated $\left[\mathrm{Ca}^{2+}\right]_{i}$ corresponds to more intense white levels; arrows show adjacent platelets with different levels of $\left[\mathrm{Ca}^{2+}\right]_{i}$. Representative laser scanning images are shown, as obtained after $10 \mathrm{~min}$ of thrombin stimulation. 


\section{Platelets in Contact with Fibrin Clots}

From earlier work $[28,29]$, we inferred that the presence of a preformed (threedimensional) fibrin clot might be needed to get maximal thrombin-evoked procoagulant platelet responses. Since the microscopic imaging techniques were unsuited to monitoring this in macroscopic clots, platelet-dependent prothrombinase activity was instead measured, i.e. the capability of platelets to stimulate the factor Va/factor Xa-dependent cleavage of prothrombin [17]. Thrombin-free fibrin clots were prepared from a fibrinogen solution using the venom protease, ancrod. Preformed clots were incubated with platelets in the presence of absence of adrenaline $(10 \mu \mathrm{M})$ and/or thrombin $(4 \mathrm{nM})$, and then transferred with adherent platelets to other tubes to measure either platelet number or the prothrombinase-stimulating activity. Assaying was in the presence of $\mathrm{CaCl}_{2}$, factors $\mathrm{Va}$ and $\mathrm{Xa}$ and prothrombin under conditions that the amount of platelet material was rate-limiting for thrombin formation. Without clot, only limited amounts of thrombin were formed of about $10 \mathrm{nM} / \mathrm{min} / 10^{6}$ platelets, which reflects the basal prothrombinase activity of washed platelets in suspension [17]. In the presence of a fibrin clot, however, thrombin formation increased ten-fold when using either unstimulated or adrenaline- stimulated platelets (FIG. 7.5).

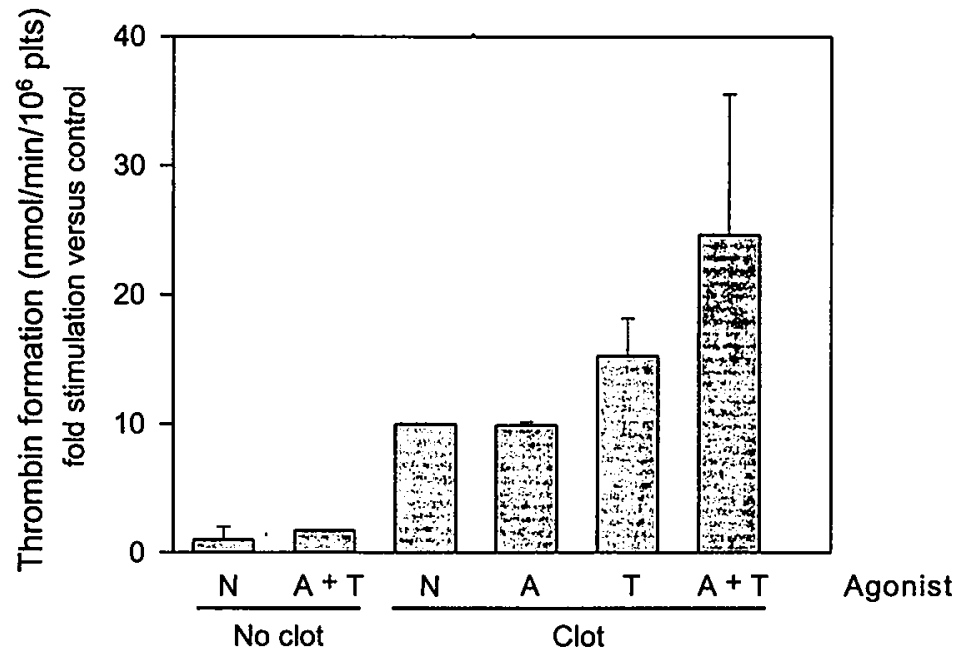

FIGURE 7.5 Effect of fibrin clots on the prothrombin-converting activity of platelets. Platelets in nominally $\mathrm{Ca}^{2+}$-free Hepes buffer $\left(1 \times 10^{8}\right.$ cells $\left./ 0.5 \mathrm{ml}\right)$ were incubated with a thrombin-free fibrin clot in the presence or absence $(N)$ of adrenaline $(A, 10 \mu \mathrm{M})$ and/or thrombin $(T, 4 \mathrm{nM})$, where indicated. Control experiments were run in the absence of a clot. After $45 \mathrm{~min}$ of incubation, fixed volumes of clots with adherent platelets were transferred to an assay mixture of $2 \mathrm{mM} \mathrm{CaCl}, 2 \mu \mathrm{M}$ prothrombin, $7 \mathrm{nM}$ factor $\mathrm{Va}$ and $0.3 \mathrm{nM}$ factor $\mathrm{Xa}$. In these mixtures, thrombin formation was followed in time (about linear from 5-15 min). Numbers of platelets per assay were determined in parallel incubations. Data are expressed as thrombin formation ( $\mathrm{nmol} / \mathrm{min} / 10^{6}$ platelets) compared to the control condition (no clot, no added agonist), which was taken as $100 \%$ (mean \pm sem, $n=3-6$ ). In a typical experiment, prothrombinase activity under control conditions was $10 \mathrm{nM}$ thrombin $/ \mathrm{min} / 10^{6}$ platelets; and $0.8 \times 10^{6}$ platelets were transferred with the clot (in the absence of agonists). 
Prestimulation with thrombin gave additional prothrombinase activity, whereas costimulation with adrenaline and thrombin duplicated the thrombin formation in comparison to the situation without added agonist. The latter effect was seen both in the absence and presence of clot (FIG. 7.5). In control experiments, where clots were incubated with the components of the prothrombinase complex in the absence of platelets, thrombin formation was absent.

Thus, regardless of the agonist present, clot addition resulted in about ten-fold increase in platelet-dependent prothrombinase activity. Apparently, the clot functions as a trap for platelets activated by thrombin that is either externally added or in situ generated during the initial phase of the prothrombinase reaction. Once bound to the clot, activated platelets apparently expose PS and potentiate the prothrombin conversion. Thus, also in this experimental setup, (in situ-generated) thrombin appears to act as a stimulator of the fibrin-clot dependent procoagulant platelet response.

\subsection{Discussion}

The present data indicate that adrenaline-activated platelets with activated integrin $\alpha_{111} \beta_{3}$ receptors adhere to and spread over a fibrin- or fibrinogen-coated surfaces with little $\mathrm{Ca}^{2+}$ signalling and no exposure of procoagulant PS. The integrin antagonist dRGDW decreases the degree of adhesion to fibrin, which is in agreement with the evidence that RGD sequences of the fibrin $\alpha$-chain forms the principal interaction site of fibrin fibers and $\alpha_{111} \beta_{3}$ integrins [29,35]. Similar observations have already earlier been made for platelets spreading over fibrinogen, which process was sometimes but not always accompanied by transient rises in $\left[\mathrm{Ca}^{2+}\right]_{i}[36,37]$. When comparing these two surfaces, it appears that fibrin is somewhat less platelet-activating than fibrinogen since, for instance, the frequency of 'spontaneous' $\left[\mathrm{Ca}^{2+}\right]_{\text {i }}$ spikes was about two-times lower for the fibrin-bound platelets. On the other hand, the present results with washed platelets differ markedly from those with earlier perfusion studies using anticoagulated whole blood, where fibrin appeared to be a more potent adhesive substrate for platelets than fibrinogen $[38,39]$. Possibly, other blood (plasma) factors may strengthen the platelet interaction with fibrin.

In three experimental settings, we found that thrombin stimulates the procoagulant response of platelets interacting with fibrin or fibrinogen. Thus, thrombin appeared to elicit exposure of procoagulant PS to the membrane surface with consequent stimulation of prothrombinase activity in case of: i) platelets adhering to fibrin- or fibrinogen-coated surfaces (TABLE 7.1), ii) platelets assembled into fibrinogen-platelet aggregates (FIG. 7.4), and iii) platelets incubated with a macroscopic clot (FIG. 7.5). As far as detectable, PS exposure was accompanied by 


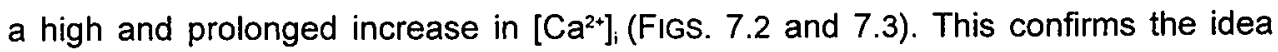
that a potent $\mathrm{Ca}^{2+}$ signal is required for this platelet reaction [20-22]. The present results, however, also suggest that integrin $\alpha_{111} B_{3}$ activation contributes in some way to this thrombin effect, since low doses of dRGDW (inhibiting platelet spreading but not the adhesion to fibrin or fibrinogen), markedly reduce the procoagulant response. The same conclusion has earlier been drawn from experiments where the fibrindependent stimulation of thrombin formation was measured in platelet-rich plasma: also in this situation, antibodies and reagents restraining integrin $\alpha_{110} B_{3}$-mediated adhesion reduced the platelet-dependent procoagulant effect $[29,40]$. The platelet literature provides indeed evidence that thrombin and integrin $\alpha_{110} B_{3}$ activation collaborate in inducing a variety of signalling pathways, such as activation of protein tyrosine kinases [41,42], protein tyrosine phosphatases [43,44], phosphoinositide 3kinase [45], and calcium-dependent proteases [46]. Whether these activation steps are indeed involved in the regulation of PS exposure and bleb formation needs to be established.

A question raising is, why thrombin activation of fibrin- or fibrinogen-bound platelets is a more weak stimulator of the procoagulant response than collagen activation (see Ref. 23). It is difficult to make a quantitative comparison of the microscopic annexin $\vee$ binding studies (FIGS. 7.1-4) and the macroscopic thrombin generation experiments (FIG. 7.5). However, because the latter experiments show that fibrin clots vigorously (ten-fold) stimulate the thrombin-generating response, it is clear that platelet-fibrin interaction can have a considerable potentiating effect on the procoagulant response. This might be achieved by the high levels of thrombin reached under conditions of continuing prothrombinase activity, but also by the reported effect of $\alpha_{111} \beta_{3}$ integrins on prothrombin binding and activation [47]. Since thrombin can also bind to fibrin [48], another factor may be that platelets in contact with the clot surface become more effectively stimulated by immobilised thrombin than unbound platelets. Finally, earlier studies with platelets in coagulating plasma have demonstrated that also other plasma or platelet factors such as von Willebrand factor and its receptor on platelets, the glycoprotein Ib/N/X complex, contribute to the thrombin/fibrin-dependent procoagulant response [3,28]. Accordingly, the presently identified effect of thrombin on platelets is likely to be only part, though important, of more complex feed-forward loops which ensure efficient thrombin generation and activity at sites of fibrinogen deposition and fibrin formation.

\subsection{Acknowledgements}

The authors acknowledge grants from the Netherlands Heart Foundation (NHS 93.166) and the Netherlands Organisation for Scientific Research (NWO 902-17- 
216). C.M.A.N. acknowledges support from Hoffmann-La Roche (Basel, Switzerland).

\subsection{References}

1. Zwaal RFA, Comfurius P, Bevers EM. Platelet procoagulant activity and microvesicle formation. Its putative role in hemostasis and thrombosis. Biochim Biophys Acta. 1992;1180: 1-8.

2. Hemker HC. Thrombin generation, an essential step in haemostasis and thrombosis; in Bloom AL, Forbes ED, Thomas DP, Tuddenham EGD (eds): Haemostasis and Thrombosis, 3rd ed. London, Churchill Livingstone, 1993, pp 477-490.

3. Beguin $S$, Kumar $R$. Thrombin, fibrin and platelets: a resonance loop in which von Willebrand factor is a necessary link. Thromb Haemost. 1997;78: 590-594.

4. Walsh PN. Different requirements for intrinsic factor $\mathrm{Xa}$ forming activity and platelet factor 3 activity and their relationship to platelet aggregation and secretion. $\mathrm{Br} J$ Haematol. 1978;40: 311-331.

5. Mann KG, Krishnawamy S, Lawson JH. Surface-dependent hemostasis. Semin Hematol. 1992;29: 213-226.

6. Weiss HJ. Scott syndrome: a disorder of platelet coagulant activity. Semin Hematol. 1994;31: 312-319.

7. Toti F, Satta N, Fressinaud E. Meyer D, Freyssinet JM. Scott syndrome, characterized by impaired transmembrane migration of procoagulant phosphatidyiserine and hemorrhagic complications, is an inherited disorder. Blood. 1996;87: 1409-1415.

8. Weiss HJ, Lages B. Platelet prothrombinase activity and intracellular calcium responses in patients with storage pool deficiency, glycoprotein $11 \mathrm{~b}-11 \mathrm{la}$ deficiency, or impaired platelet coagulant activity: a comparison with Scott syndrome. Blood. 1997;89: 1599-1611.

9. Bevers EM, Comfurius P, van Rijn JLML, Hemker HC, Zwaal RFA. Generation of prothrombinconverting activity and the exposure of phosphatidylserine at the outer surface of platelets. Eur J Biochem. 1982;122: 429-436.

10. Rosing J, van Rijn JLML, Bevers EM, van Dieijen G, Comfurius P. Zwaal RFA. The role of activated human platelets in prothrombin and factor $X$ activation. Blood. 1985;65: 319-332.

11. Sims PJ, Wiedmer T, Esmon CT, Weiss HJ, Shattil SJ. assembly of the platelet prothrombinase complex is linked to vesiculation of the platelet plasma membrane. $J$ Biol Chem. 1989;264: 17049-17057.

12. Williamson P, Bevers EM, Smeets EF, Comfurius P, Schlegel RA, Zwaal RFA. Continuous analysis of the mechanism of activated transbilayer lipid movement in platelets. Biochemistry. 1995;34: 10448-10455.

13. Bassé $F$, Stout JG, Sims PJ, Wiedmer $T$. Isolation of an erythrocyte membrane protein that mediates $\mathrm{Ca}^{2+}$-dependent transbilayer movement of phospholipid. $J$ Biol Chem. 1996; 71: 17205-17210.

14. Heemskerk JWM, Feijge MAH, Henneman $L$, Rosing $J$, Hemker $\mathrm{HC}$. The $\mathrm{Ca}^{2+}$-mobilising potency of $\alpha$-thrombin and thrombin-receptor-activating peptide on human platelets. Concentration and time effects of thrombin-induced $\mathrm{Ca}^{2+}$ signaling. Eur J Biochem. 1997;249: 547-555.

15. Jamieson GA. Pathophysiology of platelet thrombin receptors. Thromb Haemost. 1997;78: 242-246.

16. Xu WF, Andersen H, Whitmore TE, Presnell SR, Yee DP, Ching A, Gilbert T, Davie EW, Foster DC. Cloning and characterization of human protease-activated receptor 4 . Proc Natl Acad Sci USA. 1998;95: 6642-6646.

17. Tans G, Rosing J, Thomassen MCLGD, Heeb MJ, Zwaal RFA, Griffin JH. Comparison of anticoagulant and procoagulant activities of stimulated platelets and platelet-derived microparticles. Blood. 1991;77: 2641-2648. 
18. Goodwin CA, Wheeler-Jones CPD, Kakkar W, Deadman JJ, Authi KS, Scully MF. Thrombin receptor activating peptide does not stimulate platelet procoagulant activity. Biochem Biophys Res Commun. 1994;202: 321-327.

19. Pasquet JM, Dachary-Prigent J, Nurden AT. Calcium influx is a determining factor of calpain activation and microparticle formation in platelets. Eur J Biochem. 1996;239: 647-654.

20. Smeets EF, Heemskerk JWM, Comfurius P, Bevers EM, Zwaal RFA. Thapsigargin amplifies the platelet procoagulant response caused by thrombin. Thromb Haemost. 1993;70: 10241029.

21. Dachary-Prigent J, Pasquet JM, Freyssinet JM, Nurden AT. Calcium involvement in aminophospholipid exposure and microparticle formation during platelet activation: a study using Ca2+-ATPase inhibitors. Biochemistry. 1995;34: 11625-11634.

22. Pasquet JM, Dachary-Prigent $J$, Nurden AT. Microvesicle release is associated with extensive protein tyrosine phosphorylation in platelets stimulated by $A 23187$ or a mixture of thrombin and collagen. Biochem J. 1998;333: 591-599.

23. Heemskerk JWM, Vuist WMJ, Feijge MAH, Reutelingsperger CPM, Lindhout T. Collagen but not fibrinogen surfaces induce bleb formation, exposure of phosphatidylserine, and procoagulant activity of adherent platelets: evidence for regulation by protein tyrosine kinasedependent $\mathrm{Ca}^{2+}$ responses. Blood. 1997;90: 2615-2625.

24. Bennett JS, Vilaire $G$, Cines DB. Identification of the fibrinogen receptor on human platelets by photoaffinity labeling. J Biol Chem. 1982;257: 8049-8054.

25. Gogstad GO, Brosstad F, Krutnes M, Hagen I, Solum NO. Fibrinogen-binding properties of the human platelet glycoprotein Ilb-llla complex: a study using cross-radioimmunoelectrophoresis. Blood. 1982;60: 663-671.

26. Nachman RL, Leung LLK. Complex formation of platelet membrane glycoproteins IIb and IIla with fibrinogen. $J$ Clin Invest. 1982;69: 263-269.

27. Shattil SJ, Kashiwagi H, Pampori N. Integrin signaling: the platelet paradigm. Blood. 1998;91: 2645-2657.

28. Kumar R, Béguin $S$, Hemker HC. The effect of fibrin clots and clot-bound thrombin on the development of platelet procoagulant activity. Thromb Haemost. 1995;74: 962-968.

29. Reverter JC, Béguin S, Kessels H, Kumar R, Hemker HC, Coller BS. Inhibition of plateletmediated, tissue factor-induced thrombin generation by the mouse/human chimeric 7E3 antibody. Potential implications for the effects of c7E3 Fab treatment on acute thrombosis and 'clinical restenosis'. J Clin Invest. 1996;98: 863-874.

30. Heemskerk JWM, Hoyland J, Mason WT, Sage SO. Spiking in cytosolic calcium concentration in single fibrinogen-bound fura-2-loaded human platelets. Biochem J. 1992;283: 379-383.

31. Müler-Berghaus G, Roka L, Lasch HG. Induction of glomular microclot formation by fibrin monomer infusion. Thromb Diathes Haemorrh. 1973;29: 375-383.

32. Grynkiewicz, G, Poenie M, Tsien RY. A new generation of $\mathrm{Ca}^{2+}$ indicators with greatly improved fluorescent properties. J Biol Chem. 1985;260: 3440-3450.

33. Plow EF, Marguerie GA. Induction of fibrinogen receptor on human platelets by epinephrine and the combination of epinephrine and ADP. J Biol Chem. 1980;255: 10971-10977.

34. Siess W. Molecular mechanisms of platelet activation. Physiol Rev. 1989;69: 58-178.

35. Hantgan RR. Localisation of the domains of fibrin involved in binding to platelets. Biochim Biophys Acta. 1988; 968: 36-44.

36. Jen $\mathrm{CJ}$, Chen HI, Lai KC, Usami S. Changes in cytosolic calcium concentrations and cell morphology in single platelets adhering to fibrinogen-coated surface under flow. Blood. 1996;87: 3775-3782.

37. Heemskerk JWM, Vis P, Feijge MAH, Hoyland J, Mason WT, Sage SO. Role of phospholipase $\mathrm{C}$ and $\mathrm{Ca}^{2+}$-ATPase in calcium response of single fibrinogen-bound platelets. $J$ Biol Chem. 1993;268: 356-363.

38. Jen CJ, Lin JS. Direct observation of platelet adhesion to fibrinogen- and fibrin-coated surfaces. Am J Physiol. 1991;261: H1457-H1463.

39. Jirousková M, Dyr JE, Suttnar J, Holada $K$, Trnková B. Platelet adhesion to fibrinogen, fibrin monomer, and fibrin protofibrils in flowing blood; the effect of fibrinogen immobilization and fibrin formation. Thromb Haemost. 1997;78: 1125-1131. 
40. Keularts IMLW, Béguin S, de Zwaan C, Hemker HC. Treatment with a GPIIb/Ila antagonist inhibits thrombin generation in platelet-rich plasma from patients. Thromb Haemost. 1998;80: 370-371.

41. Lipfert L, Haimovich B, Schaller MD, Cobb BS, Parsons JT, Brugge JS. Integrin-dependent phosphorylation and activation of the protein tyrosine kinase $\mathrm{pp} 125^{\mathrm{FAK}}$ in platelets. $J$ Cell Biol. 1992;119: 905-912.

42. Gao J, Zoller K, Ginsberg MH, Brugge JS, Shattil SJ. Regulation of the pp72 ${ }^{\text {Syk }}$ protein tyrosine kinase by platelet integrin $\alpha_{11 !} \beta_{3}$. EMBO J. 1997;16: 6414-6425.

43. Ezumi $Y$, Takayama $H$, Okuma M. Differential regulation of protein-tyrosine phosphatases by integrin $\alpha_{110} \beta_{3}$ through cytoskeletal reorganization and tyrosine phosphorylation in human platelets. J Biol Chem. 1995;270: 11927-11934.

44. Laffargue M, Monnereau L, Tuech J, Ragab A, Ragab-Thomas J, Payrastre B, Raynal $P$, Chap H. Integrin-dependent tyrosine phosphorylation and cytoskeletal translocation of Tec in thrombin-activated platelets. Biochem Biophys res Commun. 1997;238: 247.

45. Guinebault C, Payrastre B, Racaud-Sultan C, Mazarguil $H$, Breton M, Mauco G, Plantavid M, Chap H. Integrin-dependent translocation of phosphoinositide 3-kinase to the cytoskeleton of thrombin-activated platelets involves specific interactions of $\mathrm{p} 85_{\text {_ }}$ with actin filaments and focal adhesion kinase. J Cell Biol. 129;1995: 831-842.

46. Schoenwaelder SM, Yuan $Y$, Cooray $P$, Salem HH, Jackson SP. Calpain cleavage of focal adhesion proteins regulates the cyloskeletal attachment of integrin $\alpha_{110} B_{3}$ (platelet glycoprotein Ilb/lla) and the cellular retraction of fibrin clots. J Biol Chem. 1997;272: 1694-1702.

47. Byzova TV, Plow EF. Networking in the hemostatic system: integrin $\alpha_{110} \beta_{3}$ binds prothrombin and influences its activation. $J$ Biol Chem. 1997;272: 27183-27188.

48. Bänninger $H$, Lämmle $B$, Furlan $M$. Binding of $\alpha$-thrombin to fibrin depends on the quality of the fibrin network. Biochem J. 1994;298: 157-163. 
Initial coagulation-stimulating effect of platelets in flowing rat blood is independent of platelet aggregation 


\subsection{Abstract}

Thrombin generated during the coagulation process is a potent platelet agonist causing aggregation of platelets and, under certain conditions, stimulating platelet surface changes that in turn are thrombinogenic. In coagulating blood, platelet binding to fibrin results in surface exposure of phosphatidylserine and consequent prothrombin-converting activity of the surface. Here, we studied the initial activation and aggregation of platelets in whole rat blood that was perfused under conditions of a moderately low wall shear rate $\left(250 \mathrm{~s}^{-1}\right)$ over a fibrinogen-containing surface. Triggering of citrated blood with $\mathrm{CaCl}_{2}$ and tissue factor resulted in a rapid platelet deposition to the surface, the simultaneous formation of fibrin and platelet aggregates, and in rises in cytosolic $\left[\mathrm{Ca}^{2+}\right]_{i}$ and phosphatidylserine exposure of many of the adherent platelets. The thrombin inactivators heparin and PPACK abolished platelet adhesion and activation as well as fibrin formation. The platelet inhibitors, prostaglandin $E_{1}$ (an EP receptor agonist) and AR C-316991MX (a P2Y 12 receptor antagonist), almost completely prevented aggregation of the adherent platelets, but did not influence fibrin deposition nor phosphatidylserine surface exposure. These results indicate that in flowing whole blood, platelets provide a potent, coagulationstimulating surface regardless of their clustering into aggregates.

\subsection{Introduction}

Haemostasis is a complex mechanism, involving formation of a platelet plug and stimulation of the coagulation cascade. Both platelets and thrombin play crucial roles in either process. The coagulation cascade is triggered by tissue factor, exposed at the surface of a damaged vessel wall or blood-borne, which results in the formation of thrombin. Thrombin has many actions: it potentiates the coagulation cascade and converts fibrinogen into fibrin, but also acts as a major platelet agonist. Activated platelets, in turn, are known to propagate the coagulation process, particularly by exposing phosphatidylserine and factor $V(a)$ at their outer membrane surface. The exposed phosphatidylserine and factor $V(a)$ serve as sites for the assembly and activation of the tenase and prothrombinase complexes, resulting in an almost thousand-fold increase in the formation of factor $X a$ and thrombin, respectively [1-4].

In recent years, it has been demonstrated that in platelet-containing plasma the addition or generation of fibrin clots has a strong stimulatory effect on thrombin formation and, thus, on the coagulation process $[5,6]$. Interventions in this system with antibodies against the platelet-adhesive receptors, integrin $\alpha_{11 b} \beta_{3}$ (fibrinogen receptor) and glycoprotein $\mathrm{Ib} / \mathrm{IX}$ (von Willebrand factor receptor), effectively suppress 
the platelet-dependent thrombin formation $[7,8]$. These findings confirm the presence of a potent resonance loop, in which small amounts of thrombin formed activate platelets and convert fibrinogen to fibrin, after which the formed fibrin and thrombin stimulate phosphatidylserine exposure on platelets, thus facilitating the generation of more thrombin [6].

Only little is known of the precise intracellular events and environmental conditions causing the platelet procoagulant response. Platelet signalling events involved are a prolonged increase in cytosolic $\left[\mathrm{Ca}^{2+}\right]_{i}$ and protein tyrosine dephosphorylation [9-11]. The exposure of procoagulant phospholipids is mostly accompanied by extensive rearrangements of the actin cytoskeleton, resulting in a balloon-shaped form and appearance of membrane blebs at the platelet surface, which later shed into the circulation as platelet-derived microvesicles $[9,12,13]$. Beside stimulation with $\mathrm{Ca}^{2+}$ ionophores, platelet adhesion to collagen is a potent trigger of the procoagulant response, particularly through the glycoprotein $\mathrm{VI}$ collagen receptors $[11,13]$. In contrast, platelet interaction with fibrinogen or fibrin, even after stimulation with thrombin, is no more than a weak stimulator in the absence of other plasma factors $[14,15]$. The latter observation questions the relation between other platelet responses, such as adhesion and aggregation, and the procoagulant response under conditions of coagulation.

Here, we investigated the generation of platelet procoagulant activity, as detected from the exposure of phosphatidylserine, in a physiological system consisting of whole rat blood triggered with tissue factor and flowing at low shear rate over a fibrinogen-coated surface. In this system, platelet procoagulant activity appeared to be generated early in the coagulation process already and, intriguingly, was not influenced by inhibiting platelet aggregation with different platelet inhibitors.

\subsection{Materials and methods}

\section{Materials}

H-Phe-Pro-Arg chloromethyl ketone (PPACK) was from Calbiochem (La Jolla, CA, USA). Unfractionated heparin (4th international standard heparin, 0.05 unit/ml) was bought from the National Institute for Biological Standards and Control (London, UK). Chromogenic thrombin substrate, D-Phe-Pip-Arg p-nitroanilide (S2238), was obtained from Chromogenix (Mölmdal, Sweden). Bovine fibrinogen (type IV), rat thrombin, phospholipids and prostaglandin $E_{1}$ was purchased from Sigma (St. Louis, MO, USA). Recombinant human tissue factor was supplied by Dade (Düdingen, Switzerland), Oregon Green 488-labeled annexin V (OG488 annexin V) came from Nexins Research (Hoeven, The Netherlands). AR-C69931MX was obtained from 
AstraZeneca R\&D (Charnwood, UK). Other materials were obtained from sources described before [16].

\section{Preparation of rat blood and platelets}

Male Wistar rats were anaesthetised by intraperitoneal injection with Nembutal (50 $\mathrm{mg} / \mathrm{kg}$ body weight), and subjected to abdominal aortic puncture. The studies were approved by the Institutional Animal Care Committee. For perfusion studies, the blood was collected into 0.1 volume of a mixture of $130 \mathrm{mM}$ trisodium citrate and 183 $\mathrm{mM}$ glucose.

To prepare Fluo-3-labeled platelets, the aortic rat blood was collected into 0.2 volume of a solution of $183 \mathrm{mM}$ glucose, $80 \mathrm{mM}$ trisodium acetate and $52 \mathrm{mM}$ citric acid. Platelet-rich plasma, obtained by centrifugation, was used for the preparation of washed platelets [17]. Washed platelets $\left(5 \times 10^{8} / \mathrm{ml}\right)$ were loaded with $5 \mu \mathrm{M}$ Fluo-3 acetoxymethyl ester in the presence of $0.5 \mathrm{mg} / \mathrm{ml}$ Pluronic F-127 for 45 minutes, according to the procedure described for Fura-2 loading [18]. The labelled platelets were suspended at a concentration of $1 \times 10^{9} / \mathrm{ml}$ in Hepes buffer $\mathrm{pH} 7.45(136 \mathrm{mM}$ $\mathrm{NaCl}, 5.6 \mathrm{mM}$ glucose, $5 \mathrm{mM}$ Hepes, $2.7 \mathrm{mM} \mathrm{KCl}, 2 \mathrm{mM} \mathrm{MgCl}_{2}, 0.42 \mathrm{mM} \mathrm{NaH}_{2} \mathrm{PO}_{4}$ and $0.1 \%(\mathrm{w} / \mathrm{v})$ bovine serum albumin). These platelets were added to (autologous) anticoagulated whole blood as to give a fraction of $2 \%$ labelled platelets.

\section{Preparation of flow chambers and perfusion protocol}

Glass coverslips (50 $\times 24 \mathrm{~mm}$, Menzel-Glaser, Braunschweig, Germany) were coated with fibrinogen, as described elsewhere [11]. Coated coverslips were incubated with Hepes buffer $\mathrm{pH} 7.45$ containing $2 \%(\mathrm{w} / \mathrm{v})$ bovine serum albumin to shield any uncoated glass. The coverslip served as the basolateral side of a parallel-plate flow chamber $[19,20]$. The chamber was punched into a block of transparent poly(methyl methacrylate), and had dimensions of $0.2 \mathrm{~mm}$ (depth) $\times 5.0 \mathrm{~mm}$ (width) and $42.5 \mathrm{~mm}$ (length). Tapered ends at the two inlets reduced the total flow cell volume to approximately $60 \mu \mathrm{l}$. The coverslip area in contact with the perfusion fluid was 2.0 $\mathrm{cm}^{2}$. The flow chamber was connected, via siliconised plastic tubes and a three-way adapter, to three gas-tight syringes placed in different pulse-free perfusion pumps (Harvard Apparatus, South Natick, MA, USA). Pump 1 was equipped with a $5 \mathrm{ml}$ plastic Terumo syringe and filled with rat blood (perfusion rate was $27 \mathrm{ml} / \mathrm{hour}$, unless indicated otherwise). Pump 2 was equipped with a $2.5 \mathrm{ml}$ Hamilton glass syringe containing $167 \mathrm{mM} \mathrm{CaCl}, 153 \mathrm{mM} \mathrm{NaCl}$ and $20 \mathrm{pM}$ recombinant tissue

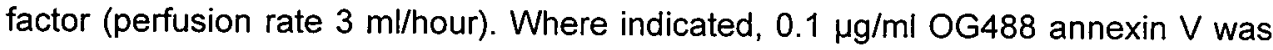
present during the flow experiment. When operating together, these pumps produced a perfusion rate of $30 \mathrm{ml} /$ hour, equivalent to a wall shear rate of $250 \mathrm{sec}^{-1}$. Pump 3 was used for rinsing purposes (flow rate $30 \mathrm{ml} /$ hour). It was armed with a $5 \mathrm{ml}$ plastic Terumo syringe, containing Hepes buffer $\mathrm{pH} 7$ supplemented with $2 \mathrm{mM} \mathrm{CaCl}_{2}$. 
Fluorescence and phase-contrast image recording during perfusion

The perfusion chamber with fibrinogen-coated coverslip was placed on the stage of an inverted microscope (Nikon Diaphot 200, Tokyo, Japan). Fluorescence from Fluo3 or OG488 annexin $V$ was monitored with a fluorescence image recording system that was connected to the microscope and controlled by a Unix/Quanticell-driven computer (Visitech, Sunderland, UK), as described elsewhere [4,11]. Excitation and emission wavelengths were $485 \mathrm{~nm}$ (half-bandwidth $22 \mathrm{~nm}$ ) and $530 \mathrm{~nm}$ (halfbandwidth $30 \mathrm{~nm}$ ), respectively. A $505 \mathrm{~nm}$ dichroic long-pass filter collected fluorescent light. Images were taken during or after perfusion with an intensified, charge-coupled device camera working at video rate (Photonic Sciences, Robertsbridge, UK), and background-subtracted and averaged real-time. Phasecontrast images were recorded upon trans-illumination with (infrared) light. The latter images were captured with a second intensified camera (Vista, Norbain, UK), which was also coupled to the inverted microscope. These images were processed by a second Unix/Quanticell 900-driven computer system.

Changes in Fluo-3 fluorescence in single platelets were converted into changes in $\left[\mathrm{Ca}^{2+}\right]_{i}$ by converting the fluorescence values in pseudo-ratio values $(F)$, by normalising for the fluorescence under resting conditions $\left(F_{0}\right)$, as described elsewhere [21]. Using the $F^{\prime}$ values, $\left[\mathrm{Ca}^{2+}\right]_{i}$ in the platelets was determined from the equation $\left[\mathrm{Ca}^{2+}\right]_{\mathrm{i}}=K_{d} \times F^{\prime} /\left(F_{\max }^{\prime}-F\right)$. The maximal pseudo-ratio fluorescence level, $F_{\text {max }}^{\prime}$, was determined using a solution of free Fluo-3 $\left(K_{d}=316 \mathrm{nM}\right)$. Images of $0 \mathrm{G} 488$ annexin $V$ fluorescence and phase-contrast transmission images ( $>5$ microscopic fields per experiment) were analysed on coverage of (fluorescent-labelled) platelets by computer-assisted image analysis [4].

\subsection{Results}

Tissue factor-stimulated coagulation induces mural fibrin formation and platelet aggregation in flowing, whole blood

An ex vivo model was developed to monitor initial stages of platelet-dependent haemostasis. Aortic rat blood, freshly collected in citrate was used which, upon recalcification, had a clotting time of $>300 \mathrm{~s}$. The citrated blood was placed in a plastic syringe and mixed with $\mathrm{CaCl}_{2}$ (16.7 mM, f.c.) from a second syringe. Immediately after mixing, the blood was perfused through a transparent flow chamber that at the basolateral side consisted of a coverslip coated with fibrinogen. The flow chamber was mounted on the stage of an inverted fluorescence microscope, equipped with intensified charge-coupled device cameras to record trans-illumination phase-contrast images and epi-illumination fluorescence images. 

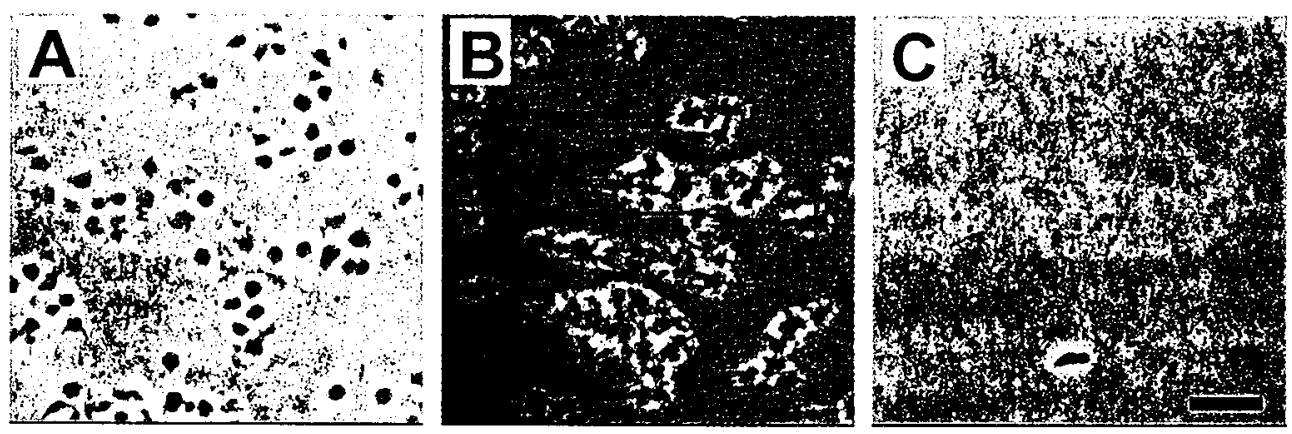

FIGURE 8.1 Initial platelet activation and coagulation in tissue factor-activated, flowing whole blood. Recalcified whole rat blood was perfused at a wall shear stress of $250 \mathrm{sec}^{-1}$ over a fibrinogen-coated coverslip. Phase-contrast, microscopic images were taken at the focal plane of the coverslip after 300 sec of perfusion. (A). Perfusion in the presence of only $\mathrm{CaCl}_{2}(16.7 \mathrm{mM})$. (B) Perfusion with $\mathrm{CaCl}_{2}$ $(16.7 \mathrm{mM})$ and recombinant tissue factor $(2 \mathrm{pM})$. (C) Perfusion of blood pretreated with heparin (0.05 $\mathrm{U} / \mathrm{ml})$ in the presence of $\mathrm{CaCl}_{2}(16.7 \mathrm{mM})$ and recombinant tissue factor $(2 \mathrm{pM})$. Images are from representative microscopic fields ( $n>4$ experiments, bar $=10 \mu \mathrm{m}$ ).

Perfusion of the anti-coagulated blood through the flow chamber at a moderately low wall shear rate of $250 \mathrm{~s}^{-1}$ resulted in adhesion of mostly individual platelets, which took a dendritic state and spread over the surface (FIG. 8.1A). Fibrin fibers were incidentally detected at the end of the 300-s perfusion period.

To stimulate the coagulation process, the anticoagulated blood was mixed with $\mathrm{CaCl}_{2}$ and recombinant human tissue factor (2 $\mathrm{pM}$, f.c.) immediately before the inlet of the flow chamber. When measured in a test tube, this concentration of tissue factor caused clotting of the blood after about $30 \mathrm{~s}$. As observed from the phasecontrast images, perfusion of the triggered blood resulted in rapid appearance of fibrin fibers. After $150 \mathrm{~s}$, a complete layer had formed of fibrin fibers, which persisted and were mostly oriented along the direction of the blood flow (FIG. 8.1B). Platelets accumulated on the coverslip often at the sites of fibers. They formed pseudopods, sometimes with fibers attached, and many were trapped into small aggregates at such a rate that about $30 \%$ of the surface was covered with platelets after $300 \mathrm{~s}$ of flow (FIG. 8.1B). The presence of fibrin and activated platelets pointed to the presence of thrombin, i.e. generated by the tissue factor/CaCl $\mathrm{C}_{2}$-induced coagulation process. Indeed, in samples taken at the outlet of the flow chamber, proteolytically active thrombin was detected after triggering of the blood with tissue factor/ $\mathrm{CaCl}_{2}(\mathrm{C}$. Nieuwenhuys, unpublished data). Involvement of thrombin was confirmed by preincubation of the anticoagulated blood with heparin, a potent anti-thrombin activator. We added unfractionated heparin at a very low dose $(0.05 \mathrm{unit} / \mathrm{ml})$, sufficient to prolong the clotting time in a test tube to about $300 \mathrm{~s}$. Indeed, after $300 \mathrm{~s}$ of perfusion with heparinised blood, fibrin formation was still not detectable and only very few platelets were loosely attached to the surface (FIG. 8.1C). Similar results were 

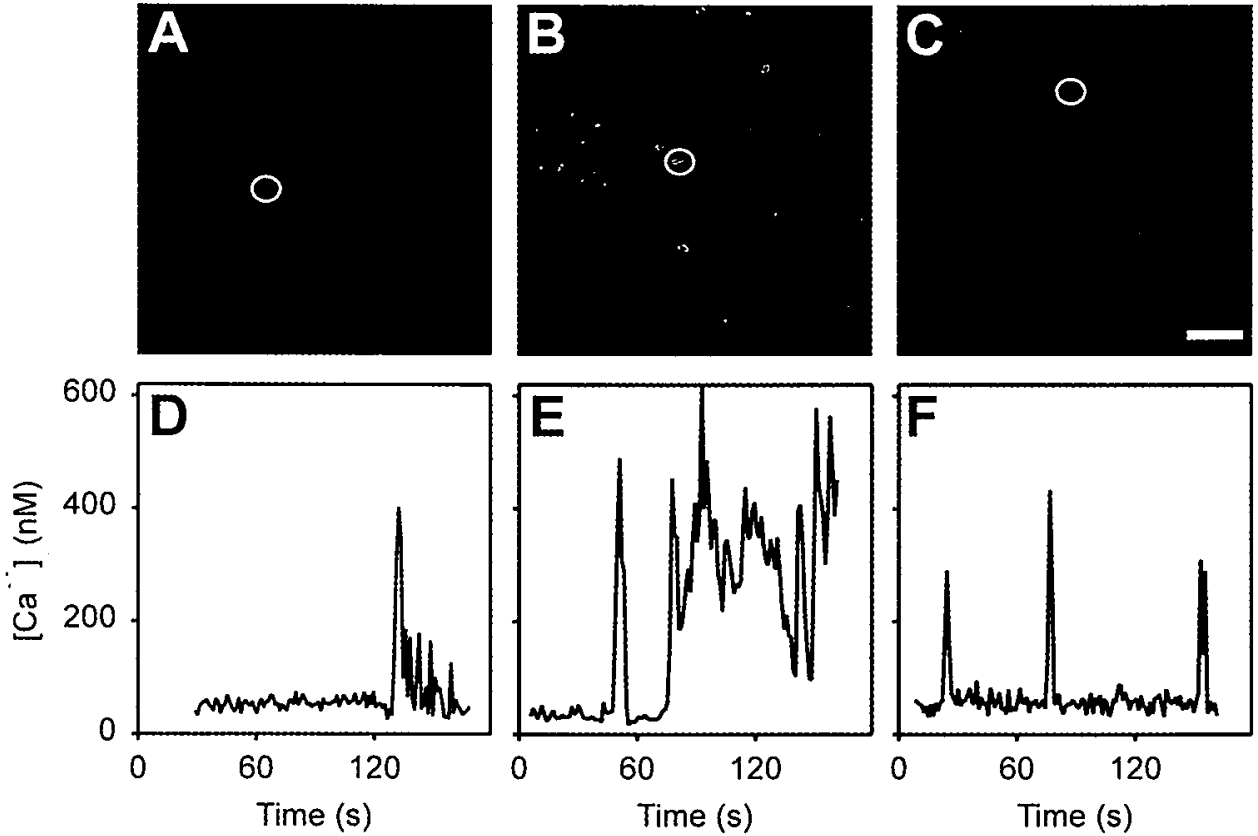

FIGURE 8.2 Calcium responses of platelets adhering from tissue factor-activated, flowing blood. Recalcified rat blood, containing autologous, Fluo-3-loaded platelets ( $2 \%$ labelled of total platelets), was perfused over fibrinogen, as indicated in FIG. 8.1. Images of Fluo-3 fluorescence were recorded after $300 \mathrm{sec}$ of perfusion $(A-C)$; changes in $\left[\mathrm{Ca}^{2+}\right]_{i}$ were determined in single, adhering platelets during the course of the experiment (D-F). Left panels: perfusion in the presence of only $\mathrm{CaCl}_{2} . \mathrm{Middle}$ panels: perfusion with $\mathrm{CaCl}_{2}$ and tissue factor. Right panels: perfusion of blood pretreated with heparin $(0.05 \mathrm{unit} / \mathrm{ml})$ in the presence of $\mathrm{CaCl}_{2}$ and tissue factor. Images are from representative microscopic fields ( $n>4$ experiments, bar $=10 \mu \mathrm{m}$ ).

obtained when the blood was pre-treated with the thrombin active-site inhibitor PPACK $(10 \mu \mathrm{M})$ instead of heparin (not shown). Thus, most if not all of the fibrin formation and platelet reactions in this system are due to the coagulation activation and thrombin formation.

Inclusion of Fluo-3-loaded platelets (2\% of total platelets) to the blood immediately before perfusion allowed monitoring of the changes in $\left[\mathrm{Ca}^{2+}\right]_{i}$ during adhesion to the coverslip. After triggering with only $\mathrm{CaCl}_{2}$ (no added tissue factor), $\left[\mathrm{Ca}^{2+}\right]_{i}$ in about $90 \%$ of the adhering, fluorescent platelets remained low during the first minutes of measurement, after which the cells showed spiking in $\left[\mathrm{Ca}^{2+}\right]_{i}$ (FIG. $8.2 \mathrm{~A}, \mathrm{D})$. In many of the other $10 \%$ of labelled platelets, spiking in $\left[\mathrm{Ca}^{2+}\right]_{i}$ started earlier. When perfusion was performed in the presence of tissue factor ( $2 \mathrm{pM})$, almost all Fluo-3-labeled platelets adhering to the surface or aggregated with other platelets showed an increase in $\left[\mathrm{Ca}^{2+}\right]_{\mathrm{i}}$, which was prolonged in shape and usually preceded by a lag-time $>60 \mathrm{~s}$ (FIG. 8.2B,E), indicative for a high activation state of the cells. With heparin present, the incidental platelets that remained attached to the 
Control
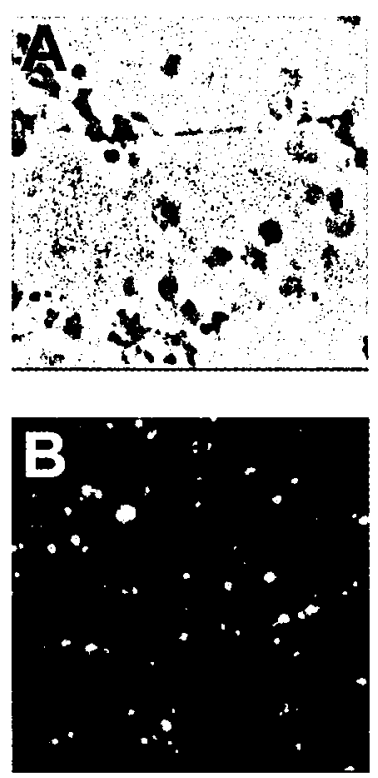

Heparin

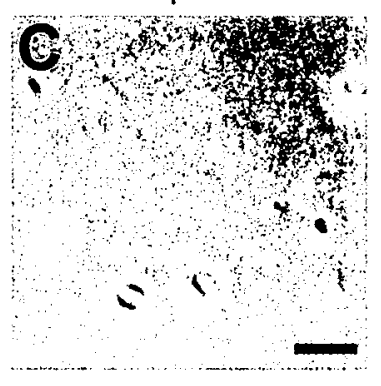

D

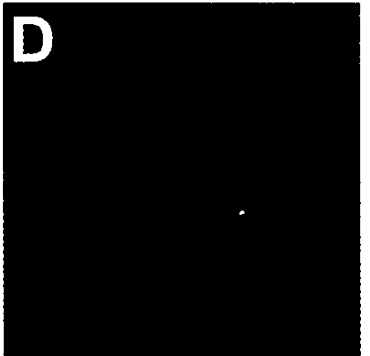

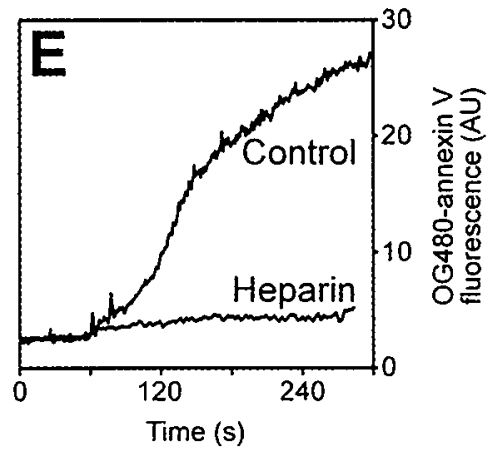

FIGURE 8.3 Procoagulant response of platelets deposited from tissue factor-activated, flowing blood. Rat blood was triggered with $\mathrm{CaCl}_{2} /$ tissue factor, and perfused over a fibrinogen-coated coverslip as described for FIG. 8.1. OG488-labeled annexin $V(0.2 \mu \mathrm{g} / \mathrm{ml})$ was present during perfusion. Left pane/s (control condition): blebbing morphology of adherent platelets (A); OG488 fluorescence image after 300-s perfusion (B). Middle panels (heparin-treated blood): platelet morphology (C); OG488 fluorescence image after perfusion (D). Right panel: accumulation of labelled platelets during perfusion (E). Bar is $10 \mu \mathrm{m}$.

surface in $300 \mathrm{~s}$ were low in $\left[\mathrm{Ca}^{2+}\right]_{i}$ with the exception of incidental $\left[\mathrm{Ca}^{2+}\right]_{\mathrm{i}}$ spikes (FIG. $8.2 \mathrm{C}, \mathrm{F})$. These results indicate that, directly or indirectly, the thrombin that is generated during the tissue factor-triggered coagulation process has a potent platelet-stimulating effect.

Procoagulant activity of platelets deposited from tissue factor-activated, flowing blood Closer inspection of the morphology of cells on coverslip showed that many of the adherent and aggregated platelets had transformed into transparent, balloon-like structures (FIG. 8.3A). This appearance, resembling that of blebbing platelets on collagen fibers, is suggestive for a procoagulant activation state of the cells, i.e. for surface exposure of coagulation-stimulating phosphatidylserine [11]. This was demonstrated by inclusion of a low concentration of OG488-labeled annexin V $(0.2$ $\mu \mathrm{g} / \mathrm{ml}$ ) in the perfused blood, which was sufficient to detect surface-exposed phosphatidylserine but too low to influence the coagulation process. Fluorescent images recorded during the perfusion experiment showed rapid accumulation of annexin-stained platelets on the coverslip (FIG. 8.3B,E). When using heparin- 
containing blood, the few adherent platelets were not shape-changed and lacked the blebbing morphology (FIG. 8.3C). The latter platelets did neither stain with OG488 annexin $V$ (FIG. 8.3D,E).

For quantification, 300-s perfusion experiments were performed (no annexin), after which the coverslips were briefly rinsed with $\mathrm{CaCl} 2 / 0 \mathrm{G} 488$ annexin $\mathrm{V}$ containing buffer. Phase-contrast and annexin- $V$ fluorescence images were then analysed, allowing determination of the platelet deposition and the procoagulant surface area. Platelets covered on average $29.7 \pm 2.6 \%$ (mean \pm sem, $n=10$ independent experiments) of the coverslip, while the platelets binding to annexin $\mathrm{V}$ covered $7.7 \pm 2.2 \%$ of the coverslip area. Heparin treatment of the blood almost completely abolished platelet adhesion $(0.2 \pm 0.1 \%, n=4)$ and annexin $V$ binding $(0.4 \pm 0.2 \%, n=4)$ over this period. Thus, the coagulation driven by tissue factor/ $\mathrm{CaCl}_{2}$ causes exposure of phosphatidylserine in about $40 \%$ of the adhering platelets. This procoagulant surface is likely to provide a potent amplification loop for the coagulation process.

\section{Effects of platelet inhibitors on coagulation and mural platelet aggregation in flowing} blood

To further determine how platelet activation interferes with to the tissue factor/ $\mathrm{CaCl}_{2}$ induced whole-blood coagulation, we made use of two inhibitors effective on rat platelets. This was the stable prostaglandin $E_{1}$, binding to the platelet EP receptors and potently inhibiting platelet activation by increase of the intracellular CAMP level
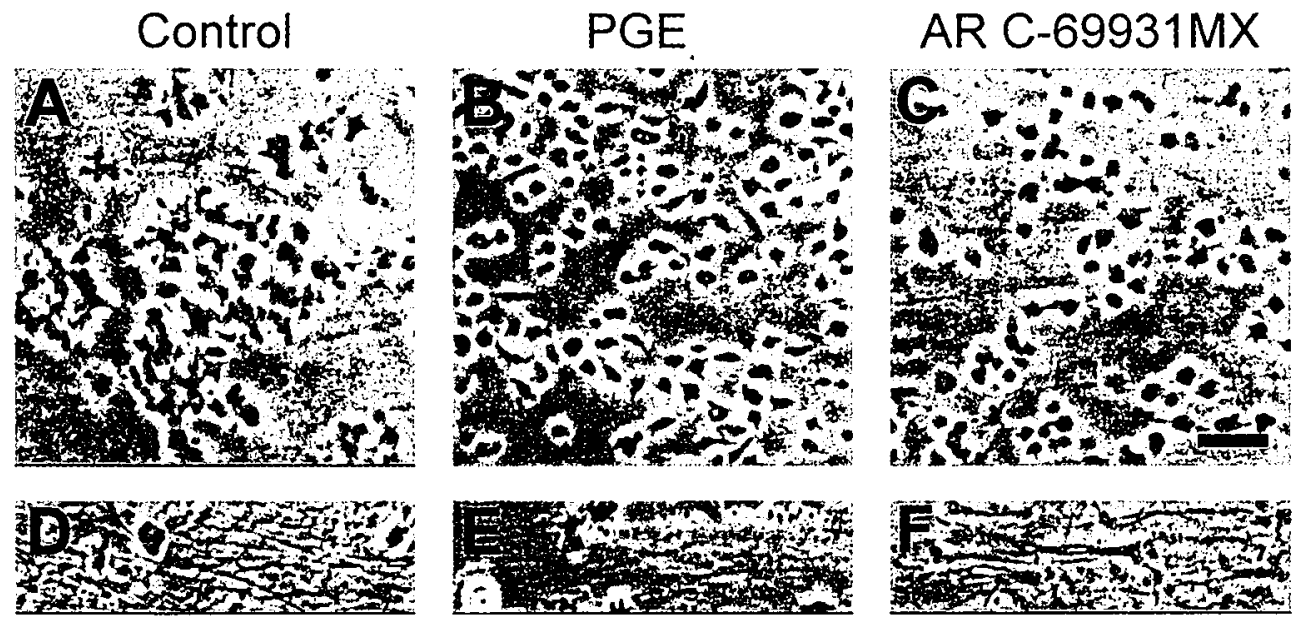

FIGURE 8.4 Effect of platelet inhibitors on platelet aggregation and fibrin formation. Recalcified rat blood was triggered with $\mathrm{CaCl}_{2}$ /tissue factor, and perfused over a fibrinogen surface (control condition, see FIG. 8.1). After $300 \mathrm{sec}$ of perfusion, images were taken slightly above the surface (A-C) and at the coverslip surface (D-F). Where indicated, the blood was pretreated for 5 min with prostaglandin $E_{1}$ $(10 \mu M)$ or AR-C69931MX $(10 \mu M)$. Images are from representative microscopic fields $(n>4$ experiments, bar $=10 \mu \mathrm{m})$. 


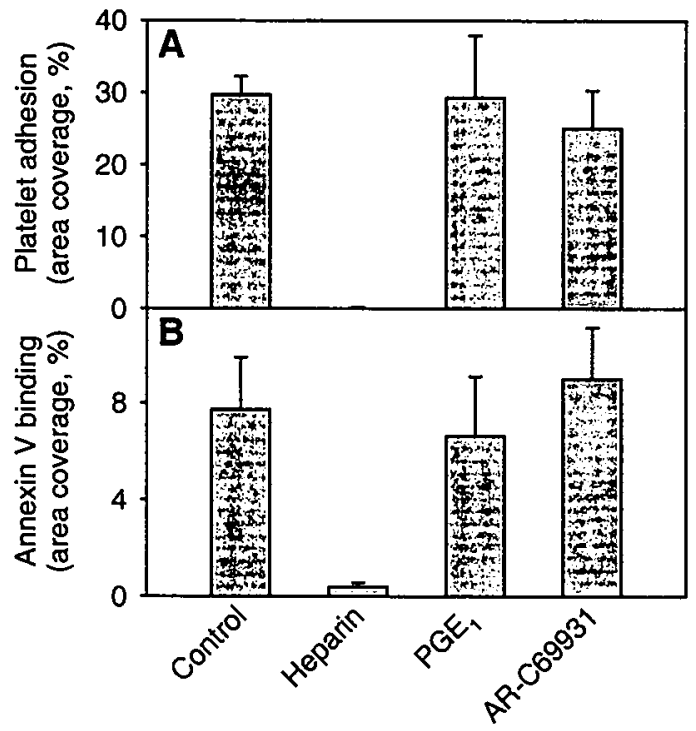

FIGURE 8.5 Effect of platelet inhibitors on platelet deposition and annexin $\mathrm{V}$ binding. Rat blood was triggered with tissue factor $/ \mathrm{CaCl}_{2}$, and perfused over a fibrinogen-coated coverslip as described for FIG. 8.1 (control condition). Where indicated, the blood was pre-treated with heparin $\quad(0.05 \quad \mathrm{U} / \mathrm{ml})$, prostaglandin $E_{1}(10 \mu \mathrm{M})$, or AR-C69931MX (10 $\mu \mathrm{M})$. After $300 \mathrm{sec}$ of perfusion, coverslips were rinsed with Hepes buffer containing $\mathrm{CaCl}_{2}(2 \mathrm{mM})$ and OG488-labeled annexin $\vee(0.2$ $\mu \mathrm{g} / \mathrm{ml})$. Microscopic fields were analysed on area coverage with platelets (A) and OG488 fluorescence (B). Data are mean values \pm sem $[n=10$ (control) or $n=4$ ].

and subsequent down-regulation of the $\mathrm{Ca}^{2+}$ signal $[18,22]$. Prostaglandin $\mathrm{E}_{1}$ also inhibits the aggregation response of human and rat platelets by blocking integrin $\alpha_{11 b} \beta_{3}$ activation [23]. We also used the $P 2 Y_{12}$ purinergic receptor antagonist, ARC69931MX, blocking the ADP-induced aggregation response of rat platelets (not shown) $[24,25]$. The recently cloned platelet-specific $P 2 Y_{12}$ receptor [26] (previously termed $\mathrm{P} 2 \mathrm{~T}, \mathrm{P} 2 \mathrm{~T}_{\mathrm{AC}}, \mathrm{P} 2 \mathrm{Y}_{\mathrm{ADP}}$ or $\mathrm{P} 2 \mathrm{CYC}$ ), is the pharmacological targets of antithrombotic drugs like clopidogrel and ticlopidine, is linked to $G_{i}$ and, as such, inducing ADP-induced platelet aggregation [27-29].

Blood perfusion through the flow chamber in the presence of prostaglandin $E_{1}$ $(10 \mu \mathrm{M})$ was of little influence on fibrin formation (FIG. 8.4). However, most platelets adhered as single cells while only few formed platelet thrombi that were smaller than in the control situation. At the end of the perfusion time, surface coverage of total platelets and annexin V-binding platelets was unchanged in comparison to the control (FIG. 8.5). When using AR-C69931MX (10 $\mu \mathrm{M})$, essentially the same effects were seen as in prostaglandin $E_{1}$-treated blood: unchanged fibrin formation (FIG. 8.4) and deposition of total and annexin V-labelled platelets (FIG. 8.5), but greatly reduced formation of platelet aggregates (FIG. 8.4). Apparently, in this initial stage of the coagulation process, either platelet inhibitor effectively blocks the aggregate formation without effect on the platelet procoagulant response. 


\subsection{Discussion}

This report describes that, in whole rat blood, activation of the coagulation system with $\mathrm{CaCl}_{2}$ and tissue factor results in the fast and almost simultaneous appearance of fibrin fibers and platelets with surface-exposed phosphatidylserine (detected with fluorescent annexin V) adhering to fibrin(ogen). In agreement with earlier studies [11], the phosphatidylserine exposure is preceded by a potent $\mathrm{Ca}^{2+}$ response and is accompanied by bleb formation, demonstrating potent activation of the platelets. These responses are likely to be mediated by thrombin that is generated during the coagulation process, because they are all completely inhibited by thrombin inactivation with heparin or PPACK. These results thus directly demonstrate that, in an environment resembling physiological using flowing whole blood, activation of the extrinsic coagulation system induces platelet phosphatidylserine exposure. This in turn potentiates the coagulation process. Under the conditions used of low shear stress we can thus monitor a potent positive feedback loop of coagulation and platelet activation.

Although thrombin is considered to be the most potent platelet agonist in coagulating plasma, it has been shown that the enzyme by itself is no more than weakly active in stimulating phosphatidylserine exposure even for platelets in contact with fibrinogen or fibrin $[4,14]$. This implies that plasma factors other than thrombin are (also) required to stimulate phosphatidylserine exposure and, thus, to feed the coagulation process. Experiments with blocking antibodies and plasmas from patients have provided evidence that glycoprotein $\mathrm{Ib} / \mathrm{V} / \mathrm{XX}$ and integrin $\alpha_{\| \mathrm{lb}} \beta_{3}$ in conjunction with their ligands, VWF and fibrin(ogen), are involved in the plateletdependent stimulation of coagulation and thrombin formation $[6,8]$. The present results can support this evidence with respect to integrin $\alpha_{11 b} \beta_{3}$, because most of the annexin $\mathrm{V}$-positive platelets were attached to the formed fibrin fibers. Whether the von Willebrand factor receptor is also involved in the procoagulant response under these conditions with rat blood is difficult to say.

The observed results with two platelet inhibitors, prostaglandin $E_{1}$ and $A R-$ C69931MX, are surprising. We find that, in the first minutes of tissue factor-induced coagulation, either compound effectively blocked the formation of mural platelet aggregates, but was without influence on the adhesion of platelets or the phosphatidylserine exposure of the adherent platelets. With respect to prostaglandin $E_{1}$, others have also described that this prostanoid suppresses aggregation, while adhesion and spreading can still occur [30]. Concerning AR-C69931MX, an antagonist of the $P 2 Y_{12}$ ADP receptor, our data indicate that ADP plays an important role in the aggregation of platelets also under conditions of coagulation. These results thus underline the evidence for a key role of ADP in the platelet aggregation process, even when primarily induced by other platelet agonists $[27,31,32]$. On the other hand, our data contrast with the finding that, also in rat plasma, $\mathrm{P} 2 \mathrm{Y}_{12}$ receptor 
inhibition with clopidogrel reduces the tissue factor-induced thrombin formation [29]. Whether this difference is due to the use of different experimental systems (flowing whole blood or platelet-rich plasma) or of different drugs (oral clopidogrel or in vitro added AR-C69931MX) is subject of current investigation.

\subsection{Acknowledgments}

The investigations were supported by grants from the Netherlands Foundation for Scientific Research (902-68-241) and from AstraZeneca R\&D (Charnwood, UK).

\subsection{References}

1. Bevers EM, Comfurius $P$, van Rijn JLML, Hemker HC, Zwaal RFA. Generation of prothrombin-converting activity and the exposure of phosphatidylserine at the outer surface of platelets. Eur J Biochem. 1982;122:429-436.

2. Swords NA, Mann KG. The assembly of the prothrombinase complex on adherent platelets. Arterioscler Thromb. 1993;13:1602-1612.

3. Zwaal RFA, Schroit AJ. Pathophysiological implications of membrane phospholipid asymmetry in blood cells. Blood. 1997;89:1121-1132.

4. Briedé JJ, Heemskerk JWM, Veer van 't C, Hemker HC, Lindhout T. Contribution of plateletderived factor $\mathrm{Va}$ to thrombin generation on immobilized collagen- and fibrinogen-adherent platelets. Thromb Haemost. 2001;85:509-513.

5. Reverter JC, Béguin S, Kessels H, Kumar R, Hemker HC, Coller BS. Inhibition of plateletmediated, tissue-factor-induced thrombin generation by the mouse/human chimeric $7 E 3$ antibody. Potential implications for the effect of c7E3 Fab treatment on acute thrombosis and 'clinical restenosis'. J Clin Invest. 1996;98:863-874.

6. Béguin S, Kumar R. Thrombin, fibrin and platelets, a resonance loop in which von Willebrand factor is a necessary link. Thromb Haemost. 1997;78:590-594.

7. Keularts IMLW, Béguin S, de Zwaan C, Hemker HC. Treatment with a GPIIb-IIla antagonist inhibits thrombin generation in platelet-rich plasma from patients. Thromb Haemost. 1998;80:370-371.

8. Béguin S, Kumar R, Keularts !, Seligsohn U, Coller BS, Hemker HC. Fibrin-dependent platelet procoagulant activity requires GPIb receptors and von Willebrand factor. Blood. 1999;93:564570 .

9. Dachary-Prigent $J$, Pasquet JM, Freyssinet JM, Nurden AT. Calcium involvement in aminophospholipid exposure and microparticle formation during platelet activation, a study using $\mathrm{Ca}^{2+}$-ATPase inhibitors. Biochemistry. 1995;34:11625-11634.

10. Pasquet JM, Dachary-Prigent J, Nurden AT. Calcium influx is a determining factor of calpain activation and microparticle formation in platelets. Eur J Biochem. 1996;239:647-654.

11. Heemskerk JWM, Vuist WMJ, Feijge MAH, Reutelingsperger CPM, Lindhout T. Collagen but not fibrinogen surfaces induce bleb formation, exposure of phosphatidylserine, and procoagulant activity of adherent platelets: evidence for regulation by protein tyrosine kinasedependent $\mathrm{Ca}^{2+}$ responses. Blood. 1997; 90:2615-2625.

12. Solum NO. Procoagulant expression in platelets and defects leading to clinical disorders. Arterioscier Thromb Vasc Biol. 1999;19:2841-2846. 
13. Heemskerk JWM, Siljander PRM, Bevers EM, Farndale RW, Lindhout T. Receptors and signalling mechanisms in the procoagulant response of platelets. Platelets. 2000;11:301-306.

14. Sanders MW, Nieuwenhuys CMA, Feijge MAH, Rook M, Béguin S, Heemskerk JWM. The procoagulant effect of thrombin on fibrin(ogen)-bound platelets. Haemostasis 1998;28:289300.

15. Andersen $H$, Greenberg DL, Fujikawa $K, X u$ WF, Chung DW, Davie EW. Protease-activated receptor 1 is the primary mediator of thrombin-stimulated platelet procoagulant activity. Proc Natl Acad Sci USA. 1999;96:11189-11193.

16. Heemskerk JWM, Feijge MAH, Henneman L, Rosing J, Hemker HC. The Ca ${ }^{2+}$-mobilizing potency of $\alpha$-thrombin and thrombin-receptor-activating peptide on human platelets. Concentration and time effects of thrombin-induced $\mathrm{Ca}^{2+}$ signaling. Eur $\mathcal{J}$ Biochem. 1997;249:547-555.

17. Heemskerk JWM, Feijge MAH, Simonis MAG, Hornstra G. Effects of dietary fatty acids on signal transduction and membrane cholesterol content in rat platelets. Biochim Biophys Acta. 1995; 1255:87-97.

18. Heemskerk JWM, Feijge MAH, Sage SO, Walter U. Indirect regulation of $\mathrm{Ca}^{2+}$ entry by cAMPdependent and CGMP-dependent protein kinases and phospholipase $C$ in rat platelets. Eur $J$ Biochem. 1994;223:543-551.

19. Sakariassen KS, Aarts PAMM, de Groot PG, Houdijk WPM, Sixma JJ. A perfusion chamber developed to investigate platelet interaction in flowing blood with human vessel wall cells, their extracellular matrix and purified components. J Lab Clin Med. 1983;102:522-535.

20. Billy D, Briedé JJ, Heemskerk JWM, Hemker HC, Lindhout T. Prothrombin conversion under flow conditions by prothrombinase assembled on adherent platelets. Blood Coagul Fibrinolysis. 1997;8:168-174.

21. Parker I, Choi J, Yao $Y$. Elementary events of Ins $\mathrm{P}_{3}$-induced $\mathrm{Ca}^{2+}$ liberation in Xenopus oocytes: hot spots, puffs and blips. Cell Calcium 1996;20:105-121.

22. Keularts IMLW, van Gorp RMA, Feijge MAH, Vuist MWJ, Heemskerk JWM. $\alpha_{2 A}$-Adrenergic receptor stimulation potentiates calcium release in platelets by modulating cAMP levels. J Biol Chem. 2000;275:1763-1772.

23. Van Willigen G, Akkerman JWN. Regulation of glycoprotein IIb/llla exposure on platelets stimulated with $\alpha$-thrombin. Blood 1992;79:82-90.

24 Ingall $\mathrm{AH}$, Dixon J, Bailey A, Coombs ME, Cox D, Mclnally JI, Hunt SF, Tomlinson W. Antagonist of the platelet P2T-receptor: a novel approach to antithrombotic therapy. $J$ Med Chem. 1999;42:213-220.

25. Storey RF, Sanderson HM, White AE, May JA, Cameron KE, Heptinstall S. The central role of the P2T receptor in amplification of human platelet activation, secretion and procoagulant activity. Br J Haematol 2000;110:925-934

26. Hollopeter G, Jantzen HM, Vincent D, Li G, England L, Ramakrishnan V, Yang RB, Nurden P, Nurden A, Julius D, Conley PB. Identification of the platelet ADP receptor targeted by antithrombotic drugs. Nature. 2001;409:202-208.

27. Daniel JL, Dangermaier C, Jin J, Ashby B, Smith JB, Kunapuli SP. Molecular basis for ADP. induced platelet activation. I: evidence for three distinct ADP receptors on human platelets. $J$ Biol Chem. 1998;273:2024-2029.

28. Hechler B, Eckly A, Ohlmann P, Cazenave JP, Gachet C. The P2Y, receptor, necessary but not sufficient to support full ADP-induced platelet aggregation, is not the target of the drug clopidogrel. Br J Haematol. 1998;103:858-866.

29. Herault JP, Dol F, Gaich C, Bernat A, Herbert JM. Effect of clopidogrel on thrombin generation in platelet-rich plasma in the rat. Thromb Haemost. 1999;81:957-960.

30. Ruggeri ZM. Mechanisms initiating platelet thrombus formation. Thromb Haemost. 1997;78:611-616.

31. Trumel C, Payrastre B, Plantavid M, Hechler B, Viala C, Presek P, Martinson EA, Cazenave JP, Chap H. Gachet C. A key role of adenosine diphosphate in the irreversible platelet aggregation induced by the PAR-1-activating peptide through the late activation of phosphoinositide 3-kinase. Blood. 1999;94:4156-4165.

32. Ohlmann P, Eckly A, Freund M, Cazenave JP, Offermanns S, Gachet C. ADP induces partial platelet aggregation without shape change and potentiates collagen-induced aggregation in the absence of $\mathrm{G} \alpha_{\mathrm{q}}$. Blood 2000; 96:2134-2139. 
9

Discussion 
This thesis describes the effects of dietary fish oil, rich in n-3 polyunsaturated fatty acids (n-3 PUFAs) of marine origin, on thrombosis and thrombosis-related processes in rats. The rat model was chosen because; i) dietary and pharmacological interventions are relatively easy to perform; ii) the previously established suitability of these animals in studying artificially induced arterial thrombosis, i.e. the thrombotic process as a whole can be measured in vivo; iii) the individual components of the thrombotic process, such as the processes of platelet activation, coagulation, fibrinolysis and vessel wall function, can be measured in the same animals in vitro. The present work focuses on the measurements of these processes either separately or in combination.

\subsection{Arterial thrombosis tendency and platelet activation}

In the first study (CHAPTER 2), rats were fed with diets containing increasing amounts of a fish oil preparation consisting of a mixture of eicosapentaenoic acid (EPA) and docosahexaenoic acid (DHA). In the consecutive dietary study (also described in CHAPTER 2), the rats were fed a diet containing a fixed amount of fatty acids either as a mixture of n-3 PUFAs or as purified preparations of EPA or DHA. All diets contained 50 -energy\% as fat; the fatty acid composition of the basal fat (without added $n-3$ PUFAs) was comparable to that of the fat on average consumed by the Dutch population [1].

After 12 weeks of dietary intervention, arterial thrombosis was determined in the rats by measuring the obstruction time of a loop-shaped cannula that was implanted in the abdominal aorta. This method to measure arterial thrombosis tendency in rats was previously found to be sensitive to platelet inhibitors and anticoagulants as well as to dietary fats [2-4]. In CHAPTER 2 it appeared that the diet containing 2.5 -energy $\%$ as n-3 PUFAs had an optimum reducing effect on the thrombosis tendency. Remarkably, higher doses of n-3 PUFAs from fish oil did not further reduce the thrombosis tendency. This may partially be explained by an earlier made observation that this measurement of arterial thrombosis is highly sensitive to the ratio between the total amount of saturated fatty acids and the total content of $n$ 3 and n-6 PUFAs [5]. In the cited study, a specific effect of n-3 PUFAs could not be detected due to the inclusion of only a limited number of fish-oil groups. In addition, most of the fish oil preparations contained relatively large amounts of saturated fatty acids.

Ex vivo platelet activation was determined in whole blood (impedance method) taken from the diet-modified rats, and anti-coagulated with hirudin (a thrombin inhibitor). In general, the effects of the various n-3 PUFA preparations on platelet aggregability were small. However, especially higher doses of dietary n-3 
PUFAs led to an increased disaggregation when collagen was used as plateletactivating agonist. With ADP as agonist, platelet aggregation was in all cases followed by almost complete disaggregation, which may the absence of differences in aggregation tendency between the diet groups. Because the rate of disaggregation was inversely related to the amount of thromboxane $A_{2}$ produced by the activated platelets (measured as thromboxane $B_{2}$ ), it seems that high thromboxane production is required to achieve irreversible platelet aggregation. Indeed, it is known that cyclooxygenase blockers like aspirin tend to shift the platelet aggregation response from irreversible to reversible [6]. In addition, platelet shape change and the rate of aggregation were found to be dependent on the amount of U46619 (a thromboxane $A_{2}$ analogue) $[7,8]$.

Detailed investigations as to the effects of the n-3 PUFA diets on platelet activation properties are described in CHAPTERS 3 and 5 . Measurements with suspensions of washed platelets and platelet-rich plasma showed that the calcium and aggregation responses of the platelets to ADP, collagen or thrombin were hardly influenced by the dietary amount of n-3 PUFAs consumed (either as a fish oil mixture or as purified EPA or DHA preparations). Even dietary intervention with a dose as high as 10 -en\% n-3 PUFAs (the $16 \%$ FO group) did not significantly influence the platelet activation tendency. This is in good agreement with earlier studies, where rats were fed with fish oil or n-6 PUFAs, and where the platelets from these animals showed a comparable activation tendency $[7,8]$. Note that we observed this unchanged platelet activation tendency in spite of a clearly reduced thromboxane $A_{2}$ production by the platelets (see below).

The question why platelets from n-3 PUFA-fed rats show an essentially unaltered activation tendency in spite of a lower production of (platelet-activating) thromboxane has previously been answered. In earlier studies with rats, it was recognised that dietary fish oil or n-6 PUFAs significantly potentiate the thromboxane $\mathrm{A}_{2}$-mediated platelet activation responses. Most likely, this was the result of an increased cholesterol content in the membrane of these platelets and a consequent potentiation of signal transduction [7-9]. In the present diet experiments, we confirmed the higher sensitivity of platelets from n-3 PUFA-fed rats towards thromboxane (CHAPTER 5). Thus an increased thromboxane-dependent platelet aggregation was found not only after feeding the animals with n-3 PUFA mixture but also after supplying the purified EPA and DHA preparations. Evidence for increased thromboxane-sensitivity was also obtained from the ex vivo measurements of wholeblood aggregation (CHAPTER 2).

Another question is why the n-3 PUFA effect on platelet disaggregation in whole blood (CHAPTER 2) is not reflected by an altered activation of platelets in buffer medium or platelet-rich plasma (CHAPTERS 3 and 5), in spite of the fact that thromboxane $A_{2}$ production is decreased in all n-3 PUFA-fed animals. Though we have not directly investigated this question, partly because of the still poor 
understanding of the phenomenon of platelet disaggregation, it is worthwhile to put forward a number of possible explanations. In this respect, it would be important to verify the dietary effect on disaggregation in whole blood (measured indirectly from changes in impedance) and disaggregation of platelets in plasma/buffer (in the present studies measured more directly as changes in turbidity) using new methods, such as that of single-platelet counting [10].

First, the apparent discrepancy between whole blood and plasma/buffer aggregation effects of $n-3$ PUFAs might be contributed to the inactivation of platelet derived agonists, e.g. ADP, by leukocytes and/or erythrocytes. Here, it is sufficient to say that, with washed platelets or platelets in plasma, (turbidometric) disaggregation is only observed upon stimulation with low doses of weak agonists, e.g. when the platelets have not released their granules [6]. This seem to be relevant because $A D P$, derived from the granules of activated platelets, is considered to be one the major physiological agonists causing platelet aggregation through the $P 2 Y_{1}$ and $P 2 Y_{12}$ purinergic receptors [11-13].

Second, in the buffer/plasma measurements the platelet concentration was always adjusted to the same level, while in the whole blood assays platelet counts (or total platelet volume) were somewhat different between diet groups, i.e. lower in rats fed with n-3 PUFAs (CHAPTER 5). Third, irreversible aggregation is known to occur especially at low concentrations of extracellular $\mathrm{Ca}^{2+}$, i.e. in case of using citrated platelet-rich plasma or platelets in buffer medium $[14,15]$.

Forth, of relevance may also be the observation that lipoproteins, and in particular the low-density lipoproteins, have a stimulating effect on platelets. This holds for both native lipoproteins $[16,17]$ and mildly oxidised lipoproteins [18], which may also influence the processes of atherosclerosis, inflammation or thrombogenesis. The latter two occur at both ends of the aortic loop in the experimental animals $[2,3]$. Since the $n-3$ PUFA-containing diets in most of our studies cause a reduction in lipoprotein levels (CHAPTERS 5 and 6 ), it is conceivable that, as a result, platelet activation becomes diminished. However, such a lipoprotein effect - if present - is likely to be small, because we measured roughly similar dietary effects on platelet activation in buffer medium and in (lipoprotein-containing) plasma.

In general, the present observations resemble those made by Umemura and co-authors $[19,20]$ who, using a different rat thrombosis model, have measured a reduced acute arterial thrombosis tendency in response to dietary DHA. This was accompanied by a slightly diminished whole-blood aggregation, but not by altered activation of the platelets in plasma. In addition, Mark and Sanders [21] found that moderate, but not high, intakes of dietary fish oil increased the mesenteric bleeding time. Taken together, this work thereby supports the suggestion that the optimal reducing effect of $2.5-\mathrm{en} \% \mathrm{n}-3$ PUFAs on the thrombosis tendency in rats fed with fish-oil (CHAPTER 2) can not be explained by an altered platelet function. 


\subsection{Platelet- and vessel wall-derived prostanoids: modulatory effects on platelet activation}

From the present experiments (CHAPTER 2, 3 and 5) and also from earlier studies $[3,7,22,23]$, it appears that dietary n-3 PUFAs results in efficient incorporation of EPA and DHA in the phospholipids of both platelets and the vessel wall. Thus, the levels of arachidonate in the platelet and aortic phospholipids were significantly decreased by the dietary intervention in favour of EPA and DHA. This indicates that the supplemented n-3 PUFAs are adequately metabolised by the animals. Regardless of the source of the n-3 PUFAs (fish-oil mixture or purified preparation of EPA or DHA, the amounts of EPA found in platelet phospholipids were always higher than the amounts of DHA (CHAPTERS 2, 3 and 5), implying that retroconversion of DHA into EPA did also occur in the platelet progenitor cells. In contrast to this, in the aortic phosphospholipids the levels of DHA were higher in comparison to those of EPA, suggesting that retroconversion of DHA is less prominent in the vessel wall. This is in accordance with in vitro studies with cultured bovine [24] or human endothelial cells [25], in which docosapentaenoic acid (22:5 n-3) was found to arise largely from elongation of EPA rather than from retroconversion of DHA.

The data of CHAPTER 3 indicate that the diet-induced displacement of arachidonic acid by $n-3$ PUFAs in the phospholipids of platelets and vessel wall leads to a reduced production of thromboxane $A_{2}$ by the platelets and a reduced formation of prostaglandin $I_{2}$ by the aortic endothelium. This confirms the earlier notion that an altered fatty acid composition of the phospholipids by dietary $n-3$ PUFAs does not only affect the prostanoid formation in platelets but also influences that of vascular endothelium [22-24]. Thus, the level of the arachidonate substrate in platelet/endothelial phospholipids is a determinant of the amount of thromboxane formed under certain activation conditions, as recognised earlier $[3,8,26]$.

In experiments with platelets and incubates from aortic tissue it appeared that the effect of dietary n-3 PUFAs on the platelet activation process was due to a reduced formation of endothelial prostaglandin $I_{2}$ rather than by decreased platelet-derived thromboxane $A_{2}$. Thus, the dietary modulation of vascular prostaglandin production (mainly prostaglandin $I_{2}$ ) had a stronger effect on both the thrombin- and collagen-induced platelet activation processes than the dietary effect on platelet thromboxane generation (CHAPTER 3). That indeed prostaglandin $\mathrm{I}_{2}$ plays a more prominent role than thromboxane $A_{2}$ in regulating platelet activation was also concluded from the following observations. The platelet-inhibiting effect of prostaglandin $\mathrm{I}_{2}$ : i) was independent of the type of agonist; ii) involved both thromboxane $A_{2}$-dependent and -independent activation responses; iii) inhibited the agonist-induced formation of thromboxane $A_{2}$ and finally, iv) was more prolonged in time than the brief, stimulatory effect of thromboxane $A_{2}$. Taken together, this 
suggests that in rats dietary fish oil exerts an unfavourable effect on the thromboxane-prostaglandin balance of platelet activation, i.e. the n-3 PUFA-evoked reduction in thromboxane formation appears to be insufficient to compensate for the reduction in vascular prostaglandin production.

There is little doubt that platelet activation in vivo is both positively and negatively regulated by the vessel wall [27]. The intact endothelium has a potent down-regulating effect on platelets that is principally achieved by the production of prostaglandin $\mathrm{I}_{2}$ and/or nitric oxide. This has also been shown in rabbits $[28,29]$. For instance, in a microcirculation model, prostanoids derived from both the vessel wall and platelets were found to play antogonistic roles in the thromboembolic reaction evoked in the mesenteric arterioles of living rabbits [28]. The authors concluded from their in vivo observations that platelet-inhibiting prostaglandins from the vessel wall have a more potent effect on the platelet aggregation than the thromboxane derived from platelets.

It should be noted that, in the reasoning above, it is implicitly assumed that the $n-3$ PUFA-derived thromboxane $A_{3}$ and prostaglandin $I_{3}$ are only marginally produced in rats, as was originally described by Hornstra et al. [23]. Though the literature on the biological effects of $n-3$ PUFA-derived prostanoids is rather inconsistent, there is evidence from the eighties that rabbit and bovine aorta tissue produces prostaglandin $I_{3}$, which increases cyclic AMP production and inhibits platelet aggregation [30]. Taken all this into account, it is tempting though difficult to compare the fish oil effects on arterial thrombosis tendency (CHAPTER 2) and on thromboxane-prostaglandin balance of platelet activation (CHAPTER 3 ). In comparison, the literature indicates that low doses of aspirin (effective in inhibiting only thromboxane production) but not high doses of aspirin (inhibiting both thromboxane and prostaglandin production) were effective in reducing electrically injured carotid artery thrombosis and prostanoid formation in male rats $[31,32]$. That platelet-derived prostanoids do play a significant role in the present rat model of arterial thrombosis has earlier been demonstrated [3,4]. In summary, it is possible that platelet- and vessel wall-derived prostanoids compete in a different way in the various models of thrombosis, i.e. in the microvasculature of rabbits and in the occlusion of a loop inserted in the aorta of rats. In addition, it has been reported that not only prostanoid production is involved in thrombosis, plasma factors also play an important role [70]. Other diet-dependent factors contributing to the modifications of the haemostatic system, will be discussed below. 


\subsection{Coagulation activity and role of vitamin $\mathrm{K}$}

The early literature suggests that dietary fish oil has relevant albeit small effects on the coagulation activity (CHAPTER 1). Assays measuring clotting times (prothrombin time or activated partial thrombin time) are however rather insensitive to detect small changes in coagulation tendency. Therefore, we adapted a more sensitive, integrative coagulation assay for use with rat plasma. The new test measures, in a continuous way, the formation and inactivation of thrombin in plasma, i.e. the endogenous thrombin potential (ETP) of the plasma. The ETP, defined as the free thrombin-time integral of coagulating plasma, is thus a measure of the enzymatic activity of thrombin in activated plasma over a certain time interval. It provides an adequate way to detect hypo- and hypercoagulant conditions. For instance, an association between an increased ETP and hypercoagulant activity, such as in deep venous thrombosis and stroke, has been published [33]. A reduction in ETP, i.e. a reduced formation of total proteolytically active thrombin, is likely to reflect a hypocoagulant state. It has also been shown that the ETP of platelet-poor and platelet-rich plasma from patients with haemophilia A (factor VIII deficient) and of patients with von Willebrand disease type 3 (von Willebrand factor deficiency) is reduced, i.e. in patients with a history of major bleeding [34].

Use of the ETP assay allowed direct comparison of the rate of thrombin formation and inactivation in coagulating human and rat plasmas (CHAPTER 4). Using autologous tissue factor to trigger the coagulation process, the ETP of either type of plasma appeared to be comparable in value. However, in rat plasma the thrombin formation rate was relatively high, which can be explained by relatively high concentrations of the coagulation factors II, V, VII and VIII. The thrombin decay was also much faster in rat plasma, which is likely to be due to a relatively high level of antithrombin. As anticipated, the ETP of rat plasma was sensitive to hypocoagulant conditions, i.e. low doses of heparin, short-term in vivo administration of vitamin $\mathrm{K}$ antagonists or administration of a vitamin K-deficient diet. An interesting observation made during this work was that, with non-limiting tissue factor levels, the prothrombin concentration was rate-limiting in both the rate of thrombin formation and the total ETP. This suggests that, at least in rats, prothrombin is a risk factor of hypercoagulation and perhaps thrombosis.

The ETP assay was applied to plasmas from rats fed with fish oil (CHAPTER 5). Note that we used here a manual measurement of the ETP, because this method was the golden standard at the time of investigation. We found that dietary fish oil, when supplied at an amount $>2.5-\mathrm{en} \% \mathrm{n}-3$ PUFAs caused a significant reduction in the ETP. This was not due to an increased antithrombin concentration, but was probably caused by a reduction in the plasma levels of the vitamin K-dependent coagulation factors II and VII. These results, supported by recent data from another 
group [35,36], thus provide firm evidence that dietary fish oil at this dose causes a hypocoagulant effect in rat, in a comparable way, as does a low dose of warfarin.

Intriguingly, in a subsequent study, feeding of the rats with about 2.5-energy $\%$ of $n-3$ PUFAs - supplied as fish oil or preparations of EPA or DHA - resulted in a no more than small reduction in coagulation (factors) (CHAPTER 6). We hypothesised that this marginally effect was due to the combination of a rather low intake of n-3 PUFA (2.5-en\%) as part of a high fat diet (50-energy \% supplied as fat) containing high amounts of vitamin $\mathrm{K}$. Vitamin $\mathrm{K}$ is an apolar molecule requiring fat particles for transport in the body. We considered it important to evaluate the effects of a low dose of dietary n-3 PUFAs (equivalent to about $1 \mathrm{~g} /$ day for man, see below) on the coagulation system. A study was designed in which rats were fed for a long period with a low amount of fish oil in combination with low vitamin $\mathrm{K}$ and low total fat. The animals were first made vitamin $K$ deficient by feeding with an essentially vitamin $K$ free diet. Subsequently, the rats were maintained on either a low-fat or a high-fat diet (10 or 50 energy \% as fat, respectively) containing $1 \mu \mathrm{g} / \mathrm{g}$ vitamin $\mathrm{K}$. In the diet of half of the rats from each group, about $3-e n \%$ of the diet was composed of $n-3$ PUFAs (CHAPTER 6).

We found that dietary fish oil caused a reduction in both the ETP and the levels of vitamin K-dependent coagulation factors (factors II and VII) were only in case of the low-fat diet. In combination with the high-fat diet, there was only a tendency of reduction in coagulation activity. This difference was reflected in the vitamin $\mathrm{K}$ levels in the livers of the animals. Accordingly, it was concluded that this low amount of fish oil can indeed cause a hypocoagulant effect when the intake levels of fat and vitamin $K$ are relatively low. This is a clear indication that at least part of the hypocoagulant effect is due to a reduced formation of the vitamin Kdependent coagulation factors. A similar conclusion has been drawn by others, who measured a reduced coagulation tendency caused by a much higher intake of n-3 PUFAs, which was corrected after intraperitoneal or dietary administration of vitamin $K$ [35]. These authors suggest that the n-3 PUFAs directly or indirectly modify the vitamin K-dependent $\gamma$-carboxylation step in coagulation factor formation.

An unexpected finding in CHAPTER 6 was that the fish oil caused both in the low-fat and high-fat groups a reduction in the vitamin K-independent coagulation factor $V$. This indicates that also mechanisms other than a reduced formation of vitamin K-dependent coagulation factors may play a role in the hypocoagulant effect of fish oil. Whereas it is clear that factor II and, to a much lesser degree, factor VII levels determine the ETP value of rat plasma, we have not yet determined the contribution of factor $V$ to the outcome of this assay. However, it has been shown that reduced levels of factor $V$ in a synthetic (i.e. reconstructed) plasma system reduce the initiation phase of thrombin generation [37]. Some human diet-studies report on a decrease in factor $V$ [38], whereas others fail to report effects on factor $V$ activity [39]. 
It has been reported for humans that plasma triglyceride levels tend to associate with vitamin K-dependent coagulation factors [40-43]. In the rat, we found a reduction in triglycerides and in coagulation tendency at high (CHAPTER 5) but not at low (CHAPTER 6, study A) doses of dietary fish oil. Comparing the effects of the last study, where n-3 PUFAs were given as part of low-fat or high-fat diets (CHAPTER 6 , study $B$ ), it appeared that triglyceride levels were only reduced in the case of high fat supplementation. This argues against a causal relationship between the concentrations of triglycerides and (vitamin K-dependent) coagulation factors in rats. Such lack of correlation was also seen when feeding the rats with n-6 PUFAs: i.e. reduced triglyceride levels were not accompanied with lowered coagulation tendency (CHAPTER 5).

\subsection{Interactions of coagulation and platelet activation}

As discussed above, dietary n-3 PUFAs seem to have typical effects on the processes of both platelet activation (reduced prostanoid formation) and clotting activity (reduced coagulation factors) in rat. Pioneering work at the University of Maastricht has pointed to the importance of the mutual interactions of the processes of (human) platelet activation and coagulation [44] (and for review [45]). We thus set out a number of experiments that would allow us to study the influence of fish oil diets on the platelet-dependent stimulation of the coagulation process in rat plateletrich plasma or rat whole blood.

Under strong activation conditions, it is known that platelets expose procoagulant phosphatidylserine at their outer membrane surface, following a rise in intracellular $\left[\mathrm{Ca}^{2+}\right]_{i}[46,47]$. The exposed phosphatidylserine stimulates over thousand-fold the formation of activated factor $X$ and thrombin from their inactive precursors in plasma [45]. The generated thrombin conversely acts as a potent platelet activator. In experiments with (human) coagulating platelet-rich plasma triggered with tissue factor, it was detected that platelets have a potent stimulatory effect on the activation of the coagulation system [48-51]. This process is dependent of the platelet surface proteins, integrin $\alpha_{11 b} \beta_{3}$ and glycoprotein $\mathrm{lb}$, and is probably further stimulated by the surface secretion of factor $V$ from platelets $[52,53]$. The notion that in this plasma system, platelet interaction with fibrin stimulates the platelet procoagulant activity in an integrin $\alpha_{116} \beta_{3}$-dependent way stimulated us to investigate the fibrin effect also under plasma-free conditions. As described in CHAPTER 7 , integrin $\alpha_{11 b} \beta_{3}$-dependent binding of human platelets to fibrin(ogen) was completely ineffective in inducing exposure of phosphatidylserine on the platelet surface. High concentrations of purified thrombin did no more than moderately stimulate the platelet procoagulant response. This result suggests that other factors than only 
thrombin and integrin $\alpha_{11 \mathrm{~b}} \beta_{3}$ are involved in the potent phosphatidylserine-exposing effect of coagulating platelet-rich plasma.

Moving back to the rat system, we thus considered it necessary to study the mutual interactions of platelet and coagulation activation in a plasma environment or, even more physiological, in flowing whole blood. Using microscopic video imaging techniques, we monitored fibrin formation and platelet accumulation and activation under conditions where the blood was activated with $\mathrm{Ca}^{2+}$ and tissue factor and perfused at low shear over a fibrinogen surface (CHAPTER 8 ). In this ex vivo flow system fast deposition of platelets and increases in cytosolic $\left[\mathrm{Ca}^{2+}\right]_{i}$ were detected, followed by the appearance of fibrin fibers and platelet procoagulant activity, possibly by the in-situ generated thrombin. Importantly, potent platelet inhibitors such as prostaglandin $E_{1}$ (with similar action as prostaglandin $I_{2}$ ) and AR C-69931MX (a $\mathrm{P}_{2 Y_{12}}$ purinoreceptor antagonist) greatly inhibited aggregation of the perfused platelets but were without effect on the procoagulant response or fibrin formation. Thus, on the one hand, platelets appear to be important to support thrombin formation - i.e. coagulation - in plasma while, on the other hand, platelet aggregate formation is not required for the platelet procoagulant response. Inhibition of platelet aggregation implicitly assumes downregulation of the signalling pathways mediated by the fibrinogen receptors (integrin $\alpha_{111} \beta_{3}$ ). However, it still needs to be resolved what precisely the involvement is of integrin $\alpha_{11 b} \beta_{3}$ in the platelet-dependent coagulation process, at least in the part that is insensitive to prostaglandin $E_{1}$ or $A R$ C-69931MX inhibition.

Taken together, these data indicate that, also in the rat system, the processes of platelet activation and coagulation are intimately connected. It is therefore tentative to assume that a decreased coagulation activity in blood also diminishes the platelet activation process, and thus downregulates the feedforward loop of platelet activation and coagulation. Dietary fish oil might well be able to cause such a downregulation.

\subsection{Multiple effects on the haemostatic system}

We have described that dietary fish oil in rats can cause an antithrombotic effect that is accompanied by a variety of alterations in the haemostatic system (FIG. 9.1). Replacement of arachidonic acid in the membranes of platelets and vessel wall results in an altered prostanoid formation. This does not necessarily change the thromboxane-prostaglandin balance of platelet activation in a favourable way, because the decreased endothelial prostaglandin $I_{2}$ production seems to have a more profound effect on the (suppression of) platelet activation than the reduction in platelet-derived thromboxane $A_{2}$. Furthermore, dietary fish oil reduces the levels of 


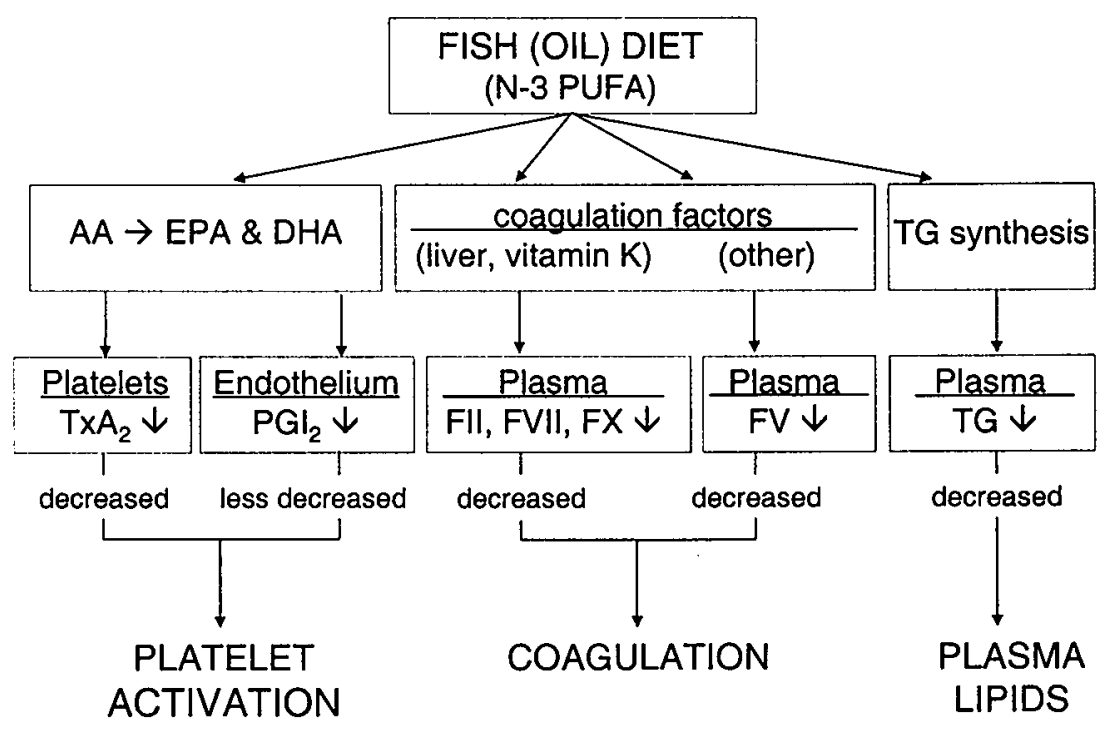

FIGURE 9.1 Summary of principal effects of dietary n-3 PUFAs on the haemostatic system of rats. For explanations, see text. Abbreviations: $A A$, arachidonic acid; DHA, docosahexaenoic acid; EPA, eicosapentaenoic acid; FII, FV, FVII and FX, coagulation factors II, V, VII and X; PUFA, polyunsaturated fatty acids; TG, triglycerides; $T X A_{2}$, thromboxane $A_{2} ; P G I_{2}$, prostaglandin $I_{2}$.

vitamin K-dependent and -independent coagulation factors in such a way that the coagulation potential of the plasma is decreased. This effect can only partially be explained by reduced accumulation of vitamin $\mathrm{K}$ in the liver. In addition, fish oil changes the plasma lipid metabolism by reducing the basal triglyceride levels. Moreover, fish oil also reduces platelet count (CHAPTER 5).

Having established that in rat plasma, like in man, there is a potent amplification spiral of platelet activation and coagulation, it is to be expected that dietary fish oil especially acts on the amplification system. Thus, fish oil can interfere with various driving 'engines' of this feedforward loop (FIG. 9.2): it reduces the thromboxane $\mathrm{A}_{2}$-mediated potentiation of platelet activation (though the effects on platelet activation itself are probably small), it lowers the levels of a number of coagulation factors and reduce the coagulation 'input' in the system; in addition, it reduces the thrombin formation and thereby the potent thrombin-mediated potentiation of both coagulation and platelet activation. As a result, dietary fish oil or $n-3$ PUFAs may delay haemostasis and thrombosis. Finally, fish oil lowers the blood lipid levels with possible reducing effects on platelet activation and coagulation $[16,17,71]$.

The model thus designed can explain the lack of dose-response in the effect of dietary fish oil on arterial thrombosis tendency in rat (CHAPTER 2). First, the 


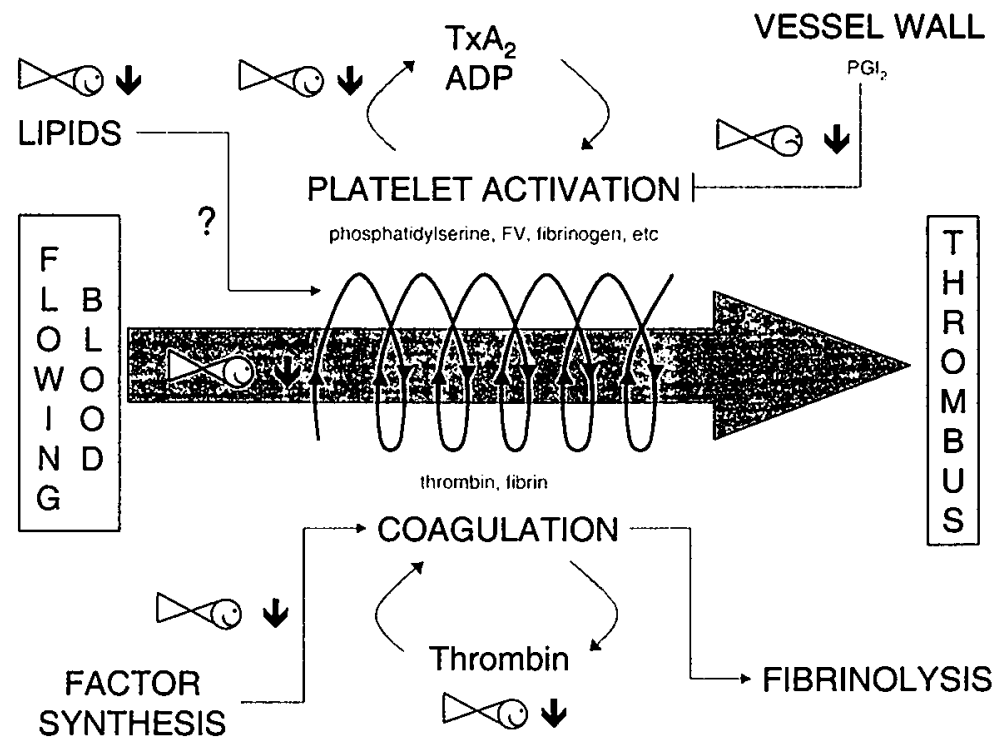

FIGURE 9.2 Generalised scheme of relations between platelet activation, coagulation, lipids, vessel wall function and fibrinolysis and their involvement in thrombosis. Recognised positive and negative effects of dietary fish oil are indicated by different pictograms. Arrows point to activation while blocking lines represent inhibition of a reaction or process. For abbreviations, see FIG 9.1.

antithrombotic effect of fish oil is unlikely to be merely due to a reduction in (vitamin $\mathrm{K}$-dependent) coagulation factors, because rather high doses of the vitamin $\mathrm{K}$ antagonist warfarin need to be administered to rats to reduce the arterial thrombosis tendency [4]. Yet, administration to the rats of high doses of vitamin $\mathrm{K}_{1}$ increases the thrombosis tendency [54], indicating that changes in coagulation potential do affect arterial thrombosis in this rat model. Second, it is well conceivable that at lower doses of n-3 PUFAs, favourable effects of a reduced thromboxane $A_{2}$ production prevail over less favourable influences of reduced prostaglandin $l_{2}$ formation. Because prostaglandin production must fall below a threshold level before it ceases to suppress platelet activation, it is likely that the initial beneficial effect of n-3 PUFAs at higher doses is counteracted by an unfavourable shift in the prostanoid balance.

A possible mechanistic explanation for the apparent multiple effect of $n-3$ PUFAs on plasma factors is a direct or indirect modulation of gene expression. Little is yet known of such effects of PUFAs. For the hepatic system, it is described that dietary PUFAs regulate the expression of various genes, putatively through production of specific prostanoids. For instance, feeding of n-3 PUFAs to mice downregulates the hepatic mRNA level of sterol regulatory element-binding protein-1 
(SREBP-1), which controls several lipogenic genes [55,56]. Other examples of nuclear targets of PUFAs are the peroxisome proliferator-activated receptor $\alpha$ $(\operatorname{PPAR} \alpha)$ [57], and a response element in the endotoxin receptor gene [58]. As was suggested by others; dietary n-3 PUFA may directly or indirectly modify the vitamin K-dependent $\gamma$-carboxylation step [35]. We would propose that $n-3$ PUFAs may also influence the biosynthesis of coagulation factors at different levels, e.g. hepatic genetic expression, synthesis, carboxylation or secretion.

\subsection{Implications for expected nutritional effects in man}

It is tempting though not without risk to extrapolate the present findings with rats to the human situation. A first question is how the dietary intake of $n-3$ PUFAs in rat must be compared to the consumption of fish oil in man. Let us assume a metabolic rate in rats of $1.3 \mathrm{MJ} / \mathrm{kg} /$ day (adult $250 \mathrm{~g}$ male) and in human of $0.16 \mathrm{MJ} / \mathrm{kg} / \mathrm{day}$ (adult man of $75 \mathrm{~kg}$ ) [59]. An intake in rats of 3 energy $\% n-3$ PUFAs (i.e. $5 \% \mathrm{n}-3$ PUFAs in a diet containing 50 energy \% as fat) then equals that of 0.35 energy $\%$ of $\mathrm{n}-3$ PUFAs in humans. With a total food consumption of $12 \mathrm{MJ} /$ day, the amount to be consumed is $42 \mathrm{~kJ}$ (or $10 \mathrm{kcal}$ ), i.e. about $1.2 \mathrm{gram} \mathrm{n-3} \mathrm{PUFAs} \mathrm{per} \mathrm{day.} \mathrm{This} \mathrm{content}$ of $n-3$ PUFA is provided by about 100 gram/day of fatty fish (salmon, herring or mackerel) $[60,61]$. Thus, the present results suggest that a hypocoagulant effect of fish oil can already be expected in man at a relatively low intake of fish.

These work points to combined lipid-lowering, hypocoagulant and (at best) weak platelet-inhibiting effects of dietary fish oil in rats. As we have described in CHAPTER 1 (TABLE 1), most of these effects have individually been detected - though often not consistently - in earlier human intervention studies with dietary fish or fish oil. It is thus well possible that also in man the combination of these actions sets to explain the proposed thrombosis-lowering effect of dietary fish oil. There is circumstantial evidence for this proposal from studies showing that a combined antiplatelet and anticoagulant therapy is more beneficial then either treatment alone. Such clinical studies have been performed with heparin treatment in combination with aspirin and other, new antiplatelet drugs [62-66]. It should be remarked however that in some of these studies undesirable side effects have been reported like bleeding [62], temporary coagulant activity after heparin withdrawal $[67,68]$ or other complications [69].

In conclusion, the advantageous effects of dietary n-3 PUFAs, at least in rat, appear to be multifactorial. They reduce thrombin formation, triglyceride concentration and to some extent platelet activation. Together, this may result in a reduced amplification system of platelet activation and coagulation, and as a consequence, reduced thrombosis. 


\subsection{References}

1. Sundram K, Hornstra G, Houwelingen van AC, Kester ADM. Replacement of dietary fat with palm oil: effect on human serum lipids, lipoproteins and apolipoproteins. $B r J$ Nutr. 1992;68:677-692.

2. Hornstra G, Vendelmans-Starrenburg A. Induction of experimental arterial occlusive thrombi in rats. Atherosclerosis. 1973;17:369-382.

3. Hornstra G. Dietary Fats, Prostanoids and Arterial Thrombosis. Martinus Nijhoff Publishers, The Hague, 1982.

4. Hornstra G. Effect of dietary lipids on arterial thrombus formation: rationale for the support of drug therapy by diet. Sem Thromb Hemostas. 1988;14:59-65.

5. Hornstra G, Kester ADM. Effects of the dietary fat type on arterial thrombosis tendency: systematic studies with a rat model. Atherosclerosis. 1997:131:25-33

6. Siess W. Molecular mechanisms of platelet activation. Physiol Rev. 1989;69:58-178.

7. Heemskerk JWM, Feijge MAH, Kalafusz R, Hornstra G. Influence of dietary fatty acids on membrane fluidity and activation of rat platelets. Biochim Biophys Acta. 1989;1004:252-260.

8. Heemskerk JWM, Feijge MAH, Kester ADM, Hornstra G. Dietary fat modifies thromboxane $A_{2}-$ induced stimulation of rat platelets. Biochem J. 1991;278:399-404.

9. Heemskerk JWM, Feijge MAH, Simonis MAG, Hornstra G. Effects of dietary fatty acids on signal transduction and membrane cholesterol content in rat platelets. Biochim Biophys Acta. 1995; 1255:87-97.

10. May JA, Heptinstall $S$, Spangenberg $P$. Changes in the composition of the platelet cytoskeleton in response to ADP, effects of MK-852 and ARL 66096. Blood Coagulation Fibrinol. 1996;7:221-224.

11. Cattaneo M, Gachet C. ADP receptors and clinical bleeding disorders. Arterioscler Thromb Vasc Biol. 1999;19:2281-2285.

12. Paul BZS, Jin JG, Kunapuli SP. Molecular mechanism of thromboxane $A_{2}$-induced platelet aggregation: essential role for $P 2 T_{A C}$ and $\alpha_{2 A}$ receptors. $J$ Biol Chem. 1999;274:29108-29114.

13. Hollopeter $G$, Jantzen $H-M$, Vincent $D, L i$ G, England $L$, Ramzkrishnan $V$, Yang R-B, Nurden $P$, Nurden $A$, Julius $D$, Conley $P B$. Identification of the platelet ADP receptor targeted by antithrombotic drugs. Nature. 2001;409:202-207.

14. Falcon CR, Cattaneo M, Ghidoni $A$, Mannucci PM. The in vitro production of thromboxane $B_{2}$ by platelets of diabetic patients is normal at physiological concentrations of ionised calcium. Thromb Haemost. 1993;70:389-392.

15. Mustard JF, Perry DW, Kinlough-Rathbone RL, Packham MA. Factors responsible for ADP. induced release reaction of human platelets. Am J Physiol. 1975;228:1757-1765.

16. Surya II, Akkerman JWN. The influence of lipoproteins on blood platelets. Am Heart J. 1993;125:272-275.

17. Hackeng CM, Huigsloot M, Pladet MW, Nieuwenhuis HK, van Rijn HJM, Akkerman J-WN. LoW-density lipoprotein enhances platelet secretion via integrin $\alpha_{11 b} \beta_{3}$-mediated signaling. Arterioscler Thromb Vasc Biol. 1999;19:239-247.

18. Siess W, Zangl KJ, Essier M, Bauer M, Brandl R, Corrinth C, Bittman R, Tigyi G, Aepfelbacher $M$. Lysophosphatidic acid mediates the rapid activation of platelets and endothelial cells by mildly oxidized low density lipoprotein and accumulates in human atherosclerotic lesions. Proc Natl Acad Sci USA. 1999;96:6931-6936.

19. Umemura K, Toshima Y, Asai F. Nakashima M. Effect of dietary docosahexaenoic acid supplementation on platelet function - studies in the rat femoral artery thrombosis model. Platelets. 1994;5:214-218.

20. Umemura $K$, Toshima $Y$, Asia $F$, Nakashima M. Effect of dietary docosahexaenoic acid in the rat middle cerebral artery thrombosis model. Thromb Res. 1995;78:379-387.

21. Mark $G$, Sanders $T A B$. The influence of different amounts of $n-3$ polyunsaturated fatty acids on bleeding time and in vivo vascular reactivity. BrJ Nutr. 1994:71:43-52.

22. Vossen RCRM, Dam van-Mieras MCE, Lemmens PJMR, Hornstra G, Zwaal RFA. Membrane fatty acid composition and endothelial cell functional properties. Biochim Biophys Acta. 1991;1083:243-251. 
23. Hornstra $G$, Christ-Hazelhof $E$, Haddeman $E$, Hoor ten $F$, Hughteren DH. Fish oil feeding lowers thromboxane- and prostacyclin production by rat platelets and aorta and does not result in the formation of prostaglandin $I_{3}$. Prostaglandins. 1981;21:727-737.

24. Bénistant $C$, Achard $F$, Marcelon $G$, Lagarde $M$. Platelet inhibitory functions of aortic endothelial cells. Effects of eicosapentaenoic and docosahexaenoic acids. Atherosclerosis. 1993;104:27-35.

25. Rosenthal MD, Garcia MC, Jones MR, Sprecher N. Retroconversion and $\Delta 4$ desaturation of docosatetraenoate $(22: 4(n-6))$ and docosapentaenoate $(22: 5(n-3))$ by human cells in culture. Biochim Biophys Acta. 1991;1083:29-36.

26. Lands WEM. Biosynthesis of prostaglandins. Annu Rev Nutr. 1991;11:41-60.

27. Cines DB, Pollak ES, Buck CA, Loscalzo J, Zimmerman GA, McEver RP, Pober JS, Wick TM, Konkle BA, Schwartz BS, Barnathan ES, McCrea KR, Hug BA, Schmidt AM, Stren DM. Endothelial cells in physiology and in the pathophysiology of vascular disorders. Blood. 1998;91:3527-3561.

28. Oude Egbrink MGA, Tangelder GJ, Slaaf DW, Reneman RS. Different roles of prostaglandins in thromboembolic processes in arterioles and venules in vivo. Thromb Haemost. 1993;70:826-833.

29. Broeders MAW, Tangelder GJ, Slaaf DW, Reneman RS, oude Egbrink MGA. Endogenous nitric oxide protects against thromboembolism in venules but not in arterioles. Arterioscler Thromb Vasc Biol. 1998:18:138-145.

30. Fischer $S$, Weber PC. Prostaglandin $I_{3}$ is formed in vivo in man after dietary eicosapentaenoic acid. Nature. 1984;307:165-168.

31. Philp RB, Paul ML, Killackey JJ, Killackey BA. The influence of dose, time of administration, body temperature and salicylate kinetics on the antithrombotic action of acetylsalicylic acid in male rats. Haemostasis. 1983;13:42-52.

32. Philp RB, Paul ML. Effects of aspirin dosage and time of administration on arterial prostacyclin production and platelet aggregation in rats. Prostaglandins Leukot Med. 1984;15:91-102.

33. Wielders $S$, Mukherjee M, Michiels J, Rijkers DTS, Cambus JP, Knebel RWC, Kakkar V, Hemker HC, Béguin S. The routine determination of the endogenous thrombin potential, first results in different forms of hyper- and hypocoagulability. Thromb Haemost. 1997;77:629-636.

34. Keularts IMLW. From platelet activation to thrombin generation. Maastricht. 2000.

35. Andriamampandry M, Freund M, Wiesel ML, Rhein S, Ravanat C, J.P. C, Leray C, Gachet C. Diets enriched in (n-3) fatty acids affect rat coagulation factors dependent on vitamin K. C R Acad Sci Paris. 1998;321:413-421.

36. Andriamampandry $M D$, Leray $C$, Freund $M$, Cazenave J-P, Gachet $C$. Antithrombotic effect of $(\mathrm{n}-3)$ polyunsaturated fatty acids in rat models of arterial and venous thrombosis. Thromb Res. 1999;93:9-16.

37. Butenas S, Veer van 't C, Mann KG. "Normal" thrombin generation. Blood. 1999;94:21692178.

38. Oosthuizen W, Voster HH, Jerling JC, Barnard HC, Smuts CM, Silvis N, Kruger A, Venter CS. Both fish oil and olive oil lowered plasma fibrinogen in women with high baseline fibrinogen levels. Thromb Haemost. 1994:72:557-562.

39. Brox JH, Killie JE, Osterud B, Holme S, Nordoy A. Effects of cod liver oil on platelets and coagulation in familial hypercholesterolemia (type lla). Acta Med Scand. 1983;213:137-144.

40. Burns $P$, Hoffman CJ, Katz JP, Miller RH, Lawson WE, Hultin MB. Vitamin K-dependent clotting factors are elevated in young adults who have close relatives with ischemic heart disease. J Lab Clin Med. 1993;122:720-727.

41. Constantino M, Merskey C, Kudzma DJ, Zucker MB. Increased activity of vitamin K-dependent clotting factors in human hyperlipoproteinaemia - association with cholesterol and triglyceride levels. Thromb Haemost. 1977;38:465-474.

42. Xu N, Dahlback B, Ohlin AK, Nilsson A. Association of vitamin K-dependent coagulation proteins and $\mathrm{C} 4 \mathrm{~b}$ binding protein with triglyceride-rich lipoproteins of human plasma. Arterioscler Thromb Vasc Biol. 1998;18:33-39.

43. Mennen LI, Schouten EG, Grobbee DE, Kluft C. Coagulation factor VII, dietary fat and blood lipids: a review. Thromb Haemost. 1996;76:492-499. 
44. Tans G, Rosing J, Thomassen MC, Heeb MJ, Zwaal RF, Griffin JH. Comparison of anticoagulant and procoagulant activities of stimulated platelets and platelet-derived microparticles. Blood. 1991;77:2641-2648.

45. Zwaal RF, Comfurius P. Bevers EM. Lipid-protein interactions in blood coagulation. Biochim Biophys Acta. 1998;1376:433-453.

46. Zwaal RFA, Comfurius P. Bevers EM. Mechanism and function of changes in membranephospholipid asymmetry in platelets and erythrocytes. Biochem Soc Trans. 1993;21:248-253.

47. Heemskerk JWM, Vuist WMJ, Feijge MAH, Reutelingsperger CPM, Lindhout T. Collagen but not fibrinogen surfaces induce bleb formation, exposure of phosphatidylserine, and procoagulant activity of adherent platelets: evidence for regulation by protein tyrosine kinase dependent $\mathrm{Ca}^{2+}$ responses. Blood. 1997:90:2615-2625.

48. Kumar R, Béguin $\mathrm{S}$, Hemker $\mathrm{HC}$. The effect of fibrin clots and clot-bound thrombin on the development of platelet procoagulant activity. Thromb Haemost. 1995;74:962-968.

49. Reverter JC, Béguin S, Kessels H, Kumar R, Hemker HC, Coller BS. Inhibition of plateletmediated, tissue factor-induced thrombin generation by the mouse/human chimeric 7E3 antibody. Potential implications for the effect of c7E3 Fab treatment on acute thrombosis and "clinical restenosis". J Clin Invest. 1996:98:863-874.

50. Béguin S, Kumar R. Thrombin, fibrin and platelets: a resonance loop in which von Willebrand factor is a necessary link. Thromb Haemost. 1997;78:590-594.

51. Hemker HC, Giesen PLA, Ramjee M, Wagenvoord R, Béguin S. The thrombogram: Monitoring thrombin generation in platelet rich plasma. Thromb Haemost. 2000;83:589-591.

52. Briedé JJ, Heemskerk JWM, Veer van 't C, Hemker HC, Lindhout T. Contribution of plateletderived factor $V a$ to thrombin generation on immobilized collagen- and fibrinogen-adherent platelets. Thromb Haemost. 2001;85:509-513.

53. Heemskerk JWM. Calcium and platelets. In: Pochet R, Donato R, Haiech R, Heizmann $\mathrm{C}$ and Gerke $V$ (Eds). The molecular basis of Calcium Action in Biology and Medicine. Kluwer Academic Publishers, Dordrecht, 2000, p. 45-71.

54. Ronden JE, Groenen-van Dooren MCL, Hornstra G, Vermeer C. Modulation of arterial thrombosis tendency in rats by vitamin $\mathrm{K}$ and its side chains. Atherosclerosis. 1997;132:61-67.

55. Kim HJ, Takahashi M, Ezaki $O$. Fish oil feeding decreases mature sterol regulatory elementbinding protein 1 (SREBP-1) by down-regulation of SCEBP-1C MRNA in mouse liver - a possible mechanism for down-regulation of lipogenic enzyme mRNAs. $J$ Biol Chem. 1999;274:25892-25898.

56. $\mathrm{Xu} \mathrm{J}$, Nakamura MT, Cho HP. Clarke SD. Sterol regulatory element binding protein-1 is suppressed by dietary polyunsaturated fatty acids - A mechanism for the coordinate suppression of lipogenic genes by polyunsaturated fats. J Biol Chem. 1999;274:23577-23583.

57. Jump DB, Thelen $A$, Mater $M$. Dietary polyunsaturated fatty acids and hepatic gene expression. Lipids. 1999;34:\$209-212.

58. Chu AJ, Walton MA, Prasad JK, Seto A. Blockade by polyunsaturated n-3 fatty acids of endotoxin-induced monocytic tissue factor activation is mediated by the depressed receptor expression in THP-1 cells. J Surg Res. 1999;87:217-224.

59. Beynen AC, Meijer GW. Voeding van proefdieren en resultaten van dierproeven. In: Zutphen van LFM, Baumans V and Beynen AC (Eds.) Proefdieren en dierproeven. Wetenschappelijke uitgeverij Bunge, Utrecht, 1991, p. 110-125.

60. Semplicini A, Valle R. Fish oils and their possible role in the treatment of cardiovascular diseases. Pharmacol Ther. 1994;61:385-397.

61. Schmidt EB, Dyerberg J. Omega-3 fatty acids - current status in cardiovascular medicine. Drugs. 1994;47:405-424.

62. The EPILOG Investigators. Platelet glycoprotein IIb/lla receptor blockade and low-dose heparin during percutaneous coronaru revascularization. N Eng J Med. 1997;336:1689-1696.

63. Danges G, Badimon JJ, Coller BS, Fallon JT, Sharma SK, Hayes RM, Meraj P. Ambrose JA, Marmur JD. Administratioin of abciximab during percutaneous coronary intervention reduces both ex vivo platelet thrombus formation and fibrin deposition. Arterioscler Thromb Vasc Biol. $1998 ; 18: 1342-1349$.

64. Leon MB, Baim DS, Popma JJ, Gordon PC, Cutlip DE, Ho KK, Giambartolomei A, Diver DJ, Lasorda DM, Williams DO, Pocock SJ, Kuntz RE. A clinical trail comparing three 
antithrombotic-drug regimens after coronary-artery stenting. $N$ Engl J Med. 1998;339:16651671.

65. Antiplatelet Trialists' Collaboration. Collaborative overview of randomised trials of antiplatelet therapy--Ill: Reduction in venous thrombosis and pulmonary embolism by antiplatelet prophylaxis among surgical and medical patients. Brit Med J. 1994;308:235-246.

66. Ferguson JJ, Kim P. Abciximab. In: Ferguson III JJ, Chronos NA and Harrington RA (Eds). Antiplatelet Therapy in Clinical Practice. Martin Dunitz, London, 2000, p. 113-143.

67. The RISK Group. Risk of myocardial infarction and death during treatment with low dose aspirin and intravenous heparin in men. Lancet. 1990;336:827-830.

68. Théroux $P$, Waters $D$, Lam J, Juneau M, McCans J. Reactivation of unstable angina after the discontinuation of heparin. N Engl J Med. 1992;327:141-145.

69. Schrör K. Ticlopidine and clopidogrel. In: Ferguson III JJ, Chronos NA and Harrington RA (Eds). Antiplatelet Therapy in Clinical Practice. Martin Dunitz, London, 2000, p. 93-111.

70. Hornstra G, Hemker HC. Clot-promoting effect of platelet-vessel wall interaction: influence of dietary fats and relation to arterial thrombus formation in rats. Haemostasis. 1979;8:211-226.

71. Rosenson RS, Lowe GDO. Effects of lipids and lipoproteins on thrombosis and rheology. Atheriosclerosis. 1998;140:271-280. 



\section{Summary}

In man, dietary n-3 polyunsaturated fatty acids ( $n-3$ PUFAs) from marine oils are known to have beneficial effects on risk factors for the development of cardiovascular diseases. Although not all published studies show the same effects of marine (fish) oil intervention, a majority of these reports of an increased bleeding time, a small reduction in platelet activation and/or a reduction in levels of coagulation factors and blood lipids (CHAPTER 1). There is also some evidence for altered fibrinolytic activity in response to fish oil diet. The experimental part of this thesis describes the results of diet studies, where the fish-oil derived n-3 PUFAs eicosapentaenoic acid (EPA) and docosahexaenoic acid (DHA) were supplemented to rats either alone or in combination, to establish whether these fatty acids and which of these fatty acids have a beneficial effect on arterial thrombosis tendency and thrombosis-related processes. Particular attention was thereby paid to the effects on platelet and coagulation activity and on blood lipids. Other sets of experiments were designed as to provide better mechanistic insight into the observed dietary effects.

In CHAPTER 2, a study is first described, where the rats were fed with a diet containing increasing amounts of a fish oil preparation consisting of a mixture of $19.9 \%$ EPA and $36.9 \%$ DHA ethyl esters. All diets had a high fat content, i.e. they contained 50-energy percent (en\%) of fat. After dietary intervention, arterial thrombosis tendency was determined using a validated procedure with a loopshaped cannula that was implanted in the abdominal aorta of the rats. It appeared that the diet containing 2.5-en\% n-3 PUFAs from fish oil (the 4\% FO group) had a small reducing effect on the arterial thrombosis tendency, which resembled that of an antithrombotic sunflowerseed oil diet. Higher concentrations of fish oil did not reduce the thrombosis tendency any further. In a consecutive experiment, the rats were again fed with a high-fat diet, but now supplemented with n-3 PUFA preparations (about 2.5-en\%) from either fish oil or with the purified EPA or DHA. Again, the thrombosis tendency of rats from the n-3 PUFA diet groups resembled that of animals fed with antithrombotic sunflowerseed oil. Differences between the various $n$ 3 PUFA preparations on arterial thrombosis tendency were not observed.

A number of measurements were performed to determine the dietary effects on haemostatic variables. Platelet aggregation was measured in whole blood derived from the n-3 PUFA-fed rats. The fish oil mixture caused a dose-dependent decrease in the maximal aggregation of platelets in response to collagen (CHAPTER 2). This effect could be attributed to an increase in disaggregation of the platelets, perhaps because of the reduced thromboxane $A_{2}$ production by the platelets from fish-oilmodified rats.

More detailed investigations as to the effects of these dietary interventions on platelets are described in the subsequent chapters. It appeared that, in platelet-rich plasma or suspensions of washed platelets, the aggregation and calcium responses 
of the platelets were hardly influenced by the feeding conditions of the rats, regardless of the platelet agonist given. This was the case after suppiementation of the fish oil mixture, and also after supplying the purified EPA or DHA preparations (CHAPTERS 3 and 5). Although the intake of $n-3$ PUFAs always reduced the thromboxane $A_{2}$ formation by activated platelets, this dietary effect barely influenced the platelet aggregation tendency under the tested in vitro conditions. Dietary fish oil did, however, reduce the platelet count.

As known from earlier work, dietary n-3 PUFAs replace in both platelets and the vessel wall arachidonic acid that is esterified at the $s n-2$ position of the membrane glycero phospholipids by EPA and DHA. Feeding of the rats with the fish oil mixture resulted in a dose-dependent incorporation of both EPA and DHA into the phospholipids of platelets and the aortic vessel wall (CHAPTERS 2 and 3). Supplementation with purified EPA or DHA preparations gave an increase of mainly EPA and some docosapentaenoic acid (DPA) in the platelet phospholipids, whereas the aortic phospholipids accumulated mainly DHA with some DPA. This suggests that retroconversion from DHA to EPA is more pronounced in platelets, whereas elongation from EPA to DPA is more prominent in the vessel-wall endothelial cells. In the studies performed, the diet-induced replacement of arachidonic acid was accompanied by a reduced prostanoid formation in both platelets and the aortic vessel wall. Thus, in addition to reducing the levels of platelet-derived, proaggregatory thromboxane $A_{2}$, dietary $n-3$ PUFAs also reduced the levels of endothelial-derived, anti-aggregatory prostacyclin (CHAPTERS 2 and 3 ).

To evaluate the consequences of the altered prostanoid formation, we tested the combined effects of endogenously produced thromboxane $A_{2}$ and prostacyclin on platelets (CHAPTER 3). It was found that, in contrast to the platelet-stimulating effect of thromboxane $A_{2}$, the platelet-inhibiting effect of prostacyclin was independent of the type of platelet agonist used. Furthermore, the prostacyclin effect involved both thromboxane $\mathrm{A}_{2}$-dependent and -independent activation processes, and it was also more prolonged in time than the brief stimulatory effect of thromboxane $A_{2}$. It was therefore concluded that prostacyclin plays a more prominent role in regulating platelet activation than thromboxane $A_{2}$. In aortic pieces from rats fed with $n-3$ PUFAs, the production of prostanoids (mainly prostacyclin) was reduced. Adding the aortic products from these rats to the diet-modified platelets resulted in a reduced inhibitory effect on platelet activation, especially in case of the DHA group. This may imply that dietary n-3 PUFAs shift the thromboxane $A_{2}$-prostacyclin balance towards a more thrombotic state. This is in contrast to the observations reporting that fish oil reduced thromboxane $A_{2}$ formation without altered or even increased prostacyclin production.

To further evaluate the beneficial effects of dietary fish on cardiovascular disease, we then focused on the coagulation process. Since available coagulation tests are relatively insensitive in detecting plasma hypo-coagulability, we developed 
new tests to measure fish-oil effects on the coagulation potential of rat plasma. Measurement of the endogenous thrombin potential (ETP) of coagulating plasma was expected to provide such a method, because this method has shown its validity in detecting mildly altered coagulation states of human plasma. Two ETP-based assays were developed, in which rat plasma was triggered with thromboplastin from rat or human recombinant tissue factor, procoagulant phospholipids and $\mathrm{CaCl}_{2}$ and, subsequently, the formation and inactivation of thrombin was followed in time (CHAPTER 4). In the firstly used method, thrombin was quantified in series of samples manually taken during the coagulation process (CHAPTERS 4 and 5). In the second, newer procedure, thrombin was measured in an automated way from the cleavage rate of a low-affinity chromogenic substrate (CHAPTER 4). Advantages of these methods are not only their improved sensitivity, but also that they allow measurement of the coagulation of rat plasma under fully autologous conditions.

The curve of thrombin formation and inactivation in tissue factor-activated rat plasma appeared to be comparable to that of human plasma, although the kinetics were somewhat faster in the rat system, i.e. the rate of thrombin formation was faster and the half-life time of free thrombin in rat plasma was relatively short (CHAPTER 4). The thrombin generation - and thus the ETP - of rat plasma was sensitive to antithrombin activation with heparin, to in vivo administration of vitamin $\mathrm{K}$ antagonists and to feeding of the rats with a vitamin K-deficient diet. In all these cases, global coagulation tests (prothrombin times) were only slightly increased. The thrombin generation measurements also indicated that the plasma level of prothrombin (factor II) played an important role in the initial rate of thrombin formation and in the total ETP value reached at the end of the coagulation process. The levels of other coagulation factors, like factors $V$ and VII, were of less influence on the ETP value.

This ETP method was applied to plasma from rats fed with the high-fat, fish oil-containing diets (CHAPTER 5). The fish oil reduced the ETP of tissue factoractivated plasma when given to the animals at doses of $>2.5-e n \% n-3$ PUFAs (4\% FO). This reduction was accompanied, and could at least in part be explained, by decreased levels of the vitamin K-dependent coagulation factors II and VII, while the level of the thrombin inhibitor antithrombin was not affected by the diet type. Such a hypocoagulant effect was typically not observed after feeding the rats with n-6 PUFAs from sunflowerseed oil. The levels of plasminogen activator inhibitor and tissue-type plasminogen activator, i.e. parameters reflecting fibrinolytic activity, were not changed by the type of diet. Thus, administration of fish oil appeared to induce a hypocoagulable state in rats with no more than little effect on fibrinolysis.

Feeding of the rats with about $2.5-e n \%$ of purified EPA, DHA or $n-3$ PUFAs from a fish-oil mixture did not lead to a reduction in the tissue factor-induced ETP of plasma (CHAPTER 6). It was then hypothesised that the beneficial effect of dietary fish oil may depend on the total amounts of fat and vitamin $K$ in the diet. Because vitamin $K$ is a fat-soluble molecule, the dietary fat content may be a limiting factor in its 
uptake into the body. When testing this hypothesis, it appeared that the minimal dose of dietary vitamin $\mathrm{K}$ required for optimal plasma levels of coagulation factors was similar after feeding low-fat or high-fat diets. In a subsequent diet study, n-3 PUFAs were given as part of a high-fat (50-en\%) or low-fat (10-en\%) diet in combination with a low amount of vitamin $\mathrm{K}$. It appeared that the fish-oil only in combination with the low-fat caused a reduction in the ETP of plasma (CHAPTER 6). The level of factor II (a vitamin K-dependent coagulation factor) was only significantly reduced in the low-fat group. After determination of the vitamin $\mathrm{K}$ levels in the liver, it was concluded that limited accumulation of vitamin $K$ is unlikely to be the sole explanation for the hypocoagulant effect of dietary n-3 PUFAs. This idea was confirmed by the observation that dietary fish oil also caused a reduction in the vitamin K-independent coagulation factor $V$ in both the low-fat and high-fat diet groups.

In humans, dietary fish oil is known to lower the plasma triglyceride but not the (total) cholesterol levels. In rats, we found that fish oil, when provided as part of a high-fat diet, reduced the (fasting) levels of both triglycerides and total cholesterol (CHAPTERS 5 and 6). In contrast, dietary sunflowerseed oil with n-6 PUFAs only reduced the triglyceride concentration. Human studies suggested that coagulation factor activity is associated with plasma triglyceride levels. Because a hypocoagulant effect in rat could only be measured after the fish oil diet but not after the sunflowerseed oil diet, it is unlikely that these changes in coagulation tendency are due to changes in plasma triglyceride levels.

Evidence is accumulating that the processes of platelet activation and coagulation in blood are intimately connected. Thrombin, as crucial coagulation product and potent platelet agonist, plays an important role in this connection. Knowing that dietary fish oil can influence the processes of platelet activation (reduced thromboxane $A_{2}$ formation) and coagulation (reduced levels of vitamin $\mathrm{K}$ dependent coagulation factors), it was of interest to better determine the effects of thrombin on the capability of platelets to support the coagulation process.

In a plasma-containing system, platelet interaction with fibrin stimulates the procoagulant activity of platelets in an integrin $\alpha_{\mathrm{Ilb}} \beta_{3}$ (glycoprotein $\mathrm{Ilb} / \mathrm{llla}$, a fibrin and fibrinogen receptor)-dependent fashion. This stimulated us to investigate the effects of thrombin on fibrin- and fibrinogen-bound platelets under plasma-free conditions. As described in CHAPTER 7, integrin $\alpha_{111} \beta_{3}$-dependent binding of human platelets to either fibrin or fibrinogen was completely ineffective in inducing exposure of procoagulant phospholipids or in stimulating thrombin formation on the platelet surface. Even high concentrations of thrombin were no more than slightly effective in stimulating the platelet procoagulant response. It was thus concluded that thrombin, in the absence of coagulating plasma, is only a weak inducer of platelet-dependent coagulation.

To determine the interactions of platelet activation and coagulation under more physiological conditions, whole blood derived from rats was triggered with tissue 
factor and $\mathrm{CaCl}_{2}$ to coagulate under flow conditions. Microscopic vital imaging techniques were applied to simultaneously monitor platelet activation and fibrin clot formation (CHAPTER 8). Under conditions of low shear stress, triggering of the coagulation process rapidly resulted in coagulation-supporting platelets. Intervention experiments with platelet-activation inhibitors indicated that, surprisingly, platelet aggregate formation was not required for the platelet procoagulant response. Together, these data demonstrate that, in the rat system, the processes of platelet activation and coagulation are intimately connected, but also that platelets can support the coagulation process without aggregation.

in CHAPTER 9 the data of the experimental chapters are discussed from the point of view that, in rat, dietary fish oil causes a net antithrombotic effect by a combination of alterations in the haemostatic system. Fish oil reduces the platelet count and platelet-dependent thromboxane $A_{2}$ production. The latter effect is however more than antagonised by a lower prostacyclin formation in the vessel wall, at least at higher doses of fish oil. Dietary fish oil also has a lipid-lowering effect and a hypo-coagulant effect, which is partly mediated by reduced levels of vitamin Kdependent coagulation factors. The existence of a potent amplification spiral between platelet activation and coagulation predicts that fish oil has a suppressing effect on the overall outcome of this spiral. However, this has not yet been determined directly. The multifactorial, mostly advantageous effects of fish oil thus may result in reduced haemostasis and thrombosis.

It is difficult to extrapolate these findings with rats to the human situation. We only note that a daily intake of 3-en\% of fish oil-derived n-3 PUFAs in rats equals to the consumption of about $1.2 \mathrm{~g} \mathrm{n}-3$ PUFAs (100 g of fatty fish) per day for an averaged man. Adequate studies to effects of such nutritional intervention on the (platelet-dependent) coagulation activity in humans are still lacking. 



\section{Samenvatting}

Reeds lang is bekend dat de inname van meervoudig-onverzadigde vetzuren van de $n-3$ klasse (n-3 MOV), afkomstig van voornamelijk vis(olie), een gunstig effect heeft op risicofactoren voor hart- en vaatziekten. Het merendeel van de gepubliceerde voedingsstudies rapporteert dat een regelmatige inname van visolie leidt tot een verlengde bloedingstijd, een matige verlaging van de bloedplaatjesactivatie en/of een reductie in het niveau van stollingsfactoren en bloedlipiden (HOOFDSTUK 1). Een beperkt aantal publicaties geeft daarnaast aan dat de fibrinolyseactiviteit van het bloed verandert na de inname van vis(olie). In dit proefschrift is gebruik gemaakt van de rat als diermodel om voedingseffecten van de n-3 MOV, eicosapentaeenzuur (EPA) en docosahexaeenzuur (DHA), uit visolie te bestuderen en te bepalen of de individuele of juist een combinatie van beide vetzuren een optimaal effect hadden. $\mathrm{Er}$ werd naast de bovengenoemde trombose-gerelateerde processen ook naar de arteri le tromboseneiging als zodanig gekeken. In het bijzonder werd gekeken naar de effecten van n-3 MOV op de bloedplaatjesfunctie, de stollingsneiging en de bloedlipiden. Aanvullende experimenten hadden ten doel beter inzicht te krijgen in de mechanismen van de waargenomen voedingseffecten.

In HOOFDSTUK 2 is eerst een studie beschreven, waarin ratten werden gevoed met oplopende hoeveelheden van een visoliepreparaat bestaande uit een mengsel van ethylesters van $19.9 \%$ EPA en $36.9 \%$ DHA als meest relevante n-3 MOV. De toegediende voedsels hadden alle een hoog vetgehalte, dat wil zeggen zij bevatten 50 energieprocenten (en\%) als vet. Na de voedingsinterventie werd de arteri le tromboseneiging van de ratten gemeten middels een gevalideerde methode, waarbij een lusvormige canule in de abdominale aorta werd aangebracht. Het bleek dat de interventie met 2.5 en\% n-3 MOV (de 4\% FO groep) een reductie van de tromboseneiging gaf die in grootte gelijk was aan het effect van voedingsinterventie met het antitrombotische zonnebloempitolie (met veel $n-6$ MOV). Hogere concentraties visolie hadden geen sterker reducerend effect op de tromboseneiging. In de daaropvolgende studie kregen de ratten weer een voeding met een hoog vetgehalte toegediend, maar nu in combinatie met n-3 MOV (ongeveer 2.5 en\%) afkomstig van ofwel visolie ofwel gezuiverde EPA of DHA preparaten. Ook nu was de tromboseneiging van de ratten gevoed met de diverse n-3 MOV preparaten overeenkomstig met die van ratten gevoed met zonnebloempitolie. Tussen de verschillende $n-3$ MOV voedingspreparaten werd geen onderscheid in tromboseneiging gevonden.

Experimenten werden daarnaast uitgevoerd met bloedpreparaten om de voedingseffecten op trombose-gerelateerde processen te bepalen. Zo werd de aggregatie van plaatjes gemeten in volbloed, dat afkomstig was van ratten gevoed met n-3 MOV (HOOFDSTUK 2). Interventie met visolie leidde tot een dosis-afhankelijke reductie van de maximale aggregatie onder invloed van collageen. Dit effect ging 
gepaard met een toegenomen de-aggregatie, mogelijk tengevolge van een verlaagde productie van tromboxaan $\mathrm{A}_{2}$ door de plaatjes van de visolie-gevoede ratten.

In HOOFDSTUK 3 en 5 is beschreven dat - ongeacht de soort plaatjesactivator -de aggregatieneiging en de calciumrespons van plaatjes nauwelijks waren beïnvloed in ratten gevoed met een visoliepreparaat. Alhoewel de inname van $n-3$ MOV steeds leidde tot een verminderde productie van tromboxaan $A_{2}$ door geactiveerde plaatjes, bleek het proces van plaatjesactivatie als zodanig nauwelijks te zijn beïnvloed, althans onder de gebruikte in vitro testcondities. Anderzijds reduceerde de visolie wel het plaatjesaantal in het bloed.

Zoals bekend uit eerdere studies vervangen n-3 MOV in de voeding het arachidonzuur in de celmembranen, dat veresterd is aan de $s n-2$ positie van de cellulaire glycerofosfolipiden. De vervanging van arachidonzuur door EPA en DHA vindt plaats in de membranen van zowel plaatjes als vaatwandcellen. Ook in het hier beschreven onderzoek leidde voedingsinterventie met visolie tot een dosisafhankelijke toename van EPA en DHA in de fosfolipiden van plaatjes en aortaweefsel (HOOFDSTUK 2 en 3). Voeding van de ratten met het gezuiverde EPA danwel DHA preparaat resulteerde in een toename van zowel EPA als docosapentaeenzuur (DPA) in de fosfolipiden van bloedplaatjes, terwijl de fosfolipiden van het aortaweefsel meer verrijkt waren in DHA en DPA. Dit geeft aan dat in de plaatjes het DHA uit de voeding grotendeels via retroconversie wordt omgezet in EPA, terwijl in de vaatwand het opgenomen EPA in sterkere mate verlengd wordt tot DPA. Deze vervanging van arachidonzuur onder invloed van n-3 MOV resulteerde - als verwacht - ook in een verminderde prostanoïde-productie. In de plaatjes was de vorming van tromboxaan $A_{2}$ gereduceerd, terwijl in de aorta-vaatwand de productie van prostacycline verlaagd was. Voedingsinterventie met $n-3$ MOV leidde daarmee tot verlaagde productie van een aggregatiestimulator (tromboxaan $A_{2}$ ) maar ook tot een productieverlaging van een aggregatieremmer (prostacycline).

Teneinde de consequenties van deze veranderde prostanoïde-productie te bepalen werden de gecombineerde effecten van endogeen geproduceerd tromboxaan $\mathrm{A}_{2}$ en van vaatwand afkomstig prostacycline onderzocht op de plaatjesactivatie (HOOFDSTUK 3). In tegenstelling tot het specifieke plaatjesstimulerende effect van tromboxaan $A_{2}$, bleek het plaatjes-remmende effect van prostacycline meer van algemene invloed te zijn. Prostacycline remde zowel de tromboxaan $\mathrm{A}_{2}$-afhankelijke als de -onafhankelijke activatieprocessen; dit effect was bovendien langduriger dan het kortdurende stimulerende effect van tromboxaan $A_{2}$. Hieruit werd geconcludeerd dat prostacycline een meer prominente rol speelt in het regelen van de plaatjesactivatie dan tromboxaan $A_{2}$. Wanneer vaatwandmateriaal van ratten gevoed met $\mathrm{n}-3 \mathrm{MOV}$ - met daarin een verlaagde hoeveelheid prostacycline - werd toegevoegd aan plaatjes afkomstig van dezelfde ratten werd een verminderde remming van de plaatjesactivatie waargenomen. Dit impliceert dat de voedingsinterventie met $n-3 \mathrm{MOV}$ leidt tot een verschuiving in de tromboxaan $A_{2}$ - 
prostacycline balans, in feite in een ongewenste richting. Om de gunstige effecten van visolie op hart- en vaatziekten te kunnen verklaren, was dus verder onderzoek nodig.

Metingen werden uitgevoerd aan het stollingssysteem van ratten gevoed met $\mathrm{n}-3$ MOV. Daar de beschikbare stollingstesten relatief ongevoelig zijn in detectie van een verminderde stollingsneiging, werd naar een nieuwe, meer gevoelige methode gezocht. Nagegaan werd of hiervoor gebruik kon worden gemaakt van een reeds gevalideerde, gevoelige methode voor de detectie van kleine stollingsveranderingen in humaan plasma: bepaling van de endogene trombinepotentiaal (ETP) in stollend plasma. Twee methoden waren in het laboratorium ontwikkeld om de ETP te meten, een handmatige en op later datum een geautomatiseerde techniek. Beide werden aangepast voor gebruik met rattenplasma. Het plasma werd daarbij geactiveerd met weefselfactor (rat of humaan), procoagulante fosfolipiden en $\mathrm{CaCl}_{2}$, waarna de trombinevorming en trombineafbraak continu in de tijd gevolgd werden (HOOFDSTUK 4). Bij de eerste methode werd trombine gemeten in monsters die handmatig werden genomen uit het stollende plasma (HoofDSTuK 4 en 5). Bij de tweede meer recente methode werd de trombineconcentratie in het plasma continu in de tijd met een automaat gemeten. Daarbij werd de momentane trombineconcentratie afgeleid van de snelheid waarmee een chromogeen trombinesubstraat in het stollend plasma gesplitst werd. Dit substraat had een lage affiniteit voor trombine om interferentie met de werking van het stollingssysteem tegen te gaan (HOOFDSTUK 4). Voordeel van beide methoden is niet alleen een verbeterde gevoeligheid voor stollingsverlagende condities, maar ook het bieden van een mogelijkheid om de stolling van rattenplasma onder volledig autologe condities te kunnen meten.

De curve van trombinevorming en trombineafbraak in rattenplasma geactiveerd met (ratten) weefselfactor bleek sterke gelijkenis te vertonen met die van humaan plasma, zij het dat in het rattensysteem de kinetiek sneller was. Dat wil zeggen dat bij stollend rattenplasma de trombine sneller gevormd wordt en het gevormde trombine een kortere halfwaardetijd heeft en dus een snellere inactivatie kent (HoOFDSTUK 4). De trombinegeneratie - en daarmee de ETP - van rattenplasma bleek gevoelig te zijn voor de activatie van antitrombine door heparine, voor het in vivo toedienen van stollingsremmende vitamine $K$ antagonisten, en voor voedingsinterventie met een vitamine K-defici $n$ te voeding. In al deze gevallen bleek een significante verlaging in ETP gemeten te worden, terwijl standaard stollingstesten (zoals de protrombinetijd) slechts matig verlengd waren. Metingen aan de trombinegeneratie gaven verder aan dat de protrombineconcentratie (factor II) in het plasma een belangrijke factor is voor zowel de initiële snelheid van trombinevorming als de totale trombinepotentiaal aan het einde van het stollingsproces. De concentraties van andere stollingsfactoren, zoals factoren $\mathrm{V}$ en VII, waren in deze minder van invloed op de ETP waarde.

De handmatige ETP methode werd gebruikt om de stollingsactiviteit te meten 
in plasma afkomstig van ratten, die een visolie-rijke voeding hadden gekregen (HOOFDSTUK 5). In rattenplasma dat geactiveerd werd met weefselfactor bleek de ETP verlaagd te zijn wanneer de dosis toegediend visolie hoger was dan $2.5 \mathrm{en} \%$ ( $4 \% \mathrm{FO}$ ). Deze reductie ging gepaard met, en kon voor een deel worden verklaard door, een verlaging in niveaus van de vitamine $K$-afhankelijke stollingsfactoren II en $\mathrm{VI}$, terwijl de concentratie van antitrombine onveranderd bleef. Zo'n verminderde stollings-neiging werd niet gevonden na voedingsinterventie met zonnebloempitolie. Controle-metingen wezen overigens uit dat de interventie met visolie geen effect had op parameters van de fibrinolyse-activiteit van het plasma (plasminogeen-activator inhibitor en weefseltype plasminogeen-activator). Samengevat resulteerde de voedingsinterventie van ratten met visolie in een verlaagde stollingsneiging van het plasma, terwijl er geen meetbaar effect was op de fibrinolyse-activiteit.

In het volgende hoofdstuk is beschreven dat voedingsinterventie met een relatief lage dosis van gezuiverd EPA, DHA of met ongezuiverd n-3 MOV niet leidde tot een verlaging in de ETP van plasma (HOOFDSTUK 6). Dit gebrek aan effect werd eerst toegeschreven aan de relatief hoge hoeveelheden van vet en vitamine $K$ in de betreffende voedingen. Daar vitamine $K$ een vetoplosbaar molecuul is, is het mogelijk dat de vethoeveelheid van het voedsel een beperkende factor is voor opname door het lichaam. Evenwel bleek de minimale dosis vitamine $K$ in de rattenvoeding, die nodig was voor een optimale carboxylering van de stollingsfactoren, onafhankelijk te zijn van het vetgehalte van het voedsel. Vervolgens werden ratten gevoed met visolie in combinatie met een hoog (50 en\%) of laag (10 en\%) vetgehalte en een beperkte inname van vitamine $K$. Het bleek dat met name de combinatie van visolie en laag vetgehalte leidde tot een verlaagde ETP en een relatief lage protrombineconcentratie (HOOFDSTUK 6). Verder kon beperkte accumulatie van de vitamine $K$ in de lever niet de enige verklaring zijn voor de visolie geïnduceerde verlaagde stollingsneiging. Ondersteuning hiervoor werd gevonden in het feit dat voeding met visolie ook leidde tot een verlaging van het plasmaniveau van de vitamine $K$-onafhankelijke factor $V$.

Bekend is dat bij de mens voedingsinterventie met visolie leidt tot een verlaging in de plasma triglyceridenspiegel, maar niet altijd tot een verlaging van het (totaal) cholesterolgehalte. In de onderzochte ratten verlaagde de visolie (als onderdeel van een hoogvet voeding) de plasmaconcentraties van zowel triglyceriden als cholesterol (HOOFDSTUK 5 en 6). Voeding met zonnebloempitolie resulteerde enkel in een verlaging van de triglyceridenconcentratie. Humane studies suggereren tevens dat de activiteit van bepaalde stollingsfactoren geassocieerd zijn met de triglyceridenconcentratie. Onze bevindingen geven aan dat de verminderde stollingsneiging tengevolge van visolie-inname los staat van de verandering in triglyceridenniveau.

Uit biomedisch onderzoek blijkt steeds duidelijker dat de processen van plaatjesactivatie en bloedstolling sterk met elkaar verbonden zijn. Trombine speelt als cruciale stollingsfactor en krachtige plaatjesactivator een belangrijke rol in deze 
interactie. Aangezien voeding van de ratten met visolie van invloed is op zowel plaatjesactivatie (verminderde tromboxaan $A_{2}$ productie) als stolling (verlaagde concentratie van stollingsfactoren), werd nader onderzoek gedaan naar de interactie van beide processen, gebruik makend van humaan en rattenplasma.

In experimenten met humaan plaatjesrijk plasma was gebleken, dat de interactie van plaatjes met fibrine resulteerde in het procoagulant (stolactief) worden van de plaatjes via hun integrine $\alpha_{\| b} \beta_{3}$ (glycoproteïne $\mathrm{Ib} / \mathrm{llla}$, een fibrine en fibrinogeen receptor)-afhankelijke binding. Op basis van deze bevinding werden de effecten van trombine op fibrine- en fibrinogeen-gebonden plaatjes ook onder plasma-vrije condities bestudeerd. In HOOFDSTUK 7 staat beschreven dat de integrine $\alpha_{11 b} \beta_{3}$-afhankelijke binding van plaatjes aan fibrine en fibrinogeen niet leidt tot het ontstaan van een procoagulant plaatjesoppervlak of tot trombinevorming aan het plaatjesoppervlak. Zelfs hoge concentraties trombine waren niet meer dan matig effectief in het stimuleren van de plaatjes procoagulante respons. De conclusie luidt dat trombine, in de afwezigheid van stollend plasma, slechts een zwakke stimulator van de procoagulante respons is.

Om de interactie tussen plaatjesactivatie en stolling onder meer fysiologische condities te bestuderen, werd volbloed afkomstig van ratten gestimuleerd met weefelfactor en $\mathrm{CaCl}_{2}$ onder stromingscondities. Geavanceerde beeldvormingstechnieken werden gebruikt om de plaatjesactivatie en fibrinevorming gelijktijdig te kunnen waarnemen (HOOFDSTUK 8). Onder matige stromingscondities met een lage wandafschuifsnelheid werden binnen een tijdsbestek van minuten fibrinevorming (stolling) en het ontstaan van procoagulante plaatjes waargenomen. Interventiestudies met plaatjesremmers wezen uit dat de procoagulante respons onveranderd kan plaatsvinden in de afwezigheid van plaatjesaggregatie. Dus plaatjesactivatie en stolling zijn nauw aan elkaar gekoppeld ook zonder dat de plaatjes aggregeren tot een trombus.

In HOOFDSTUK 9 worden de resultaten van de experimentele hoofdstukken verder bediscussieerd. Gesteld is dat voedingsinterventie bij de rat met visolie resulteert in een antitrombotisch effect, dat het gevolg is van een combinatie van merendeels gunstige veranderingen in het hemostase-systeem. Visolie in de voeding vermindert het plaatjesaantal in het bloed alsmede de tromboxaan $A_{2}$ productie door geactiveerde plaatjes. Het effect van deze verlaagde tromboxaanproductie wordt tegengewerkt door een verlaagde prostacyclineproductie door de vaatwand, in ieder geval bij hoge doseringen visolie. Daarnaast leidt visolie tot een verlaging in de bloedlipidenspiegels. Visolie vermindert ook de stollingsneiging, deels tengevolge van een verlaging in de concentraties van vitamine $\mathrm{K}$-afhankelijke stollingsfactoren. Aangezien de processen van plaatjesactivatie en stolling elkaar wederzijds versterken, geeft dit aan dat visolie een duidelijk remmend effect heeft op de versterkingsreactie.

Het is niet eenvouding om de hierboven beschreven bevindingen in het 
rattensysteem te extrapoleren naar de situatie bij de mens. Volstaan wordt hier met op te merken dat een inname van 3 en\% n-3 MOV uit visolie bij ratten wat overeenkomt in termen van energie-inname met de dagelijke consumptie van ongeveer 1.2 gram n-3 MOV (of 100 gram vette vis) door een volwassene. Uiteraard zijn aanvullende humane studies nodig om de effecten van een dergelijke voedingsinterventie met visolie op de plaatjes-stollings interactie bij de mens te kunnen aantonen. 


\section{Dankwoord}

Zoveel mensen hebben mij de afgelopen acht jaren met raad en daad bijgestaan, dat het haast ondoenlijk is een ieder persoonlijk te bedanken. Ook diegenen die ik vergeten ben te noemen in het navolgende, dank!

In eerste instantie wil ik mijn promoter Gerard Hornstra en co-promotor Johan Heemskerk bedanken. Alle begin is moeilijk en zo was het ook voor mij. Nadat het aantal kapiteins op het schip van drie terug gebracht was tot twee en Johan mijn dagelijkse contact persoon werd, ging het uiteindelijk beter. Beste Gerard, dank voor het opstarten van dit onderzoek en voor het in mij gestelde vertrouwen. Je wist altijd de puntjes op de -i- te zetten bij onze artikelen. Beste Johan, jij was mijn Grote Roerganger. Met name door jouw steun en inzet is dit proefschrift toch nog tot stand gekomen, en is de promotie een feit, zij het in de nacompetitie. Je hebt altijd geloofd in het tot stand komen van dit proefschrift, ondanks dat ik het moeilijk opschreef. Zonder jouw goede opbouwende kritiek en snelle correcties was het niet gelukt.

Ook de beoordelingscommissie wil ik bedanken voor de snelle en positieve reacties. Het in 5 weken doorlezen van weer een proefschrift, van nogal wat pagina's, was een aanzienlijke klus.

Mijn paranimfen Odette Buitendam en Caroline Hulshoff zijn 'trots' op de mijlpaal die ik eindelijk zal bereiken en dat gaf me veel steun bij de laatste loodjes. Ik ben vereerd dat zij mij willen bijstaan op deze dag.

Natuurlijk had dit proefschrift zonder de bijdrage van talrijke analisten niet tot stand kunnen komen. Rene Offermans was letterlijk mijn tweede en derde rechterhand. Daarnaast konden we zowel samen lachen als op elkaar mopperen. Het spijt mij zeer dat Jo Wierts de afronding van dit werk niet meer heeft mogen meemaken. Hij verrichtte bijna alle operaties en heeft samen met Nicole Bitch voor de verzorging en voedingen van de dieren gezorgd. Hasibe Aydeniz dank ik voor de aanvullende vetzuurbepalingen. Puck Muller en Jeff Emeis, bedankt voor de stollings- en fibrinolyseanalyses. Dank natuurlijk ook aan Marijke Sanders, die hoofdstuk 7 tot stand heeft gebracht. Tenslotte ben ik Marion Feijge en Adje Hennissen erkentelijk voor het voor hun rekening nemen van vrijwel het gehele technische gedeelte van Hoofdstuk 4 en 6 . Het moet niet erg stimulerend zijn geweest dat jullie dit belangrijke werk voor mij hebben gedaan terwijl ik hoog in het noorden zat. Dat merkte ik als ik weer eens in Maastricht kwam om de stand van zaken te bespreken. Mijn complimenten aan jullie voor de voor mij o zo belangrijke bijdrage.

Sommige van deze experimenten zouden in het honderd zijn gelopen zonder de adviezen van de 'specialisten'. Nogmaals Marion Feijge, de analist-specialist op het gebied van bloedplaatjes, fosfolipiden, te veel om op te noemen en niet te vergeten een uitstekende laboratorium-regentesse en haar computer 'know-how'. Frank Cox gaf waardevolle adviezen. Marianne Simonis dank ik voor haar expertise 
op het gebied van de gaschromotograaf. Prof. Hemker en Suzette Béguin wil ik bedanken voor het openstellen van het laboratorium en de inhoudelijke en technische informatie over de stolling en de trombine generatie test. Ook Simone Wielders wil ik niet overslaan. Simone, dank je wel, je maakte het voor mij aangenaam om bij jullie op het lab te werken en stond altijd klaar om wat voor me te regelen. De mensen van het vitamine K-lab mogen ook niet vergeten worden: Cees Vermeer, Berry Soute, Leon Schurgers, Jacintha Ronden en Monique Groenen. Jacco Briedé en Ron Blaser ${ }^{\dagger}$ hartelijk bedankt voor het lenen van de flow-kamers met bijbehorende attributen. Guido Tans bedankt voor de hulp en adviesen. José Govers, hartelijk bedankt voor het humaan protrombine. Stella Thomassen en Joyce Curvers bedankt voor alles, als tegenprestatie deed ik eens mee deed als proefpersoon, en met die experimenten ontdekten jullie als eersten dat ik zwanger was. Paul Schoffelen en Loek Wouters stonden altijd klaar als de computer weer eens raar deed. Arnold Kester, bedankt voor de statistische adviezen. Speciale dank ben ik ook verschuldigd aan de medewerkers van het Centraal Proefdier Verblijf, met name Peter Kelderman. Ook de medewerkers van de afdeling haematologie van het $A Z G$, in het bijzonder Rene van Oerle, dank ik voor hun medewerking.

Belangrijk zijn ook geweest mijn kamergenoten Riette van Elburg en Carin Wensing, en de andere buurtbewoners van de 'appendix' van de Humane Biologie, Liesbeth Temme, Tanja Hermans, Gerard Oostenbrug, Ronald Mensink, Susan Vermunt, Jogchum Plat, Esther Bakker en Patrick Rump. Ook de nieuwe kamerbewoners op de Humane Biologie, Karin Ansink en Kristof Vanschoonbeek, jullie kennen mij alleen als stoorzender, bedankt hoor, dat ik mijn computer steeds mocht inpluggen. Sandra Schiffelers bedankt voor de sponsoring suggesties.

Daarnaast ben ik alle medewerkers van de Biochemie dankbaar dat ik altijd wat kon komen vragen en van hun apparatuur en chemicaliën gebruik mocht maken. Mariet, bedankt dat je spontaan een oogje op de kinderen hield toen ik ze mee naar het lab had genomen en vanzelfsprekend voor alle andere zaken die je voor me hebt geregeld. Alle medewerkers van de Humane Biologie ook hartelijk bedankt. We hadden leuke uitstapjes, maar vooral de bierfeesten bij Rowwen Hèze en de Janse Bagge Bend zal ik niet snel vergeten.

Al mijn Clubgenoten, jullie wil ik met name bedanken dat jullie mijn beslissing om (tijdelijk) te stoppen hebben gerespecteerd. Dat was een enorme opluchting en ondersteuning. Vooral Toos echter was een voorbeeld om de draad weer op te pakken.

Alle familieleden, bedankt voor jullie support. Speciaal wil ik mijn ouders bedanken. Ze hebben me altijd gestimuleerd en de mogelijkheid gegeven om te leren en te studeren. Papa en Mama bedankt voor de zorg en verantwoordelijkheid die jullie op je namen om ruim een jaar 'fulltime' op Carlijn te passen, en daarna nog vele malen een week op Carlijn én Josefien. 
Tenslotte mijn dierbaren, jullie zijn voor mij het allerbelangrijkste. Cara Jan Willem, dank je wel voor het geduld dat jij hebt weten op te opbrengen ook als ik weer eens hevige nukken vertoonde. Je taalkundige visie en je inzet om ook een basaal wetenschappelijk proefschrift gesponsord te krijgen hebben een steentje aan dit proefschrift bijgedragen. Onze lieve meisjes Carlijn, Josefien en ......, sorry dat ik soms wat gestressed was, maar het is nu echt klaar. 'Big hug'. 



\section{Curriculum Vitae}

Cécilia Maria Augusta Nieuwenhuys werd geboren op 23 april 1965 te Amsterdam. In 1983 behaalde zij het HAVO diploma aan de Samenwerkingsschool te Waddinxveen. Vervolgens heeft zij de Hogere Laboratorium Opleiding aan het Van Leeuwenhoek Instituut te Delft gevolgd. Na een stage in het Anthonie van Leeuwenhoek Ziekenhuis te Amsterdam behaalde zij in 1987 het diploma. Aansluitend werd begonnen aan de studie Biomediche Wetenschappen aan de Rijksuniversiteit van Leiden. In de periode van 1990 tot 1993 werd hiervoor onderzoek verricht op de afdelingen Gerontologie van de Rijksuniversiteit te Leiden, Endocrinologie en Immunohaematologie en Bloedbank van het Academisch Ziekenhuis te Leiden. In diezelfde periode is zij tevens partime werkzaam geweest als analist op de Bloedbank te Leiden. In 1993 behaalde zij haar doctoraal diploma in de Biomedische Wetenschappen. Het onderzoek zoals beschreven in dit proefschrift werd uitgevoerd bij de capaciteitsgroepen Humane Biologie faculteit Gezondheids Wetenschappen en Biochemie faculteit Geneeskunde van de Universiteit van Maasticht (1993-1997). In 1995 behaalde zij tevens haar bevoegdheid in de proefdierkunde als artikel 9 functionaris.

Zij is gehuwd met Jan Willem van den Berg en heeft twee dochters, Carlijn (17-081996) en Josefien (4-5-1999) en verwacht eind oktober haar derde kind. 


\section{Publications}

1. Cécile M.A Nieuwenhuys and Gerard Hornstra, The effects of purified eicosapentaenoic and docosahexaenoic acids on arterial thombosis tendency and platelet function in rats, Biochim Biophys Acta, 1998; 1390:313-322.

2. Cécile M.A. Nieuwenhuys, Suzette Béguin, René F.G. Offermans, Jeff F. Emeis, G. Hornstra and Johan W.M. Heemskerk, Hypocoagulant and lipid-Lowering effects of dietary n-3 polyunsaturated fatty acids with unchanged platelet activation in rat, Arterioscler Thromb Vasc Biology, 1998;18:1480-1489.

3. Marijke W. Sanders, Cécile M.A. Nieuwenhuys, Marion A.H. Feijge, Martin Rook, Suzette Béguin and Johan W.M. Heemskerk, The procoagulant effect of thrombin on fibrin(ogen)bound platelets, Haemostasis, 1998:28:289-300.

4. Cécile M.A. Nieuwenhuys, Marion A.H. Feijge, Arnold D.M. Kester, G. Hornstra and Johan W.M. Heemskerk, Modulation of rat platelet activation by vessel wall-derived prostacyclin and platelet-derived thromboxane: effect of dietary fish oil on thromboxane-prostacyclin, Atherosclerosis, 2001154:355-366.

5. Cécile M.A. Nieuwenhuys, Suzette Béguin and Johan W.M. Heemskerk, Monitoring hypocoagulant conditions in rat plasma: Factors determining the endogenous thrombin potential of tissue factor-activated plasma: Thromb Haemost, 2000; 84: 1045-1051.

6. Cécile M.A. Nieuwenhuys, Marion A.H. Feijge, Cees Vermeer, Adje H.H.M. Hennissen, Suzette Béguin, and Johan W.M. Heemskerk, Vitamin K-dependent and -independent hypocoagulant effects of dietary fish oil in rats, submitted.

\section{Abstracts}

1. Nieuwenhuys CMA, Offermans RFG, Emeis JJ, Béguin S, Hornstra G, Heemskerk JWM, Effects of dietary n-3 polyunsaturated fatty acids (PUFA) from fish on fibrinolysis and coagulation, 'Lipids, Membranes and Thrombosis', Maastricht, Nederland (10-13 juli 1996).

2. Nieuwenhuys CMA, Offermans RFG, Emeis JJ, Béguin S, Hornstra G, Heemskerk JWM, Effects of dietary $n-3$ polyunsaturated fatty acids (PUFA) from fish on fibrinolysis and coagulation, 'Fats of life', Barcelona, Spanje (4-6 november 1996).

3. Nieuwenhuys CMA, Béguin $S$, Hornstra $G$ and Heemskerk JWM, Dietary fish oil increases disaggregation of platelets and decreases the coagulation potential in rats, 'Fourth International congress on essential fatty acids and eicosanoids', Edinburgh, Schotland (20-24 juli 1997).

4. Nieuwenhuys CMA, Feijge MAH, Béguin S, Hornstra G, Heemskerk JWM, The endogenous thrombin potential in detection of the hypocoagulant activity of rat plasma: Effects of dietary $\mathrm{n}-3$ polyunsaturated fatty acids, $\mathrm{XVII}$ congress of the international society on thrombosis and haemostasis, Washington USA (14-21 augustus, 1999), Thrombosis and Haemostasis 82: $315 S$.

5. Heemskerk, JWM, Nieuwenhuys, CMA, van Gorp, RMA, oude Egbrink, M and Sage, SO (1998) Calcium and procoagulant responses of single platelets. Platelets 8: 115.

6. Heemskerk, JWM, Nieuwenhuys, CMA, van Gorp, RMA, oude Egbrink, M and Sage, SO Calcium and procoagulant responses of single platelets. Proceedings of ETRO IVS Euroconference on Signal Transduction Pathways in Platelets and Vessel Cells, Paris (France). 1998.

7. Nieuwenhuys, CMA, Feijge, MAH, Béguin, S and Heemskerk, JWM, Interaction between platelet activation and coagulation in flowing whole blood. Proceedings of 7 th Erfurt Conference on Platelets, Erfurt (Germany), Platelets, 1998; 9: 419. 